\title{
Uma Contribuição ao Projeto Arquitetural de Ambientes de Engenharia de Software
}

\author{
Elisa Yumi Nakagawa \\ Orientador: Prof. Dr. José Carlos Maldonado
}

Tese apresentada ao Instituto de Ciências Matemáticas e de Computação - ICMC/USP, para a obtenção do título de Doutor na Área de Ciências de Computação e Matemática Computacional.

USP - São Carlos

Março de 2006 





\section{Agradecimentos}

O meu orientador, Prof. Dr. José Carlos Maldonado com quem pude aprender muito e por
ser referência para mim de profissional, professor e orientador. Obrigada pela compreen-
saçãa, pela confiança e, acima de tudo, pela amizade.

Ao Fabrício, Camila, Lucas e Vítor que tiveram que abrir mão de minha companhia para que eu pudesse me dedicar a este trabalho. Agradeço pelo amor incondicional de vocês.

Aos meus pais Yukio (mais conhecido como Maurício Japonês) e Akiko a quem mais devo essa conquista. Muito, muito obrigada.

Meus sinceros agradecimentos ao Prof. Dr. Sérgio Carlos Nahas da Faculdade de Medicina da Universidade de São Paulo pela sua dedicação, sua competência e pela oportunidade de eu poder estar vendo agora a vida de outro prisma.

Meus agradecimentos à Margarida pela sua sincera amizade, pela sua essencial ajuda durante essa quase uma década de convivência. Obrigada pela ajuda com as crianças, sendo sempre minha suplente na função de mãe.

Ao Seu Zé que sempre nos ajudou e acredito estar ajudando de onde estiver agora, e à Cristina pela sua eterna dedicação aos filhos e netos.

Aos amigos do Labes, e em especial ao Fabiano, Ellen, Valter, Adenilso e André, e a todos os demais com quem pude conviver durante todos esses anos.

Aos meus alunos de iniciação científica e de projeto de graduação, especialmente ao Thiago, Keila, Priscila, Fadú e Paulinha, que direta ou indiretamente contribuíram com esta tese.

A todos os funcionários do ICMC.

À Universidade de São Paulo e ao Centro Universitário de Araraquara-Uniara. 
1 Introdução 1

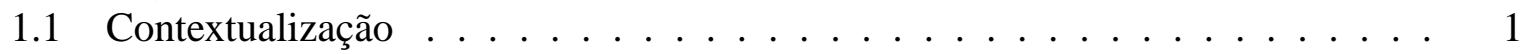

1.2 Motivação . . . . . . . . . . . . . . . . . . . . . . . . 7

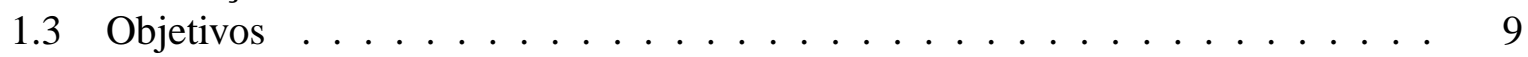

1.4 Organização do Trabalho . . . . . . . . . . . . . . . . . . . . 10

2 Revisão Bibliográfica 11

2.1 Considerações Iniciais . . . . . . . . . . . . . . . . . . . . . 11

2.2 Processo de Software . . . . . . . . . . . . . . . . . . . . . . 12

2.2.1 Padronização de Processo de Software . . . . . . . . . . . . . . . . . . . . . 14

2.2.2 Processo de Desenvolvimento de Software . . . . . . . . . . . . . . 15

2.2.3 Processo de Desenvolvimento de Software Livre . . . . . . . . . . . 17

2.3 Ambientes de Engenharia de Software . . . . . . . . . . . . . . . . 20

2.3.1 Desafios das Pesquisas em Ambientes de Engenharia de Software . . . 23

2.3.2 Linguagens para Modelagem de Processos . . . . . . . . . . . . . . 25

2.4 Arquitetura de Software . . . . . . . . . . . . . . . . . . . . . . . 29

2.4.1 Descrição de Arquiteturas de Software . . . . . . . . . . . . . . . 32

2.4.2 Arquitetura de Sistemas Web . . . . . . . . . . . . . . . . 35

2.5 Orientação a Aspectos . . . . . . . . . . . . . . . . . . . 39

2.5.1 Programação Orientada a Aspectos . . . . . . . . . . . . . . . . . . . 40

2.5.2 Desenvolvimento Orientado a Aspectos . . . . . . . . . . . . . 41

2.5 .3 Tecnologias de Apoio . . . . . . . . . . . . . . . . 44

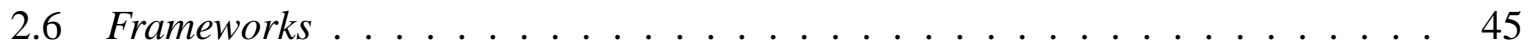

2.6.1 Processo de Desenvolvimento de Frameworks . . . . . . . . . . . . . . . 47

2.6.2 Documentação de Frameworks . . . . . . . . . . . . . . . . . . . . . . . . . . . . 48

2.6.3 Frameworks Orientados a Aspectos . . . . . . . . . . . . . . . . 49

2.6.4 Outros Mecanismos de Reutilização . . . . . . . . . . . . . . . . 51 
2.7 Ontologia . . . . . . . . . . . . . . . . . . . 53

2.7.1 Representação de Ontologias . . . . . . . . . . . . . . . . . . . 54

2.8 Teste de Software: Uma Visão Geral . . . . . . . . . . . . . . . . . . . 55

2.8.1 Técnicas e Critérios de Teste . . . . . . . . . . . . . . 57

2.8.2 Automatização de Teste de Software . . . . . . . . . . . . . . . . . . 59

2.9 Considerações Finais . . . . . . . . . . . . . . . . . . . . . . 67

3 Arquitetura de Referência de Ambientes de Engenharia de Software 69

3.1 Considerações Iniciais . . . . . . . . . . . . . . . . . . . . . 69

3.2 Requisitos Arquiteturais de Ambientes de Engenharia de Software . . . . . . . 70

3.3 Estrutura Geral e Características da Arquitetura . . . . . . . . . . . . . . . 71

3.3.1 Arquiteturas de Sistemas Interativos e de Sistemas Web . . . . . . . . 73

3.3 .2 ISO/IEC $12207 \ldots \ldots \ldots \ldots \ldots \ldots \ldots$

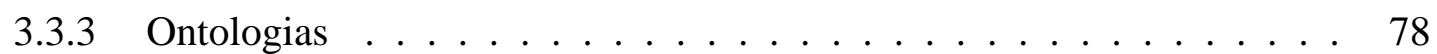

3.3.4 Separação de Interesses e Frameworks Transversais . . . . . . . . . . . . 81

3.4 Descrição da Arquitetura . . . . . . . . . . . . . . . . . . . . . . . . . 84

3.4 .1 Visão de Módulos . . . . . . . . . . . . . . . . . . . . . 84

3.4.2 Visão em Tempo de Execução . . . . . . . . . . . . . . . . . . . 86

3.4 .3 Visão de Implantação . . . . . . . . . . . . . . . . . . . . . . . . . . . 89

3.5 Evolução e Integração nos Ambientes de Engenharia de Software . . . . . . . . 90

3.5.1 Evolução dos Ambientes de Engenharia de Software . . . . . . . . . . 90

3.5.2 Integração nos Ambientes de Engenharia de Software . . . . . . . . . . . 91

3.5.3 Investigação Preliminar Sobre Uso de Workflow . . . . . . . . . . . . 93

3.6 Utilização da RefASSET . . . . . . . . . . . . . . . . . . . . . . . . . . . 96

3.7 Considerações sobre a Implementação de um AES Baseado na RefASSET . . . 99

3.8 Considerações Finais . . . . . . . . . . . . . . . . . . . . . . . . 101

4 Arquitetura de Referência de Ferramentas de Teste 103

4.1 Considerações Iniciais . . . . . . . . . . . . . . . . . . . . 103

4.2 Especialização e Instanciação Arquitetural . . . . . . . . . . . . . . . . . . 104

4.3 Investigação do Domínio . . . . . . . . . . . . . . . . . . . . . 106

4.3.1 Arquiteturas de Referência de Ferramentas de Teste . . . . . . . . . . . 106

4.3.2 Processos de Teste de Software . . . . . . . . . . . . . . . . . . . . . 109

4.3.3 Investigação de Ferramentas de Teste . . . . . . . . . . . . . . . . . . 113

4.3.4 Ontologia de Teste de Software . . . . . . . . . . . . . . . . . 116

4.3.5 Identificação das Funcionalidades Específicas e dos Conceitos do Do-

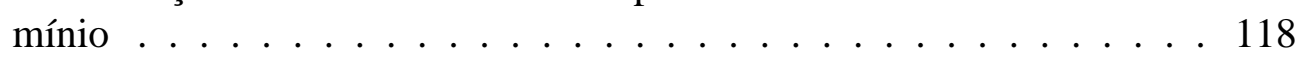

4.4 Análise Arquitetural . . . . . . . . . . . . . . . . . . . . . . . . . . . . 122

4.5 Tratamento de Frameworks Transversais . . . . . . . . . . . . . . . . . . . . 125

4.5.1 Frameworks Transversais de Propósito Geral . . . . . . . . . . . . . . 125

4.5.2 Framework Transversal de Documentação de Teste . . . . . . . . . . 129

4.5.3 Framework Transversal de Gerência de Configuração para Teste . . . . 141

4.6 Projeto Arquitetural . . . . . . . . . . . . . . . . . . . . . . . . 146

4.7 Considerações Finais . . . . . . . . . . . . . . . . . . . 151 
5 Processo Baseado em Arquitetura de Software 155

5.1 Considerações Iniciais . . . . . . . . . . . . . . . . . . . 155

5.2 Especialização e Instanciação Arquitetural . . . . . . . . . . . . . . . . . . . 156

5.3 ProSA (Process based on Software Architecture) . . . . . . . . . . . . . . 158

5.3.1 Passo 1: Investigação do Domínio . . . . . . . . . . . . . . . 160

5.3.2 Passo 2: Análise Arquitetural . . . . . . . . . . . . . . . . . 163

5.3.3 Passo 3: Tratamento de Frameworks Transversais . . . . . . . . . . . 165

5.3.4 Passo 4: Projeto Arquitetural . . . . . . . . . . . . . . . . . . . . . 167

5.3.5 Passo 5: Desenvolvimento do Sistema . . . . . . . . . . . . . . 168

5.3.6 Passo 6: Integração no Ambiente de Engenharia de Software . . . . . . 169

5.4 Considerações Finais . . . . . . . . . . . . . . . . . . . . . . 169

6 Conclusões 171

6.1 Caracterização da Pesquisa Realizada . . . . . . . . . . . . . . . . . 171

6.2 Contribuições . . . . . . . . . . . . . . . . . . . . . . 173

6.3 Dificuldades e Limitações . . . . . . . . . . . . . . . . . . . . . . . . . . . 174

6.4 Trabalhos Relacionados a esta Pesquisa . . . . . . . . . . . . . . . 175

6.5 Trabalhos Futuros . . . . . . . . . . . . . . . . 176

6.6 Publicações Esperadas . . . . . . . . . . . . . . . . . . . 178

$\begin{array}{ll}\text { Referências Bibliográficas } & 181\end{array}$

A OntoTest: Uma Ontologia de Teste de Software 221

B DTD de Documentação de Teste 229 


\section{Lista de Figuras}

2.1 Elementos Básicos da Programação Orientada a Aspectos . . . . . . . . . . . . 40

3.1 Arquitetura Geral Proposta para Ambientes de Engenharia de Software . . . . . 72

3.2 Estrutura da Norma ISO/IEC $12207 \ldots \ldots$. . . . . . . . . . . 76

3.3 Ontologia de Processo de Software . . . . . . . . . . . . . . . . . . . . . 79

3.4 Ontologia de Artefato . . . . . . . . . . . . . . . . . . . . . 80

3.5 Atividades Fundamentais x Atividades de Apoio e Organizacionais . . . . . . . . 81

3.6 Visão de Módulos da RefASSET . . . . . . . . . . . . . . . . . . . . . 85

3.7 Visão em Tempo de Execução da RefASSET (Planejamento e Gerenciamento) . 87

3.8 Visão em Tempo de Execução da RefASSET (Documentação) . . . . . . . . . 88

3.9 Visão de Implantação da RefASSET . . . . . . . . . . . . . . . . . . . . . . . 89

3.10 Comunicação de um Processo do Mundo Real para o AES . . . . . . . . . . . 94

3.11 Representação Gráfica do Método Larman Utilizando Workflow . . . . . . . . 96

3.12 Workflow em XPDL . . . . . . . . . . . . . . . . . . 97

3.13 Abordagem Proposta para Construção de Ambientes de Engenharia de Software 98

4.1 Especialização e Instanciação da RefASSET . . . . . . . . . . . . . . . . . . . 104

4.2 Arquitetura de Referência de Ferramentas de Teste . . . . . . . . . . . . . . 107

4.3 Arquitetura de Ferramentas de Teste de Aplicações Web . . . . . . . . . . . 108

4.4 Estrutura Tradicional de Ferramentas de Teste . . . . . . . . . . . . . . . . . . 108

4.5 Processo de Teste de Software . . . . . . . . . . . . . . . . . . . . 111

4.6 Processo de Teste de Mutação . . . . . . . . . . . . . . . . . . . . . . 112

4.7 Ontologia de Teste de Software . . . . . . . . . . . . . . . . . . . . . . 118

4.8 Sub-Ontologia de Passos de Teste . . . . . . . . . . . . . . . . . . . . . . . 119

4.9 Sub-Ontologia de Artefatos de Teste . . . . . . . . . . . . . . . . . . . 120

4.10 Mapeamento FI-FE-C . . . . . . . . . . . . . . . . . . . 121

4.11 Modelo Conceitual do Módulo Base da RefTest . . . . . . . . . . . . . . . . . 124

4.12 Frameworks Transversais para Persistência (Adaptado de Camargo \& Masiero (2005)) . . . . . . . . . . . . . . . . . 126

4.13 Utilização dos Frameworks Transversais de Persistência no Módulo Base . . 127 
4.14 Frameworks Transversais para Segurança (Adaptado de Camargo \& Masiero (2005)) . . . . . . . . . . . . . . . . . . . 128

4.15 Utilização dos Frameworks Transversais de Segurança . . . . . . . . . . . . 129

4.16 Origem dos Dados para a Documentação da Atividade de Teste . . . . . . . . . 133

4.17 Seqüência de Interfaces: (a) Sem o Uso do Módulo de Documentação; (b) Com o Uso do Módulo de Documentação . . . . . . . . . . . . . . . . . . . 135

4.18 Módulo de Documentação de Teste . . . . . . . . . . . . . . . . . 136

4.19 Aspecto Abstrato AbstractDocumentation . . . . . . . . . . . . . 137

4.20 Aspecto Concreto TestingDocumentation . . . . . . . . . . . . . . 137

4.21 Modelo do Framework Transversal de Documentação . . . . . . . . . . . . . . 140

4.22 Módulo de Gerência de Configuração para Teste . . . . . . . . . . . . . . . . 144

4.23 Modelo do Framework Transversal de Gerenciamento de Configuração . . . . 147

4.24 Diagrama de Pacotes do Módulo Base . . . . . . . . . . . . . . . . . . . 148

4.25 Arquitetura Geral Proposta para Ferramentas de Teste de Software . . . . . . . 149

4.26 Visão de Módulos da RefTEST . . . . . . . . . . . . . . . . . . . . . . 150

4.27 Visão em Tempo de Execução da RefTEST . . . . . . . . . . . . . . . . . . . 151

4.28 Visão de Implantação da RefTEST . . . . . . . . . . . . . . . . . . . . . . 152

5.1 Especialização e Instanciação Arquitetural . . . . . . . . . . . . . . . . . 157

5.2 Visão Geral do ProSA . . . . . . . . . . . . . . . . . . . . . . . . . . . . . 159

5.3 Visão Detalhada do ProSA . . . . . . . . . . . . . . . . . . . . . 160

5.4 Refinamento do Passo 1 do ProSA . . . . . . . . . . . . . . . . 161

5.5 Mapeamento FI-FE-C no ProSA . . . . . . . . . . . . . . . . . 163

5.6 Refinamento do Passo 2 do ProSA . . . . . . . . . . . . . . . . . . . . 164

5.7 Refinamento do Passo 3 do ProSA . . . . . . . . . . . . . . . . . 166

5.8 Refinamento do Passo 4 do ProSA . . . . . . . . . . . . . . . . . . 167

A.1 Estrutura da OntoTest . . . . . . . . . . . . . . . . . . . . 222

A.2 Ontologia de Teste de Software . . . . . . . . . . . . . . . . . 223

A.3 Sub-Ontologia de Passos de Teste . . . . . . . . . . . . . . . . . . . 224

A.4 Sub-Ontologia de Artefatos de Teste . . . . . . . . . . . . . . . . 225

A.5 Sub-Ontologia de Recursos de Teste . . . . . . . . . . . . . . . . 227

B.1 DTD de Documentação de Teste (Geral) . . . . . . . . . . . . . . . . . . . 229

B.2 DTD de Documentação de Teste (Plano de Teste) . . . . . . . . . . . . . . . 230

B.3 DTD de Documentação de Teste (Especificação de Projeto de Teste) . . . . . . 231

B.4 DTD de Documentação de Teste (Especificação de Casos de Teste) . . . . . . . . 231

B.5 DTD de Documentação de Teste (Especificação de Procedimento de Teste) . 232

B.6 DTD de Documentação de Teste (Diário de Teste) . . . . . . . . . . . . . . . 233

B.7 DTD de Documentação de Teste (Relatório de Incidentes de Teste) . . . . . . . 233

B.8 DTD de Documentação de Teste (Relatório-Resumo de Teste) . . . . . . . . . 234 
2.1 Diagramas da aSideML . . . . . . . . . . . . . . . . . 43

2.2 Ferramentas de Teste de Software . . . . . . . . . . . . . . . . . 64

3.1 Processos da ISO/IEC 12207 x Atividades do AES . . . . . . . . . . . . . 78

3.2 Frameworks Transversais de Propósito Geral . . . . . . . . . . . . . . 83

4.1 Módulos das Arquiteturas de Referência Propostas Anteriormente . . . . . . . 110

4.2 Paralelo entre Processos de Teste de Software . . . . . . . . . . . . . . . . . 113

4.3 Funcionalidades Identificadas no Processo de Teste de Mutação . . . . . . . . 114

4.4 Funcionalidades das Ferramentas de Teste . . . . . . . . . . . . . . . . . . 116

4.5 Funcionalidades Identificadas na Ontologia de Teste . . . . . . . . . . . . . . 121

4.6 Funcionalidades Específicas e Conceitos do Domínio de Teste . . . . . . . . 123

5.1 Gabarito para Anotação das Funcionalidades Específicas e dos Conceitos de um Dado Domínio . . . . . . . . . . . . . . . . . . 163

A.1 Principais Conceitos Definidos na Ontologia de Teste de Software . . . . . . 222 


\begin{abstract}
$\mathrm{A}$ TUALMENTE , uma proliferação de ferramentas e ambientes de Engenharia de Software tem sido observada, impactando positivamente na produção de software. Contudo, apesar do reúso ser foco de muitas das pesquisas em Engenharia de Software, a grande maioria dessas ferramentas e ambientes é construída de forma individual, sem a preocupação com o reúso dos esforços de desenvolvimento. Além disso, a literatura carece de trabalhos que estabeleçam arquiteturas de referência adequadas para esses ambientes, o que pode estar influenciando nas dificuldades de integração e evolução que esses ambientes têm sofrido. Não sendo diferente, o domínio de teste de software tem contribuído com uma diversidade de ferramentas de teste, viabilizando a condução de estudos comparativos de diversos critérios e técnicas de teste que vêm sendo propostos. Vale destacar também que não se encontram na literatura trabalhos que abordem o desenvolvimento de ferramentas de teste de forma efetiva e com base em reúso; adicionalmente, observa-se a carência de arquiteturas de referência adequadas, recentes e eficazes para a construção de ferramentas para esse domínio. Apesar das vantagens da Web como plataforma de disponibilização de sistemas de software, ainda são poucas as iniciativas de ferramentas e ambientes de Engenharia de Software para essa plataforma. Nesse contexto, o objetivo deste trabalho consiste em investigar mecanismos que facilitem o desenvolvimento de ambientes e ferramentas de Engenharia de Software, visando à diminuição dos custos de desenvolvimento e manutenção. Mais especificamente, será estabelecida uma arquitetura de referência de ambientes de Engenharia de Software, buscando atender, em especial, à evolução contínua e à facilidade de uso e integração que esses ambientes requerem. Para isso, serão também explorados diversos mecanismos de forma a estabelecer uma arquitetura adequada e, ao mesmo tempo, eficaz, baseado no desenvolvimento orientado a aspectos, no uso de frameworks e de ontologias, bem como na norma internacional ISO/IEC 12207. Um estudo de caso para refinamento da arquitetura de referência proposta para o domínio de teste de software é apresentado. Por fim, com base na experiência do estudo de caso, é estabelecido um processo preliminar de especialização e instanciação arquitetural para a construção de arquiteturas de referência para domínios específicos de Engenharia de Software.
\end{abstract}


$\mathrm{R}$ ECENTLY , a proliferation of Software Engineering tools and environments has been observed, with positive impact on software production. However, despite reuse being the focus of many research in Software Engineering area, most tools and environments have been built individually, without attention in the reuse of development efforts. Moreover, there is a lack of works that propose reference architectures to these environments which can be influencing in the difficulties of evolution and integration that these environments have been suffered. In the same way, a diversity of tools has been also proposed in the Software Testing domain, making it possible the conduction of comparative studies of testing techniques and criteria. It is also important to highlight that works that discuss the development of testing tools in an effective way and based on reuse can not be found; in addition, there is a lack of adequate, recent and efficient reference architectures to that domain. Despite advantages of the Web as a platform to make available software systems, there are few initiatives of Software Engineering tools and environments. In this context, this work aims at investigating facilities to develop Software Engineering tools and environments for Web platform, aiming at low cost in development and maintenance. In particular, a reference architecture for Software Engineering environment is established, aiming at attempting the continuous evolution and facilities of use and integration required by these environments. This architecture is based on diverse mechanisms, such as aspect oriented programming, frameworks, ontologies and international standard ISO/IEC 12207. Following, a case study is conducted, aiming at establishing a reference architecture for Software Testing domain. Based on this case study experience, a preliminary process that involves the architectural specialization and instantiation to derive reference architectures for specific domains, such as analysis, design and testing, is established. 


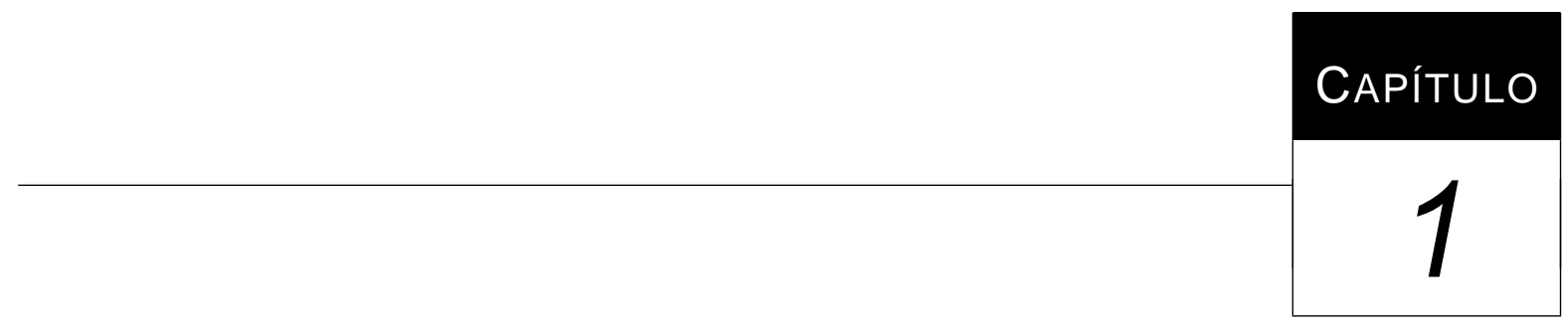

\section{Introdução}

\subsection{Contextualização}

Nas últimas décadas, sistemas de software têm conquistado papel essencial e crítico na sociedade (Humphrey, 1995; Fuggetta, 2000). Esses sistemas passaram a ser produtos grandes e complexos e, conseqüentemente, difíceis de desenvolver e testar. Aliado a isso, a satisfação do cliente tem sido a atual preocupação de muitas organizações que desenvolvem software (Paulk et al., 1995). Diante desse quadro, pesquisadores têm focado as atenções no entendimento e na melhoria da qualidade dos softwares desenvolvidos.Nesse contexto, a Engenharia de Software é uma disciplina em contínua evolução que tem como objetivo principal produzir software de alta qualidade a baixo custo.

As atividades de Engenharia de Software têm-se tornado essenciais para o desenvolvimento de sistemas de software, o que tem resultado em um forte investimento e consequiente proliferação de ferramentas de apoio a essas atividades. Essas ferramentas, bem como os AESs (Ambientes de Engenharia de Software ${ }^{1}$ ) - coleção integrada de ferramentas de Engenharia de Software - têm contribuído para melhorar a qualidade do processo de desenvolvimento de

\footnotetext{
${ }^{1}$ Neste trabalho, será utilizada a sigla AES para Ambiente de Engenharia de Software e AESs para Ambientes de Engenharia de Software.
} 
software, e conseqüentemente, a qualidade dos produtos resultantes desse processo, impactando positivamente na produção de sistemas de software.

Segundo Harrison et al. (2000), um tema que é bastante evidente nas pesquisas envolvendo AESs é a evolução e a integração. A capacidade de evolução desses ambientes é crucial, uma vez que eles precisam dar apoio à própria evolução que a área de Engenharia de Software sofre, com o advento de novos métodos, técnicas e processos, entre outros. Quanto à integração, um trabalho relevante nessa linha é o de Wasserman (1990), que classifica as integrações em: integração de plataforma, controle, processo, dados e apresentação. Para facilitar esses tipos de integração, diversos mecanismos têm sido investigados e propostos (Feng et al., 2002; Harrison et al., 2000; Nunes, 2005; Pohl et al., 1999; Reiss, 1990, 1994; Spinola, 2004); apesar desses esforços, a integração continua sendo um desafio nas pesquisas sobre AESs.

Recentemente, no contexto de Engenharia de Software, tem surgido a Engenharia Web (do inglês, Web Engineering ou WebE), uma abordagem sistemática e que usa princípios científicos, de engenharia e de gerenciamento para desenvolver, disponibilizar e manter sistemas Web de alta qualidade (Ginige \& Murugesan, 2001; Pressman, 2000). Os primeiros trabalhos nessa área são de meados da década de 90 e observa-se que as publicações têm-se multiplicado desde lá. Atualmente, muitos sistemas de software de diversos segmentos têm sido migrados para a plataforma Web, principalmente aqueles que apresentam intensiva manipulação de dados, intensiva interação com usuário e complexo processamento, tais como os sistemas de comércio eletrônico. Apesar disso, são poucas as iniciativas no domínio de Engenharia de Software, havendo então perspectivas futuras de que sistemas de domínios específicos, tais como para análise e projeto de sistemas, sejam disponibilizados sobre essa plataforma.

Assim como os sistemas "tradicionais", o desenvolvimento de sistemas Web não é uma tarefa trivial, requerendo também a aplicação de princípios disciplinados utilizados na construção de sistemas tradicionais. Assim, é relevante a investigação de métodos e técnicas de projeto, de implementação e de gerenciamento, bem como a adaptação dos métodos e das técnicas tradicionais para essa classe de software. Com relação aos métodos e técnicas que têm sido propostos para dar apoio à modelagem, destacam-se o OOHDM (Object-Oriented Hypermedia Design Method) (Rossi et al., 2001; Schwabe \& Rossi, 1995), o RMM (Relational Management Methodology) (Isakowitz et al., 1995) e as extensões dadas à UML (Baresi et al., 2001; Conallen, 1999a,b), dentre outros. Apesar da diversidade, a maioria desses métodos cobrem somente a etapa de projeto arquitetural e navegacional/interface do usuário, não apresentando apoio de maneira adequada para a união dos aspectos relacionados à apresentação da informação com às funcionalidades da aplicação. Além disso, esses métodos dão pouco apoio às atividades de VV\&T (Verificação, Validação e Teste) (Domingues, 2005). 
Tanto a Engenharia de Software quanto a Engenharia Web compreendem um conjunto de fases, muitas vezes chamado de modelo de processo de desenvolvimento de software. Um modelo de processo de desenvolvimento de software define as diferentes fases do tempo de vida de um software. Tipicamente, essas fases são a especificação de requisitos, projeto, implementação, integração, teste, operação e manutenção (Fuggetta, 2000; Sommerville, 1996). Mais recentemente, as chamadas metodologias ágeis, tais como o XP (eXtreme Programming) (Beck, 1999, 2000) e o SCRUM (Rising \& Janoff, 2000), têm surgido como uma alternativa aos modelos de processo de desenvolvimento "tradicionais" (por exemplo, Cascata (Royce, 1970) apud (Pressman, 2000) e Espiral (Boehm, 1988; Sommerville, 1996)). Adicionalmente, o processo de desenvolvimento de software livre também tem despontado como um processo viável. Observa-se que no final da década de 90 e início da década atual tem-se popularizado um tipo de software no qual o desenvolvimento e distribuição são bastante diferentes dos "tradicionais" softwares proprietários. O tema software livre (Free Software Foundation, 2001) tem chamado a atenção tanto da comunidade científica quanto da indústria de software, em virtude principalmente de sua forma de licenciamento (Free Software Foundation, 2006b) e de seu processo de desenvolvimento. Esse processo foi primeiramente descrito por Raymond (1999), ainda que informalmente em "The Cathedral and the Bazaar”, e chamado de Modelo Bazar. Atualmente, diversos trabalhos vêm sendo conduzidos no sentido de entender e sistematizar esse processo (Nakagawa, 2004a; Reis, 2003; Safe, 2003; Scacchi, 2001, 2002b; Scacchi et al., 2006), em virtude dos softwares de qualidade que têm sido obtidos desse processo. É importante salientar que as ferramentas e AESs devem possibilitar o desenvolvimento de software utilizando os diversos modelos de processo de desenvolvimento de software.

Um modelo de processo de desenvolvimento de software é, certamente, um importante ponto de partida para se definir como o software deverá ser desenvolvido. No entanto, observase que esses modelos não prescrevem as ações, as ferramentas, os procedimentos operacionais, as políticas de desenvolvimento e as limitações das organizações de forma precisa. Portanto, a adoção desses modelos não é suficiente para guiar e controlar de forma prática a construção de software (Fuggetta, 2000). Os problemas de desenvolvimento e de manutenção de software não podem ser solucionados somente com a seleção de um modelo de processo de desenvolvimento de software ou com a introdução de ferramentas e ambientes de desenvolvimento. Há a necessidade de se definir e usar processos de software que envolvam a complexa inter-relação de fatores organizacionais, culturais, tecnológicos e econômicos (Fuggetta, 2000). O processo de software define então o caminho pelo qual o desenvolvimento de software é organizado, gerenciado, medido, apoiado e melhorado, independentemente do tipo de apoio tecnológico utilizado no desenvolvimento (Montangero, 1999). 
Na década de 90, houve uma grande preocupação com a modelagem e melhoria do processo de software. Apesar disso, de acordo com Maurer et al. (1999), o desenvolvimento de software em muitas organizações é ainda mais uma arte do que uma atividade de engenharia. Nesse contexto, diversas normas e padrões na área de qualidade de software originaram-se no SEI (Software Engineering Institute) e na ISO (International Organization for Standardization); dentre elas, pode-se citar as normas ISO 9000-3 (International Organization for Standardization, 1997) e ISO/IEC 12207 (Paulk et al., 1993, 1995), o CMM (Capability Maturity Model) (Paulk et al., 1995) e o SPICE (que deverá resultar na norma ISO/IEC 15504) (Eman et al., 1997). Diversos trabalhos têm utilizado essas normas e padrões na melhoria da qualidade do processo de software (Boegh, 1999; Cass et al., 2000; Herbsleb \& Goldenson, 1996; Johnson \& Brodman, 2000; Machado et al., 1999; O’Hara, 2000).

A inerente complexidade do processo de software faz com que ambientes de automatização de processo, muitas vezes referenciados como Ambiente de Engenharia de Software Centrado em Processo (do inglês, Process-centered Software Engineering Environment ou PSEE), tornem-se indispensáveis. Na literatura disponível sobre processo de software, pode-se identificar diversas ferramentas (Ambriola et al., 1997; Bandinelli et al., 1996; Junkermann et al., 1994; Maidantchik, 1999; Maurer et al., 1999, 2000; Nguyen et al., 1997; Sommerville, 2001; Rocha et al., 2001b), dando apoio às diversas linguagens de modelagem de processos (Ambriola et al., 1997; Bandinelli et al., 1993; Belkhatir et al., 1991; Chen, 1997; Conradi \& Jaccheri, 1999; Nguyen et al., 1997; Sutton et al., 1995; Sutton \& Osterweil, 1997), muitas delas baseadas nos paradigmas de programação "convencional”, tais como funcional, lógico e imperativo.

As iniciativas de componentização de software e de desenvolvimento orientado a objetos na década de 80 despertaram a comunidade de software para as oportunidades e vantagens da reutilização de código-fonte. O sucesso dessas iniciativas levou a estender a reutilização para diversas etapas do processo de desenvolvimento de software, incluindo subprodutos de trabalho, tais como o projeto arquitetural, documentos, especificações e modelos, entre outros, o que contribui ainda mais para a perspectiva de redução de custos e tempo, bem como o ganho de produtividade e qualidade. Dessa forma, observa-se atualmente que o reúso tem sido foco de muitas pesquisas em Engenharia de Software. Nesse contexto, dispor de mecanismos que contribuam nessa perspectiva é certamente relevante, inclusive quando se trata do desenvolvimento de sistemas que automatizam atividades de Engenharia de Software. 
Vale destacar que dentre os mecanismos de reutilização sendo investigados, pode-se citar os frameworks $^{2}$, a abordagem de linhas de produto, os geradores de aplicação e as arquiteturas de software, mais especificamente, as arquiteturas de referência ${ }^{3}$.

Uma vez que arquiteturas de software têm desempenhado um papel significativo na determinação do sucesso de sistemas de software na última década, a Arquitetura de Software tem emergido como uma área de pesquisa na qual engenheiros de software e pesquisadores têm investido seus esforços. Garlan \& Perry (1995) dizem que arquiteturas de software podem ter um impacto positivo em diversos aspectos do desenvolvimento de software, tais como no entendimento, na reutilização, na evolução, na análise e no gerenciamento do sistema. Observa-se, dessa forma, que a arquitetura de software constitui-se num fator de suma importância na qualidade dos sistemas de software. Nesse contexto, arquiteturas de referência para os mais diversos domínios têm sido propostos (Barber et al., 2002; Bass et al., 2003; Batory et al., 1995; Eickelmann \& Richardson, 1996; Perrochon, 1995; Sandkuhl \& Messer, 2000; Zdun, 2002), e também para ferramentas de Engenharia de Software, mais especificamente, para ferramentas do domínio de teste de software (Eickelmann \& Richardson, 1996).

Visando à reutilização tanto de código-fonte quanto de esforços despendidos no desenvolvimento de sistemas de software, frameworks têm sido investigados e propostos para diversos domínios de aplicação (Braga, 2003; Brant, 1999; Fayad et al., 1999b; Fayad \& Johnson, 2000; Monday et al., 2000; Pazin, 2004). A diversidade de frameworks sendo propostos evidencia sua relevância como mecanismo de apoio ao desenvolvimento de sistemas de software, contribuindo para a produtividade e qualidade dos produtos de software.

Recentemente, a separação de interesses (do inglês, separation of concerns) (Dijkstra, 1976) tem sido foco de atenção, em virtude do surgimento de uma nova abordagem de desenvolvimento de software, a programação orientada a aspectos (POA) (Kiczales et al., 1997). Segundo Elrad et al. (2001b), a programação orientada a aspectos veio para melhorar ainda mais a separação de interesses se comparada com a orientação a objetos, um paradigma de programação que já tem se evidenciado nos últimos anos e melhorado significativamente a capacidade de alcançar uma boa separação de interesses. Como resultado de uma boa separação de interesses pode-se ter a redução dos custos de desenvolvimento, bem como a facilidade no desenvolvimento e na manutenção do software (Kiczales et al., 1997; Rashid et al., 2003).

\footnotetext{
${ }^{2}$ Neste trabalho, o termo framework será utilizado de acordo com a definição de Fayad \& Johnson (2000), que diz que framework é mais do que uma arquitetura, sendo uma aplicação semi-completa contendo componentes estáticos e dinâmicos que podem ser adaptados para produzir aplicações específicas. Observa-se que esse termo é utilizado em diversos outros trabalhos com diferentes significados, tais como um componente, uma estrutura geral, um mecanismo ou um conjunto de passos.

${ }^{3}$ Entende-se por arquitetura de referência uma estrutura que provê uma caracterização das funcionalidades dos sistemas de software de um dado domínio de aplicação (Eickelmann \& Richardson, 1996).
} 
De modo geral, o principal objetivo da POA é possibilitar a manipulação dos interesses transversais (do inglês, crosscutting concerns) — interesses que estão espalhados ou entrelaçados com outros interesses do sistema - tão separados quanto possível, encapsulando-os em unidades chamadas de aspectos e, em seguida, combinando-os para construir uma aplicação completa. Pode-se identificar diversos trabalhos explorando o uso de aspectos na implementação de interesses transversais (Camargo et al., 2003; Camargo \& Masiero, 2005; Elrad et al., 2001a; Filman \& Friedman, 2000; Garcia, 2004; Kiczales et al., 1997; Rashid et al., 2003; Rocha et al., 2005). Têm-se também trabalhos que investigam o tratamento dos requisitos de sistemas orientados a aspectos (Rashid et al., 2003; Sampaio et al., 2005), bem como a análise e o projeto (Chavez, 2004; Clarke \& Walker, 2001, 2002; Stein et al., 2002; Suzuki \& Yamamoto, 1999; Clarke \& Baniassad, 2005) e o teste de sistemas (Lemos et al., 2004; Lemos, 2005; Mortensen \& Alexander, 2004). Vale ressaltar que em sua maioria, os trabalhos tratam de interesses transversais não funcionais (Camargo et al., 2003; Camargo \& Masiero, 2005; Elrad et al., 2001b; Garcia, 2004), tais como persistência e segurança. Poucos são os trabalhos que abordam interesses transversais relacionadas às regras de negócio (Camargo \& Masiero, 2005; Cibrán et al., 2003; Suvée et al., 2005).

Ainda nesse contexto, surgiu também o interesse em investigar como a programação orientada a aspectos pode ser utilizada no desenvolvimento de frameworks (Camargo \& Masiero, 2005). Desse modo, trabalhos recentes têm abordado frameworks orientados a aspectos (Camargo \& Masiero, 2005; Constantinides et al., 2000; Pinto et al., 2002; Rashid \& Chitchyan, 2003). Um tipo de framework orientado a aspectos são os frameworks transversais (do inglês, crosscutting frameworks) (Camargo \& Masiero, 2005) que implementam um único interesse transversal e que requerem o acoplamento com um código-base para ser utilizado.

Visando apoiar a aquisição, organização, reúso e compartilhamento de conhecimento, a exemplo de outras áreas, sobretudo a Medicina, Engenharia e Direito, a área de Engenharia de Software tem também investido em pesquisas envolvendo a proposição de ontologias. Como exemplos, pode-se citar a ontologia para processo de software (Falbo, 1998), a ontologia para domínios (Oliveira et al., 2000), a ontologia para documentação (Nunes et al., 2004), a ontologia de tarefas (Zlot, 2002) e a ontologia de teste de software Huo et al. (2003).

Dentre as pesquisas em Engenharia de Software, o teste de software tem-se despontado entre as áreas de pesquisa mais promissoras e importantes para a qualidade do software (Harrold, 2000), tendo fundamental importância para a identificação e eliminação de defeitos do software (Maldonado, 1991). Ainda nessa linha, Armour (2005) diz que boas práticas de Engenharia de Software não substituem a atividade de teste de software. 
Dada a relevância da atividade de teste no processo de desenvolvimento, diversos pesquisadores têm investigado técnicas e critérios de teste. Como exemplos de trabalhos publicados nessa linha têm-se (Beizer, 1990; Budd, 1981; DeMillo et al., 1978; Friedman et al., 2002; Grieskamp et al., 2002; Harrold, 2000; Miao et al., 1999; Frankl \& Weyuker, 2000; Hartmann et al., 2000; Jackson \& Woodward, 2000; Myers, 1979; Rapps \& Weyuker, 1985; Souter \& Pollock, 2000; Tikir \& Hollingsworth, 2002; Zhu et al., 1997). A exemplo desses diversos pesquisadores, o grupo de pesquisa em teste de software do ICMC/USP tem investigado técnicas e critérios de teste, tanto no nível de programa (Delamaro, 1993, 1997; Delamaro et al., 2001; Maldonado, 1991; Vincenzi, 2004) quanto no nível de especificação (Fabbri et al., 1994b, 1995; Fabbri, 1996; Fabbri et al., 1997, 1999b; Simão, 2000; Simão et al., 2000; Simão, 2004; Souza et al., 1999, 2000a,b; Sugeta, 2004). Esses trabalhos têm contribuído para a sistematização e aprimoramento da qualidade da atividade de teste e, conseqüentemente, da qualidade do produto em desenvolvimento.

A aplicação de técnicas e critérios de teste, tanto em programas quanto em especificações, é impraticável sem o apoio automatizado de ferramentas de teste de software. Diversas são as ferramentas, tanto acadêmicas quanto comerciais, identificadas na literatura (Agrawal et al., 1998; Choi et al., 1989; DeMillo et al., 1988; Horgan \& Mathur, 1992; Chaim, 1991; Chevalley \& Thévenod-Fosse, 2003; Childers et al., 2003; Delamaro, 1993, 1997; Fabbri et al., 1994a, 1999a,b; Lutz, 1990; Ma et al., 2005; Maldonado et al., 2000; Misurda et al., 2005a; Price \& Zorzo, 1990; IBM, 2006; Rocha, 2005; Simão \& Maldonado, 2000; Simão, 2004; Sugeta, 1999, 2004; Sze \& Lyu, 2000; Telcordia Technologies, 2005; Vincenzi, 2004; Yano et al., 2003) Ferramentas de teste melhoram a qualidade e produtividade da atividade de teste e vêm sendo aplicadas tanto no ambiente acadêmico quanto na indústria de desenvolvimento de software. Para dar apoio à automatização da atividade de teste de software, trabalhos como o de Eickelmann \& Richardson (1996), Yang et al. (1999) e Sun et al. (2000) têm tomado a iniciativa de propor arquiteturas de ferramentas de teste.

\subsection{Motivação}

Observa-se nos últimos anos uma proliferação de ferramentas e AESs; contudo, ainda há a necessidade de sistematizar e estabelecer uma infra-estrutura adequada ao desenvolvimento dessas ferramentas e ambientes. Além disso, a literatura carece ainda de trabalhos que envolvam AESs e arquiteturas de software. Em virtude da característica de evolução de AESs, há a necessidade de estabelecer arquiteturas de software que possibilitem uma evolução contínua desses ambientes. 
A grande maioria das ferramentas que automatizam atividades de Engenharia de Software, muitas vezes, não tem como preocupação questão de integração com as demais ferramentas. Atualmente, AESs são construídos, muitas vezes, com base em ferramentas que foram construídas previamente, a exemplo do trabalho de Lucrédio et al. (2004), sem considerar inicialmente questões mais gerais, tais como a arquitetura do ambiente. Assim, para resolver problemas de integração, há a necessidade de esforço extra no sentido de adequar as interfaces dessas ferramentas e suas bases de dados. Além disso, há uma carência de trabalhos que explorem arquiteturas de software adequadas que possibilitem a integração das diversas ferramentas que automatizam tanto atividades fundamentais quanto de apoio e organizacionais, com relação aos diversos tipos de integração.

A maioria dos trabalhos identificados na literatura sobre frameworks orientados a aspectos implementam interesses não-funcionais, tais como a persistência e a segurança. Poucos são os trabalhos que utilizam aspectos para a implementação de regras de negócios (ou requisitos funcionais). É importante salientar também que a literatura carece de frameworks orientados a aspectos que automatizam atividades de Engenharia de Software.

Pela relevância da atividade de teste, bem como de ferramentas de teste de software, é essencial propor mecanismos que viabilizem e facilitem o desenvolvimento de ferramentas de teste. Pela complexidade dessas ferramentas, observa-se que a reutilização da experiência e dos esforços despendidos em seus projetos e implementações é de fundamental importância. Apesar disso, observa-se que não se encontram na literatura trabalhos que abordem o desenvolvimento de ferramentas de teste de forma efetiva e com base em reutilização. Além disso, não há uma sistematização ou padronização no desenvolvimento dessas ferramentas. Muitas delas são construídas de forma individual, sem considerar a necessidade de evolução e reutilização dos esforços de desenvolvimento, por exemplo, para dar apoio a novas técnicas e critérios de teste. Isso se deve, muitas vezes, pela falta de separação de interesses na implementação de ferramentas de teste, o que faz com que códigos referentes a um determinado interesse encontre-se espalhado pelos diversos módulos da ferramenta. Isso também dificulta o desenvolvimento de outras ferramentas com base nas ferramentas já existentes, e também o entendimento e a manutenção dessas ferramentas. Além disso, muitas das ferramentas de teste não apresentam funcionalidades relacionadas às atividades de apoio, tais como gerenciamento de configuração e documentação, bem como funcionalidades relacionadas às atividades organizacionais, tais como o planejamento e a gerência da atividade de teste, assim como funcionalidades relacionadas aos mecanismos de ajuda (do inglês, help), tutoriais e treinamento no uso das ferramentas. Além disso, de acordo com Childers et al. (2003), as ferramentas de teste de software atuais são inflexíveis, implementando somente uma determinada técnica de teste. 
Uma vez que arquiteturas de software têm papel fundamental no processo de desenvolvimento de software, inclusive de ferramentas de teste e, considerando-se a carência de arquiteturas de referência de ferramentas de teste, a proposição de arquiteturas que sejam adequadas, recentes e eficazes para a construção de ferramentas de teste é bastante relevante.

Apesar da relevância do uso da plataforma Web para a disponibilização de sistemas de software, ferramentas e AESs para essa plataforma ainda não são largamente encontradas. Assim como outros sistemas já disponibilizados sobre essa plataforma, essas ferramentas e ambientes poderão usufruir das diversas vantagens de sistemas Web, tais como o acesso remoto e a portabilidade. Nessa linha, no trabalho de Gao et al. (1997) são discutidas as limitações de ferramentas de teste "tradicionais", motivando para ferramentas de teste para Web. Considerando-se ferramentas de diagramação (modelagem), o trabalho de Cao et al. (2004) discute os desafios para a construção de ferramentas dessa categoria para a Web.

\subsection{Objetivos}

Diante do cenário apresentado nas seções anteriores, em linhas gerais, este trabalho consiste em investigar métodos e mecanismos que facilitem o desenvolvimento de ambientes e ferramentas de Engenharia de Software, visando à diminuição dos custos de desenvolvimento e manutenção desses ambientes e ferramentas. Mais especificamente, é estabelecida uma arquitetura de referência de AESs, buscando atender, em especial, a facilidade de evolução contínua, de uso e de integração que esses ambientes requisitam. Para isso, serão também explorados mecanismos, tais como o desenvolvimento de software orientado a aspectos e o uso de frameworks e de ontologias, bem como a norma internacional ISO/IEC 12207, para estabelecer uma arquitetura adequada, e ao mesmo tempo eficaz, como mecanismo de apoio ao desenvolvimento de AESs.

Para avaliar a viabilidade de utilização da arquitetura proposta, essa arquitetura é especializada para o domínio de teste de software, resultando em uma arquitetura de referência para ferramentas de teste. Para isso, deve-se considerar a investigação e a análise do domínio de teste, uma vez que um conhecimento aprofundado desse domínio é necessário para o estabelecimento da arquitetura pretendida.

Em virtude da tendência e vantagens que a plataforma Web vem mostrando para a disponibilização de sistemas de software, as arquiteturas propostas devem possibilitar inclusive o desenvolvimento de ferramentas e ambientes para essa plataforma. 
Um outro objetivo deste trabalho é explorar o uso de aspectos para a integração em AESs, bem como no projeto e desenvolvimento de frameworks transversais para a automatização de atividades de apoio e atividades organizacionais ao desenvolvimento de software.

Buscando dar subsídios para o estabelecimento de arquiteturas de referência para outros domínios, é proposto um processo preliminar baseado em arquitetura que envolve a especialização e a instanciação da arquitetura de referência de AESs proposta.

\subsection{Organização do Trabalho}

Neste capítulo foram apresentados o contexto em que o trabalho se insere, as motivações para a sua realização e os objetivos pretendidos.

No Capítulo 2 é apresentada a revisão bibliográfica envolvendo os principais temas pertinentes ao contexto deste trabalho.

No Capítulo 3 é apresentada a arquitetura de referência de AESs que foi proposta com base em conceitos, padrões arquiteturais, normas e mecanismos relevantes ao contexto de arquiteturas para esse domínio. São também mostrados os modelos arquiteturais de modo a descrever adequadamente a arquitetura proposta.

No Capítulo 4 é apresentada a arquitetura de referência de ferramentas de teste de software, resultante de uma investigação do domínio de teste e baseada na arquitetura de AESs proposta neste trabalho. É também discutido em detalhes o projeto de frameworks transversais que possibilitam automatizar atividades de apoio e organizacionais relacionado ao desenvolvimento de software.

No Capítulo 5 é descrito um processo preliminar baseado em arquitetura para o estabelecimento de arquiteturas de referência de ferramentas de Engenharia de Software. Esse processo tem como base a especialização e a instanciação da arquitetura de AESs proposta no contexto deste trabalho.

Finalmente, no Capítulo 6 são caracterizados os principais resultados, as contribuições, bem como as perspectivas de trabalhos futuros.

Nos Apêndices A e B são apresentados, respectivamente, a OntoTest — uma ontologia para o domínio de teste de software - e um DTD (Document Type Definition) para documentação da atividade de teste de software. 


$\frac{\overline{2}}{2}$

\section{Revisão Bibliográfica}

\subsection{Considerações Iniciais}

Considerando-se a necessidade de investigar métodos e mecanismos que facilitem o desenvolvimento de ferramentas e AESs, mais especificamente, a investigação e a proposição de arquiteturas de software para essas ferramentas e ambientes, uma pluralidade de temas deve ser investigada para dar respaldo às contribuições resultantes deste trabalho. De modo geral, este trabalho está inserido nas seguintes linhas de pesquisa: Arquitetura de Software, AESs e Teste de Software. Dessa forma, neste capítulo é apresentada uma revisão dos principais temas de pesquisas, nos quais este trabalho está fundamentado.

Considerar processo de software e processo de desenvolvimento de software é fundamental para guiar o estabelecimento de arquiteturas para ferramentas e AESs, uma vez que esses últimos são elementos que automatizam e dão subsídios à execução dos processos. Na Seção 2.2 são então apresentados os temas processo de software e processo de desenvolvimento de software. Nesse contexto, embora o tema software livre não esteja ligado diretamente a este trabalho, foi reservado uma seção (Seção 2.2.3) para esse tema, em virtude de estar atualmente em evidência, apresentar um processo de desenvolvimento de software bastante diferente dos "tradicionais", ser apontado em diversos pontos deste trabalho e ser de interesse como mecanismo 
para a implementação de ferramentas e AESs. Em seguida, na Seção 2.3, é discutido o estado das pesquisas envolvendo AESs, bem como as limitações que os ambientes atuais apresentam.

Sendo um dos focos principais deste trabalho, a arquitetura de software é apresentada na Seção 2.4, juntamente com as técnicas sendo investigadas para sua representação, além de dar especial atenção às arquiteturas de sistemas Web.

Visando ao reúso, frameworks são mecanismos que têm chamado a atenção em virtude da capacidade de reúso dos subprodutos do processo de desenvolvimento de software. Assim, esse tema é apresentado na Seção 2.6. Em especial, os frameworks orientados a aspectos, apresentados na Seção 2.6.3, são de interesse no contexto deste trabalho, assim como a abordagem de desenvolvimento de software orientada a aspectos, discutida na Seção 2.5.

No contexto de reúso, visando a aquisição, organização, reúso e compartilhamento de conhecimento, ontologias têm sido investigadas e propostas na área de Engenharia de Software. Na Seção 2.7, é apresentado brevemente o tema ontologia. Por fim, uma visão geral sobre Teste de Software, com ênfase nas questões relacionadas à automatização da atividade de teste, é apresentada na Seção 2.8 .

\subsection{Processo de Software}

Organizações de desenvolvimento de software de diferentes portes têm percebido que o sucesso na entrega de seus produtos, em termos de tempo e de custo e com qualidade esperada, depende de um gerenciamento efetivo de seus processos de software (Montangero, 1999). No entanto, definir e implantar um processo de software adequado à organização não é uma tarefa trivial, uma vez que há muitos elementos e atividades que devem ser devidamente planejados e controlados.

Entende-se por processo de software um conjunto coerente de políticas, estruturas organizacionais, tecnologias, procedimentos e artefatos que são necessários para conceber, desenvolver e manter um produto de software (Fuggetta, 2000). Portanto, processos de software são inerentemente complexos, estando sujeitos às mudanças nos requisitos e nos prazos, retorno às fases anteriores do ciclo de vida, redução do orçamento, entre outros (Finkelstein et al., 1994) apud (Jäger et al., 1999). Além de Fuggetta (2000), outros pesquisadores da área têm discutido o entendimento e a abrangência de processos de software (Bandinelli et al., 1993; Humphrey, 1995; Montangero, 1999; Paulk et al., 1995; Pressman, 2000). 
A partir do trabalho publicado por Osterweil (1987), e revisado em (Osterweil, 1997), no qual é estabelecido uma analogia entre um software e um processo de software - uma vez que ambos são executáveis, possuem um conjunto de requisitos, apresentam benefícios se modelados por uma variedade de técnicas, evoluem guiados por resultados de medições, e assim por diante - houve um grande crescimento no número de pesquisas envolvendo processos de software. O trabalho de Osterweil (1987) teve grande impacto em como processos de software podem ser encarados, sendo atualmente considerado um dos trabalhos mais influentes na área de processo de software.

Desde então, pesquisas na área de processo de software têm tomado relevantes direções, principalmente na linha de métodos e técnicas de modelagem, linguagens e ferramentas de automatização de processo. Diversos estudos têm explorado o uso de técnicas de modelagem de software, tais como Redes de Petri, Statecharts e diagramas da UML (Unified Modelling Language) (Rumbaugh et al., 1999), para modelar processos (Bandinelli et al., 1993; Chen, 1997; Di Nitto et al., 2002; Fuggetta, 2000; Jäger et al., 1999; Junkermann et al., 1994; Osterweil, 1997). Para a implementação de processos, diversas linguagens têm sido propostas, implementadas e experimentadas (Ambriola et al., 1997; Bandinelli et al., 1993; Belkhatir et al., 1991; Chen, 1997, 2004; Chen et al., 2005; Conradi \& Jaccheri, 1999; Nguyen et al., 1997; Sutton et al., 1995; Sutton \& Osterweil, 1997), e segundo Conradi \& Jaccheri (1999), ainda não existe um consenso geral ou padronização entre elas. Em geral, essas linguagens têm o apoio de ferramentas que automatizam a criação e a execução dos modelos de processo; essas ferramentas são, muitas vezes, referenciadas como AESs Baseados em Processos. Discussões sobre esses ambientes, bem como técnicas para modelagem de processos, são apresentadas na Seção 2.3.

Uma outra linha de pesquisa que tem se destacado é a de modelos de qualidade e modelos de melhoria de processo, buscando-se documentar as melhores práticas de desenvolvimento de software. Um modelo de qualidade define os requisitos de uma organização ideal, ou seja, é um modelo de referência para ser utilizado para avaliar o estado da organização e o grau de melhoria alcançado ou a ser alcançado (Emmerich, 1999); como exemplos de modelos de qualidade mais reconhecidos, pode-se citar o CMM (Capability Maturity Model) (Paulk et al., 1993, 1995; Pessôa \& Spinola, 2001; Osterweil, 1997) e a ISO 9000-3 (International Organization for Standardization, 1991, 1997). Um modelo de melhoria de processo de software sugere os passos a serem executados para melhorar a qualidade de um processo de software; como exemplos mais conhecidos de modelo de melhoria, pode-se citar o PDCA (Plan-Do-Check-Act) e o IDEAL (Initiating, Diagnosing, Establishing, Acting, Learning) (Gremba \& Myers, 1997). Entende-se por melhoria de processo ter o entendimento do processo existente e as mudanças realizadas nesse processo de modo a aumentar a qualidade do produto de software e/ou reduzir custos 
e o tempo de desenvolvimento (Sommerville, 2001). Melhoria de processo pode ser definido também como as ações tomadas dentro da organização de modo a aumentar a eficácia e a eficiência das atividades e processos, provendo benefícios tanto para a organização quanto para seus clientes (Warboys, 1998).

Ainda nessa linha, pode-se observar um desenvolvimento significativo de técnicas e métodos relacionados às métricas de software e aos estudos experimentais para uma avaliação sistemática da qualidade dos processos de software (Fuggetta, 2000). Mais recentemente, uma diversidade de trabalhos que relatam experiências relacionadas à definição, implantação, controle e melhoria do processos de software podem ser identificadas; como exemplo, pode-se citar os trabalhos de Brownsword et al. (2000); Caputo (1998); Cockburn (2000); Conradi \& Fuggetta (2002); Florac \& Carleton (1999); Florac et al. (2000); Humphrey (1997); Keeni (2000); Sutton (2000); Johnson \& Brodman (2000); Morisio et al. (2000) e Pitterman (2000).

\subsubsection{Padronização de Processo de Software}

Observa-se que processo de software tem sido foco de considerável atenção em importantes instituições, tais como o SEI ${ }^{1}$ (Software Engineering Institute) nos Estados Unidos e o ESI ${ }^{2}$ (European Software Institute) na Europa, que têm direcionado seus esforços no estudo de processo de software. Organizações para padronização, como a ISO ${ }^{3}$ (International Organization for Standardization), têm-se destacado pelos relevantes esforços tendo o processo de software como objetivo central.

Como um dos resultados desses esforços, destaca-se o CMM (Paulk et al., 1993, 1995; Pessôa \& Spinola, 2001; Osterweil, 1997) e o CMMI (Capability Maturity Model Integration) (Software Engineering Institute, 2002). O CMM e o CMMI foram desenvolvidos pelo SEI na Carnegie Mellon University com o objetivo de avaliar a maturidade da capacidade dos processos de software das organizações e para identificar as práticas que são requeridas para melhorar a maturidade desses processos. Entende-se por capacidade do processo de software a habilidade inerente de um processo em produzir os resultados planejados (Paulk et al., 1995).

Além do SEI, a ISO tem investido na consolidação de diversas normas, tendo algumas delas um grande impacto no contexto de processo de software, como por exemplo a ISO/IEC $15504^{4}$

\footnotetext{
${ }^{1}$ http: //www. sei.cmu.edu/ (acessado em 23/07/2005)

${ }^{2}$ http: / / www.esi.es/ (acessado em 23/07/2005)

${ }^{3}$ http: / / www.iso.org/ (acessado em 23/07/2005)

${ }^{4}$ A ISO/IEC 15504 está atualmente publicada como um relatório técnico e é o resultado do projeto SPICE (Software Process Improvement and Capability dEtermination), iniciado em janeiro de 1993 com o objetivo de criar um padrão internacional para avaliação de processos de software.
} 
(International Organization for Standardization, 1998), um modelo de melhoria do processo e de determinação da capacidade do processo nas organizações e a ISO/IEC 12207 (International Organization for Standardization, 1995), que estabelece um conjunto de atividades envolvidas na construção de software.

A ISO/IEC 12207 - "Information Technology - Software Life-Cycle Processes" (International Organization for Standardization, 1995) e a correspondente em português, a NBR ISO/IEC 12207 - “Tecnologia da Informação - Processos de Ciclo de Vida de Software” (Associação Brasileira de Normas Técnicas, 1998) são normas que cobrem todo o ciclo de vida de desenvolvimento do software desde a concepção das idéias iniciais sobre o software até ser retirado de execução. Além disso, consistem também de processos para a aquisição e o fornecimento de produtos e serviços, bem como de mecanismos para o controle e melhoria de todos os processos envolvidos no ciclo de vida de desenvolvimento de software (Machado, 2001). A ISO/IEC 12207 foi projetada para poder adequar-se a uma organização específica ou projeto; também foi projetada para ser utilizada quando o software é uma entidade única ou quando faz parte de um sistema maior, ou mesmo, quando é um software embarcado (International Organization for Standardization, 1995). Normas como a ISO/IEC 12207 são genéricas e escritas de forma que possam ser instanciados para projetos específicos. Certamente, a implantação desses modelos em organizações que desenvolvem software traz benefícios quanto à qualidade e ao custo de desenvolvimento de software, uma vez que esses modelos são resultados de uma coletânea das melhores práticas adotadas pela comunidade de desenvolvimento de software.

A ISO/IEC 12207 tem sido utilizada para derivar outros processos, tais como o processo para a modelagem e desenvolvimento de módulos educacionais (Barbosa, 2004) e o processo de software para equipes geograficamente distribuídas (Maidantchik, 1999).

\subsubsection{Processo de Desenvolvimento de Software}

No contexto de processo de software, o processo de desenvolvimento de software aparece como tendo extrema relevância no tocante à sistematização das atividades envolvidas com a construção do software, considerando-se desde a concepção inicial até a fase de manutenção do software. Esse processo define as diferentes etapas ou estágios do tempo de vida de um software e estabelece os princípios e as diretrizes de como os diferentes estágios devem ocorrer. De acordo com Fuggetta (2000) e Sommerville (1996), de modo geral, esses estágios são a especificação de requisitos, projeto, implementação, integração, teste, operação e manutenção. 
Na literatura disponível sobre Engenharia de Software, pode-se identificar diversos modelos de processo de desenvolvimento de software. Entre os mais clássicos estão o Modelo Seqüencial Linear (também conhecido como Modelo Cascata ou Ciclo de Vida Clássico) (Royce, 1970) apud (Pressman, 2000), a Prototipação (Pressman, 2000) e o Modelo Espiral (Boehm, 1988; Sommerville, 1996). Baseados nesses modelos, diversos outros têm sido propostos, dentre eles o RAD (Rapid Application Development) (Kerr \& Hunter, 1994) e o Modelo Baseado em Componentes (Nierstrasz et al., 1992). Nessa mesma linha, modelos de processo para o desenvolvimento de sistemas Web também têm sido propostos (Pressman, 2000).

Observa-se que cada modelo apresenta pontos fortes e limitações, o que necessita uma análise das características específicas de cada organização ou projeto para sua adoção. Contudo, pesquisadores na linha de metodologias ágeis, também referenciadas como processos ágeis de desenvolvimento de software (do inglês, agile software processes), têm visto esses modelos como antigos e inadequados para o desenvolvimento de software nas organizações atuais, principalmente naquelas em que são desenvolvidos sistemas para a plataforma Web (Maurer \& Martel, 2002). Os processos ágeis têm então surgido como uma alternativa aos modelos de processo de desenvolvimento "tradicionais", tendo por objetivo melhorar a eficiência da organização em desenvolver software enquanto buscam diminuir a "burocracia" do desenvolvimento (Maurer $\&$ Martel, 2002). Atualmente, uma diversidade de processos ágeis têm sido propostos. Como exemplos mais conhecidos têm-se o XP ${ }^{5}$ (eXtreme Programming) (Beck, 1999, 2000), o Scrum (Rising \& Janoff, 2000), o FDD (Feature-Driven Development) (Palmer \& Felsing, 2002) e o processo de desenvolvimento de software livre (Mockus et al., 2002; Raymond, 1999). Vale ressaltar que ainda não há um consenso sobre a classificação ou não do processo de desenvolvimento de software livre como um processo ágil.

O XP tem-se destacado e vem sendo alvo de atenção de pesquisadores; diversos trabalhos têm investigado esse processo de desenvolvimento. Como exemplo, pode-se citar os trabalhos de Cockburn \& Williams (2000); Martin (2000); Maurer \& Martel (2002); Müller \& Tichy (2001); Poole \& Huisman (2001) e Williams et al. (2000). XP é um processo de desenvolvimento leve (do inglês, lightweight) com muita pouca burocracia, tendo-se equipes pequenas de 5 a 15 desenvolvedores - produzindo softwares incrementalmente e analisando requisitos à medida que são fornecidos pelo cliente. A documentação é quase que inexistente e quando existe, é mínima e mantida junto com o código-fonte, requerendo que o desenvolvedor escreva códigos auto-explicativos. Esse processo não apresenta as fases do ciclo de vida do software claramente definidas; o projeto, a implementação e o teste são realizados quase que paralelamente e não apresenta atividades de revisão ou inspeção formal.

\footnotetext{
${ }^{5}$ http: //www. extremeprogramming . org/ (acessado em 23/07/2005)
} 
Considerando-se as características de sistemas Web, principalmente o fato de requerer um desenvolvimento rápido e evolução e manutenção contínua, processos ágeis podem ser adotados como processo de desenvolvimento que melhor se encaixa à construção desse tipo de sistema. Nessa linha, o trabalho de Maurer \& Martel (2002) investiga a aplicação das práticas do XP no desenvolvimento de sistemas Web; resultados do estudo de caso mostram o aumento da produtividade quanto ao número de linhas de código produzidas pelos desenvolvedores.

\subsubsection{Processo de Desenvolvimento de Software Livre}

Nos últimos anos, o movimento de software livre teve um grande impulso. Observa-se o surgimento de uma diversidade de softwares para atender às necessidades dos usuários da indústria, das universidades e de outros ramos de aplicação da informática. Vale ressaltar que se pode identificar softwares livres no qual a porcentagem de utilização é superior se comparada a de softwares proprietários com funcionalidades equivalentes; é o caso do Apache (Mockus et al., 2000, 2002).

Em nível nacional, softwares livres têm assumido importância cada vez maior em órgãos e autarquias do Governo Federal, Estadual e Municipal, em especial, dentro das universidades e mesmo nas empresas privadas. Contudo, o conceito de software livre é bastante antigo e vem das décadas de 60 e 70, quando os computadores chegaram às universidades e eram objeto de pesquisa e o código-fonte dos softwares era distribuído gratuitamente (Bollinger \& Beckman, 1999; Yamauchi et al., 2000). A idéia de software livre tem sido popularizada a partir de 1984 quando Richard Stallman fundou a Free Software Foundation ${ }^{6}$ e o projeto GNU ${ }^{7}$, liderando o que é conhecido atualmente como Movimento de Software Livre.

É importante ressaltar que atualmente o tema software livre não está somente restrito aos esforços e interesses individuais. Grupos de pesquisas de diversas universidades têm direcionado suas atenções para o estudo e entendimento de software livre, seu processo de desenvolvimento, impactos econômicos e sociais, entre outros. Como exemplos, tem-se o grupo de pesquisa do Institute for Software Research ${ }^{8}$ da University of California (Scacchi, 2001, 2002b; Scacchi et al., 2006) e do ICMC/USP (Nakagawa, 2004a; Reis, 2003; Safe, 2003). Pode-se citar inclusive o surgimento de eventos científicos envolvendo especificamente o tema software livre, tais

\footnotetext{
${ }^{6}$ http: / / www. fsf.org (acessado em 23/07/2005)

${ }^{7}$ http: //www.gnu.org (acessado em 23/07/2005)

${ }^{8}$ http: / / www.isr.uci.edu/research-open-source.html (acessado em 09/02/2006)
} 
como o Workshop on Open Source Software Engineering ${ }^{9}$, o International Conference on Open Source Systems ${ }^{10}$ e o Workshop de Software Livre ${ }^{11}$.

A definição mais largamente aceita do termo software livre é a dada em (Free Software Foundation, 2001), que diz que qualquer software caracterizado como software livre deve fornecer a seus usuários as seguintes liberdades: (i) executar o programa para qualquer propósito; (ii) estudar o funcionamento do programa e modificá-lo, adaptando-o às suas necessidades; e (iii) redistribuir cópias do código-fonte, juntamente com as alterações que forem realizadas. De fato, um software é considerado livre quando é acompanhado de uma permissão para uso, cópia, distribuição e redistribuição, realizando ou não modificações, de forma gratuita ou cobrando uma taxa. Para que a modificação seja possível, o código-fonte deve acompanhar o software. Um mecanismo que garante essas permissões são as licenças de software livre ${ }^{12}$. Atualmente, pode-se identificar algumas dezenas de licenças de software livre (Free Software Foundation, 2006b; Perens, 1999; Open Source Initiative, 2006), sendo que a GPL (General Public License ou Licença Pública Geral) (Free Software Foundation, 2006b) é reconhecidamente a licença mais popular da comunidade de software livre. Observa-se que a filosofia de software livre e as imposições feitas pelas licenças de software livre estão em consonância com os imperativos morais ditados pelo código de ética da ACM (Anderson, 1992), entre eles: honrar os direitos de propriedade incluindo direitos autorais e patente; e dar crédito apropriado à propriedade intelectual. Além das licenças livres, um outro tema que tem também atraído atenção para software livre é seu processo de desenvolvimento, por isso, discutido brevemente na seção seguinte.

Frente ao sucesso dos diversos projetos de softwares livres, pesquisadores e organizações de desenvolvimento de software têm direcionado seus esforços na investigação das práticas utilizadas no processo de desenvolvimento desse tipo de software e na sistematização desse processo, de modo que possa ser posteriormente adotado para o desenvolvimento de software. Como exemplos de alguns trabalhos nessa linha pode-se citar (Asundi, 2001; Cook, 1999; Cubranic \& Booth, 1999; Godfrey \& Tu, 2000; Mockus et al., 2002; Nakagawa, 2004a; Safe, 2003; Scacchi, 2001, 2002a,b; Scacchi et al., 2006; O’Reilly, 1999; Reis, 2003; Simon, 2002; Van Der Hoek, 2000; Vixie, 1999; Yamauchi et al., 2000). Diferentemente dos processos tradicionais de desenvolvimento, esse processo apresenta como principais características (Mockus et al., 2002): (i) envolvimento de centenas, ou muitas vezes, milhares de desenvolvedores voluntários, embora alguns projetos de softwares livre possam ser apoiados por empresas e mesmo

\footnotetext{
${ }^{9}$ http: / / opensource. ucc. ie/ (acessado em 23/07/2005)

${ }^{10}$ http: //oss2006.dti.unimi.it/ (acessado em 06/03/2006)

${ }^{11}$ http: //fisl. softwarelivre.org/7.0/www/ (acessado em 23/02/2006)

${ }^{12} \mathrm{~A}$ licença de software é um documento que estabelece a forma como o proprietário do copyright permite a distribuição e cópia de um software.
} 
desenvolvedores não voluntários; (ii) os desenvolvedores têm a liberdade de escolher o trabalho que desejam realizar; (iii) não se pode identificar um projeto em nível de sistema ou detalhado de forma explícita; e (iv) não há plano de projeto, cronograma ou lista de tarefas muito bem definidos. Na literatura, esse processo foi primeiramente descrito, ainda que informalmente, por Raymond (1999) e chamado de Modelo Bazar, tornando-se um dos trabalhos mais referenciados quando se discute o processo de desenvolvimento de software livre. Apesar das pesquisas no sentido de entender e sistematizar o processo de desenvolvimento de software livre, não está ainda definitivamente estabelecido um processo para o desenvolvimento de software nos moldes do Modelo Bazar. Contudo, pode-se identificar as principais atividades que compõem o processo de desenvolvimento da maioria dos softwares livres, que, embora não estejam formalmente especificadas, são a especificação de requisitos, o projeto e a implementação (Vixie, 1999). Apesar disso, observa-se que em muitos projetos de software livre, o software é codificado diretamente, sem atenção especial às fases de especificação de requisitos e projeto (Vixie, 1999). Além disso, algumas atividades de garantia de qualidade em projetos de software livre podem ser identificadas, sendo que o trabalho de Zhao \& Elbaum (2000) é um dos primeiros trabalhos a tratar essa questão. A grande maioria dos projetos emprega de alguma forma o gerenciamento de configuração (Asklund \& Bendix, 2001; Van Der Hoek, 2000), sendo a ferramenta CVS (Concurrent Versions System) (Free Software Foundation, 2006a), uma das mais utilizadas.

Segundo Hecker (1999) e Zhao \& Elbaum (2000), o Modelo Bazar tem resultado em uma sucessão de lançamentos de diversos produtos de qualidade. Observa-se, contudo, que para se obter sucesso com a utilização do Modelo Bazar, é necessário considerar alguns requisitos (Simon, 2002): um objetivo bem definido do que será desenvolvido, uma motivação fácil de ser compreendida, um bom líder que mantenha os desenvolvedores motivados e o objetivo em mente, uma comunidade de participantes que trabalhe com entusiasmo e de forma descentralizada e uma tecnologia que possibilite a comunicação de forma eficiente. Assim, o sucesso do Modelo Bazar não depende somente de disponibilização do código-fonte. Segundo Hecker (1999), há a necessidade de organizar e coordenar todo o processo de forma apropriada. Além disso, de acordo com Zhao \& Elbaum (2000), um dos pontos fracos do Modelo Bazar é a falta de um plano de teste sistematizado, apesar de que atividades de inspeção e revisão de código são realizadas, muitas vezes, pelos interessados no sistema.

Todo projeto de software livre requer um conjunto mínimo de recursos que viabilizem o seu desenvolvimento. Atualmente, o requisito fundamental e básico é a Internet, que dá apoio ao desenvolvimento compartilhado e possibilita o acesso instantâneo a um grande volume de informações. Nessa linha, Yamauchi et al. (2000) diz que as práticas de desenvolvimento de 
software livre têm sido de grande interesse para pesquisadores em trabalho cooperativo apoiado por computador (CSCW - Computer Supported Cooperative Work), uma vez que esse é um processo que envolve uma intensa coordenação de desenvolvedores dispersos geograficamente e que requisita um conjunto de tecnologias colaborativas, tais como endereços de correio eletrônico, Web e sistemas de controle de versões. Da área de processo de software, pode-se citar o trabalho de Maidantchik (1999) que estabelece um processo padrão para o desenvolvimento de software com equipes de desenvolvedores geograficamente dispersos, retratando em linha gerais a forma como ocorre o processo de desenvolvimento de software livre.

Uma descrição mais detalhada sobre conceitos relacionados ao software livre, licenciamento, histórico, processo de desenvolvimento, utilização, bem como exemplos de software livre, são encontrados em (Nakagawa \& Maldonado, 2006).

\subsection{Ambientes de Engenharia de Software}

Ferramentas e AES, referenciados também como ADSs (Ambientes de Desenvolvimento de Software), têm-se tornado cada vez mais cruciais para o desenvolvimento de software, dado que a demanda, a diversidade e a complexidade de sistemas de software têm aumentado, enquanto que o tempo necessário para o software estar no mercado tem diminuído (Harrison et al., 2000). Além disso, tem também aumentado a diversidade de processos de software que esses ambientes e ferramentas precisam dar apoio (Grundy et al., 2004). Atualmente, eventos científicos envolvendo o tema de AESs, tais como o Workshop on Directions in Software Engineering Environment ${ }^{13}$ e o International Conference on Automated Software Engineering ${ }^{14}$, têm discutido as direções e perspectivas com relação a esses ambientes, dando respaldo à importância que esse tema tem tomado dentro das pesquisas em Engenharia de Software.

Um dos trabalhos que traz um histórico sobre ferramentas e AESs é o de Harrison et al. (2000), intitulado "Software Engineering Tools and Environment: A Roadmap". Esse trabalho apresenta uma visão abrangente das diversas ferramentas e AESs que têm sido propostos ao longo das últimas três décadas. De modo geral, os AESs atuais evoluíram muito se comparados aos primeiros "ambientes" de Engenharia de Software do início da década de 80 quando correspondiam a uma coleção de ferramentas stand-alone ${ }^{15}$, tais como compiladores, depuradores e outros utilitários, cujas entradas e saídas podiam ser inter-conectadas por meio de pipes

\footnotetext{
${ }^{13}$ http: //Www.cs.auckland.ac.nz/ herm/WoDiSEE2004/ (acessado em 13/01/2006)

${ }^{14}$ http: / / www. ase-conference.jp/index.html (acessado em 13/01/2006)

${ }^{15} \mathrm{Neste}$ trabalho, entende-se por sistemas stand-alone aqueles que são executados em um determinado computador, sem requerer processamento em outros computadores para ser executado.
} 
e redirecionadores, e que podiam ser utilizadas de forma combinada para o desenvolvimento de software. Os primeiros esforços no sentido de produzir ambientes integrados de desenvolvimento de software foram os Ambientes de Apoio à Programação (do inglês, Programming Support Environment - PSE) que começaram a surgir em meados da década de 80. De acordo com Harrison et al. (2000), a principal limitação dos PSEs é que eles suportam somente a atividade de codificação. Em seguida, a identificação da necessidade de apoio integrado às atividades de Engenharia de Software levou ao surgimento de AESs que correspondem a um conjunto de ferramentas que dão apoio às atividades que ocorrem ao longo de todo ciclo de vida de um software. Atualmente, uma linha de pesquisa bastante dinâmica no domínio de AESs são as pesquisas envolvendo AESs centrados em processo (do inglês, Process-centered Software Engineering Environment). Essas ferramentas podem apoiar a definição e a execução de várias fases do processo de software; para isso, os ambientes devem fornecer a definição explícita dos procedimentos cooperativos e apoiar a sincronização e o compartilhamento de dados entre as pessoas envolvidas no processo (Ambriola et al., 1997; Bandinelli et al., 1996). De modo geral, a automatização do processo de software inclui mecanismos para guiar a seqüência de atividades definidas no processo, gerenciar os produtos que estão sendo desenvolvidos, executar as ferramentas necessárias para a realização das atividades, permitir a comunicação entre as pessoas, coletar dados de métricas automaticamente, reduzir erros humanos e prover o controle do projeto à medida que esse é executado (Christie, 1995).

Atualmente, observa-se que uma vasta coleção de ferramentas (protótipos ou comerciais) têm sido propostas e/ou construídas, dentre eles, pode-se citar (Ambriola et al., 1997; Bandinelli et al., 1993; Boudier et al., 1989; Braga et al., 1999; Falbo et al., 2003; Junkermann et al., 1994; ad E. Morris, 1993; Lucrédio et al., 2004; Maidantchik, 1999; Maurer et al., 1999, 2000; Nguyen et al., 1997; Reiss, 1990, 1994, 1999; Taylor et al., 1988; Rocha et al., 1990, 2001b; Sharon \& Anderson, 1997; Travassos, 1994), cobrindo várias atividades de Engenharia de Software. Algumas dessas ferramentas têm sido desenvolvidas no contexto de ambientes integrados, como é o caso do PCTE (Portable Common Tool Environment) (Boudier et al., 1989; ad E. Morris, 1993), outras possibilitam alguma integração, no entanto, muitas delas são autônomas (Harrison et al., 2000). A integração, bem como a adaptação e evolução, são dois temas de pesquisa que requer ainda investigação; a integração é discutida em mais detalhes na Seção 2.3.1.

Esses ambientes podem oferecer apoio a uma ou mais fases do ciclo de vida do processo. Pode-se identificar ainda ambientes que apresentam diferentes linguagens de modelagem para as diferentes fases do ciclo de vida do processo de software (Ambriola et al., 1997), como é o caso da ferramenta do projeto OIKOS (Montangero \& Ambriola, 1994) apud (Ambriola et al., 
1997), ao ambiente EPOS (Ambriola et al., 1997; Nguyen et al., 1997) e o SPADE (Bandinelli et al., 1993).

Diversos ambientes têm sido propostos com o objetivo de auxiliar no processo de software dentro das organizações. Ambriola et al. (1997) fazem um estudo de avaliação e comparação dos diversos ambientes de desenvolvimento de software centrado em processo e Maurer et al. (2000) citam diversos outros ambientes. Uma vez que as linguagens de processos - que são discutidas na Seção 2.3.2 - apresentam limitações para serem utilizadas amplamente na prática, os problemas com essas linguagens se refletem nos ambientes de desenvolvimento de software, sendo muitos deles complexos e intrusivos (Fuggetta, 2000).

O projeto Taba ${ }^{16}$ (Rocha et al., 1990; Travassos, 1994) tem como objetivo a construção de uma Estação de Trabalho configurável para o desenvolvimento de software, para atender às particularidades de domínios de aplicação e projetos específicos. A motivação para a realização desse projeto está na constatação de que domínios de aplicação e projetos diferentes têm características diferentes e que essas devem incidir nos ambientes de desenvolvimento através dos quais os engenheiros de software desenvolvem as aplicações.

Pode-se identificar também ambientes de desenvolvimento de software com base em ontologias ${ }^{17}$. O ODE (Ontology-based software Development Environment) (Falbo et al., 2003) é um ambiente de desenvolvimento de software centrado em processo, que tem sua fundamentação baseada em ontologias. A premissa do projeto de ODE é a seguinte: se as ferramentas de um ambiente de desenvolvimento de software são construídas baseadas em ontologias, a integração dessas ferramentas pode ser facilitada, pois os conceitos envolvidos estão bem definidos nas ontologias. Uma das principais características que distingue ODE de outros ambientes de desenvolvimento de software é a sua base ontológica (Nunes et al., 2004).

Pode-se identificar na literatura ambientes para automatização de processo de software sendo disponibilizados em plataforma Web, a exemplo do MILOS (Maurer et al., 1999) e do HyperDev (Maidantchik, 1999). Cao et al. (2004) apresentam uma ferramenta de diagramação para ambiente Web e discute os desafios para a construção de ferramentas dessa categoria para a Web. Outros exemplos que possibilitam execução via rede de computadores, mas não em ambiente Web, é a Merlin (Junkermann et al., 1994) que possibilita o acesso coordenado às informações compartilhadas, possui um servidor de mensagens dedicado e um mecanismo de gerenciamento de tarefas a serem realizadas. Um outro exemplo é o Orion (Lucrédio et al., 2004) que apresenta a possibilidade de ser utilizado remotamente, ou seja, por meio de uma rede e de um banco de dados centralizado, acessar artefatos gerados pelas ferramentas que integram

\footnotetext{
${ }^{16}$ http: //ramses.cos.ufrj.br/taba/ (acessado em 13/01/2006)

${ }^{17} \mathrm{O}$ tema ontologia é apresentado na Seção 2.7 .
} 
esse ambiente e que estejam instalados em máquinas remotas. É importante ressaltar que há a preocupação da comunidade científica em investigar e propor ferramentas de Engenharia de Software para a plataforma Web, no entanto, a literatura carece de AESs disponibilizados sobre essa plataforma, podendo ser considerada uma linha de pesquisa que ainda requer investigação.

Com o intuito de inserir os conceitos de reúso no desenvolvimento de sistemas de software, o ambiente Odyssey ${ }^{18}$ (Braga et al., 1999) propõe o uso da Engenharia de Domínio e do Desenvolvimento Baseado em Componentes, o que apóia a reutilização de artefatos, por exemplo, modelos do software e código-fonte, construídos durante o desenvolvimento de software.

Apesar da diversidade de ferramentas e AESs propostos na literatura, não existem ainda um consenso sobre qual seria a melhor maneira de estruturar, organizar e disponibilizar essas ferramentas e ambientes. Muitos dos trabalhos dessa área não dão atenção à arquitetura de software, o que poderia estar impactando nas dificuldades e desafios que essa área vem enfrentando, principalmente no que tange à integração e à evolução das ferramentas e ambientes existentes. Na seção seguinte é discutida em mais detalhes os desafios da área de AESs.

\subsubsection{Desafios das Pesquisas em Ambientes de Engenharia de Software}

Apesar da diversidade de ferramentas e AESs que têm surgido, de acordo com Harrison et al. (2000), o estado da prática em Engenharia de Software não tem avançado paralelamente a esse conjunto de ferramentas, isso devido principalmente ao fato das ferramentas e ambientes ainda serem altamente específicos para algum contexto. Muitas vezes, eles requerem que os software que eles manipulam sejam escritos em uma determinada linguagem, ou representados utilizando uma determinada técnica. Além disso, eles podem ser específicos para uma plataforma de hardware ou software; e até mesmo, usando um determinado compilador, depurador e outros.

De acordo com Harrison et al. (2000), a evolução, a adaptação e a integração dos AESs são, muitas vezes, custosos e difíceis. Então, o maior desafio para a comunidade que investiga ferramentas e AESs é encontrar meios para construir e integrar ferramentas de forma que eles possam ser facilmente adaptadas para serem usadas em novos contextos, ou seja, por exemplo, para outras linguagens de programação, outras plataformas de software e hardware, ou mesmo novos métodos e técnicas. Além disso, novos domínios, tais como computação pervasiva e comércio eletrônico, irão requerer metodologias, ferramentas e AESs diferentes dos tradicionais. Como conseqüência, ainda segundo Harrison et al. (2000), há a necessidade de propor

\footnotetext{
${ }^{18}$ http://reuse.cos.ufrj.br/reuse/index.html (acessado em 13/01/2006)
} 
arquiteturas e outras abordagens para o desenvolvimento de AESs que facilitem a integração e a adaptação desses ambientes.

Observa-se que há uma diversidade de trabalhos envolvendo ferramentas e AESs que se focam no problema de integração, podendo-se citar (Feng et al., 2002; Harrison et al., 2000; Nunes, 2005; Reiss, 1990, 1994, 1999; Spinola et al., 2004), evidenciando a relevância dada pela comunidade científica ao tema, o que motiva para que se investiguem mecanismos de integração mais novos, eficazes e eficientes. O trabalho de Spinola (2004) apresenta um levantamento de diversas ferramentas/AESs e discute seus mecanismos de integração. Um trabalho bastante citado em diversos trabalhos que discutem a integração em AESs é o de Wasserman (1990) que classificou as integrações que pode ocorrer nesses ambientes em cinco tipos distintos, a saber:

- Integração de plataforma: refere-se à plataforma de software e de hardware que podem fornecer serviços e dão apoio à execução do AES;

- Integração de apresentação: As ferramentas que compõem o ambiente devem compartilhar uma mesma interface, ou seja, um "look and feel" comum do ponto de vista do usuário;

- Integração de dados: $\mathrm{O}$ ambiente deve possibilitar o compartilhamento de dados entre as ferramentas que compõem esse ambiente. Por exemplo, integração de dados pode ser alcançada pela definição de um esquema de base de dados comum e armazenar esses dados em uma base de dados centralizada que possa ser acessada pelas diversas ferramentas que compõem o ambiente;

- Integração de controle: O ambiente deve dar apoio à notificação de eventos entre ferramentas que o compõem e deve também ter a capacidade de ativar outras ferramentas; e

- Integração de processo: O ambiente deve possibilitar o gerenciamento de processos de software, para isso, muitas vezes, é requerido o uso de linguagens de modelagem de processos.

Recentemente, as pesquisas envolvendo integração têm explorado o uso do XML como base para a integração de dados (Harrison et al., 2000; Feng et al., 2002; Spinola, 2004). Já o ambiente Field faz integração de controle por meio do uso de um servidor central de mensagens (Reiss, 1990, 1994). Outros trabalhos como o de Nunes (2005) utiliza a atividade de gerência de configuração de software como núcleo do AES. 
Visando à fácil adaptação e integração nos AESs, a adequada separação de interesses (do inglês, separation of concerns) (Dijkstra, 1976) tem também sido investigada. Além disso, uma separação de interesses inadequada é a maior barreira para a portabilidade de software (Harrison et al., 2000). Observa-se que diferentes interesses são importantes para cada atividade nos diversos estágios do ciclo de vida do software e, também importantes para pessoas com diferentes papéis e envolvidos no processo de software. Assim, os AESs de múltipla visão têm apresentado diferentes decomposições dependendo do estágio. Pesquisas nessa linha têm proposto a separação de acordo com mais de um tipo de interesse (Kiczales et al., 1997; Tarr et al., 1999). O desafio é então criar mecanismos, métodos, bem como ambientes e ferramentas de Engenharia de Software que dêem apoio à separação adequada de interesses (Harrison et al., 2000).

\subsubsection{Linguagens para Modelagem de Processos}

No contexto de processo de software, deve-se considerar duas facetas (Montangero, 1999; Warboys, 1998):

- processo P: o processo de produção de software do mundo real, incluindo pessoas, ferramentas, procedimentos, entre outros, que auxiliam as atividades de desenvolvimento do produto de software; e

- modelo de processo MP: uma representação do mundo real que captura o estado corrente das atividades envolvidas no processo, guiando ou automatizando partes do processo de produção.

Idealmente $P$ e $M P$ deveriam estar perfeitamente alinhados de modo que o estado interno do modelo de processo seja uma representação fiel do estado atual das atividades do mundo real, ou seja, $P$ seja uma instância de $M P$.

Assim como Montangero (1999), Conradi \& Jaccheri (1999) dizem que um modelo de processo é uma representação das atividades de um processo de produção de software do mundo real. Pode ser visto como um veículo para melhor entender e comunicar um processo do mundo real (Ambriola et al., 1997) e também como uma representação abstrata de uma família de processos expressa em uma notação adequada de modelagem de processos (Montangero, 1999), abstraindo detalhes e focalizando em questões mais relevantes, de forma a tornar os processos mais claros e mais fáceis de serem entendidos (Osterweil, 1997). 
Uma vez que processos de software são inerentemente dinâmicos e complexos, há a necessidade de se proporem modelos de processos que atendam às características dos processos do mundo real. Pesquisadores têm então investigado métodos, técnicas e linguagens que permitam modelar de maneira precisa e compreensiva processos de software, uma vez que inconsistências entre $P$ e $M P$ podem levar a conseqüências desastrosas quanto à qualidade do produto final (Montangero, 1999; Warboys, 1998). De um modo geral, métodos, técnicas e linguagens deverão possibilitar a modelagem do papel das pessoas, da estrutura e natureza dos artefatos a serem criados e mantidos e das ferramentas de software a serem utilizadas; enfim, possibilitar a modelagem das atividades que precisam ser realizadas para alcançar os objetivos do processo.

Diversas abordagens (métodos ou técnicas) (Bandinelli et al., 1993; Chen, 1997; Fuggetta, 2000; Junkermann et al., 1994; Osterweil, 1997) têm sido investigadas, muitas delas utilizadas tradicionalmente na modelagem de software, tais como Redes de Petri, Máquinas de Estado Finito e Diagrama de Entidade-Relacionamento. Observa-se que modelos de processos descritos por meio de diferentes abordagens apresentam vantagens e desvantagens. Por exemplo, modelos baseados em Redes de Petri são bastante adequados para modelar o paralelismo e a concorrência, contudo, não é muito apropriado para modelar os artefatos — por exemplo, pessoas e produtos — envolvidos no processo (Osterweil, 1997).

Recentemente, a abordagem orientada a objetos tem sido explorada para a modelagem de processo. Di Nitto et al. (2002) e Jäger et al. (1999) propõem a utilização da UML para modelar processos de software, uma vez que a UML apresenta um conjunto de diagramas que permite modelar tanto aspectos estruturais quanto comportamentais, possibilitando assim a modelagem das características dinâmicas dos processos de software.

Além das abordagens sendo utilizadas na modelagem de processos do mundo real, é de extrema relevância a utilização de linguagens de modelagem de processos que possibilitem "traduzir" processos reais para uma representação em uma linguagem suportada pelo ambiente em questão e que possibilitem a automatização de processos de software de forma mais fácil (Chen, 1997). Assim, na literatura disponível sobre processo de software, pode-se identificar algumas dezenas de linguagens, dentre elas, CSPL (Chen, 1997), Adele (Belkhatir et al., 1991), EPOS (Nguyen et al., 1997), SLANG (Bandinelli et al., 1993), JIL (Sutton \& Osterweil, 1997) e APPL/A (Sutton et al., 1995), cada qual com suas particularidades, vantagens e limitações. É importante ressaltar que, apesar da diversidade de linguagens, não foi ainda proposta uma linguagem simples e de fácil utilização; e segundo Fuggetta (2000), as linguagens existentes atualmente são complexas, extremamente sofisticadas e fortemente orientadas à modelagem detalhada do processo. 
As linguagens de modelagem de processos podem ser utilizadas para diferentes propósitos, dentre eles, para um melhor entendimento do processo, uma vez que permitem representar de maneira precisa como um processo está estruturado e organizado. Além disso, uma descrição precisa do processo contribui no treinamento e na educação, podendo ser útil no ensino dos procedimentos e operações envolvidos com um processo às pessoas de uma organização. Possibilita ainda a simulação e otimização, avaliando possíveis problemas e oportunidades para a melhoria do processo (Ambriola et al., 1997; Fuggetta, 2000).

Ambriola et al. (1997), Conradi \& Jaccheri (1999) e Sutton \& Osterweil (1997) mostram uma discussão sobre as linguagens de modelagem de processos pertencentes a diferentes paradigmas. Pode-se identificar tentativas de classificação dessas linguagens (Curtis et al., 1992), (Lonchamp, 1994) apud (Ambriola et al., 1997); contudo, questões relacionadas à taxonomia das linguagens de processo ainda encontram-se em aberto (Ambriola et al., 1997). Além dessas linguagens, mais recentemente, workflows têm sido utilizados para a representação de processos de software.

\section{Workflow para Representar Processos}

Segundo a WfMC $(1999 b)^{19}$, workflow é um conceito que foi aplicado primeiramente no contexto das organizações que tinham a preocupação de automatizar procedimentos, nos quais documentos, informações e tarefas eram passadas de um participante (recursos humanos ou de software) para outro, de acordo com um conjunto de regras para alcançar ou contribuir para os objetivos da organização. Segundo Hollingsworth (1995), workflow é então um mecanismo automatizado que facilita o processo de negócio, em todo ou em parte. De modo geral, workflow é o aspecto operacional de um procedimento de trabalho e relaciona-se a como as tarefas são estruturadas, quem desempenha as tarefas, qual a relação entre as tarefas, como as tarefas são sincronizadas, como as informações fluem entre as tarefas, e como as tarefas estão sendo executadas. Pode-se citar Hollingsworth (1995) e a WfMC (2006) como duas boas referências sobre workflow.

Recentemente, o conceito de workflow tem sido empregado na área de Engenharia de Software para a automatização de processos, tais como no processo de inspeção de software (Kalinowski, 2004) e no processo de desenvolvimento e manutenção de software (Barnes \& Gray, 2000), sendo esse trabalho um dos primeiros a utilizar workflow para a construção de ferramenta

\footnotetext{
${ }^{19}$ WfMC é uma organização internacional sem fins lucrativos que agrega pesquisadores de universidades e centros de pesquisa, bem como empresas, analistas e usuários de workflow (http: / / www . wfmc . org/about . htm (acessado em 07/01/2006)).
} 
de gerenciamento de processos de software. Vale ressaltar que essa é uma linha de pesquisa que requer ainda mais investigação.

Um ponto importante quando se utiliza workflow é a sua automatização. Assim, pode-se identificar uma diversidade de sistemas de gerenciamento de workflow (do inglês, Workflow Management System), dentre eles, pode-se citar a PatternFlow (Kalinowski, 2001) e a Enhydra JaWE/Shark ${ }^{20}$. Esses sistemas apóiam a definição, gerenciamento e execução de workflows cuja ordem de execução é dirigida por uma representação da lógica do workflow (Kalinowski, 2004). Segundo (Chaffey, 1998) apud (Kalinowski, 2004), sistemas de gerenciamento de workflow podem trazer benefícios no sentido de garantir o controle, o acompanhamento e a auditoria de processos.

\section{Linguagens para Representar Workflow}

Frente a relevância de workflow no contexto de automatização de processos, uma diversidade de linguagens para representar workflow pode ser identificada, por exemplo, a WPDL (Workflow Process Definition Language) (WfMC, 1999a), a PIF (Process Interchange Framework) (Lee et al., 1994) e a PSL (Process Specification Language) (NIST, 2006). Pode-se identificar também iniciativas de utilização da UML para representar workflow. Riesco et al. (2003) e Dumas \& ter Hofstede (2001) propõem extensões do diagrama de atividades da UML para a representação de workflow.

Linguagens de descrição de workflow baseadas na XML (Extensible Markup Language) (Bray et al., 2004), tais como a WSFL (Web Service Flow Language), BPEL4WS (Business Process Execution Language for Web Services) (IBM, 2002) e a XPDL (XML Process Definition Language) (WfMC, 2005), têm sido propostas, uma vez que um documento de descrição de workflow em XML pode facilitar a automatização. XPDL foi proposta pela WfMC e provê um arquivo no formato XML que pode ser utilizado para intercâmbio de modelos de processos entre ferramentas. Recentemente, a XPDL tem sido citada como um dos mecanismos a serem utilizados no desenvolvimento de software na abordagem de linhas de produto (Chen, 2004; Chen et al., 2005), e segundo García-Rubio et al. (2004), considerada uma das melhores linguagens para representar processos. Ferramentas para edição/execução de workflow em XPDL estão disponíveis, inclusive sob licença de software livre. Como exemplos de ferramentas livres, pode-se citar a Enhydra JaWE/Shark e a WfMOpen ${ }^{21}$.

\footnotetext{
${ }^{20}$ http: / / jawe. objectweb.org/ (acessado em 07/01/2006)

${ }^{21}$ http: //wfmopen. sourceforge. net/(acessado em 13/01/2006)
} 
Apesar da diversidade de trabalhos propondo linguagens para representar workflow, não há ainda um consenso sobre a melhor linguagem para representar workflow, inclusive para o contexto de Engenharia de Software.

\subsection{Arquitetura de Software}

À medida que a complexidade e o tamanho dos sistemas de software têm aumentado, engenheiros de software têm lançado mão de princípios de projeto, tais como a modularização e o ocultamento da informação, de modo a obter sistemas com maior qualidade e a um baixo custo (Mendes, 2002). Para isso, o projeto da estrutura global do software é uma questão que vem sendo considerada. No decorrer da década de 90, houve uma crescente preocupação em compreender a organização dos sistemas de software, culminando com o surgimento da área de Arquitetura de Software, uma área de pesquisa relativamente nova dentro da Engenharia de Software.

Atualmente, há uma diversidade de eventos científicos abordando especificamente arquiteturas de software, podendo-se citar a SEI Software Architecture Technology User Network Workshop $^{22}$, a International Conference on the Quality of Software Architectures ${ }^{23}$, o Workshop on Architecture-Centric Evolution ${ }^{24}$, o Workshop Infusing Software Architecture into Software Engineering Curricula ${ }^{25}$ e a Refactoring of Software at Architectural Level IEEE Workshop ${ }^{26}$, dentre outros, o que mostra a atenção que essa linha de pesquisa tem despertado na comunidade científica.

Wasserman (1996), em seu artigo “Toward a Discipline of Software Engineering”, cita oito conceitos que constituem a base para uma disciplina de Engenharia de Software viável. Dentre eles, a arquitetura de software é dita como tendo principal papel na determinação da qualidade e da manutenibilidade do software, na mesma linha do trabalho de Software Engineering Institute (2005), que afirma que os atributos de qualidade dos sistemas de software são estreitamente relacionados às suas arquiteturas, ou seja, a qualidade de sistemas de software depende diretamente da qualidade de suas arquiteturas. De acordo com Garlan (2000) e a SEI (Software Engineering Institute $)^{27}$, a arquitetura de software é uma estrutura de componentes de um programa/sistema, os relacionamentos entre esses componentes, os princípios e diretrizes que governam os pro-

\footnotetext{
${ }^{22}$ http://www.sei.cmu.edu/architecture/saturn/ (acessado em 19/01/2006)

${ }^{23}$ http: //se.informatik. uni-oldenburg. de/ qosa (acessado em 13/02/2006)

${ }^{24}$ http: //wi.wu-wien.ac.at/home/uzdun/ACE2005/ (acessado em 13/02/2006)

${ }^{25}$ http: / / www. unf.edu/ asanchez/cseet 05-w3/ (acessado em 13/02/2006)

${ }^{26}$ http: //www.proinf.de/arch-refactoring/ (acessado em 13/02/2006)

${ }^{27}$ http : / / www . sei.cmu.edu (Acessado em 10/02/2006)
} 
jetos e a evolução dos softwares. Os blocos de construção (ou seja, os componentes) de uma arquitetura são constituídos de unidades que desempenham o comportamento do sistema; são constituídos também de conexões que mostram como essas unidades transmitem ou comunicam informações e de conexões que mostram como as várias operações do programa são ativadas seqüencial ou concorrentemente.

Uma arquitetura de software deve dar apoio a importantes questões de projeto, tais como a organização do sistema como uma composição de componentes, as estruturas de controle globais, os protocolos de comunicação, a composição dos elementos do projeto e a designação das funcionalidades dos componentes do projeto (Rocha et al., 2001a).

Observa-se que é cada vez mais evidente que processos de desenvolvimento de software requeiram projetos arquiteturais de software. De acordo com Mendes (2002) (i) é importante ser capaz de reconhecer estruturas comuns em sistemas já desenvolvidos, possibilitando o reconhecimento das relações existentes entre sistemas e desenvolver novos sistemas com base em variações de sistemas antigos; (ii) o entendimento de arquiteturas existentes possibilitam a tomada de decisão sobre arquiteturas alternativas; (iii) a descrição arquitetural é essencial para a análise e descrição das propriedades de um sistema complexo; e (iv) o uso de uma notação formal para descrição das arquiteturas facilita a comunicação entre as pessoas.

$\mathrm{Na}$ área de Arquitetura de Software, têm sido propostos termos e conceitos de modo a facilitar a comunicação entre os pesquisadores. Dessa forma, os termos instância arquitetural, estilo arquitetural, arquitetura de referência e arquitetura de software de domínio específico têm sido propostos. Algumas vezes, alguns desses termos têm sido utilizados como sinônimos.

Para um determinado sistema de software, pode-se descrever sua arquitetura; essa arquitetura é referenciada como instância arquitetural. Mais abrangentes são os estilos arquiteturais que definem as restrições sobre a forma e a estrutura de uma família de instâncias arquiteturais (Garlan \& Perry, 1995). Um estilo arquitetural permite que um profissional (projetista, arquiteto ou engenheiro) determine a classe a qual pertence a organização de um sistema. Características dos componentes (subsistemas) e conectores do sistema, topologia da arquitetura, restrições semânticas e mecanismos de interação entre os componentes ajudam a identificar o estilo que retrata a arquitetura de software do sistema (Mendes, 2002). O uso de estilos arquiteturais no desenvolvimento de software facilita a comunicação entre as pessoas envolvidas no desenvolvimento, bem como o entendimento do projeto. Pode-se identificar diversos estilos arquiteturais (Mendes, 2002; Shaw \& Clements, 1997). Como exemplos de estilos arquiteturais mais co- 
nhecidos, pode-se citar o Pipes e Filtros, Camadas, Cliente-Servidor, entre outros, bem como estilos resultantes da combinação de estilos arquiteturais.

Alguns autores utilizam os termos estilos arquiteturais e arquitetura de referência como sinônimos (Mendes, 2002). No entanto, Eickelmann \& Richardson (1996) dizem que arquitetura de referência pode ser vista como uma estrutura que provê uma caracterização das funcionalidades dos sistemas de software de um dado domínio de aplicação.

Diversas são as arquiteturas de referência para os mais diversos domínios de aplicação; como exemplos de trabalhos nessa perspectiva, têm-se (Barber et al., 2002; Batory et al., 1995; Eickelmann \& Richardson, 1996; Sandkuhl \& Messer, 2000; Zdun, 2002). Outros exemplos são a arquitetura de referência para sistemas de comércio eletrônico (Bass et al., 2003) e a arquitetura de referência para servidores WWW (World Wide Web) envolvendo múltiplos autores (Perrochon, 1995). Não sendo diferente, na área de Engenharia de Software, uma arquitetura de referência para ferramentas de teste foi proposta (Eickelmann \& Richardson, 1996). Contudo, há uma carência de trabalhos que propõem arquiteturas de referência para AESs. Apesar desse fato, arquiteturas de ambientes bem conhecidos, tais como a Taba (Oliveira et al., 2000) e a Arcadia (Taylor et al., 1988), têm feito consideráveis contribuições no sentido de mostrar algumas das possibilidades de arquiteturas para esses ambientes.

As arquiteturas de referência constituem um elemento fundamental para o desenvolvimento de linhas de produto (do inglês, product lines) de software, ou seja, podem servir de base para a implementação de novas ferramentas de um dado domínio de aplicação (Mendes, 2002), na mesma linha do proposto por Garlan \& Perry (1995), que afirmam ainda que o sucesso de uma linha de produtos depende de uma arquitetura adequada. Em linhas de produto, arquiteturas têm sido construídas por combinar as melhores práticas, padrões, plataformas e componentes padronizados para criar e especializar família de produtos de um determinado domínio. Arquiteturas de referência podem também ser consideradas como o primeiro e essencial passo para o desenvolvimento de frameworks de aplicação.

Apesar disso, algumas limitações podem ser identificadas: (i) carência de ferramentas que possibilitam a automatização e a representação dessas arquiteturas; (ii) dificuldade de projetar arquiteturas de referência em virtude da dificuldade de generalizar a partir de exemplos concretos, ou seja, a partir de sistemas de softwares existentes; e (iii) falta de técnicas e métodos específicos para a representação dessas arquiteturas. Segundo Eickelmann \& Richardson (1996), a proposição de arquiteturas de referência para sistemas de um dado domínio de aplicação não é uma tarefa trivial, envolvendo profundo conhecimento sobre o domínio para o qual a 
arquitetura de referência está sendo criada. Além disso, arquiteturas de referência promovem o reúso do projeto arquitetural e o entendimento de uma área específica (Zhao \& Kearney, 2003).

Já uma arquitetura de software de domínio específico (do inglês, Domain Specific Software Architecture - DSSA) fornece uma base estrutural para a interoperabilidade de componentes dentro de um domínio. Além disso, uma DSSA pode dar apoio a uma abordagem de desenvolvimento de domínio específico que possibilite a configuração de componentes reutilizáveis (Mendes, 2002). De acordo com (Taylor et al., 1995) apud (Mendes, 2002), um DSSA compreende um modelo de domínio, requisitos de referência, uma arquitetura de referência, infra-estrutura ou ambiente de apoio e um processo de desenvolvimento.

No contexto das pesquisas em arquitetura de software, a avaliação da qualidade das arquiteturas de software tem sido investigada de modo a aumentar a qualidade dos produtos de software resultantes dessas arquiteturas. Métodos de avaliação arquitetural têm sido propostos (Babar et al., 2004), sendo que os exemplos mais evidentes encontrados na literatura são o SAAM (Scenario based Architecture Analysis Method) (Kazman et al., 1994) e o ATAM (Architecture Trade-off Analysis Method) (Kazman et al., 1998). Há, entretanto, pouco consenso sobre quais questões deveriam ser tratadas pelo método a ser adotado e qual método é mais adequado para uma particular situação. Há também uma carência de trabalhos que abordem uma sistemática classificação e comparação entre os métodos existentes, sendo um dos primeiros e únicos é o trabalho de Babar et al. (2004). A proposição e a análise de arquiteturas de software são utilizadas para determinar se uma decomposição estrutural específica e a alocação funcional para uma estrutura do sistema apóia ou impede que certas características de qualidade, tais como eficiência, usabilidade, manutenibilidade e reusabilidade, estejam presentes no sistema (Eickelmann \& Richardson, 1996).

Uma vez que sistemas de software disponibilizados na plataforma Web têm estado em evidência nos últimos anos, e diversas têm sido as arquiteturas investigadas para esses sistemas. $\mathrm{Na}$ seção a seguir serão discutidas primeiramente questões mais gerais relacionadas aos sistemas Web e em seguida, arquiteturas para sistemas disponibilizados nessa plataforma.

\subsubsection{Descrição de Arquiteturas de Software}

Apesar da relevância de arquiteturas de software, na prática, muitas das descrições das arquiteturas são feitas ainda informalmente. Na grande maioria dos casos, arquiteturas são representadas como grafos contendo componentes e conectores. Os componentes definem as grandes funcionalidades e dados armazenados pelo sistema; como exemplo, têm-se clientes, servidores, 
filtros e bases de dados. Já os conectores definem a interação entre os componentes, podendo ser, entre outros, pipes, chamadas de procedimento ou comunicação entre clientes e servidores (Garlan \& Perry, 1995). Para a representação dessas arquiteturas, pode-se utilizar alguma técnica como, por exemplo, a notação proposta pelo SAAM (Software Architecture Analysis Method) (Kazman et al., 1994), um método de análise de arquiteturas de software que disponibiliza também uma notação para representar as arquiteturas. A representação de arquiteturas de software utilizando-se uma mesma notação pode contribuir para facilitar o entendimento e realização de comparações.

Em função da necessidade por notações formais para representar arquiteturas de software que propusessem uma sintaxe e uma estrutura conceitual que permitissem caracterizar uma arquitetura (Mendes, 2002), linguagens de descrição arquitetural (do inglês, Architecture Description Language - ADL) têm sido propostas e utilizadas para a especificação de projetos arquiteturais. Pode-se identificar uma diversidade de linguagens, sendo que entre as mais referenciadas na literatura estão a C2 (Medvidovic et al., 1996), a Rapide (Luckhama et al., 1995) e a Wright (Allen, 1997). Segundo Medvidovic \& Taylor (2000), essas três linguagens constituem um conjunto representativo das capacidades encontradas em linguagens de descrição arquitetural mais recentes. Apesar da diversidade de linguagens de descrição arquitetural, segundo Babar et al. (2004), existe ainda pouco consenso sobre uma definição universalmente aceita pela comunidade de arquitetura de software do que seria de fato uma linguagem de descrição arquitetural. De modo geral, há o entendimento de que uma linguagem de descrição arquitetural é uma linguagem formal usada para representar a arquitetura de um sistema de software (Medvidovic \& Taylor, 2000). Além disso, diferentemente das linguagens de programação, as linguagens de descrição arquitetural não apresentam nenhuma classificação ainda bem estabelecida na literatura (Medvidovic et al., 2002).

Além das linguagens de descrição arquitetural, a necessidade de se ter múltiplas visões de uma arquitetura de software tem sido largamente reconhecida na literatura (Bachmann et al., 2003; Kruchten, 1995; IEEE, 2000; Medvidovic et al., 2002). Apesar disso, pesquisadores da área de Arquitetura de Software ainda não tem um consenso sobre quais visões são necessárias e sobre quais métodos e técnicas são apropriadas para expressar essas visões (IEEE, 2000). Apesar disso, as visões estrutural e comportamental da arquitetura de software têm sido as mais consideradas, o que pode ser observado em (Kruchten, 1995; IEEE, 2000; Medvidovic et al., 2002).

Merson (2005) propõe o uso de cinco visões para documentar arquiteturas de software, a saber, a visão de módulos (do inglês, module view), a visão de implantação (deployment view), a visão em tempo de execução (runtime view), a visão de dados (data view ou data 
model) e a visão de implementação (implementation view). A visão em tempo de execução, também chamadas de visão C\&C (Component \& Connector) (Clemens et al., 2003), mostra o sistema em tempo de execução, ao contrário da visão em módulos que apresenta a estrutura do código-fonte. Essa visão possibilita o entendimento do funcionamento do sistema e a análise das propriedades que se manifestam em tempo de execução, tais como o desempenho (Merson, 2005). A visão em tempo de execução também possibilita apresentar os grandes componentes, bem como a interação entre esses componentes, as bases de dados, bem como aquelas que são compartilhadas, os elementos replicados, o fluxo de dados no sistema, além das partes do sistema que são executadas em paralelo. As linguagens de descrição arquitetural podem ser utilizadas para representar essa visão, no entanto, notações informais ou semi-formais (UML, por exemplo) têm sido adotadas e largamente aceitas. A visão de dados é normalmente utilizada quando o sistema possui uma base de dados cuja estrutura precisa ser modelada. Esse modelo inicia como um modelo conceitual/lógico que vai sendo refinado até conter toda informação necessária para a criação da base de dados física. A visão de implantação mostra a estrutura de hardware (tipicamente uma rede) na qual o sistema é executado. A visão de implementação mostra a estrutura do software (como é ou como deverá ser) em termos de arquivos organizados em diretórios, tanto para o ambiente de desenvolvimento quanto de produção

Mais recentemente, a UML tem emergido como uma notação para representar arquiteturas de software. Trabalhos nessa linha têm surgido (Bachmann et al., 2003; Bass et al., 2003; Garlan \& Kompanek, 2000; Medvidovic et al., 2002), abordando o mapeamento dos conceitos das linguagens de descrição arquitetural "tradicionais" em notação orientada a objetos por meio de técnicas da UML. Segundo Garlan \& Kompanek (2000), a utilização da UML para documentar arquiteturas de software apresenta benefícios, tais como a familiaridade dos desenvolvedores, facilidade de mapeamento para a implementação e o apoio de ferramentas de software. Vale ressaltar, no entanto, que não há ainda um consenso entre os pesquisadores da área de Arquitetura de Software sobre quais das técnicas da UML são as mais adequadas para a modelagem de arquiteturas de software. Além disso, não existe ainda um consenso sobre quais as extensões da UML devem ser estabelecidas para serem utilizadas de fato como uma linguagem de descrição arquitetural.

Particularmente, a UML e as visões arquiteturais são relevantes no contexto deste trabalho, uma vez que serão utilizadas como mecanismo para estabelecimento e documentação das arquiteturas de referência propostas. 


\subsubsection{Arquitetura de Sistemas Web}

Uma diversidade de sistemas de software tem surgido recentemente e disponibilizada por meio da plataforma Web. Esses sistemas, chamados de sistemas Web, aplicações Web ou sistemas baseados na Web (do inglês, Web-based systems), apresentam características de aplicações hipermídia. Entende-se por aplicação hipermídia um conjunto de informações estruturadas que possibilitam ser "navegadas" pelos usuários com o objetivo de realizar uma determinada tarefa. São compostos de nós (unidades de informações) e âncoras (representações visuais da ligação ${ }^{28}$ que representam os pontos de origem das ligações, ou seja, os pontos a partir dos quais ligações podem ser ativadas).

Sistemas disponibilizados na plataforma Web possibilitam a utilização sem a necessidade de instalação dos sistemas localmente. Além disso, um conjunto de características específicas podem ser identificadas na grande maioria dos sistemas Web. Primeiramente, esses sistemas são altamente interativos e, muitas vezes, a informação é dinâmica (para cada usuário, a informação a ser mostrada pode ser diferente), o que requer especial atenção ao projeto de interação usuário-computador; nessa linha, Kerer \& Kirda (2001) dizem que, atualmente, os sistemas Web provêem serviços dinâmicos, personalizados e interativos com o usuário. Uma outra característica de aplicações Web é "servir" simultaneamente diversos usuários, quase sempre distribuídos ao redor do mundo (Conallen, 1999b; Hendrickson \& Fowler, 2002). Além disso, a evolução contínua e a necessidade de construção rápida são outras características (Jacyntho et al., 2002; Pressman, 2000). Paralelamente, os três principais atributos de qualidade de sistemas Web são a confiabilidade, a usabilidade e a segurança (Offutt, 2002); na mesma linha, no trabalho de Olsina et al. (2001) é proposto um conjunto de características e atributos de qualidade de Websites, no entanto, para o domínio de aplicações acadêmicas. Esse conjunto é baseado na ISO 9126, para avaliação de produtos de software, e é composto da usabilidade, funcionalidade, confiabilidade e eficiência.

Frente às características de sistemas Web, em especial a evolução contínua e a necessidade de disponibilização rápida, arquiteturas de sistemas Web devem ser flexíveis e possibilitar a evolução desses sistemas. Diversos são os trabalhos que têm investigado questões relacionadas à arquitetura de sistemas Web, buscando facilitar a evolução desses sistemas; dentre eles, podese citar (Anderson, 2004; Draheim et al., 2003; Jacyntho et al., 2002; Kerer \& Kirda, 2001; Zhao \& Kearney, 2003).

\footnotetext{
${ }^{28}$ Do inglês, link ou hyperlink. Uma ligação conecta os nós formando uma rede de informações que define a estrutura organizacional, tendo como função definir os caminhos de navegação pela aplicação.
} 
Recentemente, como uma das subáreas de pesquisa em Engenharia de Software, tem surgido a Engenharia Web (do inglês, Web Engineering ou simplesmente WebE). A Engenharia Web é uma abordagem sistemática e que usa princípios científicos, de engenharia e de gerenciamento para desenvolver, disponibilizar e manter sistemas Web de alta qualidade (Ginige \& Murugesan, 2001; Pressman, 2000). No tocante ao desenvolvimento de sistemas Web, Pressman (2000) propõe um modelo de processo de desenvolvimento, referenciado como modelo de processo de engenharia Web (do inglês, Web Engineering process ou WebE process), baseado no modelo Espiral (Boehm, 1988; Sommerville, 1996) no qual para a fase de engenharia sugere-se a utilização de métodos e técnicas específicos para a modelagem de sistemas Web. Observa-se que a atividade de engenharia difere dos processos de desenvolvimento de sistemas “convencionais". Nessa atividade, deve-se considerar questões técnicas e não técnicas. Com relação às questões técnicas, considera-se (i) o projeto arquitetural, que corresponde à modelagem da estrutura arquitetural do sistema; (ii) o projeto navegacional, que se refere à modelagem dos caminhos de navegação que possibilitam ao usuário a interação com o sistema; e (iii) o projeto de interface, em que se deve considerar questões relacionadas à interface com o usuário. Deve-se dar especial atenção a esse projeto, uma vez que se trata de sistemas baseadas na Web, nos quais a interface tem importância significativa.

De acordo com Jacyntho et al. (2002), uma "boa" aplicação Web deveria ser primeiro uma "boa" aplicação hipermídia, uma vez que a Web é baseada no paradigma de hipertexto composto de um conjunto de páginas relacionadas entre si. Assim, o uso de boas práticas de projeto hipermídia tornam os sistemas Web fáceis de utilizar, provendo um espaço navegacional amigável. Dessa forma, para a realização das atividades de engenharia, métodos e técnicas têm sido propostos para dar apoio à modelagem de sistemas Web; o RMM (Relationship Management Methodology) (Isakowitz et al., 1995), o HDM2000 (Garzotto et al., 1999), a WebML (Ceri et al., 2000) e o OOHDM (Object-Oriented Hypermedia Design Method) (Rossi et al., 2001; Schwabe \& Rossi, 1995) têm sido propostos e a UML tem sido estendida também para possibilitar a modelagem de sistemas Web (Baresi et al., 2001; Conallen, 1999a,b). Apesar dessa diversidade, ainda não está estabelecido um método ou técnicas largamente reconhecidas para a modelagem de sistemas Web. Observa-se que a maioria dos métodos de projeto de sistemas Web faz uma clara separação do projeto de dados com os aspectos comportamentais, bem como de questões relacionadas à navegação e interface da aplicação Web. Dessa forma, a separação de interesses é largamente considerada como aspecto chave para obter qualidade e reutilização de projeto, além de facilitar a evolução e manutenção do sistema (Jacyntho et al., 2002). 
Dentre os padrões de software (do inglês, software patterns), os padrões arquiteturais ${ }^{29}$ são responsáveis por expressar o esquema ou a organização estrutural fundamental de sistemas de software ou hardware. Esses padrões podem ainda ser utilizados no início do projeto de alto nível, quando se faz a especificação da estrutura fundamental de uma aplicação. Existem padrões arquiteturais específicos para cada tipo de software: sistemas distribuídos, adaptativos, interativos, entre outros. Para sistemas interativos, no qual se pode incluir os sistemas Web, um dos mais conhecidos é o padrão arquitetural MVC (Model-View-Controller ou Modelo-VisãoControlador) (Buschmann et al., 1996). A MVC divide a aplicação em três componentes: o Modelo (Model) que contém as funcionalidades básicas e principais e gerencia os dados; a Visão (View) que gerencia informações a serem mostradas para o usuário; e o Controlador (Controller) que processa as entradas (eventos) do usuário, considera o estado corrente do cliente e determina o próximo estado do sistema. Baseado no próximo estado a ser invocado, o Controlador invoca uma Visão apropriada que mostra ao usuário as saídas adequadas; o Controlador determina o fluxo de controle do sistema.

Uma outra arquitetura sendo experimentada em sistemas Web é a arquitetura em 3-camadas (do inglês, 3-tiers architecture) (Sadoski \& Comella-Dorda, 1997). Essa arquitetura vem sendo utilizada largamente como padrão arquitetural para aplicações cliente-servidor baseadas em interface gráfica do usuário (Zhao \& Kearney, 2003) e tem surgido em virtude das limitações que a arquitetura em 2-camadas (do inglês, 2-tiers architecture) (Edelstein, 1994) tem mostrado. Basicamente, a arquitetura 3-camadas é composta da camada do cliente, da camada de aplicação e da camada de base de dados (ou camada de persistência). A camada de cliente contém a interface do usuário onde residem os serviços do usuário, tais como as sessões, a entrada de dados e o gerenciamento do que é mostrado ao usuário. A camada de aplicação contém a lógica de negócio, ou seja, as principais funcionalidades e dados da aplicação. O papel da camada de persistência é gerenciar os objetos/elementos persistentes da aplicação. De acordo com Anderson (2004), aplicações baseadas em arquiteturas 3-camadas são mais flexíveis; além disso, aplicações baseadas nessa arquitetura podem ser fisicamente implantadas em diferentes servidores, por exemplo, a camada de negócios e a de persistência em dois diferentes servidores. Assim, a escalabilidade do sistema e a capacidade de processar requisições de diversos clientes podem ser promovidas.

O trabalho de Zhao \& Kearney (2003) propõe uma arquitetura Web, chamada H-PCA ( $H i$ erarchical Presentation-Control-Abstraction), derivada da arquitetura em 3-camadas proposta

\footnotetext{
${ }^{29}$ Padrões arquiteturais apresentam a organizações estrutural fundamental de sistemas de hardware ou software, sendo um dos tipos de padrões de software (Buschmann et al., 1996; Gamma et al., 1995) que têm o propósito de documentar experiências adquiridas no desenvolvimento de software e sintetizá-las em forma de problema e solução, de modo que essas experiências possam ser reutilizadas em situações semelhantes.
} 
inicialmente por Sadoski \& Comella-Dorda (1997). Segundo Zhao \& Kearney (2003), a arquitetura em 3-camadas não se adequava bem quando se consideram aplicações Web. Assim, é proposta a divisão da camada do cliente em duas outras. A camada de cliente dessa arquitetura é dividida em camada do cliente (no qual se encontra o navegador Web no lado do cliente) e a camada de interação com o usuário e controle da aplicação (camada de apresentação que reside no lado do servidor); essas camadas comunicam-se por meio do protocolo HTTP (HyperText Transfer Protocol). Na mesma linha, mais recentemente, o trabalho de Anderson (2004) propõe a junção do padrão arquitetural MVC e a arquitetura 3-camadas, na qual a camada de apresentação da arquitetura 3-camadas contém o Controlador e a Visão, e a camada de aplicação contém o Modelo. Essa proposta de Anderson (2004) vem sendo experimentada e com resultados bastante positivos no desenvolvimento de sistemas Web no contexto do Projeto Memória Virtual de São Carlos (Mem, 2004; Nakagawa, 2004b; Nakagawa et al., 2005; Orikasa, 2005).

Além dessas arquiteturas, o serviço Web (do inglês, web service), como definido pela W3C Web Services Architecture Working Group (W3C, 2006), é uma aplicação de software identificada por uma URI (Uniform Resource Identifier), cujas interfaces e bindings são capazes de serem definidas, descritas e descobertas por artefatos XML. Um serviço Web suporta interação com outros agentes de software por meio de mensagem baseadas em XML sobre protocolos baseados na Internet (Ferris \& Farrell, 2003). Em uma arquitetura orientada a serviços, um provedor de serviço (do inglês, service provider) possui um serviço projetado para ser utilizado por outros. O provedor cria a descrição do serviço em uma WSDL (Web Services Description Language) que detalha sua interface. Em seguida, o provedor publica a descrição do serviço por ele fornecido para um ou mais discovery agencies. Tipicamente, o papel desses agencies é gerenciar os diversos provedores de serviço e facilitar sua disponibilização. Eventualmente, um consumidor de serviço (do inglês, service requester) encontra a descrição de um serviço por meio dos agencies. O consumidor usa então a descrição em WSDL para desenvolver ou configurar um cliente que interagirá com o serviço por meio do provedor de serviço.

Com a proliferação de sistemas Web, os mecanismos considerados importantes no desenvolvimento de softwares "tradicional" — arquiteturas de software, padrões, métodos e técnicas para análise e projeto, entre outros — devem ser investigados e adaptados para essa classe de sistemas. Contudo, ainda não existe um consenso sobre qual a melhor arquitetura, o método e as técnicas mais adequadas para o desenvolvimento dessa classe de sistemas. Com relação às arquiteturas de software, apesar de atualmente estarem sendo investidos esforços no desenvolvimento de sistemas dividindo-os em camadas, ainda não existe uma estudo consolidado sobre a arquitetura mais adequada dos sistemas que se pretendem disponibilizar sobre a plataforma Web. 


\subsection{Orientação a Aspectos}

A separação de interesses tem sido um princípio que tem guiado a Engenharia de Software por décadas. Esse princípio foi primeiro descrito por Dijkstra (1976) e refere-se à habilidade de identificar, encapsular e manipular aquelas partes de um software que são relevantes para um particular conceito, objetivo, propósito, propriedade, ou área de interesse. De acordo com Kiczales et al. (2001b), entende-se por separação de interesses a idéia de projetar e implementar sistemas de softwares com unidades naturais de interesse, refletindo a maneira como "o ser humana pensa", ao contrário de usar unidades impostas por uma abordagem, técnica, linguagem ou ferramenta. Assim, de acordo com o princípio de separação de interesses, um sistema complexo poderia ser decomposto em problemas menores, de modo que diferentes interesses relacionados a cada um desses problemas poderia ser resolvido separadamente de uma forma mais natural, e então ser combinado para produzir uma solução completa.

Esses interesses podem variar de noções de alto nível, como segurança e qualidade de serviço, a noções de baixo nível, como sincronização e manipulação de buffers de memória; eles podem ser ainda funcionais, tais como características ou regras de negócio, ou não-funcionais, tais como gerenciamento de transação e persistência (Elrad et al., 2001b). Além disso, podem ser de um domínio específico ou não (Camargo et al., 2003).

Nesse contexto, segundo Harrison et al. (2000), a maior barreira para a portabilidade de software é a separação de interesses inadequada. Além disso, a separação de interesse tem uso limitado se os interesses que forem separados não puderem ser integrados. Assim, a abordagem de separação de interesses deve ter sua correspondente abordagem de integração.

No desenvolvimento de software utilizando abordagens tradicionais, como a procedimental e a orientada a objetos, os sistemas são geralmente organizados em módulos funcionais, expressas em procedimentos, módulos ou objetos, que representam os interesses funcionais da aplicação. Contudo, de acordo com Camargo et al. (2003), há interesses em um sistema que abrangem mais de um componente funcional; como exemplos desses interesses pode-se citar a persistência e o controle de segurança. A orientação a objetos, o paradigma de programação que tem se evidenciado nos últimos anos, tem melhorado significativamente a capacidade de alcançar uma boa separação de interesses. Contudo, segundo Elrad et al. (2001b), a orientação a objetos apresenta limitações. Uma dessas limitações é o fato de que um interesse, muitas vezes, espalha-se por diversos módulos do sistema de software. Além disso, recentemente, pesquisadores têm acreditado que linguagens de programação baseado em uma simples abstração — procedimentos, objetos, entre outros — são inadequados para muitas aplicações complexas (Kiczales et al., 1997). Dessa forma, a Programação Orientada a Aspectos (POA) (Kiczales et 
al., 1997) tem sido investigada como uma nova abordagem que suporta melhor a separação de interesses e reflete mais adequadamente a forma como os desenvolvedores "pensam" sobre o sistema.

Apesar da área de pesquisa envolvendo orientação a aspectos ser relativamente nova, podese identificar diversos esforços da comunidade científica em investigar essa área. Em nível nacional, diversos grupos têm-se consolidado, inclusive direcionando esforços no sentido de padronizar uma tradução da terminologia envolvida na POA (AOSDbr, 2006; Garcia et al., 2004).

\subsubsection{Programação Orientada a Aspectos}

A POA tem sido vista como uma abordagem para melhorar a separação de interesses em software, podendo também ser considerado um paradigma de programação que propõe um novo tipo de abstração — denominado aspecto (do inglês, aspect) — que permite a descrição modular de propriedades que, em geral, se encontram espalhadas por vários pontos de um sistema. Nessa mesma linha, Elrad et al. (2001a) e Kiczales et al. (1997) dizem que a POA consiste na separação dos interesses de um sistema em unidades modulares (os aspectos) e posterior combinação (do inglês, weaving) desses módulos em um sistema completo, como ilustrado na Figura 2.1. Nessa figura é exemplificado como pode ocorrer a decomposição. A funcionalidade básica (ou código-base) do sistema e os interesses transversais (do inglês, crosscutting concerns) — interesses que estão entrelaçados com outros interesses dentro do sistema — podem ser desenvolvidos separadamente, com as respectivas linguagens de programação que melhor se adequarem-se, e o combinador (do inglês, weaver) fica encarregado de produzir o código em formato executável (Kiczales et al., 1997).

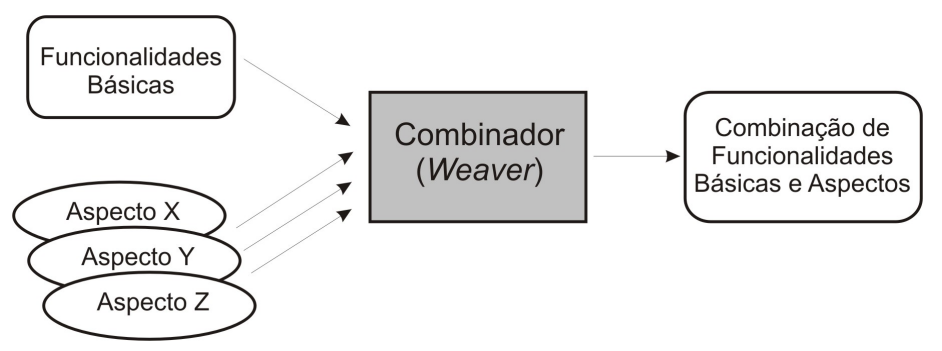

Figura 2.1: Elementos Básicos da Programação Orientada a Aspectos (Adaptado de (Kiczales et al., 1997)

Além disso, trabalhos recentes têm mostrado benefícios da utilização de POA no desenvolvimento de software (Camargo et al., 2003). De acordo com Kiczales et al. (1997), a principal vantagem da POA é a possibilidade de manipular interesses transversais tão separadamente 
quanto possível, encapsulando-os em unidades chamadas de aspectos. Assim, engenheiros de software podem concentrar-se primeiramente nas características básicas do sistema e, em seguida, combinar os aspectos que encapsulam os interesses transversais com as características básicas, produzindo assim um sistema completo.

Encapsulando-se os interesses transversais em módulos separados (os aspectos), a modularização do sistema pode ser facilitada. Dessa forma, como resultado da separação de interesses, pode-se ter a redução do custos de desenvolvimento, com facilidade no desenvolvimento e na manutenção (Kiczales et al., 1997; Rashid et al., 2003). A POA pode ser aplicada sobre abordagens existentes, abordagens essas que já têm feito melhoramentos significativos com relação à modularidade de software (Filman \& Friedman, 2000; Kiczales et al., 2001b). Quando se aplica a POA, pode-se utilizar conjuntamente procedimentos, objetos e aspectos para a construção do sistema, cada qual quando for mais apropriado (Elrad et al., 2001a).

De acordo com Garcia (2004), o paradigma orientado a aspectos é ainda muito recente. Portanto, é muito difícil determinar quais são as melhores decisões de projeto e de implementação para desenvolvimento de software orientado a aspectos. Há, no entanto, um certo consenso dos pesquisadores da área de desenvolvimento orientado a aspectos de que há interesses transversais clássicos e óbvios, tais como a manipulação de exceção e a persistência, que deveriam ser modularizados em aspectos.

A abordagem orientada a aspectos tem também sido investigada para o desenvolvimento de sistemas de software em diversos contextos (Camargo \& Masiero, 2005; Garcia, 2004; Rocha et al., 2005), inclusive diversos projetos de software livre (SourceForge.net, 2006). Por exemplo, o trabalho de Garcia (2004) apresenta uma abordagem orientada a aspectos para o desenvolvimento de sistemas baseados em agentes. A abordagem dá apoio à modularização e à composição das propriedades de agentes, tais como a adaptabilidade, a mobilidade, a autonomia e a capacidade de aprendizagem, por meio de abstrações e mecanismos do paradigma orientado a aspectos. Além disso, tais propriedades são incorporadas de forma transparente à funcionalidade básica dos sistemas baseados em agentes.

\subsubsection{Desenvolvimento Orientado a Aspectos}

Os conceitos de POA têm sido estendidos também para outras fases do ciclo de vida de desenvolvimento de software, além da fase de implementação, contribuindo para uma nova abordagem de desenvolvimento de software, o Desenvolvimento de Software Orientado a Aspectos (DSOA) (do inglês, Aspect-Oriented Software Development - AOSD). Observa-se que tem sur- 
gido trabalhos que vêm inserindo o conceito de aspectos cada vez mais cedo no ciclo de vida de desenvolvimento de software. Para a fase de fase de projeto arquitetural tem-se o trabalho de Rocha et al. (2005), para engenharia de requisitos pode-se citar (Rashid et al., 2003; Sampaio et al., 2005), para a fase de análise e projeto têm-se (Chavez, 2004; Clarke \& Walker, 2001, 2002; Stein et al., 2002; Suzuki \& Yamamoto, 1999; Clarke \& Baniassad, 2005), sendo que esse último propõe um método de análise e projeto orientado a aspectos. Na linha de teste de software, o teste de programas orientados a aspectos também tem despertado atenção de pesquisadores (Lemos et al., 2004; Lemos, 2005; Mortensen \& Alexander, 2004). Assim como no desenvolvimento tradicional de software, tais como na orientação a objetos, é essencial tratar os interesses transversais o quanto antes no ciclo de vida do software. Apesar disso, considerar interesses na fase de engenharia de requisitos está ainda imaturo e não há nenhum consenso sobre o que é um interesse nessa fase e como ele é mapeado para outros artefatos em fases mais adiante no processo de desenvolvimento de software. Um dos poucos trabalhos nessa linha é o de Rashid et al. (2003), que propõe um modelo genérico para engenharia de requisitos orientado a aspectos. Todas essas pesquisas ainda são emergindo, requerendo ainda mais investigação para a consolidação dos resultados.

De acordo com Constantinides et al. (2000), além do DSOA apresentar as vantagens do desenvolvimento orientado a objetos, ele proporciona uma melhor separação de interesses. Como vantagens do DSOA pode-se citar: manutenibilidade, reusabilidade e facilidade de escrever software. Além disso, de acordo com Rashid et al. (2003), os sistemas de software atuais estão sendo utilizados em um ambiente onde as regras de negócio mudam constantemente; portanto, os sistemas de software devem apresentar facilidade de adaptação e evolução. Nesse contexto, o DSOA pode contribuir para o desenvolvimento de sistemas de software que evoluem constantemente, ou seja, que apresentam desenvolvimento incremental. Rashid et al. (2003) alertam ainda que se os interesses transversais de um sistema não forem tratados adequadamente, esses podem inibir a capacidade de evolução dos sistemas.

\section{Modelagem de Sistemas Orientados a Aspectos}

Vale observar que recentemente diversas iniciativas no sentido de estabelecer um conjunto de técnicas, bem como métodos para apoio à análise e projeto de sistemas orientados a aspectos, têm sido propostos (Chavez, 2004; Clarke \& Baniassad, 2005); contudo, ainda não foi estabelecido um método e técnicas subjacentes largamente aceitas pela comunidade para o desenvolvimento de softwares orientados em aspectos.

Diversos trabalhos têm proposto o uso da UML, por meio de extensões dadas a essa linguagem, para a modelagem de sistemas baseados em aspectos, podendo-se citar (Camargo et 
al., 2003; Clarke \& Walker, 2001, 2002; Rashid et al., 2003; Rocha, 2005; Stein et al., 2002; Suzuki \& Yamamoto, 1999). Tem-se usado em particular o mecanismo de estereótipos, tais como «aspect», «introduces», «introduction», «crosscuts»e «crosscutting», para representar elementos específicos da POA. Ainda não foi estabelecido um profile $e^{30}$ para UML largamente aceito e utilizado pela comunidade.

Além desses, o trabalho de Chavez (2004) propõe uma linguagem de modelagem para especificação e comunicação de projetos orientados a aspectos, chamada de aSideML. Essa linguagem oferece semântica, notação e regras que permitem que o projetista construa modelos cujo foco sejam os principais conceitos, mecanismos e propriedades de sistemas orientados a aspectos, nos quais os aspectos e entrecortes sejam explicitamente tratados. Na Tabela 2.1 é mostrado o conjunto de diagramas que compõem a linguagem aSideML. Observa-se que essa linguagem dá apoio à modelagem estrutural, comportamental, bem como o processo de combinação entre os elementos base (classes no caso de orientação a objetos) de forma a enfatizar as melhorias proporcionadas pelos elementos aspecturais.

Tabela 2.1: Diagramas da aSideML (Chavez, 2004)

\begin{tabular}{|l|l|l|}
\hline Modelo & Diagrama & Elemento \\
\hline \hline Estrutural & - Diagrama de Aspectos & $\begin{array}{l}\text { - aspecto, interface transver- } \\
\text { sal, característica transversal } \\
- \text { aspecto, crosscutting, inter- } \\
\text { face transversal, order }\end{array}$ \\
\hline Comportamental & - Diagrama de Classe Estendido & $\begin{array}{l}- \text { ponto de combinação dinâ- } \\
\text { mico } \\
- \text { instância de aspecto, colabo- } \\
\text { ração aspectual } \\
- \text { instância de aspecto, intera- } \\
\text { ção aspectual }\end{array}$ \\
& - Diagrama de Colaboração Aspectual \\
& - Diagrama de Seqüência & $\begin{array}{l}- \text { classe combinada } \\
- \text { colaboração combinada } \\
\text { - interação combinada }\end{array}$ \\
\hline Processo de Combinação & - Diagrama de Classes Combinadas \\
& - Diagrama de Colaboração Combinadido \\
& - Diagrama de Seqüência Combinada
\end{tabular}

Além do trabalho de Chavez (2004), Clarke \& Baniassad (2005) propõem o Theme, um método de desenvolvimento de software orientado a aspectos que trabalha com interesses (do inglês, concerns) desde a fase de análise até o projeto e a composição. De modo geral, os interesses são encapsulados em temas do tipo base ou do tipo transversal. Os temas base agrupam funcionalidades bem identificáveis do domínio do problema, enquanto que os temas transversais encapsulam comportamentos que se encontram espalhados por várias partes do sistema. Os

\footnotetext{
${ }^{30}$ Entende-se por profile um conjunto de extensões da UML, em particular, baseadas em esteriótipos e tagged values, que possibilita representar modelos que originalmente a UML não possibilita descrever.
} 
temas podem se relacionar de duas formas: compartilhando conceitos ou entrecortando-se. $\mathrm{O}$ compartilhamento de conceitos ocorre quando o mesmo elemento de projeto aparece em mais de um tema. Nesse caso, os temas devem ser compostos por relacionamentos de intercalação (do inglês, merge) ou sobreposição (do inglês, override). Já, quando um tema encapsula um interesse que é transversal, sua composição com outros temas ocorre por meio de um relacionamento de ligação (do inglês, bind).

Apesar da importância da definição e representação das interfaces entre os diversos elementos que compõem um sistema orientado a aspectos, poucos são os trabalhos que têm abordado essa questão, sendo o trabalho de Chavez et al. (2005) um dos poucos que tratam essa questão.

\subsubsection{Tecnologias de Apoio}

Atualmente, frente ao interesse pela abordagem orientada a aspectos e a necessidade de implementação dos aspectos, diversas ferramentas e linguagens (ou abordagens lingüísticas ${ }^{31}$ ) têm surgido para dar apoio à POA (Alwis, 2002; Coady et al., 2001; Gal et al., 2001; Kiczales et al., 2001a,b; Kim, 2002). De modo geral, esses ambientes e linguagens implementam os quatro componentes básicos que uma tecnologia de apoio à POA deve apresentar (Elrad et al., 2001a): (i) um modelo de pontos de junção (do inglês, join point); (ii) um mecanismo de identificação dos pontos de junção; (iii) unidades que encapsulem tanto as especificações dos pontos de junção quanto os comportamentos que se deseja adicionar; e (iv) um processo para combinar as unidades com o programa base.

As abordagens lingüísticas mais conhecidas são as extensões de linguagens de programação de propósito geral, tais como Java e C. Dentre elas, pode-se citar a Hyper/J $\mathrm{J}^{32}$ e o AspectJ ${ }^{33}$ (Kiczales et al., 2001a,b) para Java, AOPHP ${ }^{34}$ para PHP, Apostle ${ }^{35}$ (Alwis, 2002) e AspectS ${ }^{36}$ para Smalltalk, e AspectC ${ }^{37}$ (Coady et al., 2001), AspectC $++^{38}$ (Gal et al., 2001) e AspectC\# ${ }^{39}$ (Kim, 2002) para as linguagens $\mathrm{C}, \mathrm{C}++$ e $\mathrm{C} \#$, respectivamente. Observa-se que dentre as abor-

\footnotetext{
${ }^{31}$ Entende-se por abordagens lingüísticas, mecanismos que têm o objetivo de entrelaçar aspectos dentro do comportamento funcional de um sistema de software de modo a produzir um sistema completo (Constantinides et al., 2000).

${ }^{32}$ http: //www.research.ibm.com/hyperspace/HyperJ/HyperJ.htm (acessado em 17/02/2006)

${ }^{33}$ http: / / eclipse.org/aspectj/ (acessado em 17/02/2006)

${ }^{34}$ http: //www. aophp. net/ (acessado em 17/02/2005)

${ }^{35}$ http: //www.cs.ubc.ca/labs/spl/projects/apostle/ (acessado em 17/02/2005)

${ }^{36}$ http: // citeseer.ist.psu.edu/hirschfeld01aspects.html (acessado em 17/02/2005)

${ }^{37}$ http: / / www . aspectc.org/ (acessado em 17/02/2006)

${ }^{38}$ http: / / www . aspectc.org/ (acessado em 17/02/2006)

${ }^{39}$ http: //www.dsg.cs.tcd.ie/index.php?category_id=169 (acessado em 17/02/2006)
} 
dagens lingüísticas, o AspectJ é um dos que mais tem-se destacado, talvez em virtude da própria linguagem Java estar em evidência.

O AspectJ foi desenvolvida no Xerox Palo Alto Research Center e agregada, posteriormente, ao Projeto Eclipse ${ }^{40}$. Consiste em uma linguagem de apoio à POA de forma genérica, estendendo a linguagem Java. O AspectJ permite dois tipos de implementação de interesses transversais (Kiczales et al., 2001b): a dinâmica e a estática. A implementação dinâmica permite que comportamentos adicionais sejam executados quando pontos bem definidos do fluxo de execução de um programa são atingidos (os pontos de junção). A implementação estática permite a inserção de novos atributos e novas operações em tipos (classes) já existentes.

As construções básicas apresentadas pelo AspectJ para permitir a implementação de interesses transversais são: conjuntos de junção (do inglês, pointcut), adendos (do inglês, advice), declarações inter-tipos (do inglês, inter-type declaration) e aspectos (do inglês, aspect). Uma discussão e apresentação mais detalhada sobre essas construções podem ser encontradas em (Eclipse.org, 2006).

\subsection{Frameworks}

Frameworks são mecanismos que têm sido investigados para a reutilização não somente de trechos de código-fonte, mas também de esforços despendidos em todas as fases do desenvolvimento de software. Com isso, a produtividade e a qualidade dos produtos de software resultantes do desenvolvimento baseado em frameworks podem ser melhorados (Braga, 2003). Observa-se que frameworks são atualmente alvo de atenção de pesquisadores e da indústria de desenvolvimento de software, podendo-se identificar frameworks para os mais diversos domínios de aplicação: frameworks de propósito geral, frameworks de domínios específicos, frameworks de aplicação e até para o desenvolvimento de sistema de baixo nível, tal como para sistemas de apoio à comunicação e à impressão. Como exemplos de frameworks bastante conhecidos tem-se o IBM SanFrancisco (Monday et al., 2000), um framework bastante utilizado para o desenvolvimento de software para gestão de negócios. Um outro exemplo é o HotDraw (Brant, 1999), para a construção de editores gráficos. O GREN (Braga, 2003) é um framework para o desenvolvimento de sistemas para o domínio gestão de recursos de negócios. Além desses, no trabalho de Braga (2003) e de Pazin (2004) são apresentados diversos outros exemplos. Observa-se que essa diversidade de frameworks evidencia a relevância de sua utilização no desenvolvimento de software.

\footnotetext{
${ }^{40}$ http: / / www.eclipse.org (acessado em 19/02/2006)
} 
Na literatura disponível sobre frameworks, podem ser encontradas diversas definições para frameworks, sendo que a mais citada nos trabalhos dessa área é a de Fayad \& Johnson (2000) que dizem que um framework é mais do que uma arquitetura, sendo uma aplicação semicompleta contendo componentes estáticos e dinâmicos que podem ser adaptados para produzir aplicações específicas. Frameworks são compostos de uma coleção de classes abstratas e concretas e uma interface entre elas, representando o projeto de um subsistema (Pree, 1995). De acordo com Buschmann et al. (1996), frameworks são compostos de partes fixas e partes variáveis (do inglês, frozen spots e hot spots, respectivamente). As partes fixas definem a arquitetura geral de um sistema de software e são utilizadas sem nenhuma modificação nos sistemas construídos com base no framework. Por outro lado, as partes variáveis, em geral implementadas por meio de callbacks e polimorfismo, possibilitam a adaptação e extensão do framework para uma determinada aplicação.

Apesar do desenvolvimento de um "bom" framework ser bastante caro (Roberts \& Johnson, 2006), o uso de um framework pode apresentar uma redução considerável no custo de desenvolvimento de aplicações, um vez que possibilita a reutilização tanto de projeto quanto de código-fonte de sistemas de software de um dado domínio de aplicação. De acordo com Fayad et al. (1999b,a), frameworks podem permitir a redução de aproximadamente $90 \%$ na quantidade de código-fonte a ser escrito se comparado ao desenvolvimento convencional utilizando-se biblioteca de funções. Um fato interessante a observar é que excelentes frameworks são ainda produtos de processos de desenvolvimento mais ou menos caóticos (Fayad et al., 1999a). Além disso, bons frameworks são usualmente resultado de muito esforço e muitas interações de projeto. A complexidade de frameworks, causada pela dificuldade tanto em construí-los quanto em utilizá-los, é um dos inibidores da utilização desse mecanismo para o desenvolvimento de sistemas de software (Braga, 2003).

Diversas são as classificações dadas a frameworks; uma delas que é comumente encontrada na literatura disponível sobre frameworks baseia-se na técnica utilizada para estendê-los; Fayad \& Johnson (2000) estabelecem as seguintes classes: caixa branca e caixa preta. Os frameworks caixa branca baseiam-se nas características de linguagens orientadas a objetos para alcançar capacidade de extensão. Nessa classe de frameworks, a extensão e adaptação é feita por meio de herança e sobreposição de métodos pré-definidos. Por outro lado, os frameworks caixa preta definem um conjunto de interfaces para componentes que podem ser conectados aos frameworks por meio de composição de objetos. Frameworks caixa branca são mais fáceis de projetar; entretanto, podem apresentar dificuldade de aprendizado para a utilização. Por outro lado, frameworks caixa preta são mais fáceis de aprender e utilizar se comparado com os de 
caixa branca, mas são menos flexíveis. Uma outra classe é o de caixa cinza na qual a extensão se dá por meio herança e ligação dinâmica e também pela definição de interface.

\subsubsection{Processo de Desenvolvimento de Frameworks}

Frente às vantagens de utilização de frameworks no desenvolvimento de software, pode-se identificar diversos trabalhos que buscam de alguma forma descrever passos de como projetar frameworks, dentre eles, pode-se citar (Braga, 2003; Pree, 1999; Ré, 2002; Roberts \& Johnson, 2006; Schmid, 1999). Vale ressaltar que esses trabalhos descrevem passos muitos gerais, não entrando em detalhes dos métodos e das técnicas a serem aplicados, ou apresentam uma certa burocracia para serem utilizados, envolvendo, muitas vezes, padrões e linguagens de padrões (Coplien, 1998), requerendo então vasto conhecimento e experiência dos desenvolvedores envolvidos.

Um dos trabalhos bastante citados na literatura disponível sobre frameworks é o de Roberts \& Johnson (2006), que descreve uma linguagem de padrões que mostra como projetar frameworks; contudo, detalhes sobre os métodos e técnicas a serem aplicados em cada um das atividades envolvidas não são apresentados. Mais detalhados são os trabalhos de Pree (1999) e de Schmid (1999). Por exemplo, Schmid (1999) propõe uma abordagem na qual primeiramente faz-se o projeto de uma aplicação específica de um dado domínio e, em seguida, generaliza-se esse projeto. Cada aspecto variável do framework deve ser tratado um de cada vez. Após a criação de um modelo de classe de uma dada aplicação do domínio, faz-se uma análise de altonível da parte variável, ou seja, identifica-se quais são as partes variáveis. Em seguida, para cada parte variável, faz-se uma especificação (textual) descrevendo-o. Faz-se então um projeto de alto nível de cada parte variável e, por fim, faz-se a generalização, juntando os projetos das partes variáveis. Mais abrangente ainda, tem-se o trabalho de Braga (2003), que propõe a utilização de uma linguagem de padrões para apoiar todo o processo de desenvolvimento do framework, desde a identificação da funcionalidade do framework, seu projeto, implementação, validação, até sua instanciação para sistemas específicos do domínio.

Apesar da atividade de teste de software ser considerada um elemento crítico para assegurar a qualidade do software, ainda são poucos os trabalhos que investigam a aplicação do teste em frameworks. Trabalhos como o de Fayad et al. (1999a) e Jeon et al. (2002) alertam para a necessidade do teste em frameworks, uma vez que eles são repetidamente utilizados para o desenvolvimento de software. Nesse contexto, deve-se inclusive considerar o teste do framework em si, bem como o teste de cada uma das instanciações resultante da adaptação e extensão do framework. Segundo Jeon et al. (2002), o teste convencional de software podem ser aplicado 
no teste de frameworks, contudo, esses frameworks apresentam características que dificultam o teste das partes adaptadas de forma eficaz; usualmente, o controle da execução das partes adaptadas é controlado pelo framework, o que dificulta ter controle das condições do teste.

\subsubsection{Documentação de Frameworks}

Como qualquer tipo de software reusável, um framework deveria requerer menos tempo para entender e utilizá-lo do que construir uma aplicação equivalente sem o framework. Em virtude do tamanho e da complexidade de muitos frameworks, a habilidade de entendê-los rapidamente e aplicá-los é uma questão crítica (Froehlich et al., 1997). Nesse contexto, diversos mecanismos têm sido utilizados para a documentação de frameworks (Beck \& Johnson, 1994; Campbell \& Islam, 1992; Froehlich et al., 1997; Fontoura et al., 2002; Gangopadhyay \& Mitra, 1995; Hammouda et al., 2003; Johnson, 1992; Krasner \& Pope, 1988; Painter \& Turner, 1996; Sanada \& Adams, 2002; Schmid, 1995; Schwabe et al., 2001).

Segundo Johnson (Johnson, 1992), três tipos de documentação são necessários para documentar um framework: propósito, utilização e projeto do framework. O propósito do framework refere-se à descrição do domínio em que se encontra o framework e suas limitações; trabalhos nessa linha são os de Johnson (1992); Krasner \& Pope (1988) e de Painter \& Turner (1996). A documentação da utilização do framework deve conter a descrição detalhada de como usar o framework, uma vez que o uso é uma boa maneira de entender o framework. Froehlich et al. (1997); Johnson (1992); Krasner \& Pope (1988) e Painter \& Turner (1996) têm proposto mecanismo para esse tipo de documentação. O projeto do framework refere-se à descrição do projeto detalhado do framework, incluindo as diferentes classes e seus relacionamentos. Beck \& Johnson (1994); Campbell \& Islam (1992); Fontoura et al. (2002); Froehlich et al. (1997); Gangopadhyay \& Mitra (1995); Hammouda et al. (2003); Sanada \& Adams (2002); Schmid (1995) e Schwabe et al. (2001) têm conduzido trabalhos envolvendo o projeto de frameworks. Apesar da diversidade de mecanismos propostos, de acordo com Froehlich et al. (1997), de modo geral, pode-se identificar diversos trabalhos que envolvem a documentação do projeto e da arquitetura do framework; contudo, são menos os trabalhos que têm se dedicado à documentação do propósito e da utilização do framework.

Extensões da UML têm também sido propostas para a representação de frameworks (Fontoura et al., 2002; Hammouda et al., 2003; Sanada \& Adams, 2002). Por exemplo, Fontoura et al. (2002) propõem um profile para a UML para a representação de projeto e da arquitetura de frameworks. De modo geral, esse profile restringe-se ao uso de elementos da UML, for- 
nece notações novas e especializa a semântica de elementos da UML de modo a possibilitar a representação das especificidades de frameworks.

\subsubsection{Frameworks Orientados a Aspectos}

Com o advento da programação orientada a aspectos (Kiczales et al., 1997) e de linguagens, tais como o AspectJ (Kiczales et al., 2001b,a), surgiu também o interesse em investigar como esses novos conceitos e linguagens podem ser utilizados no desenvolvimento de frameworks (Camargo \& Masiero, 2005). Desse modo, têm surgido recentemente diversos trabalhos envolvendo frameworks orientados a aspectos (Camargo \& Masiero, 2005; Constantinides et al., 2000; Pinto et al., 2002; Rashid \& Chitchyan, 2003). Entende-se por frameworks orientados a aspectos um conjunto formado de unidades básicas de programação orientada a objetos (as classes), cuja presença não é obrigatória, e unidades básicas de programação orientada a aspectos (os aspectos) (Camargo \& Masiero, 2005). Assim como um framework orientado a objetos, um framework orientado a aspectos pode ser definido como um sistema semi-completo e reutilizável que pode ser instanciado por um desenvolvedor de aplicações. A arquitetura de um framework orientado a aspectos possui uma parte fixa e uma parte variável, sendo que essa última deve ser adaptada para que o framework seja acoplado a uma aplicação já existente ou produza uma nova aplicação. A adaptação geralmente envolve a concretização de um mecanismo de composição abstrato, no caso dos aspectos, e de classes e métodos abstratos, no caso das classes (Camargo \& Masiero, 2005).

A maioria dos frameworks orientados a aspectos tratam de interesses transversais nãofuncionais (Camargo \& Masiero, 2005), sendo que é muito comum a literatura de frameworks e aspectos mencionar a persistência e a segurança como exemplos. Pode-se identificar iniciativas no uso de aspectos na codificação de regras de negócio (Cibrán et al., 2003; Suvée et al., 2005), mas há ainda uma carência de trabalhos que apresentam exemplos de implementação de aspectos desse tipo na forma de frameworks (Camargo \& Masiero, 2005). É importante salientar também que a literatura carece inclusive de frameworks orientados a aspectos que automatizam atividades de Engenharia de Software, tanto atividades fundamentais quanto de apoio e organizacionais.

Os frameworks orientados a aspectos podem ser classificados em frameworks de aplicação orientados a aspectos e frameworks transversais (do inglês, crosscutting frameworks) (Camargo \& Masiero, 2005). Os frameworks de aplicação orientados a aspectos implementam uma arquitetura genérica de um domínio e sua instanciação produz uma aplicação desse domínio. A arquitetura do framework de aplicação orientado a aspectos é projetada com classes e aspectos 
(implementando provavelmente interesses transversais e regras de negócios) de forma integrada dentro da arquitetura do framework. Os frameworks de aplicação orientados a aspectos são semelhantes aos frameworks de aplicação orientados a objetos com relação ao seu propósito e suas diferenças estão na sua arquitetura, que usa aspectos abstratos e concretos, bem como classes abstratas e concretas para implementar partes variáveis de seu código e que, portanto, são concretizados quando ocorre a instanciação de uma aplicação. Nesses frameworks o princípio de inversão de controle continua válido (Camargo \& Masiero, 2005).

Os frameworks transversais possuem mecanismos de composição abstratos e variabilidades correspondentes a um único interesse transversal, como por exemplo, persistência e autenticação, sendo que esse interesse pode ser particionado em sub-interesses. Como exemplo de trabalho que apresenta frameworks transversais, pode-se citar o de Camargo \& Masiero (2005) que apresenta frameworks de segurança, persistência, de desenvolvimento e mais dois frameworks de interesses funcionais. Vale observar que frameworks desse tipo só podem ser utilizados se forem acoplados a algum código-base existente. Sendo assim, seu processo de reúso possui duas etapas "semanticamente" distintas (Camargo \& Masiero, 2005): instanciação e composição.

A instanciação de um framework transversal refere-se ao processo convencional de reúso de frameworks orientados a objetos tradicionais e consiste em especializar partes do código-fonte especialmente projetado para isso. É o processo pelo qual implementam-se os ganchos do framework, escolhe-se alguma funcionalidade alternativa ou implementa-se uma nova. Isso é feito normalmente sobrepondo-se métodos que retornam valores da aplicação específica (Camargo \& Masiero, 2005).

Basicamente, a composição de framework transversais consiste de duas etapas (Camargo \& Masiero, 2005): identificação dos pontos de junção e fornecimento de regras de composição. A identificação dos pontos de junção consiste em identificar no módulo base os pontos de junção adequados ao acoplamento e deve ser feita com base nas "alternativas de composição" disponíveis no framework. É interessante que os framework transversais sejam projetados com alternativas de composição, principalmente aqueles que necessitam de dados da aplicação em seu processamento. Essas alternativas aumentam as chances de acoplamento com códigos-base já existentes, além de diminuir a complexidade das regras de composição que precisam ser fornecidas. A necessidade de alternativas de composição torna-se mais evidente quando o framework deve ser acoplado a um código-base já existente. No caso de um novo desenvolvimento, o código-base já pode ser projetado com vistas ao acoplamento que será feito. Contudo, esse “desenvolvimento orientado às alternativas de composição" pode tornar o código-base confuso e difícil de manter, pois pode ser que pontos de junção fictícios tenham que ser criados apenas para o acoplamento (Camargo \& Masiero, 2005). 
Já o fornecimento de regras de composição consiste em fornecer as regras que unem as variabilidades escolhidas/implementadas do framework com o código-base e para isso tarefas orientadas a aspectos devem ser realizadas como, por exemplo, a concretização de um mecanismo de composição abstrato ou a utilização de declarações inter-tipo, no caso da linguagem AspectJ. Em alguns casos, a etapa de composição depende de informações que são determinadas na etapa de instanciação, o que determina uma ordem de realização: primeiro a instanciação e depois a composição. Mas também pode ocorrer de não haver essa dependência, fazendo com que essas etapas possam ser feitas em qualquer ordem ou em paralelo (Camargo \& Masiero, 2005).

Vale observar que, assim como discutido por Camargo \& Masiero (2005), o módulo base é responsável pelo fluxo principal, ou seja, quando se utiliza um framework transversal junto a um módulo base, não há inversão de controle do ponto de vista desse módulo, pois é esse módulo que tem a responsabilidade pelas chamadas e fluxo de controle. No entanto, do ponto de vista interno do framework transversal, a inversão de controle ocorre como em qualquer framework orientado a objetos. Com relação à integração entre dois frameworks transversais, quando aspectos contidos em um framework transversal afeta um outro framework, por exemplo, quando o framework de persistência afeta o framework de documentação, esse último é responsável pelo fluxo principal.

\subsubsection{Outros Mecanismos de Reutilização}

Além dos frameworks, na literatura disponível sobre Engenharia de Software, diversas têm sido as linhas de pesquisa no sentido de propor mecanismos, abordagens e processos de modo a promover a reutilização de software, e conseqüentemente, o aumento da produtividade no desenvolvimento de software. Nesta seção são discutidos brevemente, geradores de aplicação, linhas de produto e componentes de software.

\section{Geradores de Aplicação}

De acordo com Cleaveland (1988), geradores de aplicação possibilitam customizar e reutilizar projetos (do inglês, design) de software, contribuindo para melhorar a produtividade e a manutenibilidade de sistemas de software. Entende-se por gerador de aplicação, um programa que gera outros programas, sendo que o programa gerado encontra-se em uma linguagem de programação de alto nível (Smaragdakis et al., 2004). Geradores de aplicação traduzem a especificação em um programa aplicativo. A especificação descreve o problema ou as tarefas a 
serem realizadas pelo programa. Essa especificação poderia apresentar-se na forma de um diálogo interativo, no qual o usuário seleciona de um conjunto de menus; ou então, a especificação poderia aparecer na forma gráfica, no qual o usuário edita um diagrama. Também, a especificação pode ser escrita em uma linguagem, chamado de linguagem orientada a aplicação ou de quarta geração (Cleaveland, 1988). Dessa forma, a especificação é utilizada pelos geradores de aplicação para gerar automaticamente um ou mais "produtos" - tipicamente um segmento de código-fonte, uma subrotina ou um sistema de software completo (Cleaveland, 1988). Ainda segundo Cleaveland (1988), o uso de geradores de aplicação tem resultado em sucesso para alguns tipos de software, a saber, construção de sistemas de processamento de dados, interface do usuário e de bases de dados.

De acordo com Smaragdakis et al. (2004), os primeiros trabalhos sobre geradores de aplicação surgiram juntamente com as primeiras pesquisas em Ciência da Computação. Alguns dos trabalhos que mais têm-se destacado e que consolidam conhecimento dessa área de pesquisa são de Jones \& Glenstrup (2002) e de Smaragdakis \& Batory (2000).

\section{Linhas de Produto}

De modo geral, o desenvolvimento de software é semelhante ao desenvolvimento de qualquer produto industrializado; assim, a estratégia de produção baseada em família, muito comum quando se discute produção de bens industrializados, pode também ser aplicada ao desenvolvimento de software. No contexto de Engenharia de Software, o objetivo de linhas de produto é alcançar escopo econômico por meio do desenvolvimento sinérgico de produtos de software (Knauber \& Succi, 2000). Ao contrário do desenvolvimento de software realizado projeto a projeto (um de cada vez), linha de produto de software é um exemplo de estratégia de reutilização (Clements \& Northrop, 2002). Entende-se por linha de produto de software, um conjunto de sistemas que usam software intensivamente, compartilhando um conjunto de características comuns, satisfazendo as necessidades de um segmento particular de mercado e que são desenvolvidos a partir de um conjunto comum de ativos principais (do inglês, assets) de forma preestabelecida Clements et al. (2002).

Nos últimos anos, diversas organizações têm utilizado a abordagem de linhas de produto. Outras organizações têm sido atraídas por essa abordagem e encontram-se em diversos estágios de integração das práticas de linhas de produto (Bergey et al., 2001). Mais recentemente, outras organizações têm proposto linhas de produto de software, podendo-se $\operatorname{citar}^{41}$ : a General Motors Powertrain Software Product Line da General Motors, a Ericsson AXE Family da Ericsson e a Salion's Product Line da Salion .

\footnotetext{
${ }^{41}$ http://www.sei.cmu.edu/SPLC2004/ (acessado em 14/03/2006)
} 
Observa-se que as pesquisas envolvendo linhas de produto têm focado em desenvolvimento de software baseado em arquitetura, definição e avaliação de arquitetura, desenvolvimento de componentes, reengenharia de sistemas legados, ativos principais, desenvolvimento de negócios para linhas de produto, entre outros (Bergey et al., 2001). Além disso, de acordo com Clements \& Northrop (2002), o sucesso de uma linha de produto depende da correta arquitetura de software adotada.

\section{Componentes de Software}

Atualmente, o desenvolvimento de software baseado em componentes tem-se evidenciado como mais um mecanismo para reutilização de software. Entende-se por componentes, entidades mais abstratas do que as classes, podendo ser considerados provedores de serviços, sendo que como características principais de componentes pode-se destacar que o componente é uma entidade executável independente que publicam suas interfaces, sendo que todas as interações com os componentes são feitas por meio dessas interfaces (Sommerville, 2001).

A Engenharia de Software Baseada em Componentes (do inglês, Component-Based Software Engineering (CBSE)) ou Desenvolvimento de Software Baseado em Componentes (do inglês, Component-Based Software Development) (Brown, 1996; SEI, 1997) emergiu no final da década de 90 como uma abordagem baseada na reutilização para o desenvolvimento de sistemas de software. Seu surgimento deu-se em virtude do desenvolvimento orientado a objetos não conduzir a um extensiva reutilização, como inicialmente foi sugerido; classes de objetos eram muito detalhadas, específicas e a utilização requisitava o conhecimento de detalhes de implementação das classes, requisititando a disponibilização do código-fonte, o que não era comercialmente interessante. Segundo Sommerville (2001), nenhum mercado significativo para as classes individuais foi desenvolvido. Vale ressaltar que, atualmente, o processo de desenvolvimento de software com o uso de componentes tem resultado em menores custos de desenvolvimento, rapidez no desenvolvimento do sistema e maior confiabilidade do sistema.

\subsection{Ontologia}

Uma ontologia é um artefato de engenharia, constituído por um vocabulário específico usado para descrever uma certa realidade, além disso, contém também um conjunto de suposições explícitas referentes ao significado pretendido para os termos usados no vocabulário. Usualmente, esse conjunto de suposições tem a forma de uma teoria lógica de primeira ordem, no qual os termos do vocabulário aparecem como nomes de predicados unários ou binários, chamados de 
conceitos e de relações, respectivamente. No caso mais simples, uma ontologia descreve uma hierarquia de conceitos relacionados; em casos mais complexos, axiomas são adicionados para expressar outros relacionamentos entre conceitos e para restringir a interpretação pretendida (Guarino, 1998; IEEE, 2005).

Uma diversidade de ontologias têm sido desenvolvidas por diferentes grupos, sob diferentes abordagens, e usando diferentes métodos e técnicas. Ontologias têm sido aplicadas sobretudo na descrição de domínios como Medicina, Engenharia e Direito (Barbosa, 2004). Não sendo diferente, na área de Engenharia de Software, alguns trabalhos têm sido conduzidos visando à definição de ontologias para apoiar a aquisição, organização, reúso e compartilhamento de conhecimento dessa área. Pode-se identificar diversas ontologias, tais como a ontologia para processo de software (Falbo, 1998), a ontologia para domínios (Oliveira et al., 2000), a ontologia para documentação (Nunes et al., 2004), a ontologia de tarefas (Zlot, 2002), a ontologia de teste de software (Huo et al., 2003), entre outras.

O desenvolvimento de ferramentas de apoio à construção de ontologias, tais como a ODEd (Mian, 2003), ObjectEditor (Beck, 2003), Protégé (Grosso, 1999), Ontolingua (Knowledge Systems Laboratory, 2006), entre outras, bem como a proposição de métodos para a construção de ontologias, tais como o SABiO (Systematic Approach for Building Ontologies) (Falbo et al., 1998), evidenciam a relevância dada pela comunidade científica ao tema.

\subsubsection{Representação de Ontologias}

Uma diversidade de notações tem sido utilizada para representar/descrever ontologias. Sendo a ontologia a consolidação do conhecimento de uma determinada área ou domínio, a leitura da ontologia não deve apresentar ambigüidade. Assim, a notação deve apresentar mecanismos que permitam a descrição formal da ontologia. Então, um aspecto a ser considerado sobre a construção de ontologias é a escolha de uma linguagem para expressá-las (Nunes et al., 2004). A princípio, qualquer linguagem de representação de conhecimento formal, ou até mesmo informal, poderia ser usada (Falbo, 1998). Na prática, contudo, algumas linguagens têm sido mais utilizadas, tais como a BNF (Backus Naur Form) (Huo et al., 2003), Ontolingua (GRUBER, 1992), OWL (Web Ontology Language) (W3C, 2006), entre outras. Além dessas, extensões da UML, tal como a proposta em (Cranefield \& Purvis, 1999) e em (Mian, 2003), têm sido utilizadas como linguagens para definir ontologias. De modo geral, é utilizado o diagrama de classes, que fornece uma notação para definição de classes, seus atributos e relacionamentos (Cranefield \& Purvis, 1999). Os benefícios de usar a UML são (Cranefield \& Purvis, 1999): a UML pos- 
sui uma comunidade de usuários ampla e que se estende rapidamente, sendo mais familiar aos desenvolvedores; e existe uma representação gráfica padrão para modelos expressos em UML.

\subsection{Teste de Software: Uma Visão Geral}

Dentre as atividades do processo de desenvolvimento de software, o teste de software aparece como um elemento crítico para assegurar a qualidade do software e representa a revisão das fases de especificação, projeto e codificação. De acordo com Harrold (2000), o teste tem-se despontado como uma das áreas de pesquisa mais promissoras e importantes. Nas organizações de desenvolvimento de software é usual que $30 \%$ a $40 \%$ do esforço total de desenvolvimento de software sejam gastos com a fase de teste de software (Pressman, 2000); de acordo com Perry (1995), essa porcentagem chega a ser em torno de 50\% e, no domínio de sistemas críticos, essa porcentagem é maior que 50\% (Harrold, 2000).

Embora durante todo o processo de desenvolvimento de software sejam utilizadas técnicas, métodos e ferramentas de modo a evitar que defeitos ${ }^{42}$ sejam introduzidos no produto de software, a atividade de teste continua sendo de fundamental importância para a eliminação de defeitos que persistem no software (Maldonado, 1991; Perry, 1995). Mesmo nos melhores softwares comerciais, raramente encontra-se softwares com menos de dez defeitos a cada 100.000 linhas de código (Lee et al., 2000). Assim, o teste tem o objetivo de revelar defeitos, contribuindo para demonstrar que as funções do software estão sendo desempenhadas de acordo com a especificação (Myers, 1979; Pressman, 2000).

Apesar de não ser possível, por meio da atividade de teste, provar que um programa está correto, o teste, quando conduzido sistemática e criteriosamente, contribui para aumentar a confiança de que o software desempenha as funções especificadas e evidenciar características mínimas do ponto de vista da qualidade do software.

O teste de software envolve basicamente quatro etapas, a saber, o planejamento de testes, o projeto de casos de teste, a execução e a avaliação dos resultados dos testes (Maldonado, 1991; Pressman, 2000). Com o objetivo de facilitar a atividade de teste de software, o teste é dividida em fases, sendo que a classificação mais comumente utilizada são o teste de unidade, de integração, de sistema e de regressão.

\footnotetext{
${ }^{42}$ Segundo a IEEE (1990), entende-se por defeito (do inglês, fault), um passo, um processo ou uma definição de dados incorreta; um erro (do inglês, error) é a diferença entre o valor obtido e o valor esperado, ou seja, qualquer estado intermediário incorreto ou resultado inesperado na execução do programa; e uma falha (do inglês, failure) é a produção de uma saída incorreta com relação à especificação.
} 
Dentre as etapas do teste de software, o projeto e a avaliação de casos de teste são essenciais; essas atividades englobam um conjunto de técnicas, critérios e métodos de projeto e avaliação de casos de teste, fornecendo ao projetista de software uma abordagem sistemática e teoricamente fundamentada. Dessa forma, nas últimas décadas, atividades de pesquisas na área de teste de software têm intensivamente estabelecido técnicas e critérios de teste para auxiliar na avaliação da qualidade e adequação da atividade de teste; como exemplo pode-se citar (Beizer, 1990; Budd, 1981; Delamaro, 1993, 1997; Horgan \& Mathur, 1992; Lutz, 1990; Maldonado, 1991; Myers, 1979; Myers et al., 2004; Pressman, 2000; Rapps \& Weyuker, 1985; Ricca \& Tonella, 2001; Zhu et al., 1997).

Tradicionalmente, as técnicas e os critérios de teste têm sido aplicados no teste do códigofonte de programas. A importância da realização de teste em código-fonte de programas é bastante reconhecida e fundamental para garantir níveis de qualidade em produtos de software. Contudo, segundo Perry (1995), a maioria dos defeitos ocorrem na fase de projeto; e estudos apontam que aproximadamente $65 \%$ dos defeitos são decorrentes das fases de análise e projeto e, aproximadamente $35 \%$ dos defeitos ocorrem na fase de codificação. De acordo com Perry (1995) e Pressman (2000), quanto mais cedo defeitos forem identificados, menor é o custo de eliminação do defeitos e conseqüentemente, de desenvolvimento e de manutenção do software. Assim, aplicar a atividade de teste durante todo ciclo de vida do software é, certamente, bastante relevante.

Nessa linha, um dos primeiros trabalhos que aborda a necessidade de aplicação do teste em nível de especificação é o de Kemmerer (1985), que o julga como um dos fatores de identificação de defeitos nas primeiras fases do processo de desenvolvimento de software. Para modelar a especificação de programas, especialmente especificações de sistemas reativos ${ }^{43}$, técnicas formais têm sido largamente empregadas. Como exemplos de técnicas formais de especificação, têm-se Máquinas de Estado Finito (Gill, 1962), Statecharts (Harel, 1987), Redes de Petri (Peterson, 1981) e Redes de Petri Coloridas (Jensen, 1997). Na literatura, pode-se identificar diversas ferramentas de apoio para a edição, a simulação e a validação de modelos representados com essas técnicas. Como exemplo de ferramentas pode-se citar Statemate (Harel et al., 1990), Statsim (Masiero et al., 1991) e MGASet (Nakazato, 1995). Mesmo quando técnicas formais de especificação são empregadas, defeitos podem estar presentes, apesar dessas técnicas fornecerem a base de uma especificação rigorosa, completa e precisa (Simão, 2004). Dessa forma, a aplicação de técnicas e critérios de teste sobre modelos escritos em técnicas formais, de modo a minimizar o número de defeitos que poderiam estar sendo introduzidos no código-fonte, é

\footnotetext{
${ }^{43}$ Entende-se por sistemas reativos uma classe de sistema que interagem continuamente com o ambiente, respondendo a eventos externos de forma controlada; sistemas de tempo real, sistemas embutidos e sistemas de segurança fazem parte dessa classe.
} 
bastante relevante. Diversos trabalhos vêm explorando essa estratégia, como exemplo pode-se citar (Friedman et al., 2002; Grieskamp et al., 2002; Ho \& Lin, 1999; Jagadeesan et al., 1997; Miao et al., 1999; Chang \& Richardson, 1999).

Dada a relevância que têm tomado sistemas Web, alguns trabalhos têm investigado técnicas e critérios para o teste desses sistemas, bem como proposto ferramentas de teste de sistemas Web (Domingues, 2005; Liu et al., 2000; Niese et al., 2002; Nguyen, 2001; Ricca \& Tonella, 2001; Yang et al., 1999). Particularmente, Nguyen (2001) apresenta um levantamento de diversas ferramentas de teste de aplicações Web. Apesar dessas iniciativas, desenvolvedores de sistemas Web não podem atualmente contar com ferramentas poderosas o suficiente para testar aplicações Web; aquelas existentes concentram-se em verificar a sintaxe do programa, realizar a checagem da integridade de ligações (do inglês, link) em documentos hipertexto, medir o desempenho de aplicações Web, entre outros, inclusive muitas delas operacionais em plataforma Web. Observa-se que essa área de pesquisa é bastante recente, necessitando, portanto, de mais investigações.

Vale salientar que o teste é uma das atividades de GQS (Garantia de Qualidade de Software) e, em geral, sua utilização isolada não é suficiente para alcançar um produto de boa qualidade. Dessa forma, é fundamental que a atividade de teste seja utilizada juntamente com outras atividades da Engenharia de Software, tais como inspeções, revisões, técnicas formais e rigorosas de especificação e de verificação, walkthrough, entre outras (Maldonado, 1991; Pressman, 2000)

\subsubsection{Técnicas e Critérios de Teste}

Os critérios de teste são comumente agrupados em técnicas de teste que se diferenciam pela origem da informação utilizada para estabelecer os requisitos de teste e para avaliar ou para construir conjuntos de casos de teste (Maldonado, 1991). Basicamente, a literatura de teste classifica os critérios de teste nas técnicas Funcional, Estrutural, Baseada em Defeitos e Baseado em Estados. Vale ressaltar que essas técnicas de teste devem ser vistas como complementares e a questão está em como utilizá-las de forma que as vantagens de cada uma delas sejam melhor exploradas em uma estratégia de teste que leve a uma atividade de teste de qualidade, ou seja, eficaz e de baixo custo (Maldonado et al., 1998).

Pesquisas na área de teste de software têm investido na proposição de uma diversidade de critérios de teste de diferentes técnicas. Como exemplos de critérios da técnica Funcional, pode-se citar o Particionamento por Equivalência, Grafo de Causa-Efeito e Análise do Valor Limite (Pressman, 2000). Na técnica Estrutural, os critérios mais investigados são os Baseados 
em Fluxo de Dados (Maldonado, 1991; Rapps \& Weyuker, 1985) e os Baseados em Fluxo de Controle (Myers, 1979; Zhu et al., 1997). Dentre os critérios Baseados em Fluxo de Controle, os mais conhecidos são Todos-Nós, Todos-Arcos e Todos-Caminhos (Myers, 1979; Zhu et al., 1997). Já os critérios Baseados em Fluxo de Dados surgiram na década de 70 (Herman, 1976) apud (Vincenzi, 2004) e a motivação para a introdução desses critérios foi que, mesmo para programas pequenos, o teste baseado somente nos critérios Baseados em Fluxo de Controle não era eficaz para revelar a presença até mesmo de defeitos simples e triviais (Vincenzi, 2004). Dentre os critérios Baseados em Fluxo de Dados, destacam-se alguns dos critérios introduzidos por Rapps \& Weyuker (1985) na década de 80: Todas-definições, Todos-du-caminhos, Todosp-usos e Todos-usos. No final da década de 80 e início de 90, Maldonado (1991) definiu os critérios Potenciais Usos. A técnica Baseada em Defeitos tem os critérios Semeadura de Erros (do inglês, Error Seeding) (Budd, 1981) e Análise de Mutantes (Budd, 1981; Delamaro, 1993), sendo esse último discutido em mais detalhes na seção seguinte. Todos esses critérios vem sendo automatizados por ferramentas de teste, sendo experimentadas para investigar a viabilidade de sua utilização como mecanismo de identificação de defeitos e, conseqüentemente, de melhoria de qualidade de sistemas de software. Essa diversidade de critérios leva à necessidade de avaliar, por meio de estudos teóricos e experimentais, os pontos fortes e as limitações desses critérios possibilitando o uso complementar, e de forma semelhante ao que acontece com as técnicas de teste, estabelecer estratégias de testes de alta eficácia e de baixo custo em revelar a presença de defeitos (Vincenzi, 2004); atualmente, diversos trabalhos envolvendo estudos experimentais em teste de software têm sido conduzidos (Briand \& Labiche, 2004; Andrews, 2004; Bertolino, 2004; Juristo et al., 2004)

\section{Critério Análise de Mutantes}

A Análise de Mutantes, também chamada de Teste de Mutação, surgiu na década de 70 na Yale University e Georgia Institute of Technology, sendo que os primeiros trabalhos que descrevem o teste de mutantes foram publicados no final dessa década (Andre, 1979; Hamlet, 1977; DeMillo et al., 1978); contudo, até hoje esse critério tem sido explorado pela sua eficácia (Bieman et al., 2001; Chevalley \& Thévenod-Fosse, 2003; Ma et al., 2005; Simão, 2004; Yano, 2004).

Embora a Análise de Mutantes tenha sido proposta inicialmente para o teste de programas em nível de unidade, esse critério tem sido explorado também no teste de integração. Mutação de Interface (Delamaro, 1997) permite a aplicação dos conceitos oriundos da Análise de Mutantes no teste de integração. Um estudo conduzido por Delamaro (1997) mostra fortes evidências da eficácia da Mutação de Interface em detectar defeitos. Na linha de orientação a objetos, 
trabalhos envolvendo a avaliação e a adequação do Teste de Mutação no teste de programas orientados a objetos têm sido propostos (Bieman et al., 2001; Chevalley \& Thévenod-Fosse, 2003; Ma et al., 2005; Jackson \& Woodward, 2000; Vincenzi, 2004).

Inicialmente proposta para o teste de programa, a Análise de Mutantes tem sido também investigada e utilizada no teste de especificação de sistema. Como exemplos de algumas das publicações resultantes nessa linha têm-se (Chung \& Sidhu, 1991; Fabbri et al., 1995, 1997, 1999a,b; Petrenko \& Bochmann, 1996; Probert \& Guo, 1991; Simão, 2000; Simão et al., 2000; Simão, 2004; Souza et al., 2000b; Sugeta, 1999, 2004).

Apesar da eficácia, esse critério apresenta limitações quanto ao custo de aplicação. Um trabalho recente que visa a diminuir o custo de aplicação desse critério é o de Ma et al. (2005) que propõe a aplicação de mutação em nível de bytecode de programas em Java, diminuindo o tempo de compilação e execução dos mutantes; resultados desse estudo mostram que esse método é cinco vezes mais rápido do que a mutação em código-fonte Java e compilação separada. Ainda nessa linha, no trabalho de Vincenzi et al. (2005) é proposto um processo - o Muta-Pro - que consolida em um único trabalho resultados de diversos outros que foram conduzidos com o intuito de reduzir os custos de aplicação do Teste de Mutação, tais como a seleção dos operadores de mutação essenciais (Barbosa et al., 2000) e a BaLBEDeT (Bayesian LearningBased Equivalent Detection Technique) (Vincenzi et al., 2002), para determinação de mutantes equivalentes com base em técnicas de Inteligência Artificial.

Em virtude do grande número de mutantes que devem ser gerados, executados e comparados quando da aplicação do critério Teste de Mutação, é de suma importância a disponibilização de ferramentas de apoio à aplicação desse critério.

\subsubsection{Automatização de Teste de Software}

Sem a utilização de ferramentas que automatizam a aplicação das técnicas e critérios de teste, a atividade de teste torna-se onerosa, propensa a erros e limitada a programas muito simples (Horgan \& Mathur, 1992). Assim, a qualidade da atividade de teste, apesar de certamente depender dos critérios e das técnicas utilizadas, também depende da disponibilidade de ferramentas de teste. No entanto, essas ferramentas não podem automatizar completamente todas as atividades envolvidas no teste de software, restringindo-se à realização de tarefas mecânicas de forma sistemática. Segundo Simão (2004), a automatização completa é um objetivo teoricamente inalcançável, uma vez que existem alguns problemas inerentemente indecidíveis: (i) dado dois programas, não se pode determinar se eles são equivalentes; (ii) dado duas seqüências de co- 
mandos (caminhos), não se pode determinar se eles computam a mesma função; e (iii) dado um caminho, não se pode determinar se ele é executável ou não, ou seja, se existe algum dado de entrada que execute esse caminho.

Apesar dessas limitações, vários são os esforços para a construção de ferramentas de teste, tanto comerciais quanto acadêmicas, apoiando critérios de teste de diferentes técnicas (Agrawal et al., 1998; Choi et al., 1989; DeMillo et al., 1988; Horgan \& Mathur, 1992; Chaim, 1991; Chevalley \& Thévenod-Fosse, 2003; Childers et al., 2003; Delamaro, 1993, 1997; Fabbri et al., 1994a, 1999a,b; Lutz, 1990; Ma et al., 2005; Maldonado et al., 2000; Misurda et al., 2005a; Price \& Zorzo, 1990; IBM, 2006; Rocha, 2005; Simão \& Maldonado, 2000; Simão, 2004; Sugeta, 1999, 2004; Sze \& Lyu, 2000; Telcordia Technologies, 2005; Vincenzi, 2004; Yano et al., 2003).

Essa diversidade de ferramentas vem contribuindo como um fator determinante para a produtividade na atividade de teste. Ferramentas de teste têm sido empregadas como recursos para a condução de estudos experimentais para a avaliação e comparação dos diversos critérios de teste e para o estabelecimento de estratégias de teste. As ferramentas podem ser vistas ainda como veículo de transferência de tecnologia das pesquisas realizadas em universidades e centros de pesquisa para a indústria de produção de software. Trabalhos, como o de Horgan \& Mathur (1992), têm citado a utilização de ferramentas de teste no ensino em cursos de graduação, mais especificamente em disciplinas de Engenharia de Software.

Apesar dessas vantagens, limitações podem ser identificadas. Vale ressaltar que as observações de Horgan \& Mathur (1992) têm prevalecido até os dias de hoje. Eles dizem que, na maioria dos casos, cada ferramenta tem dado apoio a uma única técnica de teste, sendo insuficiente para a indústria e a comunidade de pesquisa e educação se deseja-se aplicar a ferramenta em um ambiente de produção de software. Ainda, de acordo com Horgan \& Mathur, uma outra limitação é a estrutura de organização particular que cada ferramenta utiliza; por exemplo, o formato de armazenamento de casos de teste em arquivos é diferente em cada ferramenta, dificultando a reutilização de casos de teste por outras ferramentas. Além disso, observa-se uma falta de padronização na interface do usuário das ferramentas de teste, ou seja, diferentes ferramentas têm apresentado diferentes interfaces. Gao et al. (1997) acrescentam ainda que a grande maioria das ferramentas são dependentes de plataforma e apresentam funcionalidade e base de dados de acesso restrito. Buscando superar algumas dessas limitações, iniciativas como a de Gao et al. (1997) e Yang et al. (1999) têm proposto uma nova geração de ambientes de apoio ao teste de software utilizando a plataforma Web. 
De acordo com Sun et al. (2000), ferramentas de teste de software são importantes mecanismos de apoio para assegurar a qualidade do software e, em virtude da contínua variação dos requisitos de teste, essas ferramentas deveriam ser extensíveis, fáceis de reutilizar e apresentar interoperabilidade.

Vale ressaltar ainda que, de um modo geral, a grande maioria das ferramentas de teste, em especial aquelas desenvolvidas no âmbito acadêmico, não constituem um ambiente completo e integrado de teste de software. A maioria não apresenta todas as funcionalidades de gerenciamento, tais como o gerenciamento de usuários, de sessão de teste, de casos de teste e nem mesmo possibilitam estabelecer plano de teste, gerenciar um projeto de teste seguindo um plano, ou gerenciar itens de configuração de teste, apesar de que já se encontram alguns trabalhos teóricos nessa linha (Binder, 1994; Boas, 2003; IEEE, 1998a), principalmente relacionados ao planejamento, à documentação e à gerência de configuração.

Diversos casos de utilização das ferramentas de teste na condução de estudos experimentais e como ferramenta de auxílio no ensino em cursos de graduação e pós-graduação têm mostrado que uma característica fundamental é a possibilidade de utilização por meio de scripts ou de interface gráfica. Dessa forma, a modularização da ferramenta e o estabelecimento de uma interface bem definida entre os módulos da interface e os módulos funcionais executáveis é um requisito fundamental para que essa característica esteja presente. Essa característica permite que usuários mais avançados façam uso da ferramenta por meio de chamadas diretas aos módulos funcionais executáveis e independentes por meio de scripts, muitas vezes, por razões de produtividade; quando é requerida da ferramenta a execução de testes muito longos, muitas vezes, levando algumas dezenas de horas para serem executados, a disponibilidade desse modo de utilização é indispensável. Por outro lado, usuários iniciantes podem explorar por meio de uma interface gráfica, os conceitos relacionados ao critério de teste de maneira controlada, possibilitando também a visualização de casos de teste e dos requisitos de teste, bem como do acompanhamento do teste de forma facilitada, a exemplo de outras ferramentas de teste, tais como Mothra e xSuds. A interface gráfica baseada em janelas da xSuds é apontada por Li \& Horgan (2000) como uma das vantagens da ferramenta, uma vez que a atividade de teste requer a manipulação de um grande volume de dados que devem ser organizados de maneira compreensível.

Uma outra característica das ferramentas de teste é a multilinguagem, ou seja, a implementação da ferramenta deve levar em conta também a modularização no sentido de facilitar a substituição de módulos para o teste de programas escritos em outras linguagens de programação. Por exemplo, a ferramenta Poke-Tool (Chaim, 1991; Chaim et al., 1997) foi configurada para o teste de programas escritos em $\mathrm{C}$, foi posteriormente instanciada para o teste de pro- 
gramas escritos em outras linguagens de programação, no caso, Clipper (Borges et al., 1995), Fortran (Fonseca, 1993) e Cobol (Leitão, 1992).

Atualmente, a maioria das ferramentas de teste investigadas estão disponíveis nos sistemas operacionais Solaris e Linux. Dessa forma, visando a uma maior disponibilidade das ferramentas de teste, uma outra característica é a multiplataforma. A disponibilidade em uma plataforma de software livre, no caso o Linux, pode ser visto como um relevante atributo se considerado o crescente uso de sistemas operacionais livres em laboratórios de universidades e centros de pesquisa. Observa-se que essa característica pode ser alcançada também com a disponibilidade das ferramentas de teste operacionais em plataforma Web.

Apesar das características e funcionalidades comuns, cada ferramenta pode apresentar características específicas, muitas vezes, impostas pelo critério de teste implementado. Por exemplo, o tipo de requisito de teste tratado pelas ferramentas pode diferir, o que leva à necessidade de funcionalidades específicas de forma a facilitar a visualização dos requisitos de teste. Por exemplo, no critério Análise de Mutantes aplicado a programas, os requisitos são os mutantes, representados de forma textual; já nos critérios que se utilizam do grafo de programa para derivar requisitos de teste, uma funcionalidade de visualização do grafo de programa seria conveniente. A Poke-tool, por exemplo, pode trabalhar de forma integrada com a ferramenta ViewGraph (Vilela, 1994; Vilela et al., 1997), que possibilita a visualização de grafos de programa de modo a facilitar a atividade de teste e depuração de programa.

Observa-se que assim como o levantamento das funcionalidades e características comuns, a investigação das particularidades das ferramentas é de suma importância para o entendimento da arquitetura de ferramentas de teste e mesmo para o estabelecimento de um framework para o desenvolvimento de ferramentas de teste.

\section{Ferramentas de Teste de Software}

Diversas são as ferramentas de teste tanto acadêmicas quanto comerciais, que têm sido desenvolvidas para o apoio à atividade de teste de software. Dentre as mais citadas na literatura disponível sobre teste, encontram-se as seguintes ferramentas:

ASSET (A System to Select and Evaluate Tests) (Frankl \& Weyuker, 1985, 1988): Essa ferramenta tem sido considerada um dos primeiros esforços no sentido de automatizar a aplicação dos critérios Baseados em Fluxo de Dados em programas escritos em Pascal. Basicamente, a ASSET gerencia casos de teste, aplica critérios de teste em programas e mostra resultados da aplicação dos critérios; 
ATAC (Automatic Test Analysis for C) (Horgan \& Mathur, 1992) e xSuds xSuds (Telcordia's Software Visualization and Analysis Toolsuite) (Agrawal et al., 1998; Li \& Horgan, 2000; Telcordia Technologies, 2005): Essas ferramentas são consideradas um dos esforços mais significativos no contexto de ferramentas de teste. A ATAC apóia a aplicação de critérios Baseados em Fluxo de Controle e de Fluxo de Dados no teste de programas escritos nas linguagens $\mathrm{C}$ e $\mathrm{C}++$. A xSuds é um ambiente de apoio às atividades de teste, análise e depuração de programas escritos em $\mathrm{C}$ e $\mathrm{C}++$, da qual a ATAC é uma das ferramentas. Observa-se que tanto a ATAC quanto a xSuds são algumas das evidências dos esforços alocados pela indústria no desenvolvimento de ferramentas de teste de software;

ATACOBOL (Sze \& Lyu, 2000) e Ada-PINE (Lee et al., 2000): Como extensão da ATAC, tem-se a ATACOBOL , uma ferramenta que apóia a aplicação de critérios Baseado em Fluxo de Dados em programas escritos em COBOL. Nessa mesma linha, a ferramenta Ada-PINE possibilita a aplicação de critério Baseados em Fluxo de Dados, tais como c-uso, p-uso e todos-usos, em sistemas de tempo real escritos em Ada; e

Mothra (Choi et al., 1989; DeMillo et al., 1988; Horgan \& Mathur, 1992): É uma das primeiras ferramentas que implementou esse critério Análise de Mutantes. Essa ferramenta apóia a aplicação desse critério no teste de programas escritos em Fortran-77. Em virtude da quantidade de mutantes gerados e da necessidade de execução desses mutantes, diversas versões da Mothra foram construídas, tais como a utilização de processadores vetoriais (Mathur \& Krauser, 1988), máquinas SIMD (Simple Instruction Multiple Data) Krauser et al. (1991), máquinas hipercúbicas (Choi \& Mathur, 1993; Offutt et al., 1992) e redes de computadores (Zapf, 1993).

De modo geral, as ferramentas de teste podem ser classificadas em ferramentas de teste de programa e ferramentas de teste de especificação. A primeira classe possibilita a aplicação de critérios de teste em código-fonte de programas escritos em linguagem de programação, tais como C, C++, Fortran e Java, auxiliando na identificação de defeitos contidos no código-fonte; todas as ferramentas descritas acima enquadram-se nessa classe. Já as ferramentas de teste de especificação utilizam como entrada especificações de programas escritos em técnicas de modelagem de sistema, tais como Redes de Petri, Statecharts e Máquinas de Estado Finito, buscando a identificação de defeitos em tais especificações. Nessa linha, o grupo de pesquisa em teste de software do ICMC/USP, junto a outros grupos de pesquisa, tem desenvolvido ferramentas de apoio tanto para o teste de programa quanto para o de especificação. Na Tabela 2.2 faz-se uma síntese das ferramentas desenvolvidas pelo grupo de pesquisa ao qual faz parte este trabalho, juntamente com o critério de teste implementado, o nível de abstração em que está o 
artefato sendo testado (programa ou especificação de programa) e a linguagem/técnica em que está representado o artefato.

Tabela 2.2: Ferramentas de Teste de Software

\begin{tabular}{|l||l|l|l|}
\hline Ferramenta & Critério de Teste & Nível de Teste & Linguagem/ Técnica \\
\hline \hline Proteum & Análise de Mutantes & Código-fonte & C \\
\hline Proteum/IM & Mutação de Interface & Código-fonte & C \\
\hline Proteum/IM 2.0 & $\begin{array}{l}\text { Análise de Mutantes e } \\
\text { Mutação de Interface }\end{array}$ & Código-fonte & C \\
\hline Proteum-RS/FSM & Análise de Mutantes & Especificação & $\begin{array}{l}\text { Máquina de Estado Fi- } \\
\text { nito }\end{array}$ \\
\hline Proteum-RS/ST & Análise de Mutantes & Especificação & Statechart \\
\hline Proteum-RS/PN & Análise de Mutantes & Especificação & Rede de Petri \\
\hline Proteum/SML & Análise de Mutantes & Código-fonte & $\begin{array}{l}\text { SML (Standard Meta } \\
\text { Language })\end{array}$ \\
\hline Proteum/CPN & Análise de Mutantes & Especificação & Rede de Petri Coloridas \\
\hline Poke-Tool & $\begin{array}{l}\text { Todos-nós, Todos-usos, } \\
\text { Potenciais-Usos }\end{array}$ & Código-fonte & $\begin{array}{l}\text { C, Fortran, Cobol e Clip- } \\
\text { per }\end{array}$ \\
\hline CATSDL & $\begin{array}{l}\text { Fluxo de controle, Fluxo } \\
\text { de dados e Análise de } \\
\text { Mutantes }\end{array}$ & Especificação & $\begin{array}{l}\text { SDL (Specification and } \\
\text { Description Language) }\end{array}$ \\
\hline JaBUTi & $\begin{array}{l}\text { Fluxo de dados e Aná- } \\
\text { lise de Mutação }\end{array}$ & Código-fonte & Java \\
\hline
\end{tabular}

A Família Proteum (Maldonado et al., 2000) é composta de um conjunto de ferramentas que dão apoio à aplicação do critério Análise de Mutantes, tanto em nível de programa quanto em nível de especificação. Fazem parte dessa família as ferramentas Proteum (Delamaro, 1993; Delamaro et al., 1993; Delamaro \& Maldonado, 1996), Proteum/IM (Delamaro, 1997), ProteumRS/FSM (Fabbri et al., 1994a, 1999a,b), Proteum-RS/ST (Sugeta, 1999), Proteum-RS/PN (Simão \& Maldonado, 2000), Proteum/SML (Yano et al., 2003; Yano, 2004) e Proteum/CPN (Simão, 2004). Dentre essas ferramentas, uma das mais referenciadas é a Proteum, a primeira dessa linha e que implementa o critério Análise de Mutantes para o teste de unidade de programas escritos em C. A Poke-tool (Potential Uses Criteria Tool for Program Testing) apóia a aplicação dos critérios Potenciais-Usos e também outros critérios estruturais como Todos-nós e Todos-arcos. Foi inicialmente desenvolvida para o teste de unidade de programas escritos em C, mas em virtude de sua característica de multi-linguagem, também existem configurações para o teste de programas em COBOL (Leitão, 1992), Fortran (Fonseca, 1993) e Clipper (Borges et al., 1995). A CATSDL (Sugeta, 2004) apóia o teste e depuração de especificações em SDL (Specification and Description Language), por meio da aplicação dos critérios de teste baseados em fluxo de controle, em fluxo de dados e em mutação. Já a JaBUTi (Vincenzi, 2004) 
apóia a aplicação dos critérios de teste baseados em fluxo de dados e em mutação em programas escritos em Java.

Vale ressaltar que essas ferramentas foram resultados de esforços individuais e desenvolvidas não se considerando uma metodologia sistematizada ou uma arquitetura de referência. Apesar disso, essas ferramentas de teste vêm sendo utilizadas atualmente em centros de pesquisa e universidades, em especial, na condução de estudos experimentais na avaliação dos critérios de teste. Como exemplo de alguns resultados de aplicação dessas ferramentas têm-se (Barbosa, 1998; Delamaro, 1997; Souza, 1996; Vincenzi, 1998).

Como recursos para a implementação das ferramentas apresentadas na Tabela 2.2, softwares livres têm sido largamente empregados, principalmente em virtude do custo minimizado para utilização e a disponibilidade de código-fonte. As ferramentas livres GCC (Stallman, 2000), Tcl/Tk (Foster-Johnson, 1997; Welch, 1997), PHP (Moulding, 2001; Welling \& Thomson, 2001), MySQL (DuBois \& Widenius, 1999; Welling \& Thomson, 2001) e Perl (Perl Institute, 2001) vêm sendo utilizados.

Pode-se observar que na literatura diversos trabalhos fazem referência às ferramentas de teste que abordam o teste de programas escritos em linguagens procedimentais. Mais recentemente, com a proliferação de programas orientados a objetos, uma linha que tem tomado as pesquisas em teste de software é o estudo e a proposição de critérios e ferramentas de teste de programas orientados a objetos (Bieman et al., 2001; Chevalley \& Thévenod-Fosse, 2003; Domingues, 2002; Hoffman \& Strooper, 2000; IBM, 2006; Ma et al., 2002, 2005; Misurda et al., 2005b,a; Offutt et al., 2004; Rocha, 2005; Vincenzi, 2004). Recentemente, as ferramentas Mujava (Ma et al., 2005; Offutt et al., 2004), JavaMut (Chevalley \& Thévenod-Fosse, 2003), Jazz (Misurda et al., 2005b,a), Roast (Hoffman \& Strooper, 2000), JFut (Rocha, 2005) e JaBUTi (Vincenzi, 2004) têm automatizado o teste de programas escritos em Java, observando que a comunidade científica de teste tem atentado para essa linguagem de programação.

Mais recentemente, a Web tem sido investigada como sendo uma plataforma sobre a qual se pode construir ferramentas de apoio à Engenharia de Software (Gao et al., 1997). Pode-se identificar então algumas iniciativas de ferramentas de teste operacionais em plataforma Web; como exemplos pode-se citar a Fujitsu Test Information Management System (Gao et al., 1997), a Proteum/SML (Yano et al., 2003) e a Proteum/CPN (Simão, 2004).

Além das ferramentas de teste de software que implementam técnicas e critérios de teste, pode-se identificar uma outra categoria de ferramentas de apoio às atividades de teste de software: as ferramentas de geração de casos de teste. Como exemplos de ferramentas dessa categoria, pode-se citar a ConData (Martins et al., 2000), a Korat (Boyapati et al., 2002), a TCGS 
(Test Case Generation System) (Huaikou \& Ling, 2000), a AGEDIS (Hartman \& Nagin, 2004), além dos trabalhos de Diaz et al. (2003) e Friedman et al. (2002).

Uma discussão mais detalhada sobre as técnicas, critérios e questões relacionadas à automatização do teste podem ser encontradas em (Maldonado et al., 2004).

\section{Arquitetura de Ferramentas de Teste}

Garlan \& Perry (1995) dizem que arquiteturas de software podem ter um impacto positivo em diversos aspectos do desenvolvimento de software, tais como no entendimento, na reutilização, na evolução, na análise e no gerenciamento do sistema. Observa-se dessa forma que a arquitetura de software constitui-se num fator de suma importância no projeto de sistemas de software, inclusive de ferramentas de teste. Não sendo diferente, na área de Teste de Software, arquiteturas de ferramentas de teste vêm sendo propostas há alguns anos, sendo que na maioria dos trabalhos são abordados instâncias arquiteturais dessas ferramentas (Gao et al., 1997; Hartman \& Nagin, 2004; Lee et al., 2000; Ma et al., 2005; Richardson, 1994; Sze \& Lyu, 2000; Yang et al., 1999).

Nesse contexto, um trabalho bastante relevante é o de Eickelmann \& Richardson (1996) que propõem a primeira arquitetura de referência de ferramentas de teste. Basicamente, essa arquitetura de referência conta com os módulos de execução do teste, desenvolvimento do teste, análise de falha, medição dos resultados, gerenciamento dos dados de teste e planejamento do teste. Uma análise conduzida por Eickelmann \& Richardson (1996) envolvendo algumas instâncias arquiteturais - a saber, das ferramentas PROTest II (Belli \& Jack, 1993), TAOS (Richardson, 1994) e CITE (Vogel, 1993) - mostra que nem todas as ferramentas de teste apresentam todas as seis funcionalidades da arquitetura de referência. A funcionalidade de Planejamento não foi apresentada por nenhuma das ferramentas analisadas. Apesar de sua contribuição como a primeira arquitetura de referência, essa apresenta limitações. Essa arquitetura é apresentada em alto nível, por exemplo, não são apresentados os relacionamentos entre as funcionalidades, tais como o fluxo de dados, troca de mensagens ou comunicação por meio de um repositório de dados. Além disso, não são dados mais detalhes da descrição de cada funcionalidade, além daquela apresentada anteriormente. Assim, observa-se que essa arquitetura é bastante geral, não mostrando detalhes que auxiliem de fato a sua utilização como arquitetura de referência. Além disso, essa arquitetura, como foi proposta, não seria suficiente para a construção de ferramentas de teste de aplicações Web.

Dessa forma, com base nas arquiteturas das diversas ferramentas de teste "tradicionais" e na arquitetura de referência proposta anteriormente, Yang et al. (1999) propõem uma arquitetura 
de ferramentas de teste para o teste de aplicações Web. Essa arquitetura considera as funcionalidades de execução do teste, desenvolvimento do teste, análise de falha, medição dos resultados e gerenciamento de dados de teste, advindas da arquitetura de referência, além disso, considera também o módulo de análise do código-fonte.

De acordo com Sun et al. (2000), a estrutura tradicional de ferramentas de teste de software é geralmente centrada em dados e sua implementação é baseada em módulos. Embora não seja proposta como uma arquitetura de referência, traz também contribuições no sentido estabelecer uma estrutura tradicional de ferramentas de teste de software. Essa estrutura não embute o conceito de camadas, o que dificulta o controle da complexidade do sistema. Além disso, cada parte dessa estrutura - a saber, gerenciador do projeto, analisador sintático, analisador dinâmico e o módulo de análise e apresentação - é um grande módulo, e sua estrutura interna também é complexa, sendo que a comunicação entre os módulos é pesada, o que resulta em limitação na evolução do sistema. Vale observar que para a elaboração dessa estrutura, Sun et al. (2000) considera em seu trabalho somente ferramentas de teste estrutural em nível de código-fonte, não levando em consideração ferramentas que apóiam outras técnicas de teste e mesmo teste em nível de especificação.

Vale a pena salientar que a grande maioria das ferramentas de teste têm sido desenvolvidas de forma isolada sem se basear em uma arquitetura de referência, uma vez que há uma carência de arquiteturas de referência para o domínio de teste largamente aceitas. Segundo Eickelmann \& Richardson (1996), o estabelecimento de uma arquitetura de referência esse domínio não é uma tarefa definitiva, uma vez que deve contar com o rápido avanço que vem sofrendo o processo de teste através do ciclo de vida do software e que tem influenciado diretamente nas ferramentas de teste. Dessa forma, a proposição de uma arquitetura de referência que possa se acomodar à evolução constante das ferramentas de teste é bastante relevante.

Mesmo frente às limitações da arquitetura de referência proposta por Eickelmann \& Richardson (1996), essa e outras instâncias arquiteturais serão utilizadas no contexto deste trabalho como base para o estabelecimento da arquitetura de referência de ferramentas de teste de software.

\subsection{Considerações Finais}

Neste capítulo foi apresentada uma síntese das principais pesquisas que estão sendo conduzidas e que serviram de base para a condução das atividades referentes ao presente trabalho de dou- 
torado. Considerando-se a natureza da linha de pesquisa abordada nesta tese, uma diversidade de temas precisou ser investigada.

Por meio da revisão conduzida, pode-se identificar diversas linhas de pesquisa ainda em aberto e que merecem investigação. No que tange o apoio ao desenvolvimento de software, apesar da diversidade de trabalhos abordando ferramentas e AESs, não há ainda um consenso sobre a melhor estratégia para o desenvolvimento dessas ferramentas e ambientes. Além disso, AESs atuais são, muitas vezes, desenvolvidos sem nenhuma sistematização, o que tem resultado em ambientes difíceis de evoluir e adaptar-se. Mais especificamente, a falta de uma arquitetura de software adequada e eficaz para esse domínio pode estar comprometendo a capacidade de evolução, integração e crescimento incremental dessas ferramentas e ambientes. Isso tem atentado para a necessidade de se estabelecer arquiteturas de referência como elemento fundamentalmente relevante na qualidade das ferramentas e AESs.

Apesar do desenvolvimento de software orientado a aspectos não ser o foco principal desta tese, é interessante observar que é um tema de pesquisa emergente e que requer ainda muita investigação em quase todas as linhas, tanto em relação às linguagens de programação quanto em relação aos métodos e técnicas de análise e projeto orientados a aspectos. Apesar disso, pesquisas preliminares nessa área têm mostrado a viabilidade de seu uso no desenvolvimento de sistema software e, por isso, investigado no contexto desta tese. Nessa perspectiva, uso de frameworks orientados a aspectos, mais especificamente, frameworks transversais para a automatização de atividades de apoio e organizacionais relacionados ao desenvolvimento de software não podem ser encontrados na literatura.

Frente às lacunas identificadas nas linhas de pesquisas investigadas, no próximo capítulo é apresentado um mecanismo que procura apoiar e viabilizar o desenvolvimento de ferramentas e AESs. Mais especificamente, é proposta uma arquitetura de referência baseada em interesses (aspectos) para AESs elaborada com base no padrão internacional ISO/IEC 12207, em arquiteturas de sistemas interativos e sistemas Web bastante consolidadas, em ontologias de processo de software, bem como no uso de frameworks orientados a aspectos, visando especialmente a capacidade de evolução e crescimento incremental que esses ambientes devem apresentar. 


\begin{tabular}{|c|c|}
\hline CAPITULO \\
\hline Arquitetura de Referência de \\
\hline Ambientes de Engenharia de Software
\end{tabular}

\subsection{Considerações Iniciais}

Neste capítulo é apresentada uma arquitetura de referência de AESs baseada em interesses (aspectos), chamada de RefASSET (Reference Architecture for Software Engineering Tools), que visa dar apoio à fase de projeto arquitetural no processo de desenvolvimento de ambientes e ferramentas de Engenharia de Software. Com base nessa arquitetura, pode-se desenvolver ambientes integrados de forma incremental e evolutiva.

A RefASSET é baseada em um conjunto de requisitos arquiteturais, listadas na Seção 3.2, que é resultado de uma investigação de AESs atuais e das limitações que elas têm apresentado. Além disso, a RefASSET é baseada na norma internacional ISO/IEC 12207 (International Organization for Standardization, 1995) e em ontologias relacionadas ao processo de software (Falbo, 1998; Nunes, 2005) que visam a agregar conhecimento do domínio de Engenharia de Software à arquitetura e também definir a estrutura geral da RefASSET. Considerando-se atualmente a relevância de sistemas de software disponibilizados por meio de ambiente Web, essa 
arquitetura possibilita também o desenvolvimento de ambientes e ferramentas ${ }^{1}$ para a plataforma Web. A estrutura geral da RefASSET e suas características são discutidas na Seção 3.3.

De um modo geral, as arquiteturas de software podem ser descritas e documentadas abordandose diferentes visões arquiteturais, dependendo da finalidade da documentação. Para melhor descrever a RefASSET, foram utilizadas três das visões arquiteturais mais comumente utilizadas pela comunidade de arquitetura de software, a saber: a visão estrutural (ou visão de módulos); comportamental (ou visão em tempo de execução); e física (ou visão de implantação). A descrição arquitetural da RefASSET é mostrada na Seção 3.4.

Como discutido anteriormente, questões relacionadas à integração em AESs estão em evidência; dessa forma, na Seção 3.5 é discutido como pode ocorrer a integração em AESs construídos com base na arquitetura de referência proposta. E, na Seção 3.6 é apresentada a abordagem proposta para a utilização e construção de AESs baseados na RefASSET.

Considerando-se a relevância que tem mostrado a plataforma Web para a disponibilização de sistemas de software, na Seção 3.7 são discutidos brevemente os mecanismos - filosofia, ferramentas e linguagens - que poderiam dar subsídios à implementação de AESs construídos com base na RefASSET para essa plataforma .

\subsection{Requisitos Arquiteturais de Ambientes de Engenharia de Software}

Com base na investigação de trabalhos envolvendo AESs identificados na literatura (Ambriola et al., 1997; Braga et al., 1999; Grundy et al., 2004; Lucrédio et al., 2004; Maidantchik, 1999; Maurer et al., 1999; Nguyen et al., 1997; Reiss, 1990, 1999; Taylor et al., 1988; Rocha et al., 1990; Sharon \& Anderson, 1997), e considerando-se as limitações apontadas para esses ambientes (Harrison et al., 2000), foi estabelecido um conjunto de requisitos arquiteturais de AESs, listados a seguir:

(i) A arquitetura deve possibilitar o desenvolvimento de AESs que devem dar apoio a qualquer atividade de Engenharia de Software, sejam elas, fundamentais, de apoio ou organizacionais;

\footnotetext{
${ }^{1}$ Neste e nos capítulos seguintes, ferramenta refere-se aos sistemas de software que implementam atividades básicas (ou fundamentais) ao desenvolvimento de software, a saber: gerência de requisitos, análise, projeto, codificação, teste e manutenção.
} 
(ii) A arquitetura deve possibilitar o desenvolvimento de AESs que devem dar apoio a modelos distintos de processos de desenvolvimento de software, ou seja, a arquitetura deve possibilitar a utilização do AES em diferentes processos, tais como nos processos de desenvolvimento clássico e nos processos de desenvolvimento de software livre;

(iii) A arquitetura deve possibilitar o desenvolvimento de AESs que devem ser capazes de evoluir de maneira incremental e evolutiva por meio da integração de novas ferramentas ou módulos que automatizam atividades — tanto fundamentais quanto de apoio e organizacionais — de Engenharia de Software;

(iv) A arquitetura deve possibilitar o desenvolvimento de AESs que devem ser capazes de evoluir de forma fácil por meio da incorporação de novas técnicas, novas linguagens de programação, novos critérios, entre outros, que vêm sendo constantemente propostos na área de Engenharia de Software;

(v) A arquitetura deve possibilitar o desenvolvimento de AESs stand-alone, bem como para aqueles que possam ser disponibilizados por meio da plataforma Web;

(vi) A arquitetura deve possibilitar o desenvolvimento de AESs que permitam que ferramentas de Engenharia de Software desenvolvidas independentemente dessa arquitetura possam ser integradas a esse ambiente; $\mathrm{e}$

(vii) A arquitetura deve possibilitar o desenvolvimento de AESs que devem apresentar facilidade de integração de apresentação, dados, controle, plataforma e processo.

\subsection{Estrutura Geral e Características da Arquitetura}

Buscando satisfazer os requisitos arquiteturais identificados para arquiteturas de referência de AESs apresentados na seção anterior, uma arquitetura de referência para o desenvolvimento de AESs, chamada de RefASSET, ilustrada na Figura 3.1, é proposta. A RefASSET é baseada em diversos resultados de pesquisas da área de Engenharia de Software, a saber a norma internacional ISO/IEC 12207 (International Organization for Standardization, 1995) que cobre todo o ciclo de vida de desenvolvimento do software desde a concepção das idéias iniciais sobre o software até esse ser retirado de execução, a ontologia de processo de software (Falbo, 1998) e de artefato de software (Nunes, 2005), e a separação de interesses (Dijkstra, 1976), um conceito antigo, mas bastante consolidado, e que atualmente vem sendo explorado no contexto da programação orientada a objetos e mais recentemente, da programação orientada a aspectos. 


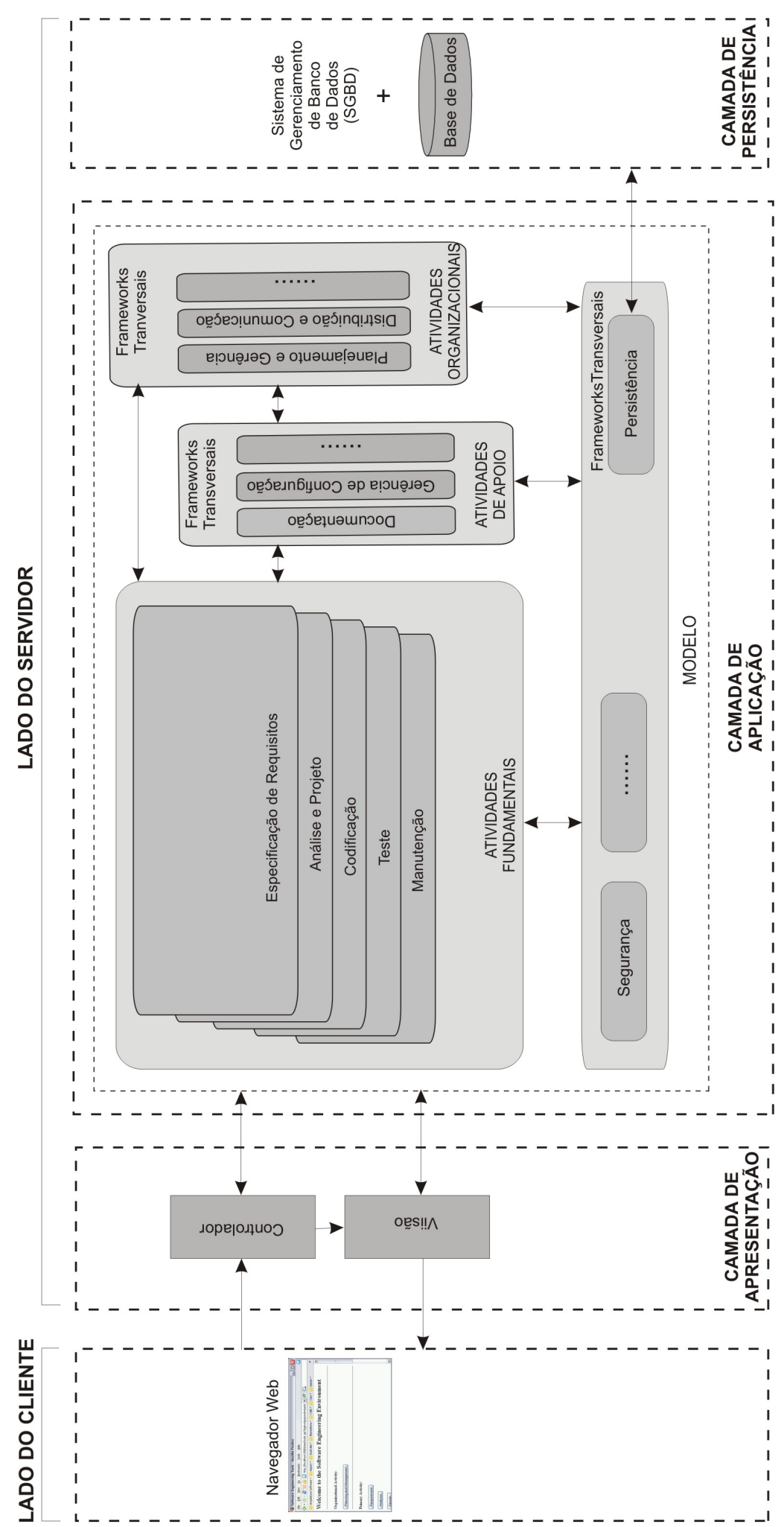

Figura 3.1: Arquitetura Geral Proposta para Ambientes de Engenharia de Software 
Além disso, considerando-se as perspectivas futuras de utilização da plataforma Web para a disponibilização de sistemas de software dos mais variados domínios de aplicação, as arquiteturas mais comumente utilizadas para sistemas Web foram investigadas: arquitetura ClienteServidor (Tanenbaum, 1997), arquitetura web services (W3C, 2006) e arquitetura Cliente-Servidor Distribuído (Ramakrishnan \& Gehrke, 2000).

Para a arquitetura de referência proposta, será inicialmente considerada a arquitetura ClienteServidor, mais especificamente arquiteturas de sistemas interativos e sistemas Web consolidadas da literatura, a saber, a arquitetura 3-camadas (Anderson, 2004; Sadoski \& Comella-Dorda, 1997) e o padrão arquitetural MVC (Model-View-Controller ou Modelo-Visão-Controlador) (Buschmann et al., 1996).

Como trabalhos futuros, a investigação de AESs construídos com base em outras arquiteturas deve ser conduzida, principalmente quanto ao uso da arquitetura de web service, uma vez que essa é bastante diferente da arquitetura Cliente-Servidor que já se encontra mais consolidada. Uma outra arquitetura que merece investigação é a Cliente-Servidor Distribuído que é bastante semelhante à Cliente-Servidor, contudo, um cliente acessa um servidor central e esse encaminha a requisição do cliente a um servidor adequado.

Nas subseções a seguir são descritas em mais detalhes cada uma das principais características da RefASSET. Na Seção 3.3.1 são discutidas as arquiteturas de sistemas interativos e sistemas Web que deram base à RefASSET; na Seção 3.3.2 é mostrada como a ISO/IEC 12207 influenciou na arquitetura proposta; na Seção 3.3.3 é mostrado como as ontologias serviram de base à arquitetura e, por fim, na Seção 3.3.4 é discutido como a separação de interesses adequada pode contribuir para a arquitetura e conseqüentemente para os AESs que vierem a ser construídos com base nessa arquitetura.

\subsubsection{Arquiteturas de Sistemas Interativos e de Sistemas Web}

Uma vez que sistemas de softwares de diversos domínios de aplicação vêm sendo migrados para a plataforma Web, observa-se que mesmo sistemas de software de domínios específicos, tais como do domínio de Engenharia de Software, poderiam também ser largamente disponibilizados por meio dessa plataforma em um futuro próximo. Além disso, vale ressaltar que há poucos ambientes e ferramentas de Engenharia de Software disponibilizados sobre essa plataforma. Dessa forma, baseado em arquiteturas de aplicações Web, a RefASSET possibilita o desenvolvimento de ambientes e ferramentas de Engenharia de Software que poderão ser disponibilizados sobre a plataforma Web. 
Baseado na arquitetura de sistemas interativos e sistemas Web, a arquitetura proposta é dividida em lado do cliente (do inglês, client side) e do servidor (do inglês, server side), como mostrado na Figura 3.1. O lado do cliente corresponde à interface gráfica que possibilita ao usuário interagir com a ferramenta ou com o AES por meio de um navegador Web. Baseado especificamente na arquitetura em 3-camadas e suas adaptações (Anderson, 2004; Sadoski \& Comella-Dorda, 1997; Zhao \& Kearney, 2003), o lado do servidor é dividido em camada de apresentação, camada de aplicação e camada de persistência. A camada de apresentação constrói a interface do usuário e gerencia essa interface. A camada de aplicação implementa as regras de negócio, ou seja, as funcionalidades principais, além de manipular os dados da ferramenta/AES. O papel da camada de persistência é gerenciar os elementos/objetos persistentes que a ferramenta/AES gerencia. Para cada tipo de ferramenta de Engenharia de Software, é necessária uma investigação sobre quais elementos serão persistidos. Persistência é, muitas vezes, alcançada por meio da utilização de uma base de dados gerenciada por um SGBD (Sistema de Gerenciamento de Banco de Dados).

Uma vez que o padrão arquitetural MVC tem sido largamente utilizada na organização arquitetural e uma das mais conhecidas para sistemas de software interativos (Anderson, 2004; Krasner \& Pope, 1988; Nakagawa et al., 2005), RefASSET é também baseada nesse padrão. Deve-se ressaltar que a escolha do MVC como base para a RefASSET se deve ao fato de possibilitar uma melhor modularização dos AESs que venham a ser desenvolvidos com base nessa arquitetura.

O MVC divide o AES em três componentes: o modelo que implementa as funcionalidades principais do AES e manipula os dados gerenciados pelo ambiente; a visão que gerencia informações a serem mostradas para o usuário; e o controlador que processa as entradas (eventos) do usuário que foram feitas por meio do navegador Web, considera o estado corrente do cliente e determina o próximo estado do sistema. Baseado no próximo estado a ser invocado, o controlador invoca uma visão apropriada que mostra ao usuário as saídas adequadas; assim, o controlador determina o fluxo de controle do sistema. A visão e o controlador constituem a interface do usuário, ou seja, correspondem à camada de apresentação que gerencia a interface do usuário. A independência da camada de apresentação da camada de aplicação facilita o desenvolvimento da interface do usuário de forma independente, contribuindo inclusive para a manutenibilidade.

Além disso, uma vez que a camada de aplicação concentra a estrutura e as funcionalidades de AES, isso possibilita que essa camada seja base inclusive para o desenvolvimento de AES stand-alone. 
Certamente, AES disponibilizados na plataforma Web contribuem para o CSCW (Computer Supported Cooperative Work ou Trabalho Cooperativo Apoiado por Computador), na linha de pesquisa de trabalhos apresentados, por exemplo, na ACM Conference on Computer Supported Cooperative Work ${ }^{2}$; no entanto, o enfoque deste trabalho não envolve essa linha de pesquisa e por isso, não será tratado no contexto deste trabalho.

\subsubsection{ISO/IEC 12207}

De modo geral, a grande maioria dos AESs identificados na literatura não automatizam todas as atividades que de fato podem ocorrer em processos de desenvolvimento de software. Além disso, geralmente, esses ambientes não prevêem essas atividades e quando desejam inserir novos módulos que implementam novas atividades, muitas vezes, suas arquiteturas não apresentam facilidades para uma evolução incremental. Assim, neste trabalho, a norma internacional ISO/IEC 12207 insere-se nessa perspectiva como base para o estabelecimento de uma arquitetura de referência de AES, uma vez que essa norma define uma série de processos e atividades que podem ou devem ser empregados durante todo o ciclo de vida de desenvolvimento dos sistemas de software. Além disso, essa norma propõe três grupos de processos processos fundamentais, processos de apoio e processos organizacionais - que classificam as atividades que ocorrem no desenvolvimento de software de acordo com sua natureza. Na Figura 3.2 é mostrada a estrutura da norma, bem como os processos e as classes a que pertencem esses processos.

Os processos fundamentais, de apoio e organizacionais da ISO/IEC 12207 foram utilizados para dar origem aos módulos que implementam atividades fundamentais, de apoio e organizacionais, respectivamente, da arquitetura proposta. Esses três grupos de atividades encontram-se dentro da camada de aplicação, como mostra a Figura 3.1.

Como proposto pela ISO/IEC 12207, os processos fundamentais englobam as atividades referentes ao contrato entre o cliente e o fornecedor, ao desenvolvimento, à operação e à manutenção do software, ou seja, correspondem a um conjunto de atividades básicas de desenvolvimento de software. Neste trabalho, está se considerando como atividades básicas aquelas que comumente aparecem em modelos "tradicionais" de processo de desenvolvimento de software, tais como no Modelo Seqüencial Linear (Royce, 1970) apud (Pressman, 2000). As atividades fundamentais são então a gerência de requisitos, análise, projeto, implementação, teste e manutenção, descritas a seguir:

\footnotetext{
${ }^{2}$ http://www.acm.org/cscw2004/ (acessado em 10/02/2006)
} 

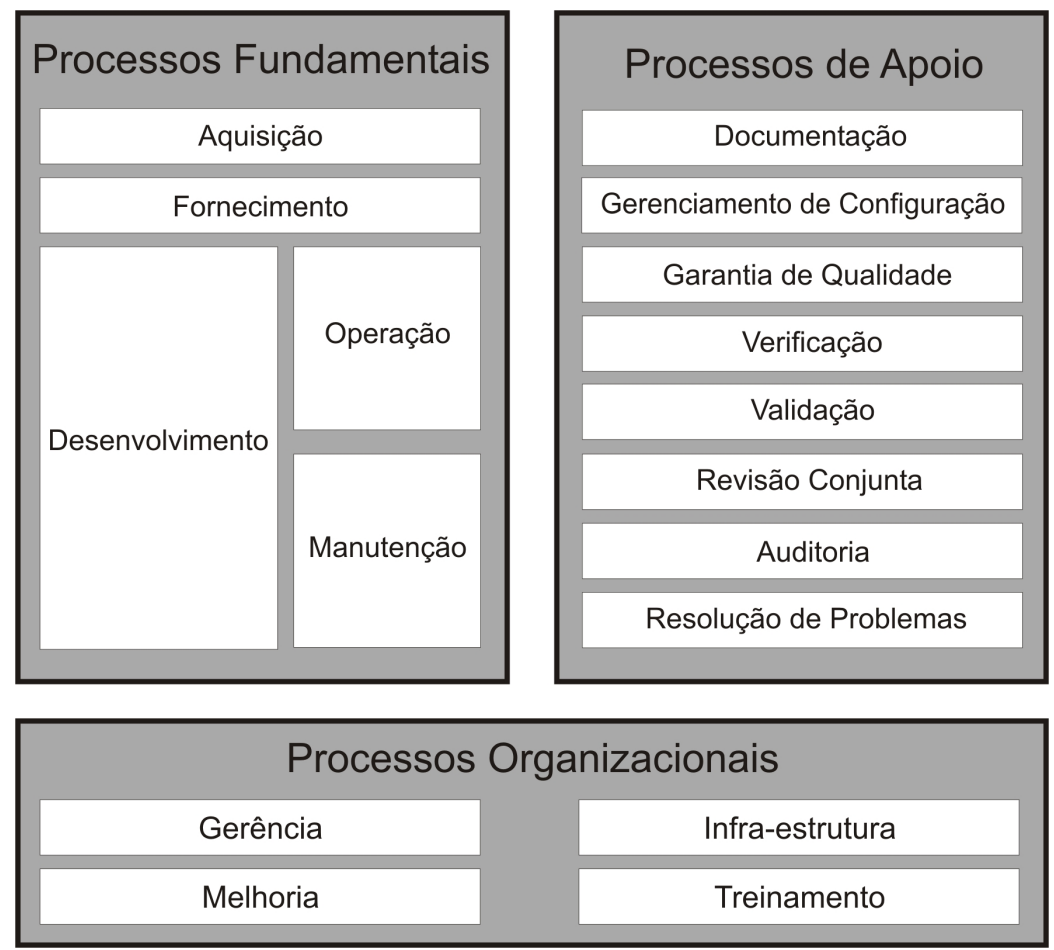

Figura 3.2: Estrutura da Norma ISO/IEC 12207

- Gerência de requisitos: Essa atividade refere-se à gerência dos requisitos do software a ser desenvolvido, além de categorizar e priorizar os requisitos por sua importância. Deve realizar a rastreabilidade que permite visualizar os relacionamentos entre os requisitos e casos de uso, funcionalidades a serem implementadas e entre os próprios requisitos. Além disso, gerencia também as restrições funcionais e de projeto;

- Análise e Projeto: Essa atividade refere-se à construção de modelos arquiteturais e de análise, bem como os modelos de projeto do software, dando apoio a identificação de interfaces, classes e componentes. Além disso, dá apoio também ao projeto da base de dados do software;

- Implementação: Essa atividade refere-se à tradução dos modelos do software em uma linguagem de programação. Se o projeto for realizado de maneira detalhada, a tradução pode ser realizada de maneira automática cabendo ao desenvolvedor acrescentar detalhes de implementação. Pode-se referir também à implementação sem ter por base os modelos do software, assim como ocorre em alguns processos ágeis de desenvolvimento de software, que concentra as atenções na codificação ao invés de concentrar-se na modelagem do sistema; 
- Teste: Essa atividade consiste na análise dinâmica do software com o objetivo de verificar a presença de defeitos no software e aumentar a confiança de que o software esteja correto. Para isso, fases de teste, a saber, teste de unidade, de integração e de sistema, podem ser requeridos. Além disso, técnicas e critérios de teste podem ser utilizadas para sistematizar a atividade de teste; $\mathrm{e}$

- Manutenção: A atividade de manutenção em sistemas de software é inevitável. Então AES precisam dar apoio a essa atividade. Essa atividade deve registrar as manutenções requeridas e as realizadas, os autores, os motivos, data, ou seja, deve gerenciar o histórico das manutenções. Deve também priorizar e controlar as manutenções e indicar quais outros artefatos necessitam também ser modificados.

As atividades fundamentais (contida na camada de aplicação da RefASSET e ilustrada na Figura 3.1) apresentam-se em várias camadas no qual cada camada corresponde a uma atividade fundamental e que contém as especificidades de cada atividade. Por exemplo, para a camada de análise e projeto pode-se citar como especificidade a construção de modelos (em UML, por exemplo) de sistemas de software. Num outro exemplo, sabe-se que a atividade de gerência de requisitos pode utilizar, dentre outras, as atividades de documentação ou de gerência de configuração; no entanto, essas duas atividades não são tarefas específicas da atividade de gerência de requisitos e, portanto, são tratadas em separado como atividades de apoio.

As atividades de apoio melhoram a qualidade das atividades fundamentais, e conseqüentemente, melhoram a qualidade do processo de software como um todo, na linha do proposto pela ISO/IEC 12207. A documentação e a gerência de configuração são atividades que certamente melhoram a qualidade do processo de software, e portanto, consideradas como atividades de apoio.

As atividades organizacionais relacionam-se aos interesses da organização responsável pelo desenvolvimento do software e envolve o planejamento do processo de software, os recursos humanos envolvidos (suas tarefas e responsabilidades), às atividades relacionadas à infra-estrutura envolvida, dentre outras.

Observa-se que as atividade de apoio e as organizacionais melhoram e contribuem para a qualidade das atividades fundamentais e, a disponibilidade de um AES integrado, disponibilizando as atividades fundamentais, de apoio e organizacionais trabalhando em conjunto contribuem para a qualidade dos processos e dos produtos de software gerenciados por esse ambiente.

Na Tabela 3.1 é mostrado o resultado da identificação das atividades da RefASSET para os processos da ISO/IEC 12207. A primeira coluna corresponde aos três grandes grupos de proces- 
sos estabelecidos pela ISO/IEC 12207. A segunda coluna refere-se aos processos pertencentes a cada um desses três grandes grupos. A terceira coluna contém o resultado da identificação das atividades de apoio e atividades organizacionais correspondentes aos processos de apoio e organizacionais da ISO/IEC 12207, respectivamente.

Tabela 3.1: Processos da ISO/IEC 12207 x Atividades do AES

\begin{tabular}{|l|l|l|}
\hline $\begin{array}{l}\text { Grupo de Processos da } \\
\text { ISO/IEC 12207 }\end{array}$ & Processos da ISO/IEC 12207 & Atividades da RefASSET \\
\hline \hline Fundamental & Aquisição & - \\
& Fornecimento & - \\
& Desenvolvimento & $\begin{array}{l}\text { Requisitos, Análise, Projeto, } \\
\text { Implementação e Teste }\end{array}$ \\
& Operação & - \\
& Manutenção & Manutenção \\
\hline Apoio & Documentação & Documentação \\
& Gerência de Configuração & Gerência de Configuração \\
& Garantia de Qualidade & Inspeção \\
& Verificação & Verificação \\
& Validação & Validação \\
& Revisão Conjunta & Auditoria \\
& Auditoria & - \\
\hline Organizacional & Resolução de Problemas & Gerenciamento, Planejamento, \\
& Gerenciamento & Métricas e Estimativas \\
& & Configuração, Comunicação, \\
& Infra-estrutura & Distribuição e Sincronização \\
& & Coleta de Dados e Análise de \\
& Effectiveness \\
& Melhoria & Help On-line, Manual do Usuá- \\
& rio e Tutoriais \\
\hline
\end{tabular}

\subsubsection{Ontologias}

Trabalhos recentes têm aplicado o conceito de ontologia no domínio de Engenharia de Software, uma vez que o uso de ontologias tem um forte impacto na aquisição de conhecimento. Nessa linha, o trabalho de Falbo (1998) estabelece uma ontologia que estrutura o conhecimento sobre processo de software. Adicionalmente, Nunes (2005) estabelece uma ontologia de artefatos de software. Nas Figuras 3.3 e 3.4 são mostradas, respectivamente, a representação gráfica da ontologia de processo de software (Falbo, 1998) e a ontologia de artefato de software (Nunes, 2005). 


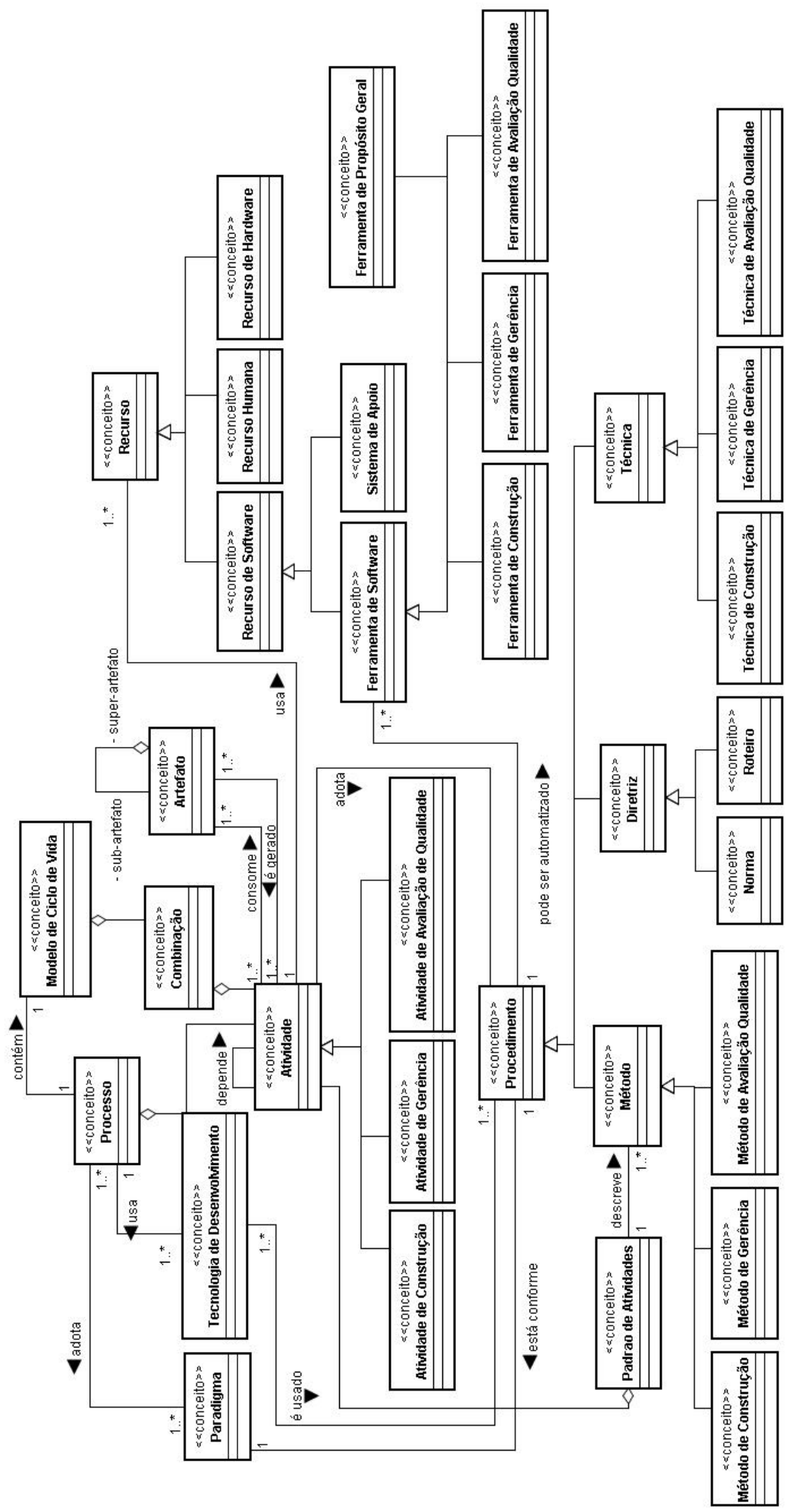

Figura 3.3: Ontologia de Processo de Software (Adaptado de (Falbo, 1998)) 


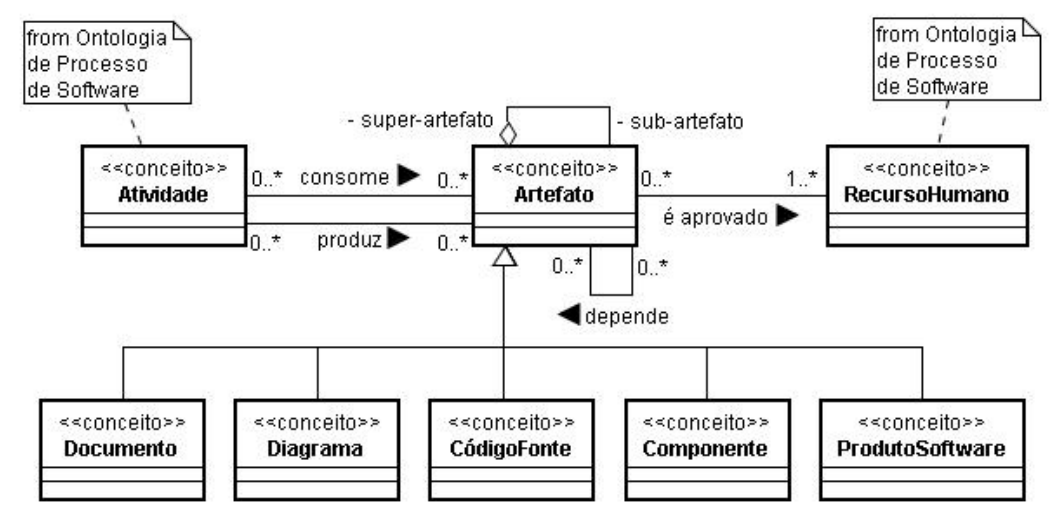

Figura 3.4: Ontologia de Artefato (Adaptado de (Nunes, 2005))

A construção de arquiteturas de referência de AESs considerando-se tanto uma ontologia de processo de software quanto de artefato de software é relevante, isso porque essas ontologias possibilitam incorporar conhecimento sobre processo de software e artefatos relacionados dentro da arquitetura.

Por meio de uma visão analítica da ontologia de processo, observa-se que pode ser estabelecido uma correspondência entre os conceitos Atividade de Construção, Atividade de Avaliação de Qualidade e Atividade de Gerência com os processos fundamentais, de apoio e organizacionais, respectivamente, da ISO/IEC 12207 e, também com as atividades fundamentais, de apoio e organizacionais da RefASSET. Para cada uma das atividades têm-se métodos, técnicas e ferramentas correspondentes.

Como mostrado na Figura 3.1, a RefASSET apresenta atividades (ou interesses) não-funcionais (que serão discutidas em mais detalhes na seção seguinte), ou seja, um conjunto de módulos que implementam funcionalidades de propósito geral. Observa-se que a ontologia de processo apresenta o conceito Ferramentas de Propósito Geral que corresponde a esse conjunto de módulos.

Os conceitos Modelo de Ciclo de Vida, Combinação, Processo e Atividade estão relacionados aos processos de software que devem ser automatizados. A RefASSET propõe o gerenciamento de processos de software por meio do uso de workflow e do módulo de gerência e planejamento. Os demais conceitos certamente estão relacionados à RefASSET, mas com menos importância para a definição ou influência na estrutura geral da RefASSET.

AESs resultantes da RefASSET são compostas de ferramentas que implementam as diversas atividades de Engenharia de Software que podem produzir e consumir artefatos, assim como estabelecido pela ontologia de artefato. Inclusive, a RefASSET prevê a possibilidade de per- 
sistência dos artefatos utilizando-se da camada de persistência. Portanto, pode-se dizer que a RefASSET está de acordo com a ontologia de processo e de artefato de software.

\subsubsection{Separação de Interesses e Frameworks Transversais}

Inevitavelmente, sistemas de software, incluindo os AESs, sofrerão modificações após terem sido liberados para utilização. No caso dos AESs, essa modificações são imprescindíveis em virtude de novas técnicas, novas linguagens de programação, novos métodos, enfim, novos contextos que vêm constantemente sendo propostos e que os AESs precisam dar apoio. Dessa forma, o desenvolvimento de AESs que apresentem facilidade para evolução é certamente desejável. Vale ressaltar que uma das abordagens que possibilita que a evolução dos AESs ocorra de forma mais fácil é o desenvolvimento modular desses ambientes. Nessa perspectiva, o emprego do conceito de separação de interesses em nível arquitetural foi proposto neste trabalho e incorporado ao RefASSET, buscando resolver um dos desafios das pesquisas em AESs que é a necessidade de adaptação das ferramentas e dos AESs para novos contextos.

Uma das constatações sobre as atividades de apoio e as atividades organizacionais estabelecidas pela ISO/IEC 12207 é a sua ocorrência durante todo o ciclo de vida do software, dos requisitos à manutenção, como ilustradas na Figura 3.5. Dessa forma, as atividades de apoio e as organizacionais podem ser vistas como interesses que entrecortam as atividades fundamentais, e chamados então de interesses transversais. Por exemplo, a gerência de configuração é uma atividade que pode ser aplicada em todas as atividades fundamentais de desenvolvimento de software; dessa forma, a gerência de configuração pode ser vista então como um interesse transversal.

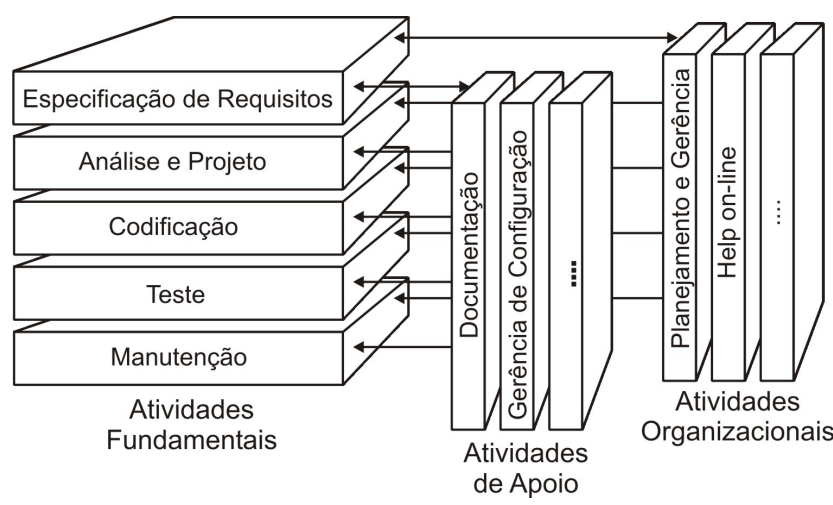

Figura 3.5: Atividades Fundamentais x Atividades de Apoio e Organizacionais 
Pode-se identificar também interesses transversais não específicos do domínio de AESs. Um bom exemplo é a persistência ${ }^{3}$, um exemplo clássico de interesse transversal proposto em diversos trabalhos da área de desenvolvimento de software orientado a aspecto (Camargo \& Masiero, 2005; Rashid \& Chitchyan, 2003; Rausch et al., 2003). De fato, a grande maioria dos AESs possuem esse e outros interesse não específicos do domínio.

Buscando explorar as vantagens da utilização de frameworks para o desenvolvimento de software, propõe-se o encapsulamento de cada um desses interesses (de apoio, organizacionais e não específicos do domínio de AESs) em frameworks transversais, facilitando o reúso dos esforços de desenvolvimento dos módulos que implementam esses interesses. Portanto, ter esses interesses encapsulados em frameworks transversais e integrados ao AES é bastante relevante. Nessa perspectiva, o trabalho de Camargo \& Masiero (2005) propõe frameworks transversais independentes de domínio da aplicação e que modularizam interesses que tratam exclusivamente de requisitos não-funcionais que são chamados neste trabalho de FTPG (Frameworks Transversais de Propósito Geral).

Dentre os frameworks propostos por Camargo \& Masiero (2005), aqueles relacionados à persistência e à segurança são de interesse da RefASSET. Os demais frameworks implementam os interesses de reajuste de valor, cálculo baseado em tabelas, garantia de políticas e rastreamento, sendo que os dois primeiros implementam interesses funcionais e os dois últimos são frameworks que podem ser utilizados durante o desenvolvimento de sistemas de software. Apesar de não estar sendo considerado de imediato na RefASSET, vale observar que esses quatro frameworks podem vir a ser utilizados tanto na fase de desenvolvimento de um AES (frameworks de garantia de políticas e rastreamento) quanto em situações nas quais é necessário a implementação de regras de negócio tratadas pelos frameworks (frameworks reajuste de valor e cálculo baseado em tabelas).

O framework de persistência será considerado na RefASSET, uma vez que é muito comum que AESs requeiram que dados consumidos e produzidos sejam armazenados em algum dispositivo de armazenamento secundário. Com relação ao framework de segurança, vale observar que AESs disponibilizados em plataforma Web deve apresentar funcionalidades relacionadas ao controle e registro de acesso, bem como a autenticação de usuários para que esses possam ter acesso às funcionalidade do ambiente. Assim, o uso de mecanismos que dêem apoio ao desenvolvimento de módulos responsáveis pelo armazenamento de dados e pela segurança é certamente relevante.

\footnotetext{
${ }^{3}$ Persistência é o processo de salvar as partes importantes do estado de um objeto em um sistema de armazenamento secundário de modo que o estado possa subseqüentemente ser restaurado.
} 
Na Tabela 3.2 são listados os frameworks de segurança e persistência. Na segunda coluna da tabela é listado o nome do framework e na última coluna, os sub-interesses que compõem esse framework. A terceira coluna mostra a classificação de cada framework em relação ao seu reúso: instanciação e/ou composição. De modo geral, esses frameworks podem ser divididos em duas classes: aqueles relacionados ao interesse de persistência (frameworks 1, 2, 3, 4 e 5) e aqueles relacionados ao interesse de segurança (frameworks 6, 7, 8 e 9).

Tabela 3.2: Frameworks Transversais de Propósito Geral (Camargo \& Masiero, 2005)

\begin{tabular}{|l||l|l|l|}
\hline No. & Framework & Forma de Reúso & Sub-interesses \\
\hline \hline 1 & Persistência & Instanciação e Composição & $\begin{array}{l}\text { Conexão, Memória Auxiliar } \\
\text { e Pooling }\end{array}$ \\
\hline 2 & Conexão & Instanciação e Composição & - \\
\hline 3 & $\begin{array}{l}\text { Memória Auxiliar "Carrega- } \\
\text { dor de Objetos" }\end{array}$ & Composição & - \\
\hline 4 & $\begin{array}{l}\text { Memória Auxiliar "Todas } \\
\text { Tuplas" }\end{array}$ & Composição & - \\
\hline 5 & Pooling & Composição & - \\
\hline 6 & Controle de Acesso & Composição & $\begin{array}{l}\text { Autenticação, Registro de } \\
\text { Acessos e Persistência }\end{array}$ \\
\hline 7 & Registro de Acessos & Instanciação e Composição & Persistência \\
\hline 8 & Autenticação & Instanciação e Composição & Política de Autenticação \\
\hline 9 & Política de Autenticação & Instanciação e Composição & - \\
\hline
\end{tabular}

Nessa mesma linha, os interesses que correspondem às atividades de apoio podem ser encapsuladas cada um em um framework transversal, chamado neste trabalho de FTA (Framework Transversal de Apoio). Paralelamente, os interesses relacionados às atividades organizacionais podem ser encapsuladas cada um em um FTO (Framework Transversal Organizacional).

Um ponto bastante relevante quando se utilizam frameworks transversais é a possibilidade de utilização de aspectos como mecanismos de integração dos módulos resultantes desse framework com outros módulos. Então, a integração dos FTAs, FTOs e FTPGs com os módulos base - módulos que automatizam atividades fundamentais - do AES são realizadas por meio da utilização de aspectos, na mesma linha do trabalho de Rausch et al. (2003).

Como consequiência dessa separação de interesses, observa-se que os módulos base podem ser projetados e implementados independentemente dos módulos que implementam as atividades organizacionais e de apoio. Esses módulos podem ser adicionados ao AES de forma incremental, possibilitando a facilidade de evolução dos AESs. Possibilita também selecionar somente os interesses (atividades de apoio e organizacionais) que se desejar para um particular ambiente. Essa arquitetura também possibilita que somente as atividades fundamentais que se desejar em um AES específico possam ser consideradas. Além disso, AESs desenvolvidos 
com base na RefASSET podem promover a reusabilidade, uma vez que frameworks são propostos para dar apoio à implementação dos interesses transversais. Pode promover inclusive a manutenibilidade dos AESs, assim como o apontado por Harrison et al. (2000).

Por fim, vale observar que a orientação a objetos tem melhorado significativamente a capacidade de alcançar uma boa separação de interesses e, recentemente, a orientação a aspectos tem sido investigada e contribuído nessa linha (Constantinides et al., 2000; Kiczales et al., 1997). Dessa forma, essas duas abordagens têm sido consideradas na arquitetura de referência proposta.

\subsection{Descrição da Arquitetura}

Com o objetivo de documentar arquiteturas de software, inclusive arquiteturas de referência, procurando comunicá-las de forma efetiva, diferentes visões arquiteturais podem ser utilizadas. Para melhor ilustrar essas visões e considerando-se que a RefASSET será base de AESs para Web, nesta seção é apresentada a descrição arquitetural da RefASSET, cobrindo três das principais visões arquiteturais: a visão estrutural ou de módulos (do inglês, module view), a visão comportamental ou em tempo de execução (do inglês, runtime view) e a visão física ou de implantação (do inglês, deployment view). A visão de dados (do inglês, data view ou data model) e a visão de implementação (do inglês, implementation view) não foram construídas, uma vez que a RefASSET encontra-se em um nível de abstração alto para a qual esses dois modelos não são adequados. Essas duas visões arquiteturais podem ser desenvolvidas quando a RefASSET for refinada para uma instância arquitetural, ou mesmo, para uma arquitetura de referência de um determinado domínio, por exemplo, requisitos e teste, se for pertinente. As técnicas utilizadas para representar essas visões estão de acordo com o proposto por Merson (2005) que, de um modo geral, indica as técnicas da UML 2.0 para documentar as arquiteturas.

\subsubsection{Visão de Módulos}

A visão de módulos da arquitetura mostra a estrutura do sistema em termos de módulos (unidades de código que implementam alguma funcionalidade, seja um pacote, interface, classe, aspecto, entre outros). A visão estrutural é essencial para o desenvolvimento do sistema, uma vez que se refere à "planta" para a construção do software. Na Figura 3.6 é apresentada a visão de módulos da RefASSET descrita em UML. 


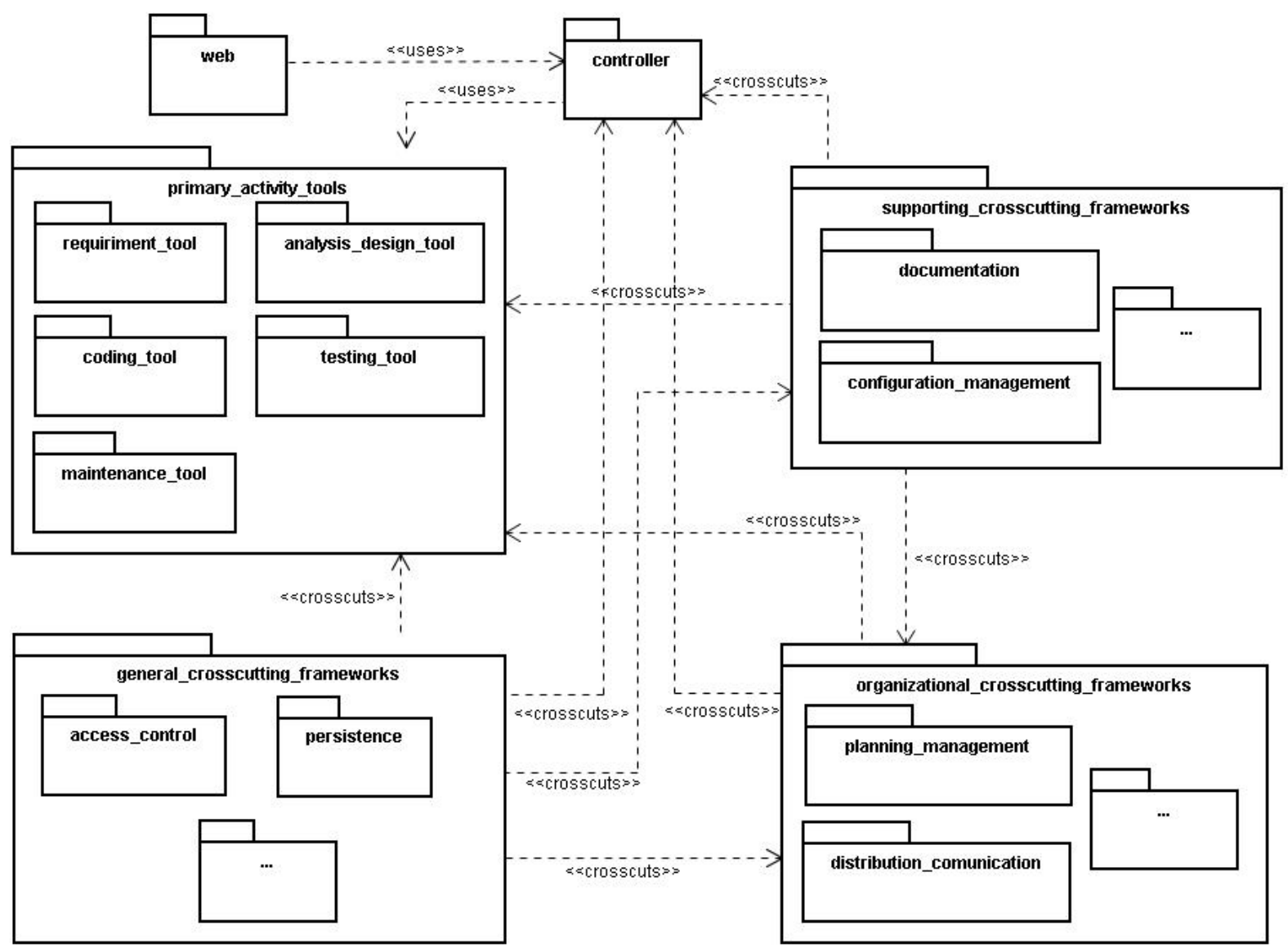

Figura 3.6: Visão de Módulos da RefASSET

Essa visão apresenta os grandes módulos (pacotes) que compõem um AES: módulo base (primary_activity_tools), FTAs (supporting_crosscutting_frameworks), FTOs (organizational_crosscutting_frameworks) e FTPGs (general_crosscutting_ frameworks).

O pacote primary_activity_tools agrega o núcleo das ferramentas que implementam atividades fundamentais relacionadas ao processo de desenvolvimento de software, tais como o gerenciamento de requisitos (pacote requirement_tool) e o teste de software (pacote testing_tool).

Os demais pacotes - supporting_crosscutting_frameworks, organizational _crosscutting_frameworks e general_crosscutting_frameworks - agregam módulos resultantes de frameworks transversais correspondendo, respectivamente, às atividades de apoio, às atividades organizacionais e às atividades de propósito geral. 
Os pacotes web e controller possuem os mecanismos de acesso às funcionalidades do AES. O pacote web possui a interface Web do usuário, enquanto que o pacote controller é responsável pelo processamento das entradas do usuário oriundas do pacote web e, em seguida, faz as chamadas às funcionalidades contidas no pacote primary_activity_tools.

O relacionamento de dependência que apresentam o esteriótipo «uses» entre os pacotes web e control ler indica que web usa (faz uma chamada) às funcionalidades do control ler. O mesmo ocorre entre os pacotes controllere primary_activity_tools.

O relacionamento de dependência cujo esteriótipo é «crosscuts» indica que o pacote de origem (supporting_crosscutting_frameworks, por exemplo) entrecorta/afeta as funcionalidade do pacote destino (pacote primary_activity_tools, por exemplo). Isso é feito por meio da utilização de aspectos que possibilitam realizar a integração entre esses pacotes.

\subsubsection{Visão em Tempo de Execução}

A visão em tempo de execução mostra o sistema em execução, ao contrário da visão em módulos que apresenta a estrutura do código-fonte. Essa visão possibilita o entendimento do funcionamento do sistema e a análise das propriedades que se manifestam em tempo de execução, tais como o desempenho (Merson, 2005). A visão em tempo de execução também possibilita apresentar os grandes componentes, bem como a interação entre esses componentes, as bases de dados, bem como aquelas que são compartilhadas, os elementos replicados, o fluxo de dados no sistema, além das partes do sistema que são executadas em paralelo. Para representar essa visão, Merson (2005) sugere o uso do diagrama de estrutura da UML.

Por problema de espaço e de clareza na representação, a visão em tempo de execução da RefASSET é dividida nas Figuras 3.7 e 3.8 que mostram dois grandes conjuntos de interações relacionados ao planejamento e gerenciamento (pacote Planning_Management) e à documentação (pacote Documentation), respectivamente. Na Figura 3.7 é mostrada somente a interação entre o módulo de planejamento e gerenciamento (Planning_Management), o módulo de persistência (Persistence) com os módulos base contidos no pacote primary_activity_ tools. Na Figura 3.8 é mostrada a interação entre o módulo de documentação (Documentation), o módulo de persistência (Persistence) com os módulos do pacote primary_activity_tools. Contudo, a representação completa ${ }^{4}$ possui as interações de todos os módulos contidos nos pacotes supporting_crosscutting_frameworks e organizational

\footnotetext{
${ }^{4}$ A descrição arquitetural completa da RefASSET encontra-se em: NAKAGAWA, E. Y.; MALDONADO, J. C. Descrição Arquitetural da RefASSET. ICMC/USP, São Carlos-SP, Documento de Trabalho, 2006.
} 
_crosscutting_frameworks com módulos do pacote primary_activity_tools, assim como ocorre com os módulos Planning_Management e Documentation.

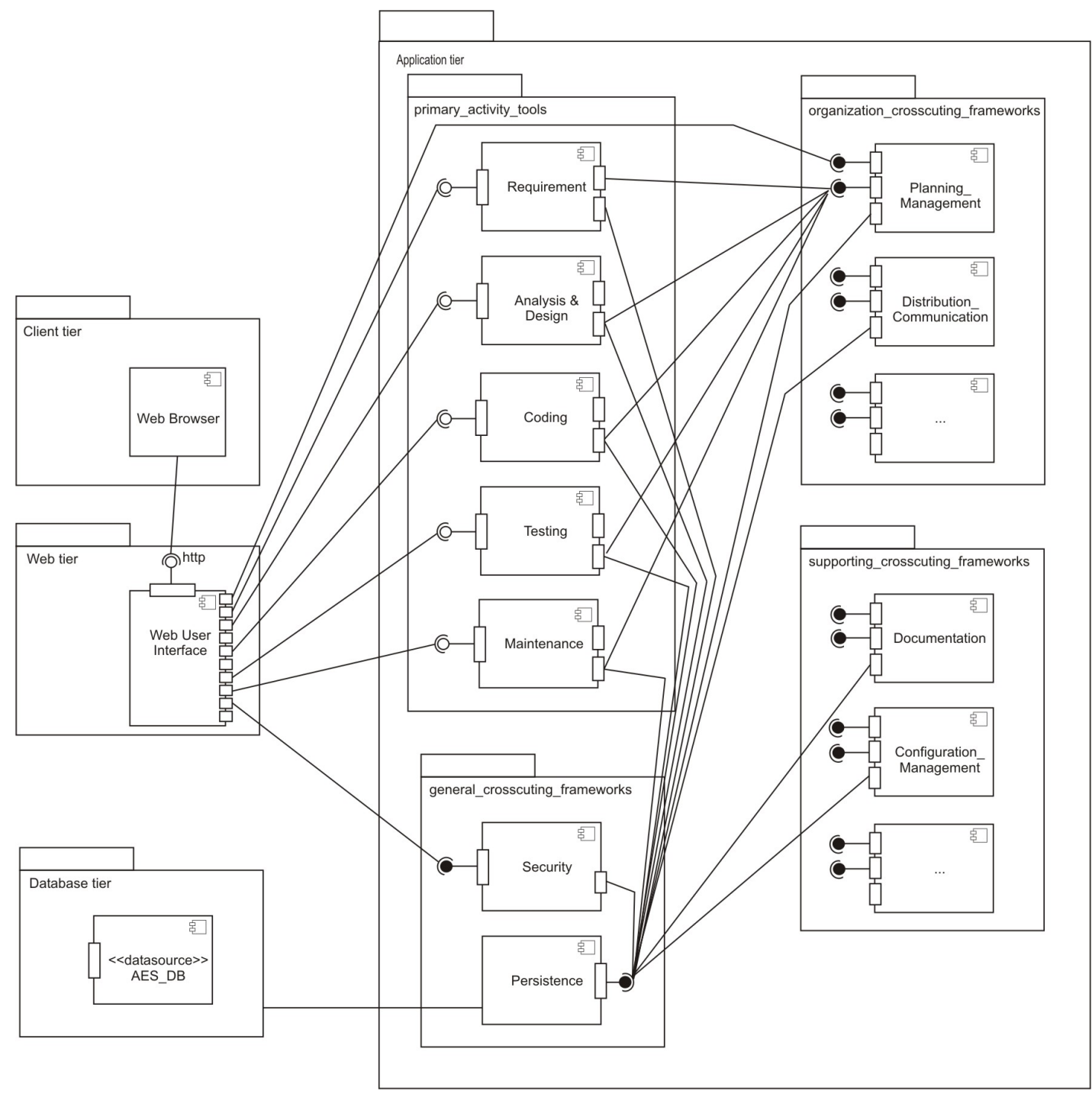

Figura 3.7: Visão em Tempo de Execução da RefASSET (Planejamento e Gerenciamento)

Originalmente, a diagrama de estrutura da UML não possui notação para representar interfaces transversais. Entende-se por interface transversal um conjunto nomeado de características transversais e operações necessárias que caracterizam conjuntos de comportamentos e estruturas crosscutting coesos definidos dentro de aspectos, sendo que uma característica transversal especifica a estrutura ou o comportamento que afetam ou melhoram a estrutura ou o comportamento de instâncias base no contexto de um relacionamento de crosscutting (Chavez, 2004). Uma vez que para representar a visão em tempo de execução da RefASSET há a necessidade de representar as interfaces transversais, foi proposto o uso de um "pirulito preenchido" como 


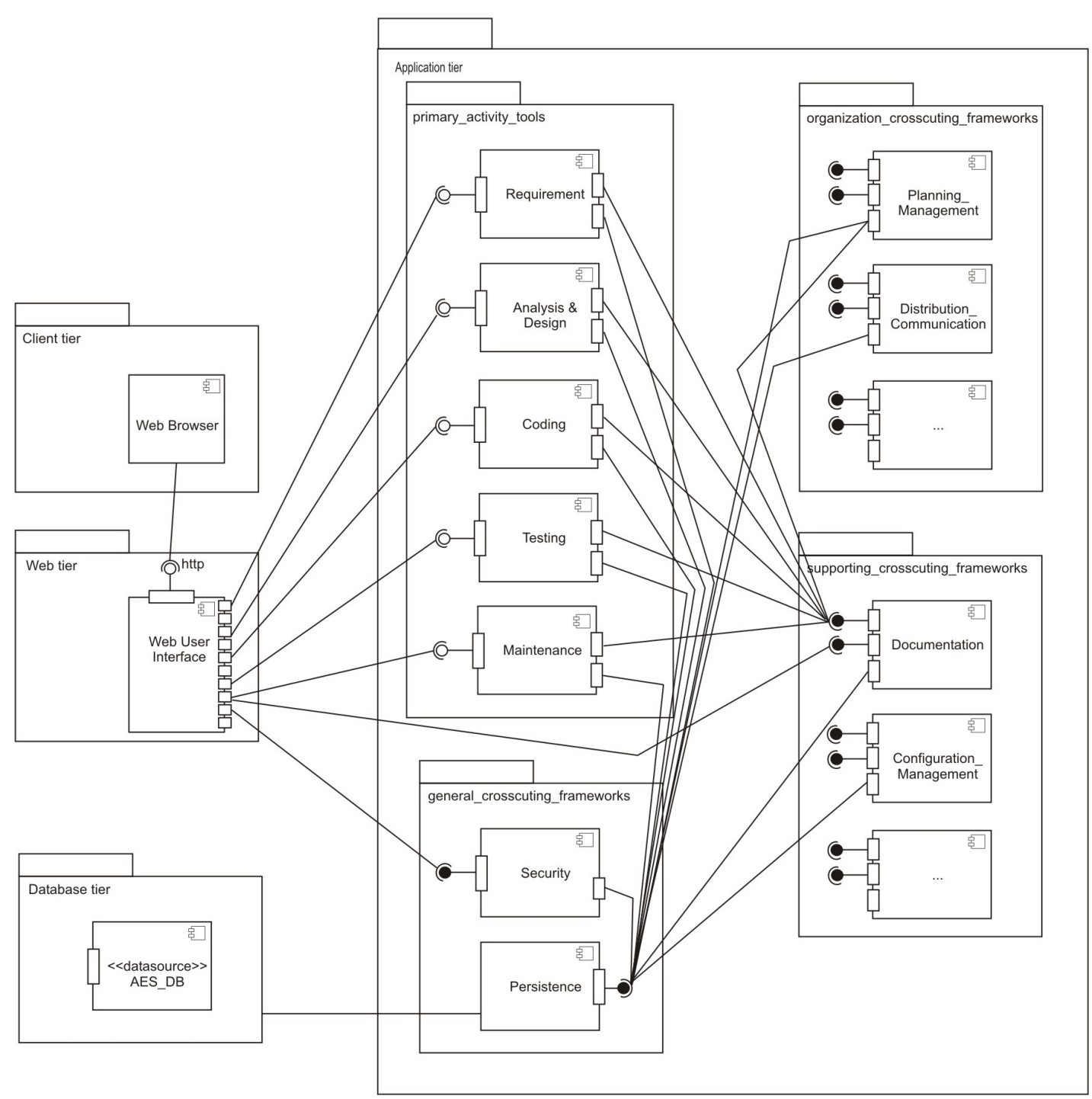

Figura 3.8: Visão em Tempo de Execução da RefASSET (Documentação)

extensão do diagrama de estrutura da UML para indicar essas interfaces transversais, na mesma linha do trabalho de Chavez et al. (2005). No entanto, Chavez et al. (2005) usam essa notação como extensão do aSideML (Chavez, 2004).

Observe que todos os módulos contidos nos pacotes supporting_crosscutting_frameworks, organizational_crosscutting_frameworks e general_crosscutting_ frameworks que possuem aspectos em sua composição apresentam interfaces transversais como pode ser observado nas Figuras 3.7 e 3.8. 


\subsubsection{Visão de Implantação}

Quando se tratam de sistemas de software nos quais a execução pode apresentar-se espalhada em diversas máquinas clientes e servidores, como é o caso dos sistemas Web, a visão de implantação da arquitetura é particularmente útil. Essa visão apresenta a estrutura de hardware na qual o sistema será executado. Considerando-se a tecnologia Web para o desenvolvimento AESs, na Figura 3.9 é mostrada uma das possíveis visões de implantação AESs baseados na RefASSET. Esse diagrama é representado utilizando-se o diagrama de implantação da UML.

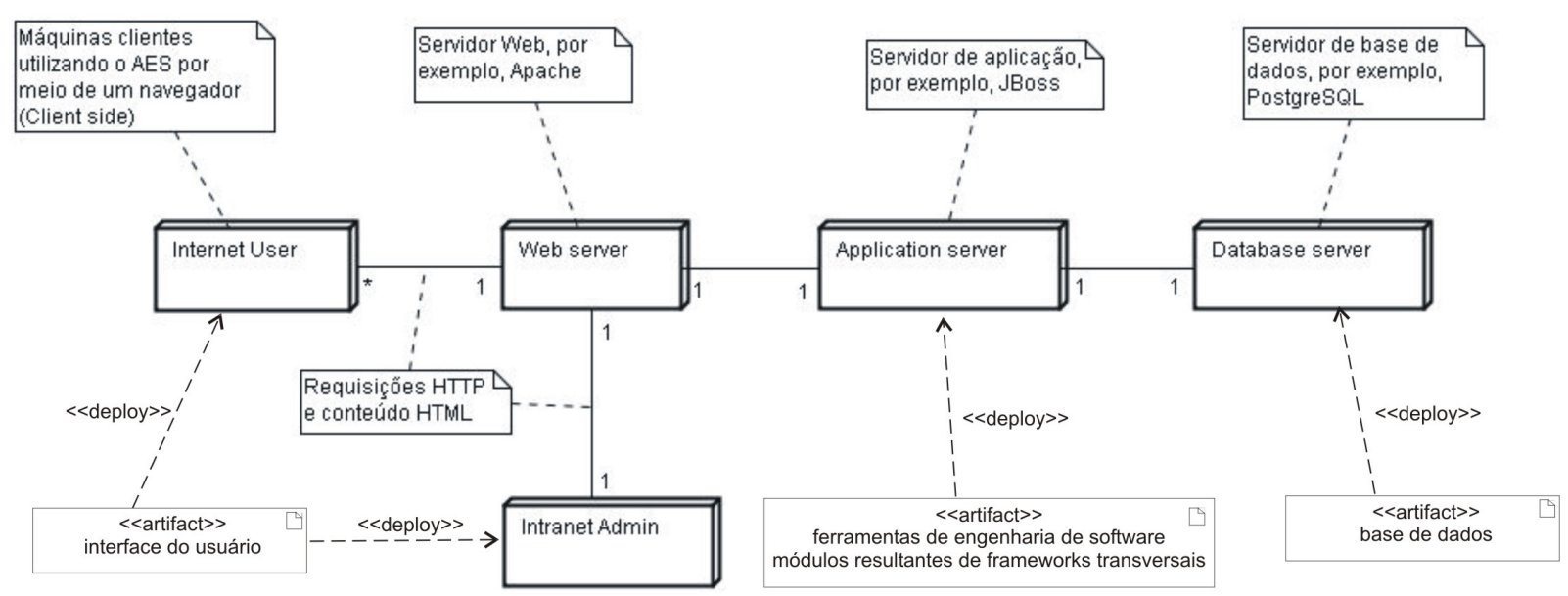

Figura 3.9: Visão de Implantação da RefASSET

Observa-se na Figura 3.9 que o AES é utilizado por meio de um navegador instalado em máquinas clientes (Internet User e Intranet Admin). Sistemas Web, inclusive AESs para Web, independem da plataforma de software (sistema operacional) da máquina cliente para serem utilizados. O servidor de Web (Web server) é responsável por fornecer às máquinas clientes respostas às requisições feitas por meio do navegador. $\mathrm{O}$ servidor de aplicação (Application server) contém todos os módulos do AES (módulos base e módulos que implementam atividades de apoio, organizacionais e de propósito geral) e é responsável por processar as requisições enviadas pelas máquinas clientes. O servidor de base de dados (Database server) é responsável por armazenar os elementos persistentes. Geralmente, utiliza-se um SGBD para isso. Uma vez que a RefASSET propõe o uso do framework transversal de persistência para gerenciar os objetos persistentes, o módulo resultante desse framework irá interagir com o servidor de base de dados. Apesar dos servidores serem ilustrados na Figura 3.9 como disponibilizados em máquinas distintas, o servidor Web, o servidor de aplicação e o servidor de banco de dados podem ser colocados fisicamente em uma única máquina. 


\subsection{Evolução e Integração nos Ambientes de Engenharia de Software}

A evolução e a integração em AESs são questões recorrentes em pesquisas envolvendo AESs; apesar disso, essas questões ainda não foram definitivamente resolvidas. A evolução refere-se à adequação do AES para novos contextos, para dar apoio, por exemplo, a novos métodos e técnicas, novas linguagens de programação e novas abordagens e processos. Já a integração no AES está relacionada com a integração em tempo de execução e que pode ser classificada em integração de dados, de controle, de plataforma, de processo e de apresentação; classificação essa proposta por Wasserman (1990). Nas subseções a seguir, é discutido como a evolução e a integração são tratadas nos AESs baseados na RefASSET.

\subsubsection{Evolução dos Ambientes de Engenharia de Software}

A evolução de um AES é inevitável se deseja-se que esse ambiente acompanhe a evolução contínua que ocorre na área de Engenharia de Software. Do ponto de vista de manutenção de software, essa evolução refere-se à manutenção evolutiva ou perfectiva, na qual novas funções são acrescentadas ao software. Vale ressaltar que essa evolução pode ser facilitada se princípios tradicionalmente conhecidos e aplicados na fase de projeto de software, mas que também são relevantes quando aplicados na fase de projeto arquitetural, tais como a alta coesão e baixo acoplamento, bem como a separação de interesses adequada for considerada quando da concepção da arquitetura desses ambientes.

A separação de interesses realizada com base na ISO/IEC 12207 possibilita a separação das funcionalidades dos AESs construídos sobre a RefASSET em módulos. No caso, têm-se os módulos base e os módulos responsáveis pela implementação das funcionalidades referentes às atividades organizacionais e às de apoio, bem como aqueles que implementam interesses transversais, e que são resultantes de FTOs, FTAs e FTPGs. Para a comunicação entre os módulos base e os demais módulos é proposto o uso de aspectos (da programação orientada a aspectos) como mecanismo para realizar essa integração, inclusive integração entre diferentes módulos que implementam interesses transversais, por exemplo, entre os módulos de documentação e de persistência. Vale ressaltar que a facilidade nesse tipo de integração colabora para a evolução incremental do AES, um dos pontos apontados como desafios em pesquisas envolvendo AESs. Além disso, dentre os diversos mecanismos sendo adotados para a integração em AESs, por exemplo, baseado em componentes (Lucrédio et al., 2004), não foi identificado na literatura trabalhos que explorem o uso de aspectos para esse fim. 
Basicamente, considerando-se o uso, por exemplo, do Eclipse ${ }^{5}$ como ferramenta para construção do AES, pacotes contendo módulos resultantes dos FTAs e FTOs são colocados no mesmo projeto que contém os módulos base do AES e compilados juntos para conseguir a integração. Caso não se deseje disponibilizar os módulos resultantes dos FTAs e FTOs no ambiente sendo construído, há somente a necessidade de remover esses pacotes do projeto, sem a necessidade de edição do código-fonte dos módulos base. A integração utilizando aspectos resulta em um acoplamento baixo e facilidade no acréscimo e retirada de módulos. Essa integração é mostrada em mais detalhes no Capítulo 4 correspondente ao estudo de caso conduzido neste trabalho.

\subsubsection{Integração nos Ambientes de Engenharia de Software}

$\mathrm{Na}$ literatura disponível sobre AESs, a capacidade de integração entre as diversas ferramentas que compõem um AES tem sido apontada como um dos desafios para a construção de ambientes que possam, de fato, dar apoio automatizado e integrado para o desenvolvimento de software. Mais especificamente, a integração entre as ferramentas de um AES pode ser classificado em integração de dados, de controle, de processo, bem como em integração de plataforma e de apresentação. Dessa forma, a seguir, é discutido como os AESs baseados na RefASSET abordam essas integrações:

- Integração de plataforma: Buscando investigar a plataforma Web para a disponibilização de AESs, a exemplo do que vem ocorrendo com diversos outros sistemas de diferentes domínios, a RefASSET foi proposta de maneira a produzir AESs para essa plataforma. Ou seja, a própria concepção da arquitetura, leva-a a produzir AESs que podem utilizar-se dos diversos serviços de apoio que essa plataforma oferece. Apesar disso, vale ressaltar que a RefASSET não se limita somente ao desenvolvimento de ambientes para essa plataforma;

- Integração de apresentação: Interfaces Web podem ser consideradas como uma das mais novas classes de interfaces para sistemas de software e, buscando disponibilizar AESs com essa classe de interface, a concepção da RefASSET dá respaldo para a construção de ambientes com essa interface. Contudo, para o desenvolvimento de interfaces Web para esses ambientes, deve-se considerar estudos sobre a usabilidade de sistemas Web (Nielsen, 1993, 2000), na linha do conduzido no trabalho de Orikasa (2005), no entanto, no contexto de interfaces para ferramentas de Engenharia de Software;

\footnotetext{
${ }^{5}$ http: / / www.eclipse.org/ (acessado em 11/01/2006)
} 
- Integração de dados: Inevitavelmente, AESs manipulam grandes quantidades de dados gerados pelas diversas ferramentas que os compõem. Além disso, as ferramentas de Engenharia de Software, muitas vezes, requerem que dados consumidos e produzidos sejam armazenados em algum dispositivo de armazenamento secundário para posterior utilização. Em processos de desenvolvimento de software, diversas situações podem ocorrer; por exemplo, duas ou mais ferramentas podem utilizar-se de um mesmo dado, ou então, dados produzidos por uma ferramenta podem constituir a entrada para outras ferramentas. Assim, AESs precisam facilitar essa integração.

Em virtude disso, a RefASSET prevê o armazenamento de dados por meio do emprego de SGBDs. O uso de SGBDs pode colaborar na integração, uma vez que ter-se-á um repositório por meio do qual todas as ferramentas poderão acessar os dados. Contudo, cada ferramenta, muitas vezes, possui um conjunto de tabelas, campos, tipos de campos e relacionamento entre tabelas específicos.

Nesse contexto, o uso da XML, na mesma linha de trabalhos conduzidos por Spinola et al. (2004); Spinola (2004), pode ser explorado como mecanismo de integração de dados entre ferramentas do módulo base. Nesse caso, há a necessidade de um conversor de XML, como o proposto por Spinola et al. (2004). No caso da RefASSET e em consonância com as suas bases, as funcionalidades desse conversor estão relacionadas com a atividade de infra-estrutura, portanto uma atividade organizacional, e pode ser implementado como um framework transversal de infra-estrutura. De modo geral, esse framework poderia interceptar uma ferramenta "A" quando essa requisitar dados gerados por uma outra ferramenta "B"; em seguida, esse framework atuaria convertendo os dados gerados pela ferramenta "B" em um formato em que a ferramenta "A" possa "entender".

Uma outra possibilidade é ter uma base de dados centralizada cujo conteúdo é de conhecimento de todas as ferramentas que compõem o AES, ou seja, todas as ferramentas podem recuperar e armazenar dados dessa base. Para essa possibilidade, a RefASSET também pode ser utilizada.

Como já discutido anteriormente, já para a integração entre os módulos base e os módulos resultantes de frameworks transversais, essa é feita por meio da utilização de aspectos. Os aspectos entrecortam objetos contidos no módulo base ou nos demais módulos, e capturam dados contidos nesses objetos ou mudam o comportamento desses objetos. Pela própria natureza dos aspectos, esse tipo de integração sinaliza para uma boa forma de integração de dados com base no estudo de caso conduzido no contexto deste trabalho e descrito no Capítulo 4, contudo, mais pesquisas devem ser conduzidas nessa linha. 
- Integração de controle: Entre o módulo base e os módulos resultantes dos frameworks transversais, a integração de controle ocorre por meio da utilização de aspectos. Aspectos são capazes de "acompanhar" o funcionamento do módulo base e atuar conforme sua necessidade, ou seja, o módulo base não requer mais o envio de eventos para os módulos que implementam atividade de apoio e organizacionais. Por exemplo, essa estratégia possibilita que uma ferramenta de teste não envie mais um evento para um módulo de documentação para que esse gerencie e armazene a documentação da atividade de teste. O módulo de documentação é o responsável por ir colhendo os documentos ou dados pertinentes para elaborar a documentação do teste.

Para apoiar a integração de controle entre os módulos que compõem o módulo base, podese utilizar workflow. A RefASSET prevê a disponibilização de um módulo responsável por gerenciar workflows e que tem a responsabilidade de enviar eventos e ativar as ferramentas. Na Seção 3.5.3 é discutido em mais detalhes como workflow poderia ser utilizado como mecanismo de integração de controle.

- Integração de processo: Para apoiar a integração de processo, pode-se utilizar workflows para representar e gerenciar os processos de software. Um módulo responsável por gerenciar workflows, mais especificamente, um módulo responsável pela automatização da atividade de gerência e planejamento ao qual a gerência de processo está relacionada é prevista na RefASSET. Na seção seguinte é apresentado como workflows poderiam ser utilizados para apoiar esse tipo de integração.

\subsubsection{Investigação Preliminar Sobre Uso de Workflow}

Nesta seção é apresentada uma investigação preliminar sobre o uso de workflows para viabilizar a integração de controle e de processo em AESs. Para a efetiva utilização de um AES há a necessidade de comunicar ao ambiente o processo que será utilizado, de tal forma que esse ambiente possa seqüenciar a ativação das ferramentas e gerenciar os artefatos produzidos e consumidos por cada ferramenta, estabelecendo o relacionamento e a dependência entre as ferramentas. Como já discutido anteriormente, workflows podem ser utilizados para representar processos de software, a exemplo de (Barnes \& Gray, 2000; Kalinowski, 2004). Nessa investigação foi escolhida a XPDL (XML Process Definition Language) (WfMC, 2005) para representar workflows e, conseqüentemente, representar processos de software. A escolha da XPDL deve-se ao fato de promover o intercâmbio de modelos de processos entre ferramentas utilizando XML (Extensible Markup Language) (Bray et al., 2004), sendo uma linguagem de recente investigação e, segundo García-Rubio et al. (2004), considerada uma das melhores linguagens para repre- 
sentar processos. Não é intuito deste trabalho fazer um estudo comparativo para identificar as linguagens mais adequadas para representar workflows e processos de software.

Na Figura 3.10 é apresentada uma abordagem de utilização de workflows em AESs. Ontologias do domínio de processo de software inserem-se na perspectiva deste trabalho, uma vez que traz o conhecimento sobre processos de software e o relacionamento entre os artefatos. Então, processos que virem a ser definidos para automatização por meio do AES devem estar de acordo com essas ontologias. Baseado em ontologias do domínio de processo de software, tais como as propostas em (Falbo, 1998) e em (Nunes, 2005), escreve-se um processo que se deseja automatizar utilizando-se de alguma ferramenta que possibilite editar workflows, obtendo-se uma representação do workflow em XPDL ${ }^{6}$. Essa representação é utilizada como entrada do AES. Em seguida, o módulo de gerencia e planejamento, responsável pela gerência de workflow e contido no AES, deve seqüenciar as atividades, ou seja, a ativação das ferramentas de desenvolvimento de software, com base no workflow. Dessa forma, uma diversidade de processos podem ser executados em um mesmo AES, uma vez que o workflow possibilita configurar o ambiente para tais processos.

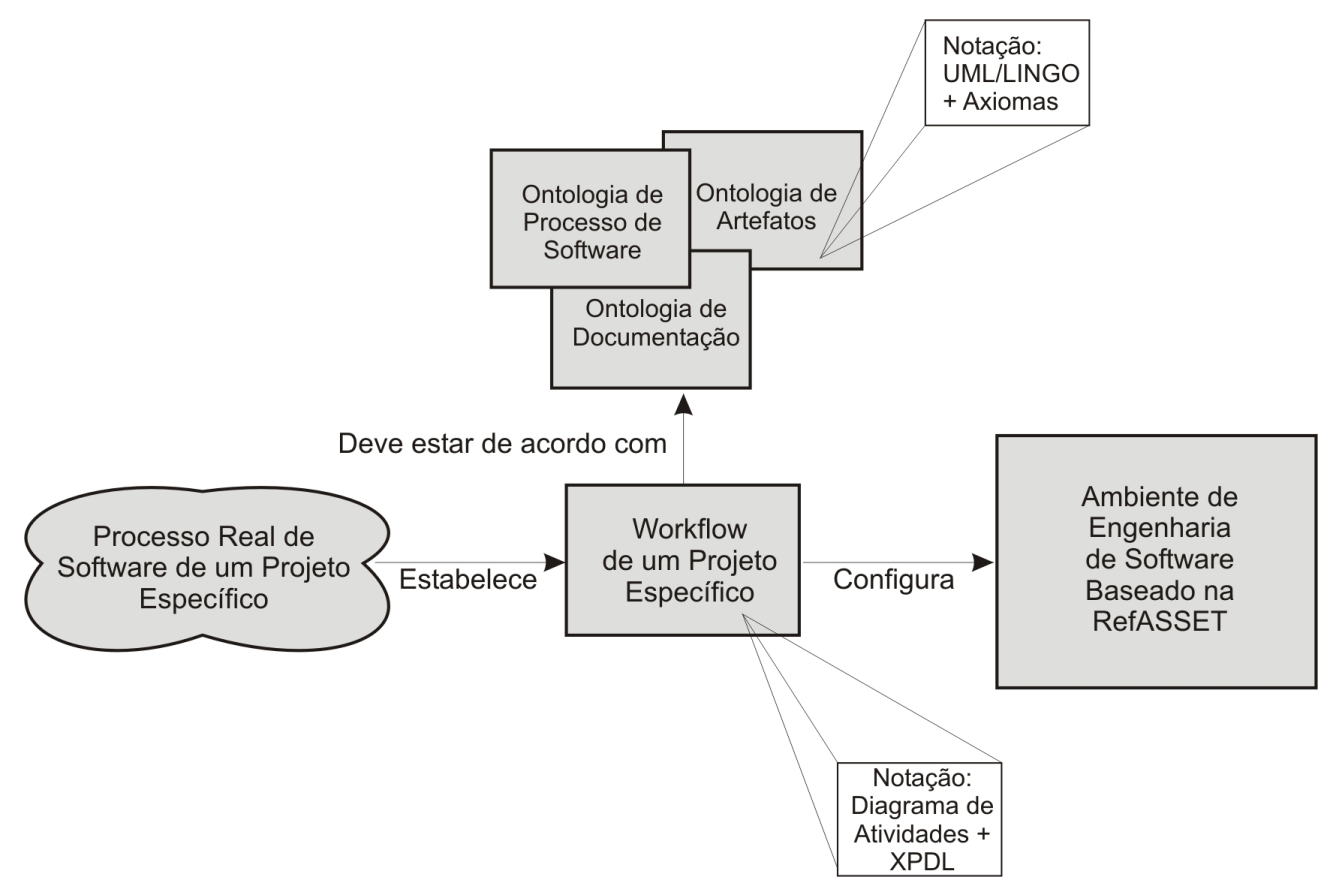

Figura 3.10: Comunicação de um Processo do Mundo Real para o AES

Observa-se assim que a integração de processo pode ser favorecida pelo uso de workflows por esse representar e apoiar o gerenciamento de processos. Esse workflows podem também

\footnotetext{
${ }^{6}$ A escrita do processo de software em XPDL pode ser feita sem intervenção de uma ferramenta; contudo, essa tarefa é bastante onerosa se realizado manualmente.
} 
colaborar para a integração de controle, uma vez que a notificação de eventos entre ferramentas fica a cargo do módulo que gerencia o workflow, sendo que esse módulo é que tem também a capacidade de ativar as ferramentas que compõem o AES.

Pela concepção da RefASSET, o gerenciamento do workflow é enquadrado como uma atividade organizacional, mais especificamente, como uma atividade de gerência e planejamento. Dessa forma, as funcionalidades referentes ao gerenciamento do workflow podem ser implementadas dentro de um framework transversal de gerência e planejamento.

\section{Exemplo de Processo em Workflow}

A critério de exemplificação, na Figura 3.11 é apresentado um processo correspondente ao Método Larman (Larman, 2000). Esse processo foi "desenhado" utilizando-se, para isso, uma ferramenta livre, no caso a Enhydra JaWE/Shark ${ }^{7}$, que possibilita descrever de forma gráfica workflows em XPDL. Essa ferramenta possibilita inclusive visualizar o workflow em formato texto, sendo que parte desse workflow é mostrado na Figura 3.12. Essa representação textual do workflow é utilizado como entrada para o AES.

Observe que o workflow estabelece e registra a dinâmica do processo, por exemplo, determinando a seqüência de atividades, atividades iniciais e finais, atividades que ocorrem concorrentemente ou seqüencialmente, bem como a dependência entre as atividades.

\section{Atividade de Gerência e Planejamento}

A gerência é uma das atividades mais críticas em projetos de software. Devido a complexidade dos sistemas de softwares atuais, bem como a necessidade de incluir uma diversidade de outras atividades - que envolvem métodos, técnica, práticas, normas, entre outros - bem como a necessidade de gerenciamento de pessoas com uma diversidade de papéis no processo de software, a atividade de gerência tem-se tornado cada vez mais indispensável. Gerenciar refere-se à execução de um conjunto de atividades e tarefas que tem como objetivo principal planejar e controlar as atividades realizadas pelas pessoas envolvidas no processo de software. Para tanto, é bastante relevante a incorporação de um módulo que automatiza a atividade de gerência em AESs.

Nos AESs baseados na RefASSET, é proposto que a atividade de gerência seja guiada por um workflow. De modo geral, além das funcionalidades relacionadas ao workflow, oframework

\footnotetext{
${ }^{7}$ http: // jawe.objectweb.org/(acessado em 07/01/2006)
} 


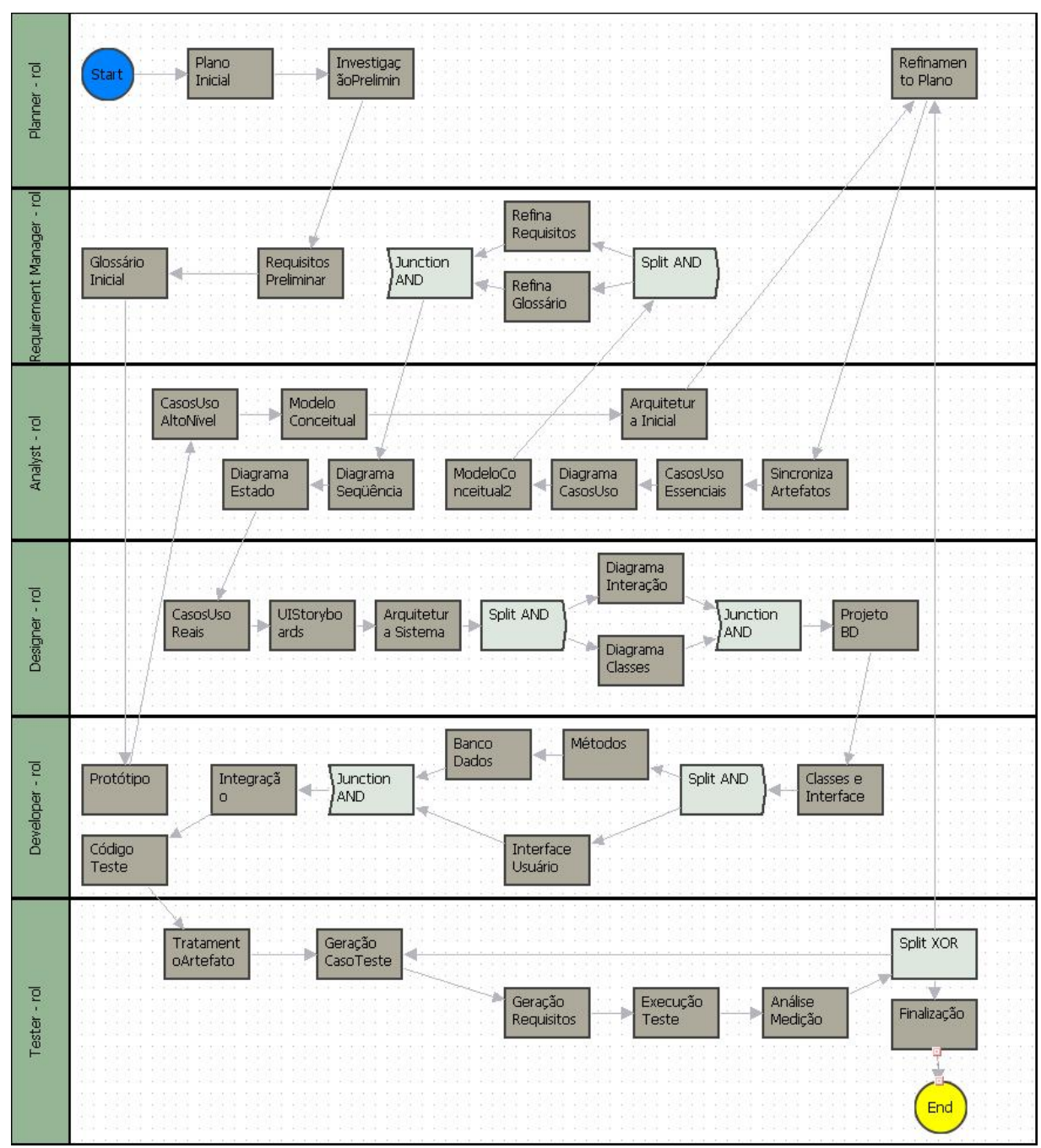

Figura 3.11: Representação Gráfica do Método Larman Utilizando Workflow

de gerência e planejamento implementa funcionalidades de planejamento, de controle de métricas e estimativas, de controle de usuários e suas prioridades, controle de sessões e projetos. Pela diversidade de funções a serem cobertas por esse framework, em termos práticos de implementação, esse framework pode ser dividido em outros sub-interesses e implementadas em frameworks transversais que tratam cada sub-interesse.

\subsection{Utilização da RefASSET}

No processo de desenvolvimento de um AES, a RefASSET pode ser utilizada em todas as fases do processo, em especial nas fases de projeto arquitetural, análise e projeto do ambiente. $\mathrm{Na}$ Figura 3.13 é ilustrada a abordagem proposta para a aplicação da RefASSET. Essa arquitetura 


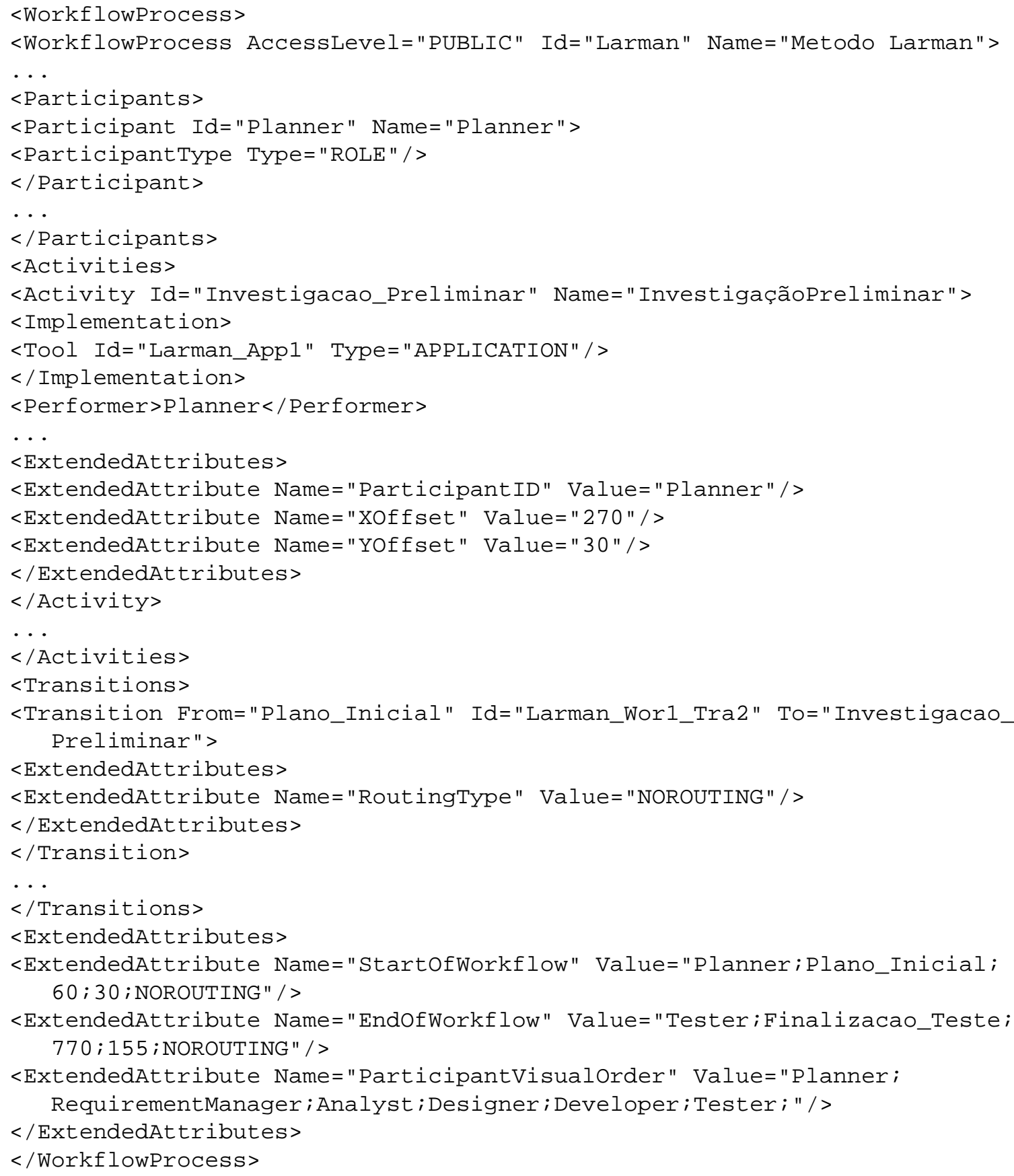

Figura 3.12: Workflow em XPDL

serve de base para o estabelecimento de arquiteturas de referências específicas de ferramentas de Engenharia de Software - por exemplo, a RefREQUIREMENT (para ferramentas de gerência de requisitos) e a RefTEST (para ferramentas de teste de software). Em seguida, cada uma 
dessas arquiteturas pode ser utilizada para o desenvolvimento de ferramentas do domínio que poderão compor, em seguida, um AES.

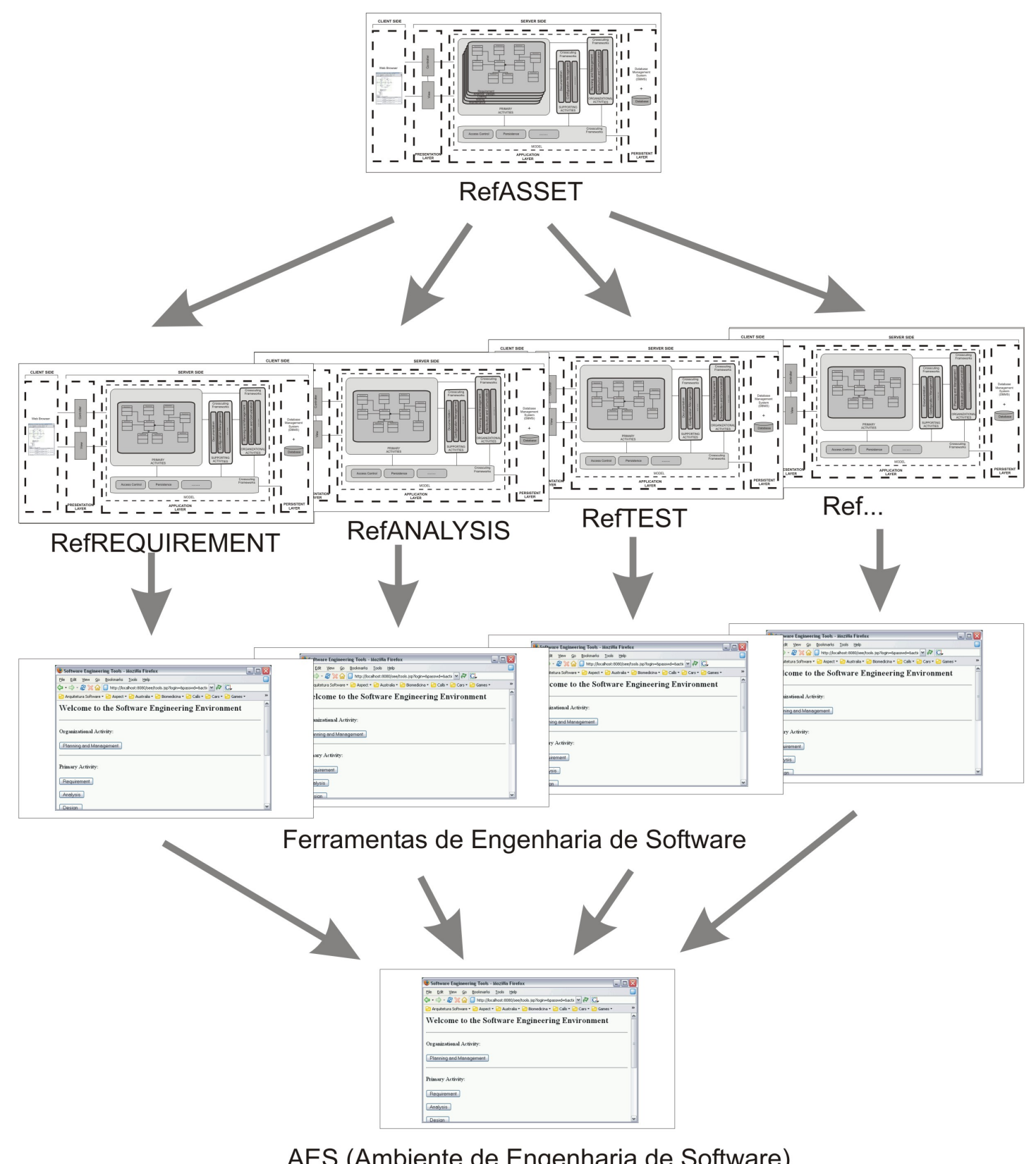

Figura 3.13: Abordagem Proposta para Construção de Ambientes de Engenharia de Software

Vale ressaltar que o estabelecimento de uma arquitetura de referência para ferramentas de Engenharia de Software não é uma tarefa trivial. Essa tarefa requer, além de conhecimento abrangente e aprofundado do domínio, uma sistematização dos passos por meio de um processo bem definido. Dessa forma, no contexto deste trabalho é estabelecido um processo que dá respaldo à abordagem apresentada na Figura 3.13. O estabelecimento de uma arquitetura de 
referência para o domínio de teste, bem como a sistematização de um processo para essa tarefa, são apresentados, respectivamente, nos Capítulos 4 e 5.

A estrutura contida na camada de aplicação (ou camada de modelo) da RefASSET, a saber, módulos que encapsulam atividades fundamentais, de apoio e organizacionais, bem como aqueles que encapsulam interesses transversais, pode ser utilizada também para o desenvolvimento de AES stand-alone e que não sejam disponibilizados em plataforma Web. Isso mostra que a RefASSET foi concebida para ser também uma arquitetura mais geral, não se restringindo somente ao desenvolvimento de ambientes para a plataforma Web.

\subsection{Considerações sobre a Implementação de um AES Base- ado na RefASSET}

A RefASSET, como qualquer arquitetura de software, é independente de mecanismos de implementação. No entanto, considerando-se a disseminação das abordagens de orientação a objetos e orientação a aspectos, bem como as vantagens apontadas pela comunidade de pesquisadores quanto à separação de interesses no desenvolvimento de software, a utilização de mecanismos - linguagens de programação, padrões, ferramentas, entre outros - que trabalhem com essas abordagens deve ser considerada. Vale observar inclusive que os modelos dos frameworks transversais, bem como as visões arquiteturais apresentadas neste capítulo, consideram essas duas abordagens.

Quanto à implementação dos AESs, a experiência adquirida no desenvolvimento de sistemas Web dentro do Projeto Memória Virtual de São Carlos (Mem, 2004; Nakagawa, 2004b), projeto a qual a doutoranda faz parte, fornece fortes indícios da viabilidade de implementação de ambientes que tenham a RefASSET como base arquitetural. Em linhas gerais, esse projeto tem como objetivo principal informatizar os acervos históricos do município de São Carlos e região, por meio do projeto e implementação de um sistema Web - chamado de Sistema Memória Virtual - que possibilite o acesso a esses acervos. Apesar desse sistema estar em um contexto bastante diferente ao de AESs, a arquitetura do Sistema Memória Virtual é baseado no padrão arquitetural MVC e na arquitetura 3-camadas (Nakagawa et al., 2005), assim como a RefASSET. A experiência tem mostrado a viabilidade de utilizar em conjunto essas duas arquiteturas para o desenvolvimento de sistemas Web.

Vale ressaltar que atualmente, com a disseminação da filosofia de software livre, bem como a proliferação de diversas ferramentas sob licença livre, e considerando-se as vantagens de 
softwares dessa categoria, principalmente quanto ao custo de utilização, a implementação e a implantação de AESs pode utilizar-se de ferramentas que possuam licença dessa categoria, a exemplo do que ocorre com o Sistema Memória Virtual.

A tecnologia adotada para o desenvolvimento do Sistema Memória Virtual faz parte da plataforma $\mathrm{J}_{2 E^{8}}$ (Java 2 Enterprise Edition). Dentro dessa plataforma, estão sendo utilizados os Servlets ${ }^{9}$ e páginas JSP $^{10}$ (Java Server Pages), que oferecem vantagens em relação ao uso de outras tecnologias, tais como PHP, ASP e CGI. Muitas dessas vantagens são herdadas da própria linguagem Java (Temple et al., 2004): (i) portabilidade (a aplicação desenvolvida em Java pode ser executada em qualquer plataforma de software sem a necessidade de alterar ou refazer a aplicação); (ii) facilidade de programação (a linguagem segue os paradigmas da programação orientada a objetos o que simplifica o desenvolvimento de sistemas complexos); e (iii) flexibilidade (Java vem sendo utilizada largamente e possui uma comunidade de desenvolvedores tornando possível a utilização de bibliotecas e o reúso de códigos prontos). Além das vantagens inerentes da linguagem, existem outros benefícios na utilização de Servlets e páginas JSP (Temple et al., 2004): (i) escalabilidade (a tecnologia Servlet possibilita distribuir a carga do processamento de aplicações entre vários servidores sendo possível adicionar ou remover um ou mais servidores conforme a necessidade da aplicação), (ii) eficiência (os Servlets são carregados apenas uma vez na memória e só são removidos quando o servidor é finalizado. Isso possibilita que as requisições que utilizarem esses Servlets compartilhem o acesso à memória); e (iii) recompilação automática (páginas JSP modificadas podem ser automaticamente recompiladas, sem que haja necessidade de interromper o funcionamento da aplicação como um todo).

Seguindo o padrão MVC, a camada de visão é composta pelas páginas JSP, por meio das quais o cliente realiza as requisições para a camada de controle que então encaminha-as para a camada de modelo. No desenvolvimento do Sistema Memória Virtual, a camada de controle é composta pelos Servlets e cada Servlet é responsável por tratar um determinado tipo de requisição vindo do navegador do cliente. Toda a lógica da aplicação, ou seja, as operações essenciais do Sistema Memória Virtual, que são basicamente operações relacionadas ao gerenciamento da base de dados, são encontradas na camada de modelo (Bianchi, 2005).

\footnotetext{
${ }^{8}$ http: //java.sun.com/j2ee/index.jsp (acessado em 17/01/2006)

${ }^{9}$ Servlets são classes Java desenvolvidas de acordo como uma estrutura bem definida, e que, quando instaladas junto a um servidor Web que implemente um Servlet Conteiner (um servidor Web que permita a execução de Servlets, muitas vezes, chamado de Servidor de Aplicações Java), podem tratar requisições recebidas do cliente (Temple et al., 2004).

${ }^{10}$ As páginas JSP foram criadas para contornar algumas das limitações no desenvolvimento com Servlets: se em um Servlet a formatação da página HTML resultante do processamento de uma requisição mistura-se com a lógica da aplicação em si, em uma página JSP essa formatação encontra-se separada da programação, podendo ser modificada sem afetar o restante da aplicação (Temple et al., 2004).
} 
Para a implementação da camada de persistência em AESs, é interessante o uso de SGBDs. Pode-se identificar uma diversidade de SGBDs, inclusive sob licença livre, tais como o PostgreSQL $^{11}$ e MySQL ${ }^{12}$. Atualmente, o framework transversal de persistência considerado neste trabalho dá apoio ao MySql, Interbase ${ }^{13}$ e o Sybase ${ }^{14}$ (Camargo \& Masiero, 2005).

Pode-se identificar uma diversidade de linguagens para a implementação de aspectos, no entanto, uma das que tem-se destacado é o AspectJ ${ }^{15}$. Dessa forma, sua utilização como mecanismo de integração entre os módulos base e os módulos resultante de frameworks transversais pode ser adotada. Inclusive, para a implementação de todos os frameworks transversais no contexto deste trabalho, o AspectJ tem sido utilizado.

Em consonância com a filosofia de software livre, o desenvolvimento do AES pode ser realizado por meio da reutilização de ferramentas livres já existentes, resultando inclusive em um AES livre. Por exemplo, para a gerência de requisitos, a ferramenta DRES ${ }^{16}$ (Distributed Requirements Engineering System) pode ser utilizada como base para o desenvolvimento do módulo base de gerência de requisitos. O desenvolvimento do framework transversal de gerência de configuração é outro exemplo; pode-se utilizar as funcionalidades básicas do CVS (Concurrent Version System) (Free Software Foundation, 2006a), um dos sistemas de gerência de configuração mais utilizados pela comunidade de software livre, como base para esse framework.

Por fim, vale ressaltar que os resultados parciais e positivos sendo alcançados pela adoção da filosofia de software livre, bem como a aplicação das arquiteturas MVC e 3-camadas em conjunto no desenvolvimento do Sistema Memória Virtual, fornece bons indícios sobre a possibilidade de desenvolvimento de AESs com base na arquitetura de referência proposta.

\subsection{Considerações Finais}

Frente à relevância e carência de arquiteturas de referência de AESs, neste capítulo foi apresentada a RefASSET, uma arquitetura baseada em interesses (aspectos) que contribui para o desenvolvimento mais sistematizado de AESs, inclusive visando ao reúso e a evolução que esses ambientes inevitavelmente sofrem. Foram discutidos os mecanismos que deram base à

\footnotetext{
${ }^{11}$ http: / / www . postgresql .org/ (acessado em 17/01/2006)

${ }^{12}$ http : / / www . mysql. com/ (acessado em 17/01/2006)

${ }^{13}$ http: //www.borland. com/br/products/interbase/ (acessado em 17/01/2006)

${ }^{14}$ http: / / www. sybase.com.br/ (acessado em 17/01/2006)

${ }^{15}$ http: //eclipse.org/aspectj/ (acessado em 17/01/2006)

${ }^{16}$ http: //ophelia.cs.put.poznan.pl/dres/about.php (acessado em 17/11/2005)
} 
RefASSET, sendo que se pode citar o padrão ISO/IEC 12207 como um dos principais mecanismos, uma vez que esse padrão tem contribuído fortemente para a separação de interesses em AESs. Salienta-se que essa arquitetura possibilita o desenvolvimento incremental e evolutivo de ferramentas e AESs, bem como o estabelecimento de processos de desenvolvimento de AESs que resultem em ambientes evolutivos e incrementais, podendo ser considerada uma contribuição relevante deste trabalho.

Em seguida, uma discussão sobre questões relacionadas à integração, evolução e utilização de AESs baseados na RefASSET é conduzida. Vale destacar que a RefASSET propõe o uso de aspectos como mecanismo de integração de módulos que implementam atividades de apoio e organizacionais, o que sinaliza para um menor acoplamento nos AESs; observa-se também que o uso de aspecto na perspectiva proposta neste trabalho é uma das primeiras iniciativas nessa linha, o que contribui para as pesquisas em AESs.

Vale a pena salientar que há uma carência de frameworks transversais que implementam atividades de apoio e organizacionais do domínio de Engenharia de Software, sendo que este trabalho toma a iniciativa de ver determinadas atividade de Engenharia de Software como um interesse transversal e desenvolver frameworks transversais para esse domínio. Contudo, há ainda a necessidade de estabelecer essa linha de pesquisa e contribuir com a disponibilização de outros frameworks para esse domínio.

Quanto à evolução dos AESs, considerando-se que existem atualmente uma diversidade de ferramentas livres que automatizam atividades de Engenharia de Software, é interessante que arquiteturas de AESs apresentem como característica a facilidade de integração de novas ferramentas, de modo que possam ser reutilizados esforços de desenvolvimento de ferramentas livre.

A arquitetura de referência proposta neste capítulo pode ser utilizada como base para o estabelecimento de arquiteturas de referências de ferramentas que automatizam atividades específicas, tais como o gerenciamento de requisitos e o teste de software. Nessa perspectiva, no capítulo seguinte é apresentado o refinamento da RefASSET para o domínio de teste de software, resultando em uma arquitetura de referência para esse domínio. 


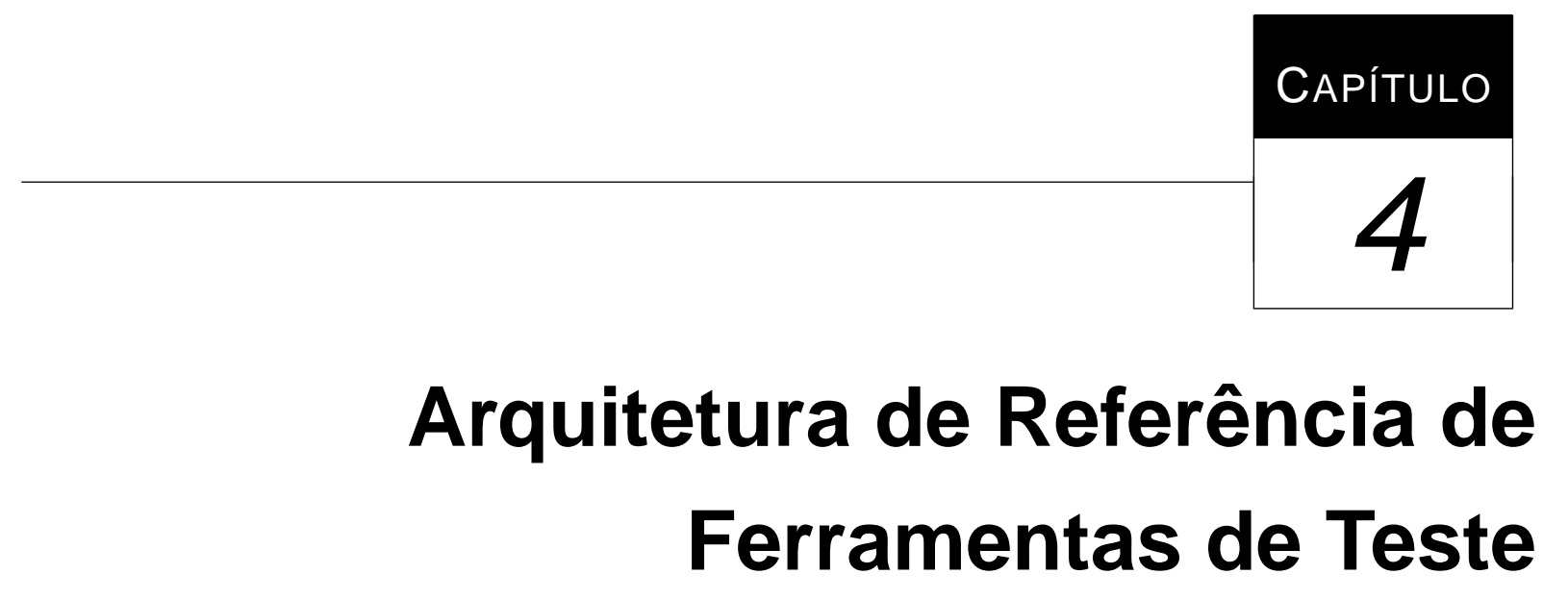

\subsection{Considerações Iniciais}

Neste capítulo é apresentada a RefTEST (Reference architecture for TESTing tools), uma arquitetura de referência para ferramentas de teste de software. Essa arquitetura é resultante da investigação do domínio de teste de software, da análise e do projeto arquitetural.

A RefTEST tem como base a RefASSET, possuindo, portanto, todas as características dessa arquitetura. Para derivar a RefTEST a partir da RefASSET foi realizado um conjunto de passos que tem a especialização arquitetural como processo chave. Na Seção 4.2 é fornecida uma visão geral sobre a especialização e a instanciação arquitetural da RefASSET para o domínio de teste de software e apontados alguns dos possíveis usos da RefTEST.

Em seguida, é mostrada em detalhes a realização do processo de especialização arquitetural que é basicamente composto de: investigação do domínio (Seção 4.3), análise arquitetural (Seção 4.4), tratamento de frameworks transversais (Seção 4.5) e projeto arquitetural (Seção 4.6). 
Em especial, com relação ao tratamento de frameworks transversais, vale observar que a RefTEST prevê o uso de módulos que automatizam atividades de apoio e organizacionais e que podem ser resultantes de frameworks transversais. Para ilustrar a viabilidade de utilização de frameworks transversais na implementação de módulos que automatizam atividades de apoio e atividades organizacionais, foi projetado e implementado o módulo de documentação da atividade de teste e em seguida, foi proposto um framework transversal de documentação. Na Seção 4.5 são apresentados o framework de documentação e o de gerência de configuração. Por fim, como resultado da especialização arquitetural conduzida, na Seção 4.6 é apresentado o projeto arquitetural da RefTEST.

\subsection{Especialização e Instanciação Arquitetural}

A especialização e a instanciação arquitetural são dois conceitos que foram adotados no contexto deste trabalho para a área de arquitetura de software e relacionam-se ao refinamento e utilização de arquiteturas de software. Na Figura 4.1 é mostrado um esquema de especialização e instanciação da RefASSET para o domínio de teste de software. Essa figura mostra arquiteturas em três níveis de abstração; no mais alto nível, encontra-se a RefASSET, uma arquitetura de referência para AES; no nível intermediário, tem-se a RefTEST, uma arquitetura de referência para ferramentas de teste de software; e no mais baixo nível de abstração, estão as instâncias arquiteturais.

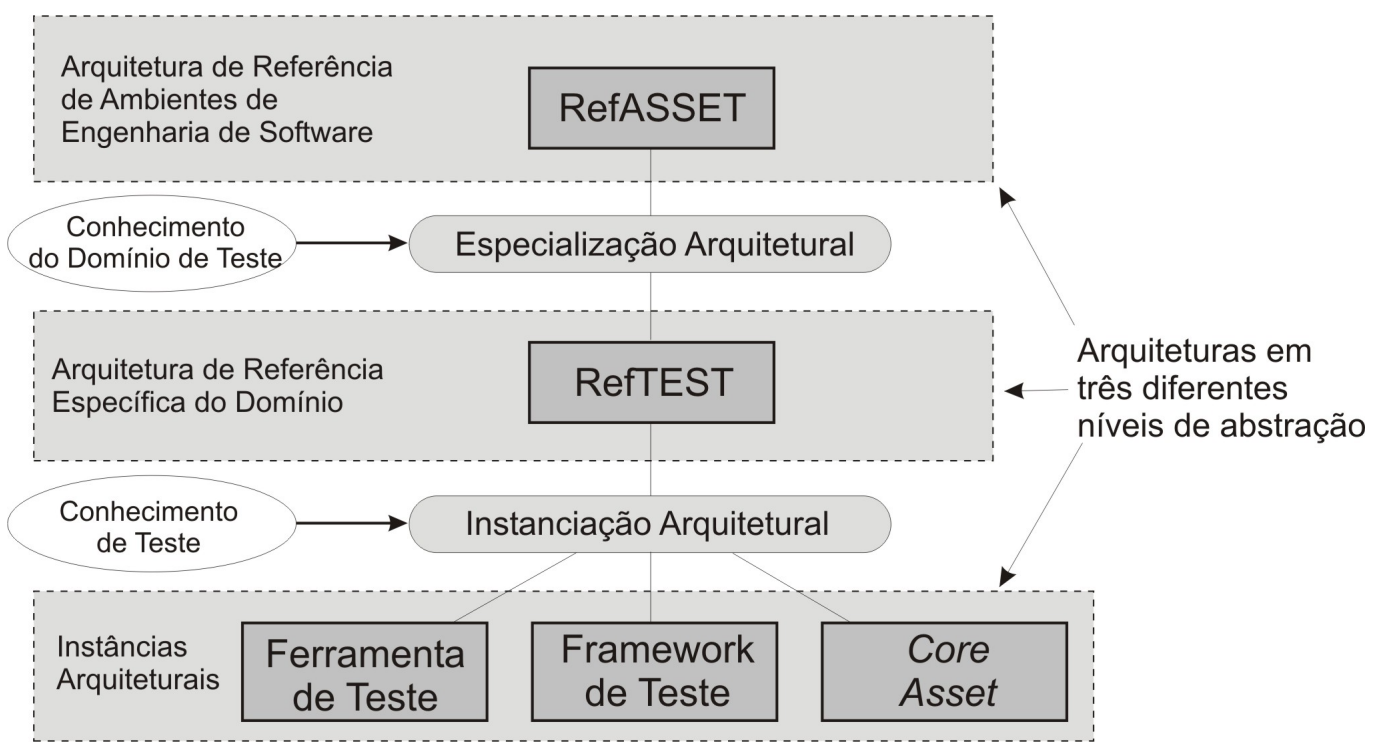

Figura 4.1: Especialização e Instanciação da RefASSET 
Na etapa de especialização arquitetural é requerido extenso conhecimento do domínio de teste de software para que essa etapa seja conduzida de forma eficaz, resultando em uma arquitetura de referência de ferramentas de teste que seja adequada como mecanismo de apoio à construção de ferramentas desse domínio. Nessa etapa, diversas fontes de informação podem ser utilizadas, tais como ferramentas de teste e suas arquiteturas, bem como outras arquiteturas de referência do domínio.

Conforme ilustrado na Figura 4.1, uma vez estabelecida uma arquitetura de referência de ferramentas de teste, essa pode ser utilizada na etapa de instanciação arquitetural para a criação de instâncias arquiteturais para os possíveis usos descritos a seguir:

- desenvolvimento de ferramentas de teste: A disponibilização de uma arquitetura de referência para o domínio de teste certamente colabora para a construção de ferramentas desse domínio, uma vez que possibilita o reúso do projeto arquitetural;

- desenvolvimento de frameworks de ferramentas de teste: Considerando-se que uma arquitetura de referência de ferramentas de teste contém conhecimento sobre o que há de comum nas ferramentas e inclusive experiência de desenvolvimento de ferramentas desse domínio, frameworks para a construção de ferramentas de teste podem ser construídas com base nessa arquitetura;

- uso como core asset de linhas de produto: A arquitetura de referência proposta neste trabalho pode ser utilizada como um core asset em abordagem de desenvolvimento de ferramentas de teste baseada em linhas de produto, na linha de trabalhos, tais como o de Clements \& Northrop (2002), que exploram o uso de arquitetura de software para esse fim.

A etapa de especialização arquitetural é realizada em quatro passos: investigação do domínio, análise arquitetural, tratamento de frameworks transversais e projeto arquitetural. De modo geral, os dois primeiros passos têm o objetivo de refinar o módulo base da arquitetura, ou seja, o núcleo das ferramentas de teste. O terceiro passo objetiva o tratamento dos módulos responsáveis pela automatização das atividades de apoio, organizacionais e de propósito geral (que implementam interesses transversais não específicos do domínio). E, por fim, o quarto passo refere-se à elaboração da descrição da arquitetura em questão. As próximas seções (Seções 4.3, 4.4, 4.5 e 4.6) detalham a condução desses passos. 


\subsection{Investigação do Domínio}

Diversas fontes foram investigadas de modo a fornecer subsídios para o refinamento do módulo base. Foram consideradas outras arquiteturas de referência já propostas na literatura, estudos das funcionalidades, modelos e arquiteturas de ferramentas de teste, processos de teste de software e também a OntoTest (Barbosa et al., 2006), uma ontologia de teste que tem sido estabelecida no contexto deste trabalho e construída em conjunto com outros pesquisadores do ICMC/USP. Dessa forma, buscou-se cobrir as diversas facetas que envolvem o teste de software.

Como resultado do passo de investigação do domínio, tem-se um conjunto de funcionalidades específicas de ferramentas de teste e conceitos relacionados a esse domínio. A seguir, são descritos cada um dos mecanismos que deram base à realização desse passo.

\subsubsection{Arquiteturas de Referência de Ferramentas de Teste}

Foram selecionados os principais trabalhos que discutem especificamente arquitetura de ferramentas de teste de software (Eickelmann \& Richardson, 1996; Sun et al., 2000; Yang et al., 1999). Eickelmann \& Richardson (1996) propuseram seis funcionalidades básicas que constituem uma arquitetura de referência inicial para ferramentas de teste, como resultado de uma análise do processo de teste de software, da automatização desse processo e de ferramentas de teste. Na Figura 4.2 é mostrada a estrutura dessa arquitetura. De acordo com Eickelmann \& Richardson (1996), a disposição das seis funcionalidades no formato de pirâmide está relacionada à evolução da atividade de teste através dos anos. No topo da pirâmide está a funcionalidade de Execução, presente na atividade de teste realizada em meados da década de 50. Na base da pirâmide encontra-se a funcionalidade de Planejamento de teste que passou a ser considerada a partir do final de década de 80 na atividade de teste. Observa-se que novas funcionalidades têm sido acrescentadas às ferramentas de teste com o passar dos anos. Cada uma das funcionalidades dessa arquitetura é descrita a seguir (Eickelmann \& Richardson, 1996):

- Execução: inclui a execução do código-fonte a ser testado e o armazenamento dos resultados da execução. Como artefatos de teste gerenciados nessa funcionalidade estão incluídos os resultados do teste, o trace de execução do teste e o andamento do teste;

- Desenvolvimento: engloba a especificação e a implementação de uma configuração de teste. Essa funcionalidade resulta em como o teste será conduzido, as entradas relacionadas aos artefatos de teste e à documentação. Os artefatos específicos desenvolvidos nessa funcionalidade incluem o oráculo, os casos de teste e o critério de adequação do teste; 


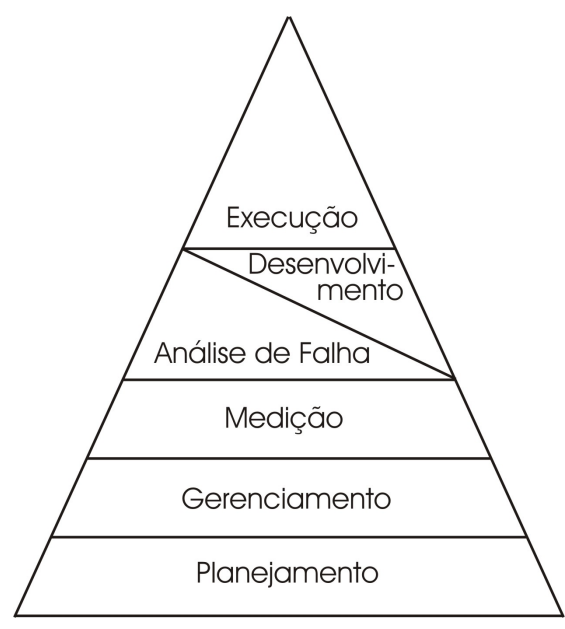

Figura 4.2: Arquitetura de Referência de Ferramentas de Teste (Eickelmann \& Richardson, 1996)

- Análise de falha: é composta da documentação e da verificação do comportamento, bem como da análise estatística da execução do teste. Artefatos específicos incluem relatórios de falhas do teste;

- Medição: refere-se à análise e à medição da cobertura do teste. Tipicamente, códigosfontes são instrumentados para coletar o trace de execução. Artefatos resultantes dessa funcionalidade incluem medidas de cobertura e medidas de falhas do teste;

- Gerenciamento: inclui o apoio ao armazenamento dos artefatos de teste, à relação entre esses artefatos, bem como ao armazenamento do estado de execução do teste; e

- Planejamento: está relacionada ao desenvolvimento de um plano de teste e às características do sistema a ser testado. Devem ser consideradas nessa funcionalidade a avaliação dos riscos, a necessidades de treinamento, os recursos requeridos e os disponíveis, estratégia de teste, alocação de papéis e responsabilidades e cronogramas.

A segunda arquitetura proposta é a de Yang et al. (1999) que propõem uma arquitetura de ferramentas de teste para o teste de aplicações Web. A Figura 4.3 mostra essa arquitetura que considera as funcionalidades de Execução, Desenvolvimento, Análise de falha, Medição e Gerenciamento, advindas da arquitetura de referência de Eickelmann \& Richardson (1996) e sendo representadas por cada um dos subsistemas. Nessa arquitetura, o subsistema de Gerenciamento é o responsável por interconectar os demais subsistemas. A comunicação é realizada por meio de fluxo de dados, representados na figura por setas sólidas entre os subsistemas. Observa-se pela figura que mais um subsistema foi acrescentado — Subsistema de Análise do Código-Fonte - uma vez que sistemas Web apresentam características bastante específicas; por exemplo, o 
código-fonte que roda no servidor é responsável por gerenciar a base de dados e gerar um conjunto de documentos para serem exibidos no lado do cliente, enquanto que esse último é mais focado na interface gráfica com o usuário; além disso, um sistema Web é, muitas vezes, escrito em diversas linguagens de programação, requerendo assim tratamento antes de serem submetidos ao teste. Uma contribuição de Yang et al. (1999) é a proposição de um modelo orientado a objetos baseado na UML para os subsistemas que compõem a arquitetura de ferramentas de teste, embora esses modelos sejam voltados mais especificamente para o teste de aplicações Web.

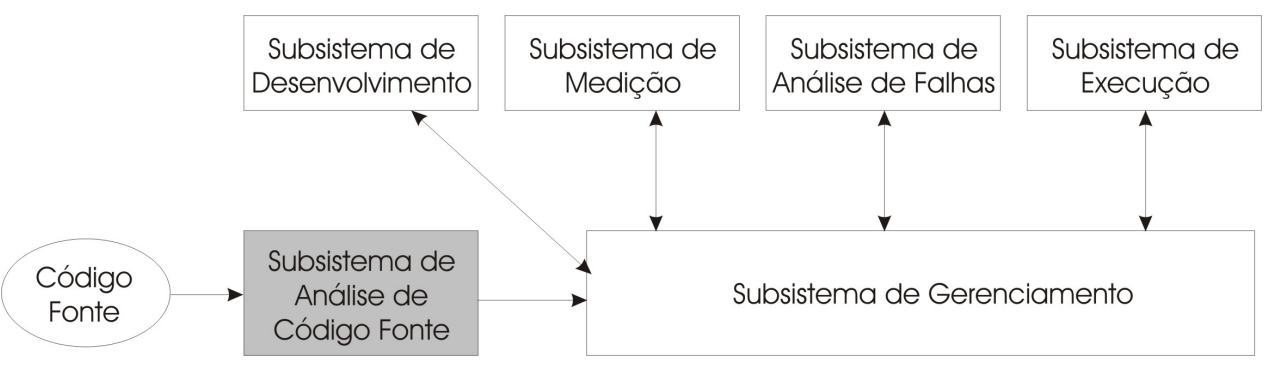

Figura 4.3: Arquitetura de Ferramentas de Teste de Aplicações Web (Yang et al., 1999)

A terceira arquitetura considerada é a proposta por Sun et al. (2000). Nesse trabalho, os autores propõem o que eles chamam de estrutura tradicional de ferramentas de teste de software. Essa estrutura é geralmente centrada em dados e sua implementação é baseada em módulos como mostrada na Figura 4.4. De acordo com Sun et al. (2000), essa estrutura dificulta o controle da complexidade do sistema. Além disso, cada parte dessa estrutura - a saber, Gerenciador do projeto, Analisador estático, Analisador dinâmico e Análise e apresentação — é um grande módulo, e sua estrutura interna também é complexa, sendo que a comunicação entre os módulos é pesada, o que resulta em limitação na evolução do sistema.

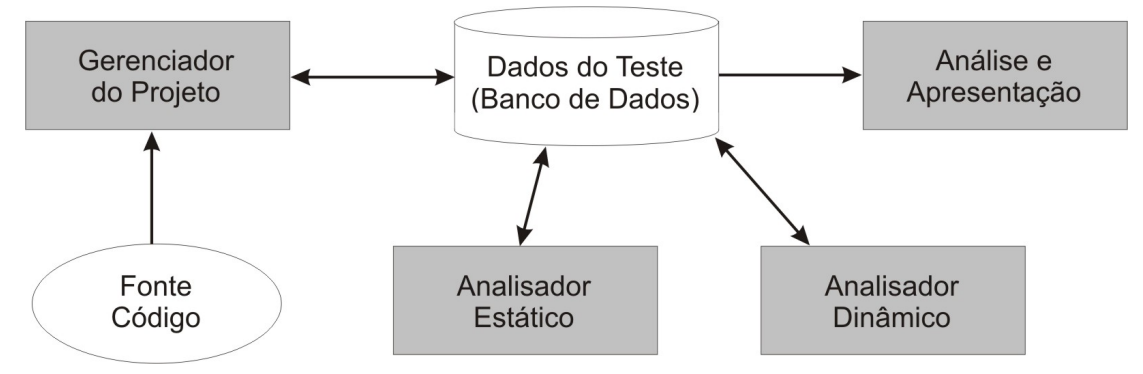

Figura 4.4: Estrutura Tradicional de Ferramentas de Teste (Sun et al., 2000)

É importante salientar que além das arquiteturas apresentadas nesta seção, há uma carência, tanto na literatura de arquitetura quanto na de teste de software, de arquiteturas de referên- 
cia para o domínio de teste de software que sejam mais recentes, adequadas e eficazes para a construção de ferramentas de teste.

Para facilitar a análise das arquiteturas consideradas, um resumo é mostrado na Tabela 4.1. O trabalho de Sun et al. (2000) não foi considerado, uma vez que não traz dados suficientes passíveis de análise. Nessa tabela, a primeira coluna corresponde à arquitetura proposta; a segunda coluna lista os módulos da arquitetura e a última coluna lista as funcionalidades relacionadas a cada módulo. Essas funcionalidades são o foco dessa tabela e foram extraídas mediante a análise das arquiteturas, dos modelos dos subsistemas apresentados por Yang et al. (1999) e de literatura relacionada às arquiteturas analisadas (Belli \& Jack, 1993; Richardson, 1994; Vogel, 1993). Por exemplo, para o módulo de Execução da arquitetura de Eickelmann \& Richardson (1996), foram identificadas as funcionalidades de Instrumenta artefato a ser testado, Executa artefato a ser testado e Armazena resultado da execução do artefato a ser testado, do trace de execução e do andamento do teste.

Observa-se que as funcionalidades identificadas para ambas as arquiteturas são bastante semelhantes, exceto com relação ao módulo de Planejamento da arquitetura de Eickelmann \& Richardson (1996) e o módulo de Análise do Código-Fonte da arquitetura de Yang et al. (1999).

Observa-se no resumo apresentado na Tabela 4.1 que nenhuma arquitetura propõe o uso de módulos que implementam atividade de apoio nas ferramentas de teste, tais como a documentação de teste e a gerência de configuração. Observa-se ainda que dentre as atividades organizacionais, somente a atividade de planejamento foi considerada.

A lista de funcionalidades identificadas e consolidadas na Tabela 4.1 serão utilizadas posteriormente para a identificação dos conceitos do domínio de teste e o refinamento do módulo base da arquitetura de referência de ferramentas de teste.

\subsubsection{Processos de Teste de Software}

Ferramentas de teste devem dar subsídios à automatização de processos de teste de software. Dessa forma, processos de teste são bons mecanismos como base para o estabelecimento da RefTEST. Sommerville (2001) apresenta um processo de teste, mostrado na Figura 4.5, contendo as grandes atividades na condução do teste de software, a saber Projeto dos Casos de Teste, Preparação dos Dados de Teste, Execução do Teste e Comparação dos Resultados.

Mais especificamente, com base em diversos trabalhos relacionados ao Teste de Mutação, dentre eles o publicado por Vincenzi et al. (2005), na Figura 4.6 é ilustrado o processo de Teste de Mutação. O Teste de Mutação utiliza um conjunto de programas com pequenos desvios 
Tabela 4.1: Módulos das Arquiteturas de Referência Propostas Anteriormente

\begin{tabular}{|c|c|c|}
\hline Arquitetura & Módulo & Funcionalidade Relacionada \\
\hline $\begin{array}{l}\text { Primeira } \\
\text { arquitetura de } \\
\text { referência } \\
\text { proposta } \\
\text { (Eickelmann \& } \\
\text { Richardson, } \\
1996 \text { ) }\end{array}$ & $\begin{array}{l}\text { - Desenvolvimento } \\
\text { - Análise de falha } \\
\text { - Medição } \\
\text { - Gerenciamento } \\
\text { - Planejamento }\end{array}$ & $\begin{array}{l}\text { - Instrumenta artefato a ser testado } \\
\text { - Executa artefato a ser testado } \\
\text { - Armazena resultado da execução do artefato a ser } \\
\text { testado, do trace de execução e do andamento do } \\
\text { teste } \\
\text { - Estabelece oráculo } \\
\text { - Gerencia casos de teste } \\
\text { - Estabelece o critério de adequação do teste } \\
\text { - Realiza análise estática da execução do teste } \\
\text { - Gera relatório de falha do teste } \\
\text { - Mede cobertura do teste } \\
\text { - Coleta trace de execução } \\
\text { - Armazena artefatos de teste e seus relacionamentos } \\
\text { - Armazena estado de execução do teste } \\
\text { - Planeja teste }\end{array}$ \\
\hline $\begin{array}{l}\text { Arquitetura de } \\
\text { ferramentas } \\
\text { de teste de } \\
\text { aplicações Web } \\
\text { (Yang et al., } \\
\text { 1999) }\end{array}$ & $\begin{array}{l}\text { - Desenvolvimento } \\
\text { - Análise de falha } \\
\text { - Medição } \\
\text { - Gerenciamento } \\
\text { - Análise do Código-Fonte }\end{array}$ & $\begin{array}{l}\text { - Instrumenta artefato a ser testado } \\
\text { - Executa artefato a ser testado } \\
\text { - Armazena resultado da execução do artefato a ser } \\
\text { testado, do trace de execução e do andamento do } \\
\text { teste } \\
\text { - Estabelece oráculo } \\
\text { - Gerencia casos de teste } \\
\text { - Estabelece o critério de adequação do teste } \\
\text { - Realiza análise estática da execução do teste } \\
\text { - Gera relatório de falha do teste } \\
\text { - Mede cobertura do teste } \\
\text { - Coleta trace de execução } \\
\text { - Armazena artefatos de teste e seus relacionamentos } \\
\text { - Armazena estado de execução do teste } \\
\text { - Prepara artefato a ser testado }\end{array}$ \\
\hline
\end{tabular}

sintáticos — os mutantes — gerados a partir de um programa em teste $P$, para avaliar o quanto um conjunto de casos de teste $T$ é adequado para o teste de $P$. Quando o comportamento de um determinado mutante difere do comportamento de $P$, diz-se que esse mutante "morre". Por outro lado, se para todo o conjunto de casos de teste $T$ o comportamento do mutante for o mesmo do que de $P$, então diz-se que o mutante está "vivo" e deve ser analisado para determinar se ele é equivalente a $P$ ou se o conjunto de casos de teste $T$ precisa ser melhorado para que seja possível matar o mutante. Assim, esse critério utiliza-se de um processo de eliminação para mostrar que o programa $P$ está correto, mostrando que nenhum dos mutantes, não equivalentes a $\mathrm{P}$, é correto. A geração de mutantes a partir de $P$ é realizada pela aplicação de operadores de mutação que definem as alterações que devem ser aplicadas ao programa em teste $P$. O objetivo 


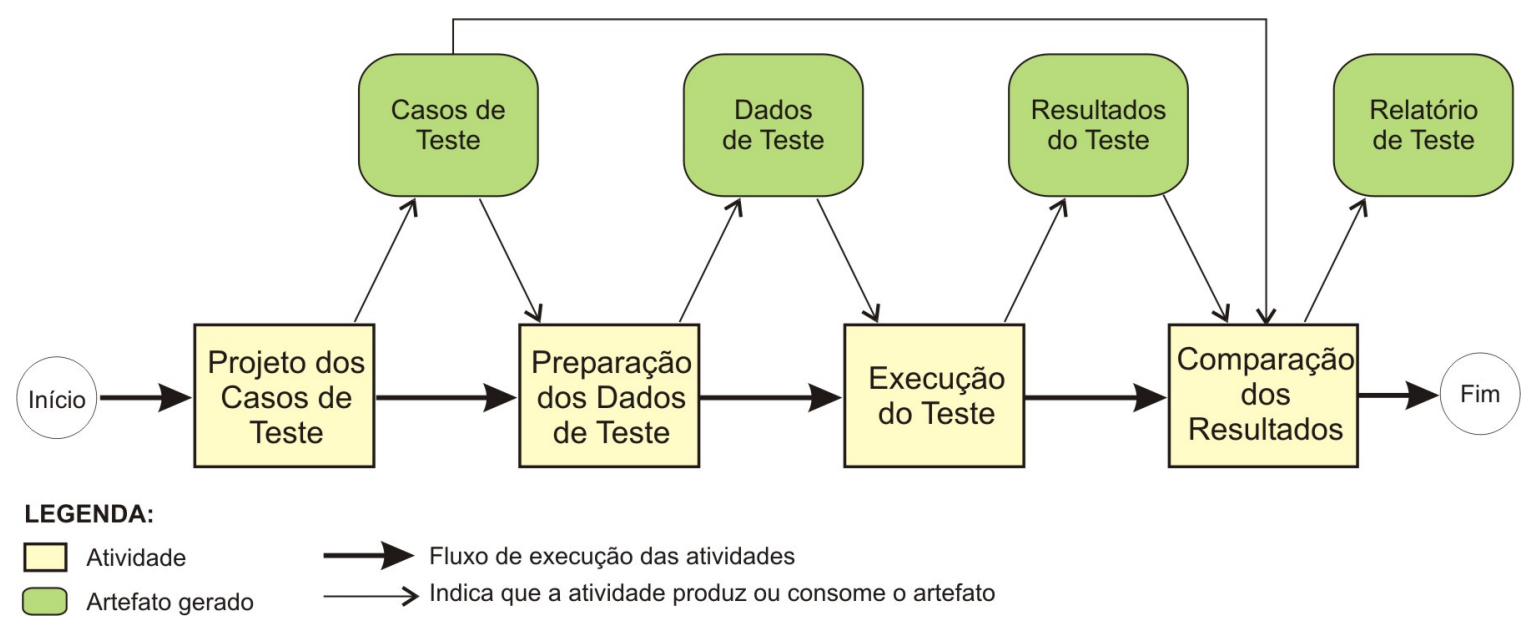

Figura 4.5: Processo de Teste de Software (Adaptado de Sommerville (2001))

desse critério é encontrar um conjunto de casos de teste $T$ que possam revelar a diferença de comportamento existentes entre $P$ e seus mutantes (DeMillo et al., 1978).

Observa-se que esse processo é similar ao proposto em Sommerville (2001), inclusive sendo mais específico e portanto, mais detalhado. De modo geral, as ferramentas de teste que implementam o Teste de Mutação (Delamaro, 1993, 1997; Fabbri et al., 1994a; Ma et al., 2005; Simão, 2000; Simão, 2004; Sugeta, 1999; Yano et al., 2003; Choi et al., 1989; DeMillo et al., 1988; Horgan \& Mathur, 1992) apresentam essas funcionalidades, representadas como atividades na Figura 4.6. Além disso, essas funcionalidades produzem e consomem diversos artefatos de teste e manipulam o artefato a ser testado.

Na Figura 4.6 são mostrados ainda os diversos mecanismos que têm sido investigados e disponibilizados com o intuito de diminuir o custo de aplicação do Teste de Mutação. Para a fase de geração de mutantes, é proposta a aplicação da sequiência de operadores de mutação definido por Vincenzi et al. (2001) e chamado de SUS (Sufficient Incremental Unit Testing Strategy), diminuindo assim o número de mutantes gerados. Quanto à execução do programa original em teste, propõem-se a instrumentação desse programa, de modo a obter informações do fluxo de controle e, quando da execução dos mutantes, evitar a execução desnecessária de casos de teste, reduzindo assim o tempo de execução dos mutantes. Ainda com relação à redução do tempo de execução dos mutantes, cria-se um meta-mutante capaz de reunir em um único mutante, códigos referentes aos vários mutantes. Um outro ponto que é abordado quando se discute o custo de aplicação do Teste de Mutação é a análise dos mutantes equivalentes. Nesse processo é proposto o uso da freqüência de execução dos mutantes e do BaLBEDet (Bayesian Learning-Based Equivalent Detection Technique) (Vincenzi et al., 2002) para análise dos mutantes e conseqüente determinação dos mutantes equivalentes. A BaLBEDet é uma técnica que 


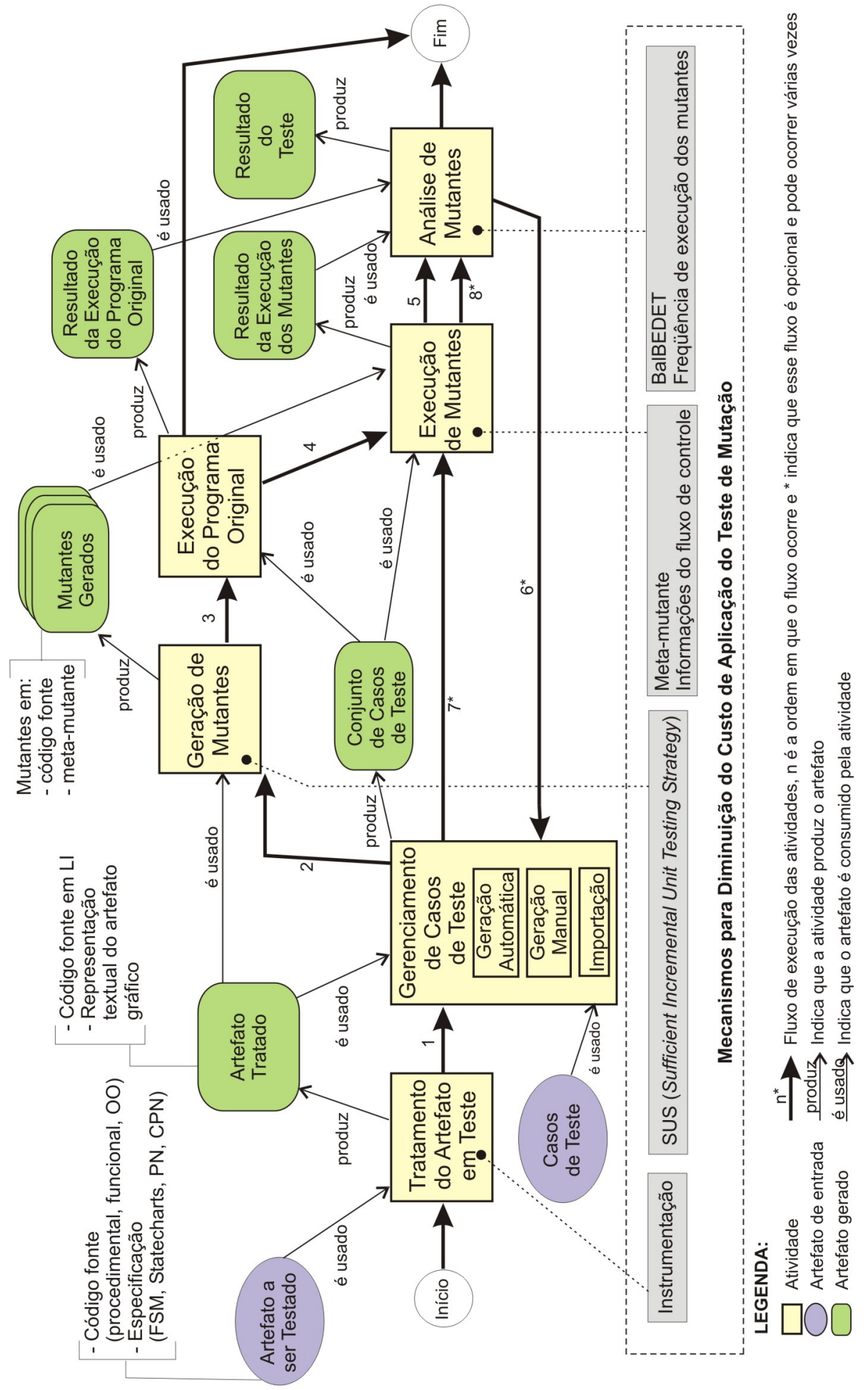

Figura 4.6: Processo de Teste de Mutação

aplica o Aprendizado Bayesiano para estimar quais grupos de mutantes deveriam ser analisados, considerando-se certo número de casos de teste, uma vez que determinados operadores 
têm a característica de gerar mais mutantes equivalentes do que outros. Vale ressaltar que a arquitetura de referência proposta neste trabalho deve possibilitar que os diversos mecanismos para diminuição do custo de aplicação do teste, tais como os sendo propostos para o Teste de Mutação, possam ser incorporados nas ferramentas de teste resultantes dessa arquitetura.

Na Tabela 4.2 é mostrado um paralelo entre o processo de teste proposto por Sommerville (2001) e o processo de Teste de Mutação. Por exemplo, a atividade Preparação dos Dados de Teste do processo de Sommerville (2001) pode ser refinado em duas atividades do processo de Teste de Mutação: Tratamento do Artefato em Teste e Geração de Mutantes. Por ser um pouco mais detalhado, o processo de Teste de Mutação será então considerado como base para a identificação das funcionalidades específicas de ferramentas de teste.

Tabela 4.2: Paralelo entre Processos de Teste de Software

\begin{tabular}{|l|l|}
\hline Processo Proposto por Sommerville (2001) & Processo de Teste de Mutação \\
\hline \hline Projeto dos Casos de Teste & Gerenciamento de Casos de Teste \\
\hline Preparação dos Dados de Teste & $\begin{array}{l}\text { Tratamento do Artefato em Teste } \\
\text { Geração de Mutantes }\end{array}$ \\
\hline Execução do Teste & $\begin{array}{l}\text { Execução do Programa Original } \\
\text { Execução dos Mutantes }\end{array}$ \\
\hline Comparação dos Resultados & Análise dos Mutantes \\
\hline
\end{tabular}

Na Tabela 4.3, na primeira coluna são apresentadas as atividades do processo de Teste de Mutação e, na segunda coluna, as funcionalidades de ferramentas de teste que deveriam dar apoio a essas atividades e que foram derivadas com base nesse processo. Por exemplo, a atividade de Geração de Mutantes deu origem à funcionalidade Gera requisitos de teste. As funcionalidades listadas nessa tabela serão utilizados posteriormente para a identificação dos conceitos do domínio de teste de software relevantes ao módulo base.

\subsubsection{Investigação de Ferramentas de Teste}

Uma outra fonte de informação considerada para o refinamento do módulo base é o estudo e investigação das ferramentas de teste propostas na literatura - ATACOBOL (Sze \& Lyu, 2000), Mujava (Ma et al., 2005; Offutt et al., 2004), Javamut (Chevalley \& Thévenod-Fosse, 2003), Jazz (Misurda et al., 2005b,a), SofTest (Childers et al., 2003) — e também desenvolvidas pelo grupo de pesquisa do ICMC/USP ao qual a doutoranda faz parte - JaBUTi (Vincenzi, 2004), JFut (Rocha, 2005), Poke-Tool (Chaim, 1991), Proteum/CPN (Ferrari, 2004; Simão, 2004), Proteum/SML (Yano et al., 2003), Proteum-RS/ST (Sugeta, 1999), Proteum-RS/PN (Simão, 2000), Proteum/FSM (Fabbri et al., 1994a), CATSDL (Sugeta, 2004). Acredita-se que esse 
Tabela 4.3: Funcionalidades Identificadas no Processo de Teste de Mutação

\begin{tabular}{|l|l|}
\hline Atividade do Processo & Funcionalidade \\
\hline \hline Tratamento do Artefato em Teste & Trata artefato a ser testado \\
\hline Gerenciamento de Casos de Teste & $\begin{array}{l}\text { Importa casos de teste } \\
\text { Inclui casos de teste manualmente } \\
\text { Gera casos de teste automaticamente }\end{array}$ \\
\hline Geração de Mutantes & Gera requisitos de teste \\
\hline Execução do Programa Original & $\begin{array}{l}\text { Executa artefato a ser testado com casos de teste } \\
\text { Fornece relatório de execução do artefato a ser } \\
\text { testado }\end{array}$ \\
\hline Execução dos Mutantes & $\begin{array}{l}\text { Executa requisito de teste com casos de teste } \\
\text { Fornece relatório de requisitos de teste }\end{array}$ \\
\hline Análise dos Mutantes & $\begin{array}{l}\text { Define requisito de teste como não-executável } \\
\text { Define requisito de teste como executável } \\
\text { Calcula satisfação do critério }\end{array}$ \\
& Fornece resultado do teste \\
\hline
\end{tabular}

\footnotetext{
${ }^{a}$ Um requisito de teste é dito não-executável quando não é possível derivar casos de teste que façam com que esse requisito seja exercitado. Por exemplo, requisitos não-executável referem-se a mutantes equivalentes no caso do critério Análise de Mutantes e a caminhos não-executáveis no caso do critério Todos-Caminhos.
}

conjunto de ferramentas seja significativo por cobrir ferramentas propostas mais recentemente, disponibilizadas em diferentes plataformas (Web e stand-alone) e por automatizar diferentes técnicas e critérios de teste.

O estudo das ferramentas de teste foi conduzido por meio da análise de instâncias arquiteturais (quando disponíveis) das ferramentas, das descrições das funcionalidades em trabalhos relacionados, dos modelos das ferramentas, bem como a instalação e execução daquelas que estavam disponíveis.

Independentemente da técnica ou do critério de teste, bem como da natureza de artefato em teste (código-fonte ou especificação), ferramentas de teste apresentam um conjunto comum de funcionalidades. Basicamente, as ferramentas investigadas apresentam as seguintes funcionalidades: gerenciamento de sessões de teste e de casos de teste, gerenciamento e execução dos requisitos de teste, elaboração de relatórios e possibilidade de acompanhamento da evolução da atividade de teste. A seguir são discutidas em mais detalhes cada uma dessas funcionalidades:

- Gerenciamento de sessões de teste: Uma sessão de teste é caracterizada por uma base de dados para armazenar informações necessárias a respeito do programa sendo testado, os casos de teste e os requisitos de teste. Cada sessão de teste é associada a um nome, o que possibilita que o teste seja interrompido e retomado posteriormente; 
- Gerenciamento de casos de teste: Essa funcionalidade possibilita a criação de uma base de dados de casos de teste, bem como a inserção e a exclusão de casos de teste durante o andamento do teste. Ainda com relação a essa funcionalidade, as ferramentas possibilitam a importação de casos de teste de outras bases. Por exemplo, a ferramenta Proteum pode importar casos de teste da Poke-tool, apesar de ambas darem apoio a critérios de teste de diferentes técnicas;

- Gerenciamento e execução de requisitos de teste: Essa funcionalidade envolve a geração, seleção, execução, bem como a análise dos requisitos de teste. No caso da Proteum, os requisitos são mutantes, enquanto que no caso da Poke-tool, os requisitos são os nós, arcos e associações;

- Geração de relatórios e acompanhamento do teste: O estado atual da sessão de teste pode ser obtida por meio de relatórios. Pode-se também obter relatórios dos casos de teste e da situação dos requisitos de teste. Além disso, essa funcionalidade possibilita obter, de forma resumida, informações para o acompanhamento do andamento do teste. De modo geral, esse tipo de informação é crucial para decidir quando parar o teste.

Muitas das ferramentas de teste apresentam funcionalidades de gerência de sessão de teste e/ou de projeto de teste, a exemplo do que ocorre com muitas outras ferramentas de programação e de análise e projeto. Apesar disso, essas funcionalidades não são consideradas funcionalidades específicas de ferramentas de teste, sendo relacionadas à atividade de gerência e planejamento, portanto, uma atividade organizacional.

Observa-se que, assim como o levantamento das funcionalidades e características comuns às ferramentas, a investigação das particularidades de cada ferramenta devem ser observadas para o estabelecimento da arquitetura de referência de ferramentas de teste e mesmo para o estabelecimento de um framework para o domínio de teste. Por exemplo, a funcionalidade Minimiza conjunto de casos de teste foi identificada especificamente na ferramenta ATACOBOL.

Na Tabela 4.4 são listadas as funcionalidades identificadas nas ferramentas de teste, resultante da análise das ferramentas consideradas. Para facilitar a leitura da tabela, as funcionalidades foram agrupadas em: relacionadas ao artefato a ser testado (funcionalidades 1 a 7), aos casos de teste ( 8 a 19), aos requisitos de teste (20 a 29) e ao critério de teste (30 a 34). 
Tabela 4.4: Funcionalidades das Ferramentas de Teste

\begin{tabular}{|c|l|}
\hline$\#$ & Funcionalidade Identificada \\
\hline \hline 1 & Adquire artefato original a ser testado \\
2 & Armazena o artefato original \\
3 & Trata artefato original (p.ex., instrumentação) \\
4 & Armazena o artefato tratado \\
5 & Executa artefato tratado com casos de teste \\
6 & Exclui artefato original a ser testado \\
7 & Permite visualização do artefato tratado \\
\hline 8 & Importa casos de teste \\
9 & Armazena casos de teste importados \\
10 & Inclui casos de teste manualmente \\
11 & Gera casos de teste automaticamente \\
12 & Armazena casos de teste \\
13 & Minimiza conjunto de casos de teste \\
14 & Habilita casos de teste \\
15 & Desabilita casos de teste \\
16 & Exporta casos de teste \\
17 & Fornece relatório de casos de teste \\
18 & Exclui casos de teste \\
19 & Permite a visualização dos casos de teste \\
\hline 20 & Gera requisitos de teste \\
21 & Importa requisitos de teste \\
22 & Armazena requisitos de teste \\
23 & Seleciona requisitos de teste \\
24 & Marca requisito de teste como não-executável \\
25 & Desmarca requisito de teste \\
26 & Executa requisitos de teste com casos de teste \\
27 & Fornece relatório de requisitos de teste \\
28 & Exclui requisito de teste \\
29 & Permite visualização dos requisitos de teste \\
\hline 30 & Permite análise dos resultados pelo testador \\
31 & Calcula satisfação do critério \\
32 & Fornece relatório de análise e medição \\
33 & Fornece relatório de erros encontrados \\
34 & Permite seleção do critério de teste \\
\hline & \\
&
\end{tabular}

\subsubsection{Ontologia de Teste de Software}

Pode-se identificar algumas iniciativas para o estabelecimento de ontologias para o domínio de teste de software (Barbosa et al., 2006; Huo et al., 2003; Zhu \& Huo, 2004). Uma delas é a OntoTest (Barbosa et al., 2006) cuja representação gráfica relevante nesse contexto é mostrada nas Figuras 4.7, 4.8 e 4.9, referentes à ontologia de teste de software, à sub-ontologia de passos de teste e a sub-ontologia de artefatos de teste, respectivamente. Essa ontologia é apresentada 
em mais detalhes no Apêndice A. A OntoTest foi desenvolvida para dar apoio à aquisição, organização, reúso e compartilhamento de conhecimento do domínio de teste. Essa ontologia é baseada no padrão ISO/IEC 12207 (International Organization for Standardization, 1995) por estabelecer uma analogia entre processo de software e processo de teste de software e no conhecimento e experiência na definição e avaliação de critérios de teste, desenvolvimento de ferramentas de teste e na condução de estudos teóricos e experimentais.

Vale ressaltar que a OntoTest pode ser considerada um mecanismo base para a especialização arquitetural da RefASSET para uma arquitetura de referência do domínio de teste, uma vez que essa ontologia busca consolidar o conhecimento e a experiência na área de teste de software. Contudo, somente a ontologia não é suficiente para a identificação das funcionalidades. Outras fontes, tais como as ferramentas de teste, podem inclusive contribuir para a identificação mais refinada das funcionalidades.

Para a análise da ontologia, os conceitos relacionados às atividades de apoio e organizacionais foram primeiramente desconsiderados. Por exemplo, o conceito TestingResource e seus subtipos (recursos de hardware, software e humanos) estão relacionados à atividade de gerência e planejamento e, por isso, não foram considerados. Um outro exemplo é o conceito Test ingProcess, referente a um conjunto de passos de teste que são requeridos para conduzir a atividade de teste; esse conceito refere-se também a uma atividade de gerência e planejamento. Em seguida, foram selecionados os conceitos que pudessem ser automatizados por ferramentas de teste; por exemplo, o conceito Testingstep (passos de teste) são de interesse de automatização, enquanto que TestingGuidance (orientação de teste) é um conceito mais relacionado à atividade de treinamento do testadores, por isso, não parece ser relevante em termos de automatização, pelo menos do módulo base. Dessa forma, os principais conceitos que serviram de base para a identificação das funcionalidades são TestingStep, PrimaryActivity, TestingArtifact, TestingCriterion, TestingPhase, PrimaryTechnique e Oracle.

Baseado nos conceitos selecionados, foi estabelecido um conjunto de funcionalidades que ferramentas de teste poderiam ter para manipular aquele conceito. É fato que muitas das funcionalidades específicas já identificadas por meio de outros mecanismos também podem ser identificados na ontologia de teste. Na Tabela 4.5 estão listadas aquelas funcionalidades identificadas por meio da ontologia. 


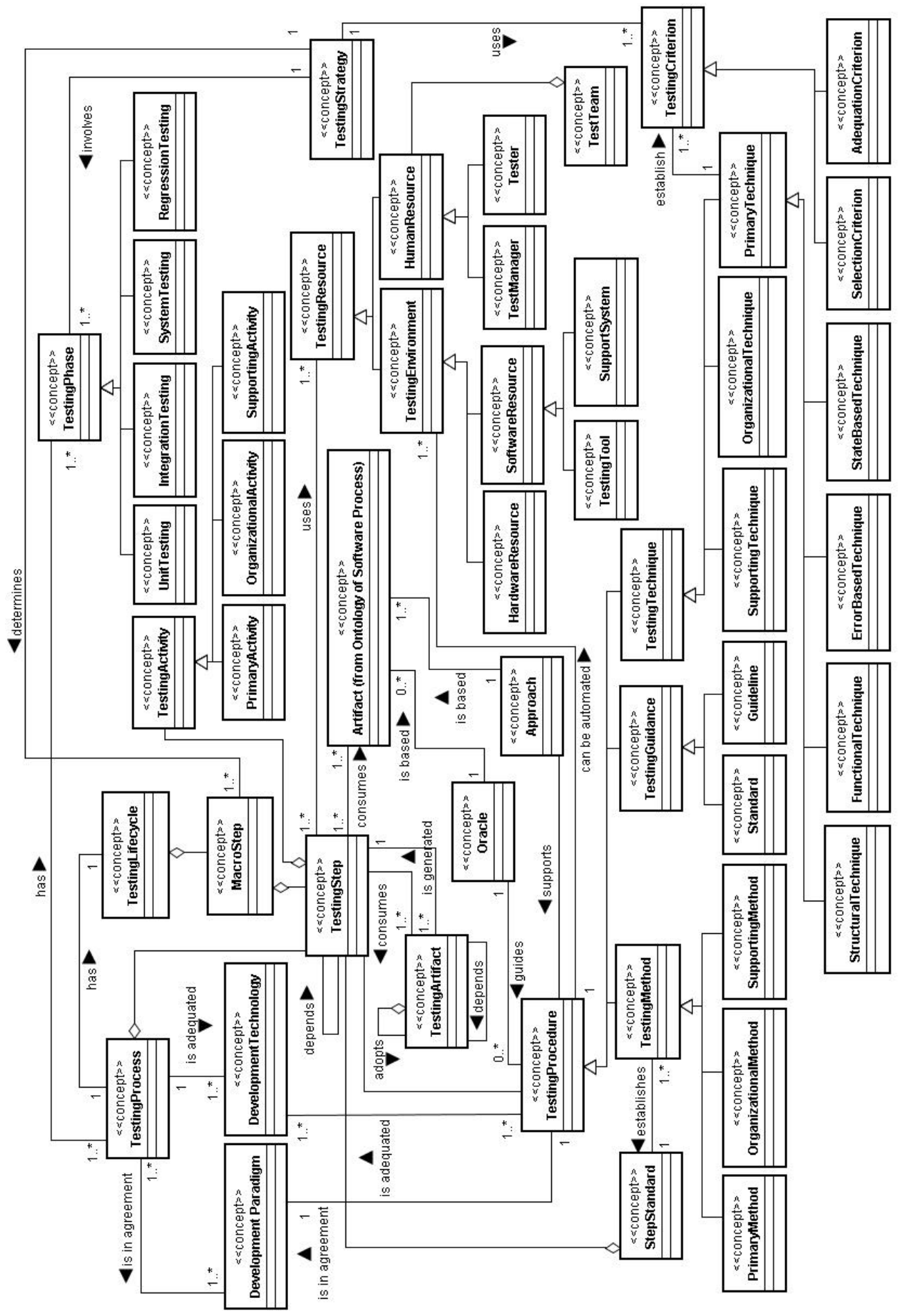

Figura 4.7: Ontologia de Teste de Software

\subsubsection{Identificação das Funcionalidades Específicas e dos Conceitos do Domínio}

Com base na investigação conduzida e descrita anteriormente, foi realizado o mapeamento FIFE-C (Funcionalidades Identificadas, Funcionalidades Específicas e Conceitos), ilustrado na 


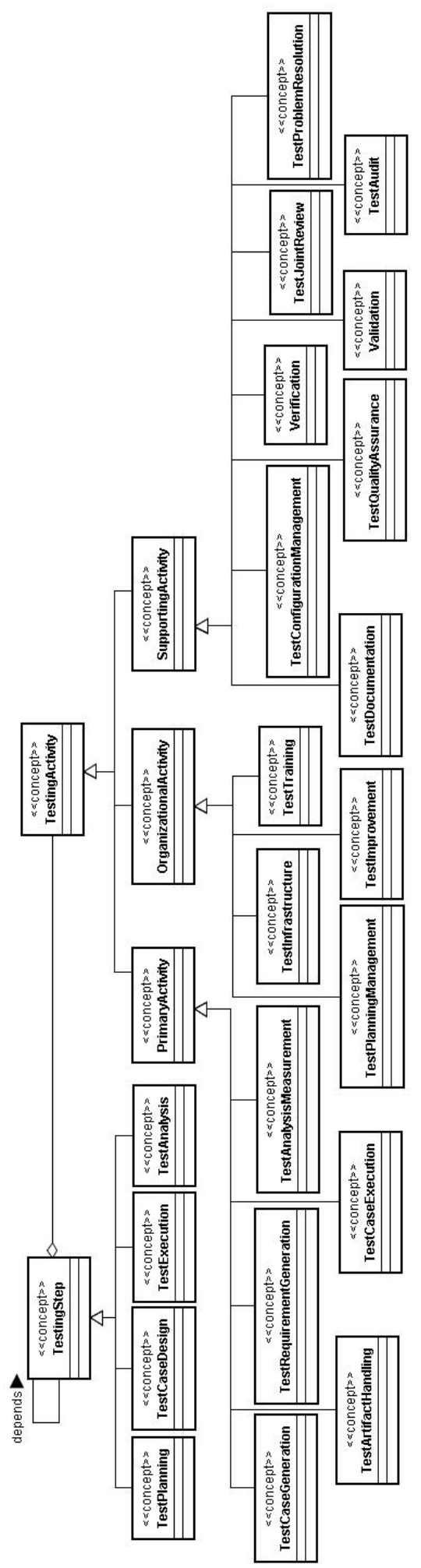

Figura 4.8: Sub-Ontologia de Passos de Teste 


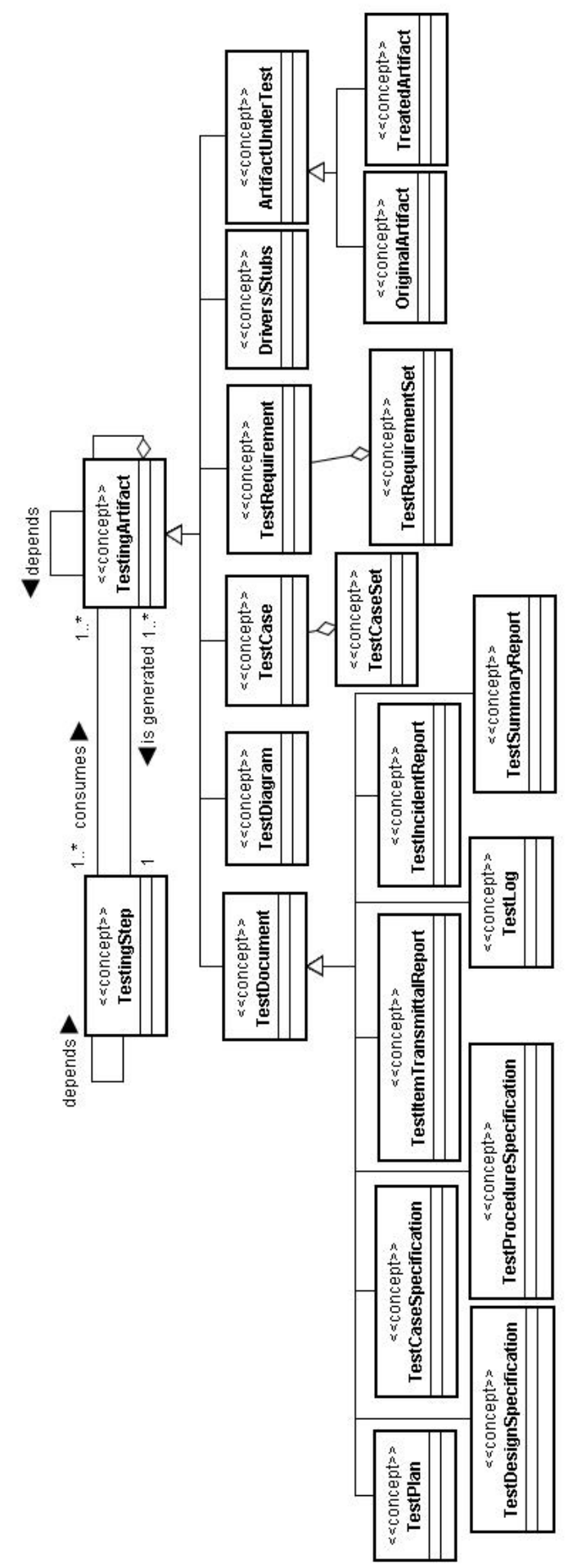

Figura 4.9: Sub-Ontologia de Artefatos de Teste

Figura 4.10. Com base nas funcionalidades identificadas por meio das diversas fontes de informação consideradas (consolidadas nas Tabelas 4.1, 4.3, 4.4 e 4.5, apresentadas anteriormente), 
Tabela 4.5: Funcionalidades Identificadas na Ontologia de Teste

\begin{tabular}{|l|}
\hline Funcionalidade Identificada \\
\hline \hline Seleciona fase de teste \\
Seleciona técnica de teste \\
Seleciona critério de teste \\
Gerencia oráculo \\
Projeta casos de teste \\
Trata artefato a ser testado \\
Gera requisitos de teste \\
Executa teste com casos de teste \\
Realiza análise e medição do teste \\
Gerencia diagrama de teste \\
Gerencia casos de teste \\
Gerencia conjunto de casos de teste \\
Gerencia requisitos de teste \\
Gerencia conjunto de requisitos de teste \\
Gerencia drivers e stubs ${ }^{a}$ \\
Gerencia artefato de teste original \\
Gerencia artefato de teste tratado \\
\hline
\end{tabular}

${ }^{a}$ Um driver é usualmente um programa principal que aceita os dados de teste e passa esses dados para o módulo a ser testado e imprime os resultados. Um stub simula um módulo subordinado que é chamado por um módulo sendo testado.

foi identificado um conjunto de funcionalidades específicas de ferramentas de teste. Essa tarefa exigiu análise minuciosa de cada uma das funcionalidades de modo a agregar funcionalidades relacionadas, renomear funcionalidades, identificar funcionalidades semelhantes que possuíam nome distintos, além de identificar funcionalidades que não fazem parte do núcleo (módulo base) de ferramentas de teste.

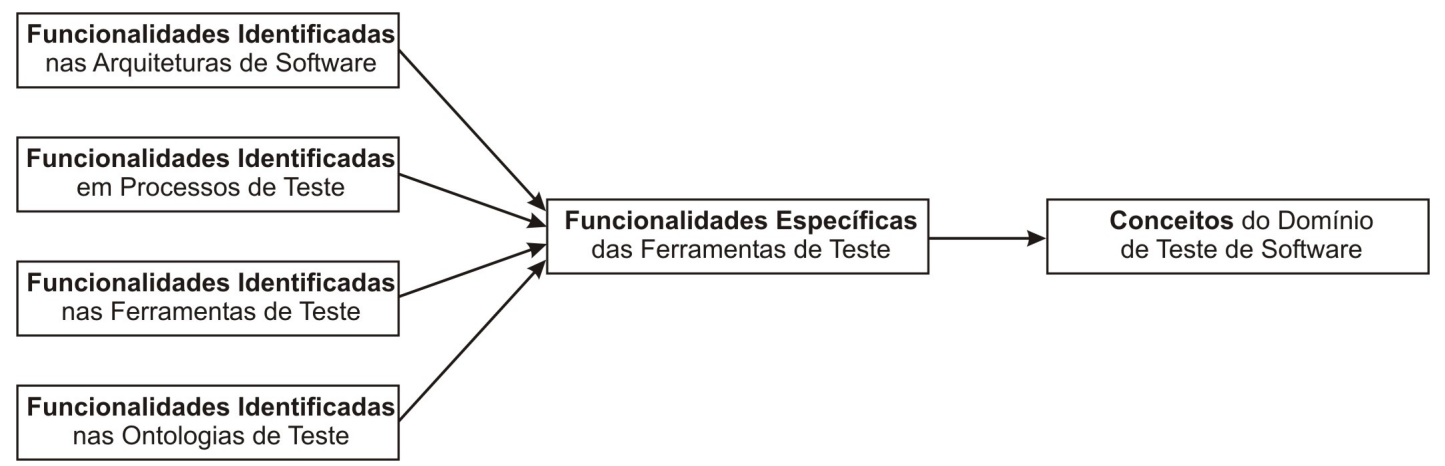

Figura 4.10: Mapeamento FI-FE-C

Em seguida, com base nas funcionalidades específicas, foram estabelecidos os conceitos relevantes do contexto de teste relacionados à automatização do núcleo das ferramentas de teste. 
O resultado é apresentado na Tabela 4.6 que lista as funcionalidades específicas (coluna 1) e os conceitos aos quais as funcionalidades estão relacionadas (coluna 3); na coluna 2 são indicadas as fontes de informação que deram origem à funcionalidade. Nessa tabela, para indicar as fontes de informação, serão utilizadas as letras A, P, F e $\circ$ para referir-se, respectivamente, às arquiteturas de software, aos processos de teste, às ferramentas de teste e à ontologia.

As funcionalidades que caracterizam a persistência de um dado elemento, seja um caso de teste ou um requisito de teste, não foram consideradas como funcionalidades específicas. Contudo, a informação de quais devem ser persistidos será utilizada posteriormente na fase de Tratamento de Frameworks Transversais (Seção 4.5).

Com base no mapeamento FI-FE-C, tem-se que os conceitos do domínio de teste relacionados à automatização do núcleo de ferramentas de teste são o Artefato em Teste, o Caso de Teste, o Requisito de Teste e o Critério de Teste.

Vale ressaltar que todas as fontes de informação consideradas para análise do domínio não fazem distinção entre as funcionalidades relacionadas às atividades de apoio, daquelas que são funcionalidades relacionadas às atividades organizacionais, bem como distinção das funcionalidades específicas de ferramentas de teste. Dessa forma, vale salientar que essa tabela traz uma visão clara de quais seriam as funcionalidades específicas (ou fundamentais) de ferramentas de teste, ou seja, do núcleo de ferramentas desse domínio, separando aquelas funcionalidades que estão relacionadas às atividades de apoio e às organizacionais.

\subsection{Análise Arquitetural}

Com base no resultado do passo anterior, ou seja, no conjunto de conceitos identificados, um modelo conceitual é construído. Se for considerado que a ferramenta de teste será um aplicação Web, esse modelo corresponde à camada de aplicação da RefASSET. Na Figura 4.11 é apresentado o modelo conceitual representado com a notação do diagrama de estrutura estático da UML. De modo geral, os conceitos apresentados nesse modelo são:

- Artefato em Teste (TestArtifact): agrega todas as funcionalidades referentes ao gerenciamento de artefatos a serem testados. Além disso, gerencia também drivers e stubs utilizados no teste;

- Casos de teste (TestCase): possui todas as funcionalidades relacionadas ao gerenciamento de casos de teste; 
Tabela 4.6: Funcionalidades Específicas e Conceitos do Domínio de Teste

\begin{tabular}{|c|c|c|}
\hline Funcionalidade Específica & Fonte & Conceito \\
\hline Adquire artefato a ser testado & $\bar{F}$ & Artefato em Teste \\
\hline Trata artefato a ser testado ${ }^{a}$ & $\mathrm{~A}, \mathrm{P}, \mathrm{F}, \mathrm{O}$ & Artefato em Teste \\
\hline Executa artefato a ser testado com casos de teste & $\mathrm{A}, \mathrm{P}, \mathrm{F}$ & Artefato em Teste \\
\hline Fornece relatório de execução do artefato a ser testado & $\mathrm{P}$ & Artefato em Teste \\
\hline Permite a visualização de artefato a ser testado & $\mathrm{F}$ & Artefato em Teste \\
\hline Exclui artefato a ser testado & $\mathrm{F}$ & Artefato em Teste \\
\hline Inclui drivers e stubs & $\mathrm{O}$ & Artefato em Teste \\
\hline Permite a visualização de drivers e stubs & $\mathrm{O}$ & Artefato em Teste \\
\hline Importa casos de teste & $\mathrm{P}, \mathrm{F}$ & Caso de Teste \\
\hline Inclui casos de teste manualmente & $\mathrm{P}, \mathrm{F}$ & Caso de Teste \\
\hline Gera casos de teste automaticamente & $\mathrm{P}, \mathrm{F}$ & Caso de Teste \\
\hline Minimiza conjunto de casos de teste & $\mathrm{F}$ & Caso de Teste \\
\hline Habilita casos de teste & $\mathrm{F}$ & Caso de Teste \\
\hline Desabilita casos de teste & $\mathrm{F}$ & Caso de Teste \\
\hline Exporta casos de teste & $\mathrm{F}$ & Caso de Teste \\
\hline Fornece relatório de casos de teste & $\mathrm{F}$ & Caso de Teste \\
\hline Remove casos de teste & $\mathrm{F}$ & Caso de Teste \\
\hline Permite a visualização de casos de teste & $\mathrm{F}$ & Caso de Teste \\
\hline Importa requisitos de teste & $\mathrm{F}$ & Requisito de Teste \\
\hline Gera requisitos de teste & $\mathrm{P}, \mathrm{F}, \mathrm{O}$ & Requisito de Teste \\
\hline Seleciona requisitos de teste & $\mathrm{F}$ & Requisito de Teste \\
\hline Marca requisito de teste como não-executável & $\mathrm{P}, \mathrm{F}$ & Requisito de Teste \\
\hline Desmarca requisito de teste & $\mathrm{P}, \mathrm{F}$ & Requisito de Teste \\
\hline Executa requisitos de teste com casos de teste & $\mathrm{P}, \mathrm{F}, \mathrm{O}$ & Requisito de Teste \\
\hline Coleta trace de execução dos requisitos & A & Requisito de Teste \\
\hline Fornece relatório de requisitos de teste & $\mathrm{P}, \mathrm{F}$ & Requisito de Teste \\
\hline Permite a visualização de requisitos de teste & $\mathrm{F}$ & Requisito de Teste \\
\hline Exclui requisito de teste & $\mathrm{F}$ & Requisito de Teste \\
\hline Estabelece critério de adequação do teste & $\mathrm{A}, \mathrm{O}$ & Critério de Teste \\
\hline Calcula cobertura do teste & $\mathrm{A}, \mathrm{P}, \mathrm{F}$ & Critério de Teste \\
\hline Fornece relatório de falhas do teste & $\mathrm{A}, \mathrm{P}$ & Critério de Teste \\
\hline Permite a análise estática da execução do teste pelo testador & $A, F$ & Critério de Teste \\
\hline
\end{tabular}

${ }^{a} \mathrm{O}$ tratamento do artefato a ser testado pode ocorrer por meio da instrumentação, gerando ou não alguma representação do artefato, por exemplo, um grafo de fluxo de controle.

- Critério de Teste (TestCriterion): as funcionalidades específicas e relacionadas ao critério de teste implementadas pela ferramenta é agregada nesse conceito;

- Requisito de teste (TestRequirement): contém as funcionalidades referentes ao gerenciamento de requisitos de teste, sua execução e informações relacionadas; e 


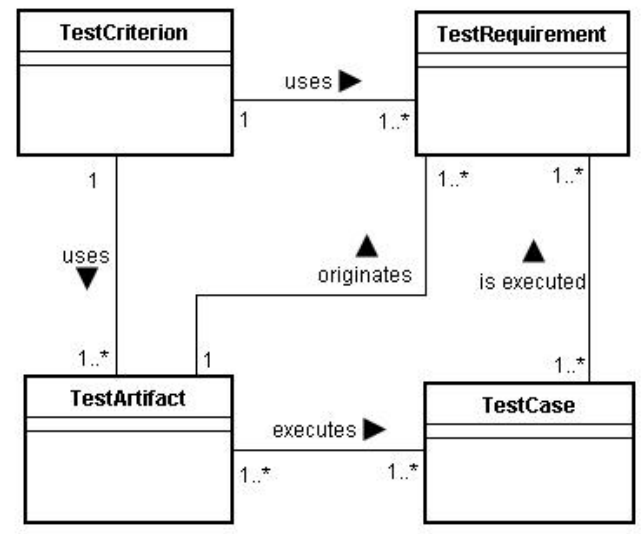

Figura 4.11: Modelo Conceitual do Módulo Base da RefTest

- Critério de Teste (TestCriterion): as funcionalidades específicas e relacionadas ao critério de teste implementado pela ferramenta é agregada nesse conceito;

É importante ressaltar que cada um dos conceitos agrega um conjunto de funcionalidades específicas (listadas na Tabela 4.6) e que devem ser consideradas no momento do projeto e codificação do módulo base, seja esse conceito implementado como um pacote, um componente, ou mesmo, um subsistema.

$\mathrm{Na}$ mesma linha do proposto por Boas (2003), os elementos que devem ser armazenados referem-se àqueles mais importantes, mais custosos de serem gerados novamente e que tem uso posterior para reexecução ou observação dos resultados do teste. Com base nisso, bem como nas listas de funcionalidades identificadas e resultantes da análise do domínio de teste, os conceitos que apresentam características de persistência são:

- Artefato em Teste (TestArtifact): na Tabela 4.4 encontra-se a funcionalidade Armazena o artefato original indicando que esse conceito tem característica de persistência;

- Casos de teste (TestCase): as funcionalidades Armazena casos de teste importados e Armazena casos de teste que aparecem na Tabela 4.4 indica que esse conceito possui característica de persistência;

- Requisito de teste (TestRequirement): sua persistência pode ser observada na funcionalidade Armazena requisitos de teste na Tabela 4.4; e

- Critério de Teste (TestCriterion): considerando-se que resultados de teste, tais como resultados de análise e medição, de satisfação do critério, bem como de erros encontrados, 
são custosos de serem obtidos, esse conceito deve também apresentar como característica a persistência.

No passo seguinte, referente ao tratamento de frameworks transversais, a informação sobre quais conceitos possuem características de persistência é essencial, uma vez que frameworks transversais serão utilizados como mecanismos para o tratamento da persistência.

\subsection{Tratamento de Frameworks Transversais}

Foram investigados frameworks transversais de propósito geral que pudessem automatizar interesses transversais. Nessa linha, o trabalho de Camargo \& Masiero (2005) propõe um conjunto de frameworks que implementam os interesses transversais de persistência e segurança. Dessa forma, esses frameworks foram considerados no contexto deste trabalho para tratar esses interesses. Em mais detalhes, esses frameworks são discutidos na Seção 4.5.1.

Nesse passo foram também investigados frameworks que pudessem dar apoio às atividades de apoio e às atividades organizacionais relacionadas ao desenvolvimento de software. Contudo, é importante salientar que em virtude de ser um tema bastante recente entre as pesquisas em Engenharia de Software, não estão disponíveis ainda frameworks transversais para atividades de apoio e organizacionais. Então, este trabalho toma a iniciativa nessa linha, no sentido de propor ou sugerir os primeiros frameworks transversais para essas atividades.

Para investigar a viabilidade de utilização de frameworks transversais na implementação de módulos que automatizam atividades de apoio e organizacionais, foi projetado e implementado um protótipo de um framework transversal para a atividade de documentação. Na Seção 4.5.2 é descrito em mais detalhes esse framework, juntamente com a implementação relacionada. A implementação desse framework foi realizada utilizando-se o Eclipse (versão 3.0.2) como ambiente de desenvolvimento para a implementação das classes em Java, o AJDT (AspectJ Development Tools) (versão 1.2), como ferramenta de apoio ao desenvolvimento de software orientado a aspectos com AspectJ, e o Apache Tomcat (versão 5.5.9) como servidor Web. Já na Seção 4.5.3 são discutidas questões relacionadas à construção do framework transversal de gerência de configuração.

\subsubsection{Frameworks Transversais de Propósito Geral}

Framework Transversal de Persistência 
Sistemas de software, muitas vezes, requerem que dados consumidos e produzidos por esses sistemas sejam armazenados em algum dispositivo de armazenamento secundário para posterior utilização. Isso também pode ser observado na maioria dos AESs, inclusive em ferramentas de teste de software. Nesse contexto, mecanismos que dêem apoio ao desenvolvimento de um módulo responsável pelo armazenamento de dados é certamente relevante. Nessa linha, diversos trabalhos, tais como os de Camargo \& Masiero (2005); Rashid \& Chitchyan (2003) e Soares et al. (2002), têm investigado a persistência como um interesse transversal e proposto mecanismos que possam ser reutilizados em diversos sistemas. Especificamente, o trabalho de Camargo \& Masiero (2005) propõe um conjunto de frameworks transversais para persistência (representados como pacotes na Figura 4.12 e contidos no pacote Persistence), composto de um framework de persistência (persistence) e de outros frameworks transversais que implementam sub-interesses de persistência: pooling (pooling), Memória Auxiliar "Carregador de Objetos" (cachingObjectLoader), Memória Auxiliar "Todas Tuplas" (cachingAllTuples) e Conexão (connection).

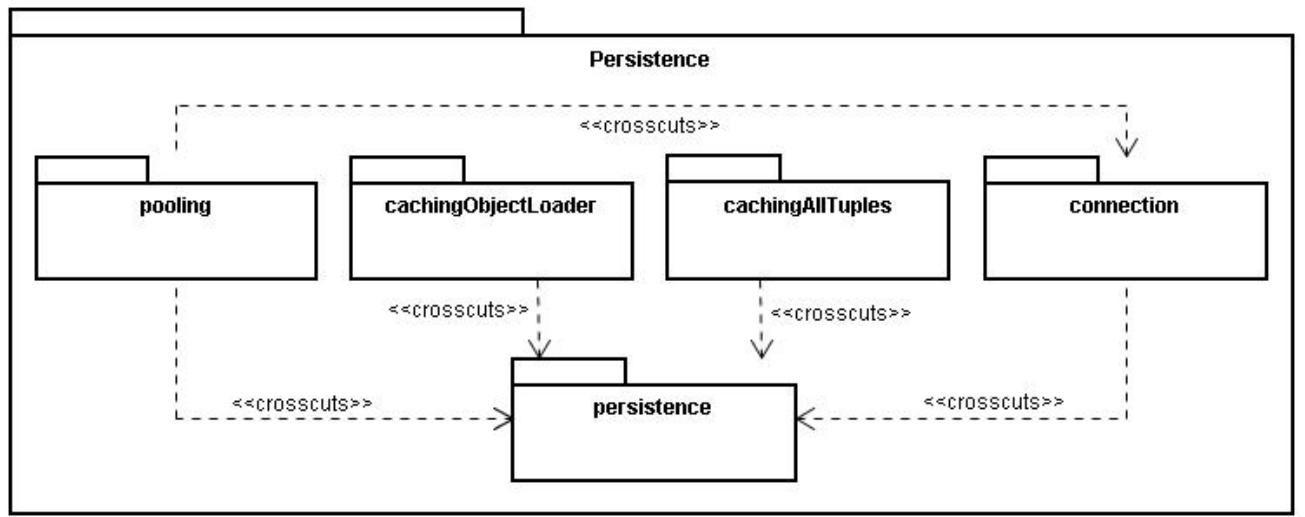

Figura 4.12: Frameworks Transversais para Persistência (Adaptado de Camargo \& Masiero (2005))

Considerando-se os conceitos do domínio de teste identificados, relacionados ao módulo base e que possuem características de persistência, na Figura 4.13 é ilustrada a utilização dos frameworks transversais de persistência junto ao módulo base de uma ferramenta de teste. Observa-se que oframework de persistência (pacote pers istence) afeta os conceitos Artefato de Teste (representado como o pacote testArtifact), Caso de Teste (testCase), Requisito de Teste (testRequirement) e Critério de Teste (testCriterion). Tendo-se o módulo base já implementado, a utilização do framework transversal de persistência ocorre por meio da instanciação desse framework, resultando no que é chamado de módulo de persistência, e subsequiente composição com o módulo base. 


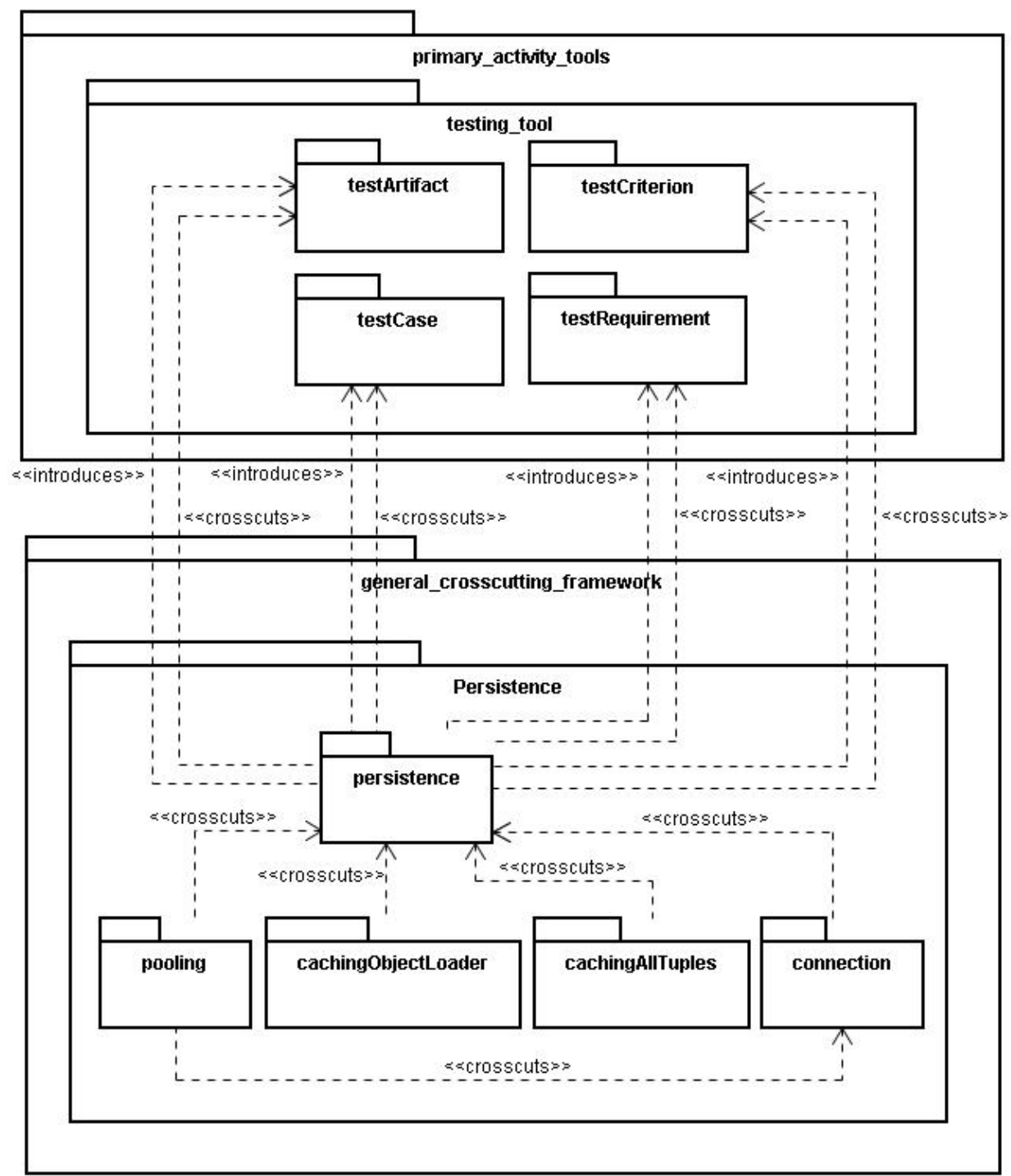

Figura 4.13: Utilização dos Frameworks Transversais de Persistência no Módulo Base

Além dos dados tratados pelo módulo base e que são persistidos, tanto os módulos que implementam atividades de apoio quanto aqueles que implementam atividades organizacionais, muitas vezes, necessitam que dados também sejam persistidos. Portanto, o frameworks transversais para persistência são também utilizados nesses módulos.

\section{Framework Transversal de Segurança}

Assim como diversos outros sistemas disponibilizados sobre a plataforma Web, ferramentas de teste sobre essa plataforma necessitam de funcionalidades de controle de acesso para seu uso. Considerando-se essa necessidade, frameworks que implementam essa funcionalidade podem ser utilizados. Nesse contexto, Camargo \& Masiero (2005) propõem frameworks transversais 
para segurança, que é apresentado na Figura 4.14 por meio do pacote Security. Mais especificamente, o framework de Controle de Acesso (pacote accesscontrol) e os frameworks transversais que implementam sub-interesses de segurança - Registro de Acessos (pacote accessLog), Autenticação (authentication) e Política de Autenticação (authenticationPolicies) - compõem o framework de segurança. Observa-se que o framework de persistência (Persistence) afeta frameworks contidos no pacote security.

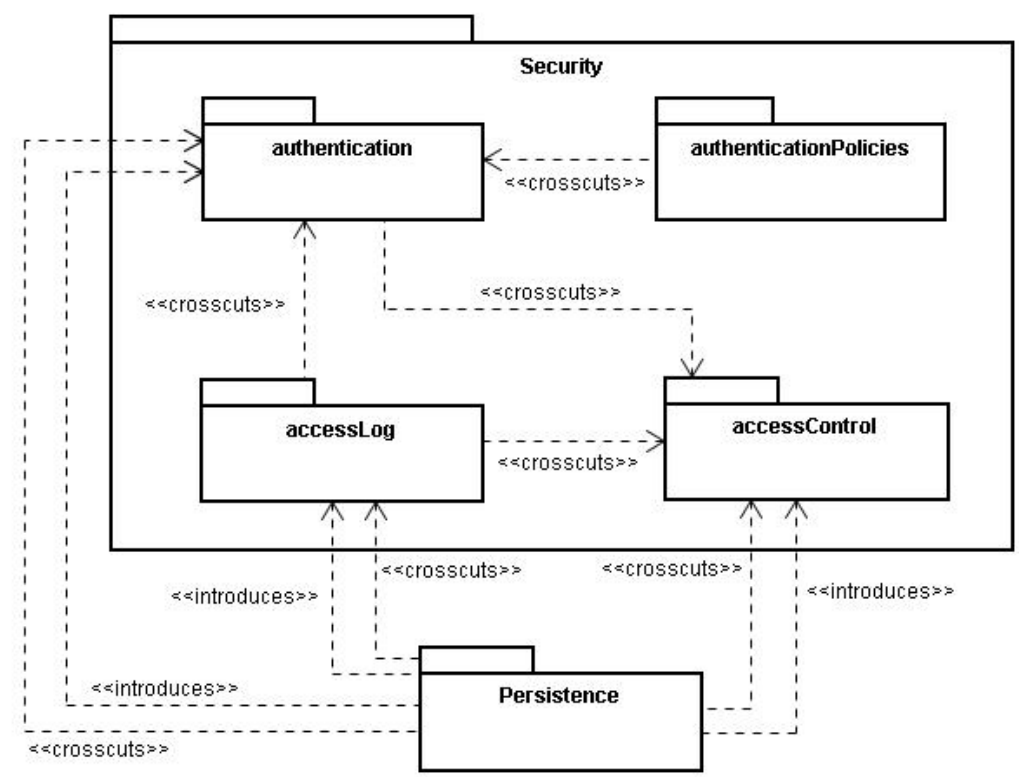

Figura 4.14: Frameworks Transversais para Segurança (Adaptado de Camargo \& Masiero (2005))

Na Figura 4.15 é ilustrada a utilização do conjunto de frameworks transversais de segurança (pacote security) em uma ferramenta de teste. Esse conjunto de frameworks acoplado à ferramenta de teste afeta o controlador (representado como o pacote controller) da camada de apresentação mudando o comportamento da interface do usuário, ou seja, o framework é responsável por disponibilizar uma janela para entrada de dados necessários à autenticação do usuário. Além disso, afeta o pacote de planejamento e gerenciamento (pacote planning_management), que tem entre outras responsabilidades, o controle de usuários da ferramenta de teste. Assim como ocorre com o framework de persistência, tendo-se o módulo base já implementado, a utilização do framework de segurança ocorre por meio da instanciação desse framework e sua subseqüente composição. 


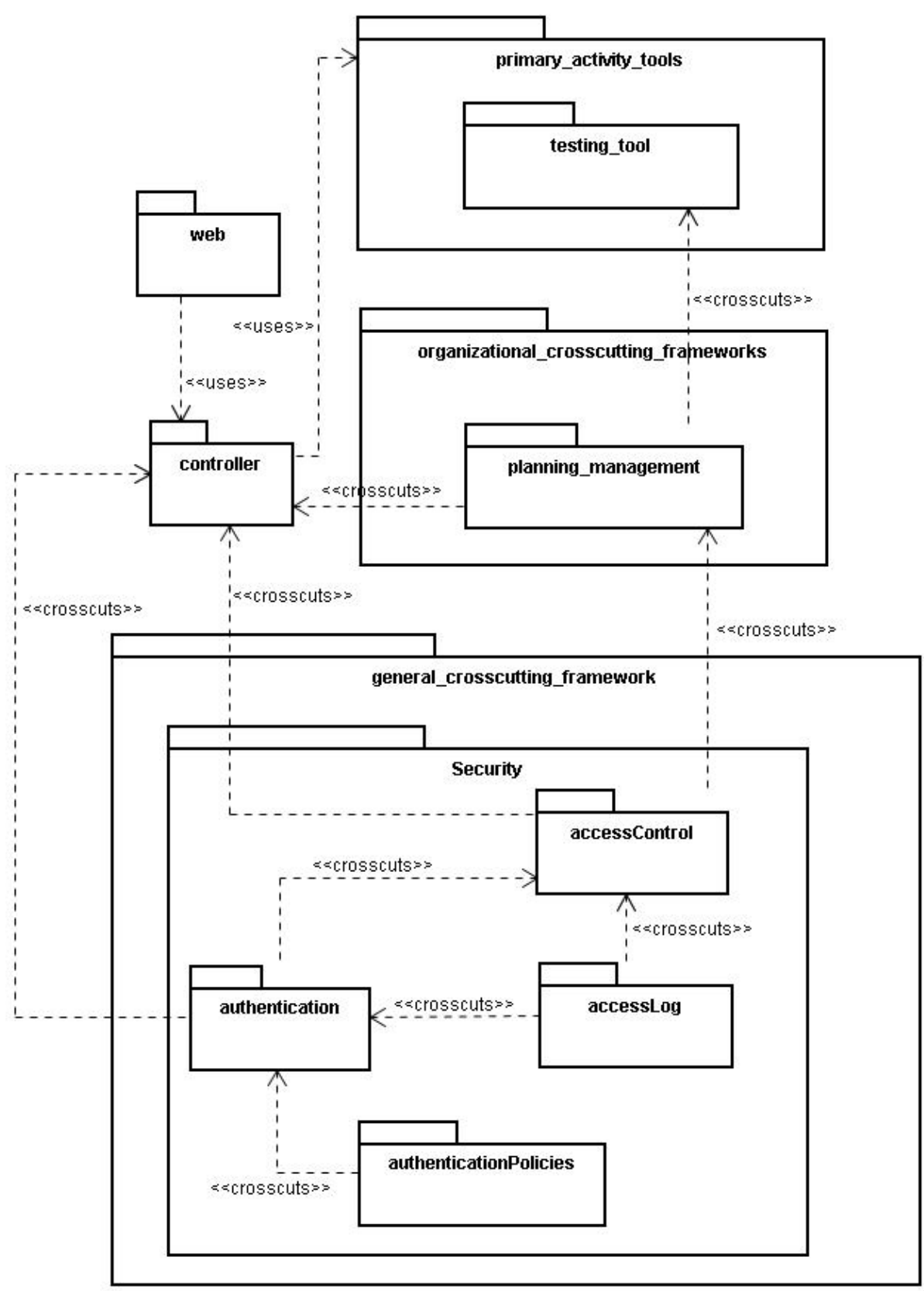

Figura 4.15: Utilização dos Frameworks Transversais de Segurança

\subsubsection{Framework Transversal de Documentação de Teste}

Nesta seção serão apresentados o projeto e a implementação de um módulo de documentação de teste de software e que foi elaborado visando o projeto de um framework transversal de documentação. No entanto, antes disso, serão discutidas as bases da documentação da atividade de teste. 
A documentação é uma atividade bastante relevante para o processo de desenvolvimento de software. Cabe a essa atividade o registro da evolução do software para que sejam criadas as bases necessárias para a utilização e manutenção do software. As tarefas que devem ser realizadas pela atividade de documentação em um AES são:

- elaboração de um plano de documentação: estabelece quais documentos serão produzidos para cada atividade fundamental;

- projeto da estrutura e organização da documentação: é estabelecido a estrutura e organização da documentação, ou seja, como os documentos estão estruturados, bem como o relacionamento com outros documentos;

- identificação dos documentos: refere-se à tarefa de identificar os documentos considerados no plano de documentação;

- produção de documentos: baseado na tarefa de identificação, os documentos são produzidos com base nos artefatos gerados pelas atividades fundamentais;

- apresentação e revisão de documentos: o módulo de documentação deve possuir mecanismos para apresentar os documentos identificados e produzidos, o que possibilita a revisão da documentação gerada; e

- gerenciamento do armazenamento de documentos: refere-se à tarefa de gerenciamento de documentos na base de dados, mais especificamente, refere-se às tarefas de armazenamento, alteração e eliminação de documentos.

Como benefícios que podem ser obtidos da atividade de documentação tem-se (Phoha, 1997): redução do tempo e do esforço despendido no desenvolvimento de software, facilidade de localização das informações, melhor compreensão das estruturas do software e facilidade e maior eficiência no uso do software. Por outro lado, fatores como alto custo, imprecisão e dificuldade de manipulação comprometem a criação e a atualização dos documentos. A combinação desses fatores inevitavelmente acarreta documentos incompletos, desatualizados, inconsistentes e caros de manter. A inconsistência também pode ser resultado da falta de relacionamento entre os documentos, uma vez que, muitas vezes, esses registram isoladamente uma determinada etapa ou atividade do desenvolvimento de software (Rocha et al., 2001a). Em virtude disso, a automatização da atividade de documentação em um processo de desenvolvimento de software e sua incorporação em um AES certamente é bastante relevante.

A atividade de teste de software, assim como as demais atividades de desenvolvimento de software, geram uma grande quantidade de informações. A documentação e o uso de modelos 
de documentos para organizar essas informações podem contribuir para as atividades de evolução, depuração e manutenção do software. Nessa perspectiva, pode-se identificar esforços de padronização de documentação para teste, como o padrão IEEE 829/1998 ${ }^{1}$ - IEEE Standard for Software Test Documentation (IEEE, 1998a) ou aqueles encontrados na literatura disponível sobre teste (Boas, 2003; Perry, 1995).

A grande maioria das ferramentas de teste, mesmo aquelas propostas mais recentemente (Ma et al., 2005; Simão, 2004; Vincenzi, 2004), não dão especial atenção à atividade de documentação. De modo geral, a documentação disponibilizada por essas ferramentas concentra-se em listar somente os casos de teste e os resultados de execução de teste. Portanto, ter um mecanismo automatizado que possibilite e apóie a documentação da atividade de teste é certamente relevante.

Antes de apresentar o módulo de documentação, bem como o framework de documentação, será discutido sobre quais elementos compõem a documentação de teste. Com base no padrão IEEE 829/1998 e nos trabalhos de Boas (2003) e Perry (1995), sete documentos são definidos, cobrindo as tarefas de planejamento, especificação e relato de testes. A seguir é descrito o documento resultante da tarefa de planejamento do teste:

- Documento A - Plano de Teste: Apresenta as atividades requeridas para preparar e conduzir os testes, os ítens do sistema a serem testados, os recursos humanos, suas responsabilidades e cronogramas, as restrições, as ferramentas de teste e o ambiente necessário para a condução dos testes. São apresentadas também as técnicas e os critérios de teste a serem utilizados, os critérios de aceitação, suspensão e retomada dos testes, os riscos e plano de contingência, bem como os documentos a serem elaborados durante a atividade de teste.

Os documentos a seguir referem-se à tarefa de especificação do teste:

- Documento B - Especificação de Projeto de Teste: Refina a abordagem apresentada no Plano de Teste e identifica as funcionalidades e características a serem testadas no projeto e por seus testes associados. Esse documento também identifica os casos e os procedimentos de teste, se existirem, e apresenta os critérios de aprovação;

- Documento C - Especificação de Casos de Teste: Apresenta o conjunto de casos de teste utilizados no teste, identificando e descrevendo resumidamente os ítens de software e as

\footnotetext{
${ }^{1}$ Esse padrão descreve um conjunto de documentos para as atividades de teste de um produto de software, independentemente das técnicas, métodos, estratégias, recursos e ferramentas de teste.
} 
características que serão exercitadas pelos casos de teste. Apresenta também o ambiente necessário e os procedimentos especiais para executar os casos de teste, além das dependências entre os casos de teste quanto às suas execuções; e

- Documento D - Especificação de Procedimento de Teste: Descreve os procedimentos de teste, ou seja, os passos necessários para a execução do conjunto de casos de testes, identificando (fazendo referência) os casos de teste que serão executados. Identifica também quaisquer requisitos especiais que são necessários para a execução dos procedimentos. Podem estar incluídos requisitos de ambiente, de habilidades da equipe de teste e ações prévias necessárias à execução dos procedimentos.

A seguir, são apresentados os documentos que se referem à tarefa de relato da atividade de teste:

- Documento E - Diário de Teste: Incluem-se nesse documento o início e o fim das atividades de teste, registrando a data e a hora da ocorrência, bem como a identidade do testador. Além disso, mostra-se também os ítens de software que estão sendo testados e os atributos do ambiente no qual o teste está sendo executado;

- Documento F - Relatório de Incidentes de Teste: Documenta qualquer evento que ocorra durante o processo de teste e que requeira análise. Apresenta um resumo dos incidentes ${ }^{2}$ ocorridos durante a atividade de teste, identificando os ítens de teste envolvidos. Indica também impacto que os incidentes podem vir a causar no plano de teste, no projeto de teste, nos procedimentos de teste ou nos casos de teste; e

- Documento G - Relatório-Resumo de Teste: Apresenta um resumo da atividade de teste realizada, identificando os ítens de software testados, o ambiente no qual as atividades de teste foram executadas, os desvios dos ítens de teste com relação às suas especificações de projeto, a abrangência do processo de teste com relação aos critérios estabelecidos no plano de teste, os resultados alcançados, a avaliação geral de todos os ítens de teste e o resumo das principais atividades.

Com base na arquitetura de ferramentas de teste sendo proposta e nos módulos que compõem as ferramentas de teste de software, bem como numa análise minuciosa sobre cada um dos elementos que compõem os documentos relacionados à documentação da atividade de teste, na Figura 4.16 são ilustradas as fontes dos dados que compõem esses documentos. Observa-se que

\footnotetext{
${ }^{2}$ Um incidente de teste é a manifestação de qualquer defeito no software ou uma anomalia no funcionamento do ambiente operacional.
} 
o módulo de planejamento e gerência ${ }^{3}$ (representado como o pacote planning_management na Figura 4.16) fornece dados para o documento A (Plano de Teste) e para o documento E (Diário de Teste). O módulo base (módulos funcionais da ferramenta de teste representado pelo pacote testing_tool) provê dados para os documentos C (Especificação de Casos de Teste), E (Diário de Teste), F (Relatório de Incidente de Teste) e G (Relatório-Resumo de Teste) e, os dados para os documentos B (Especificação de Projeto de Teste), C (Especificação de Casos de Teste), D (Especificação de Procedimento de Teste), E (Diário de Teste), F (Relatório de Incidentes de Teste) e G (Relatório-Resumo de Teste) são oriundos das entradas feitas pelo usuário por meio da interface do usuário (representado pelo pacote interface).

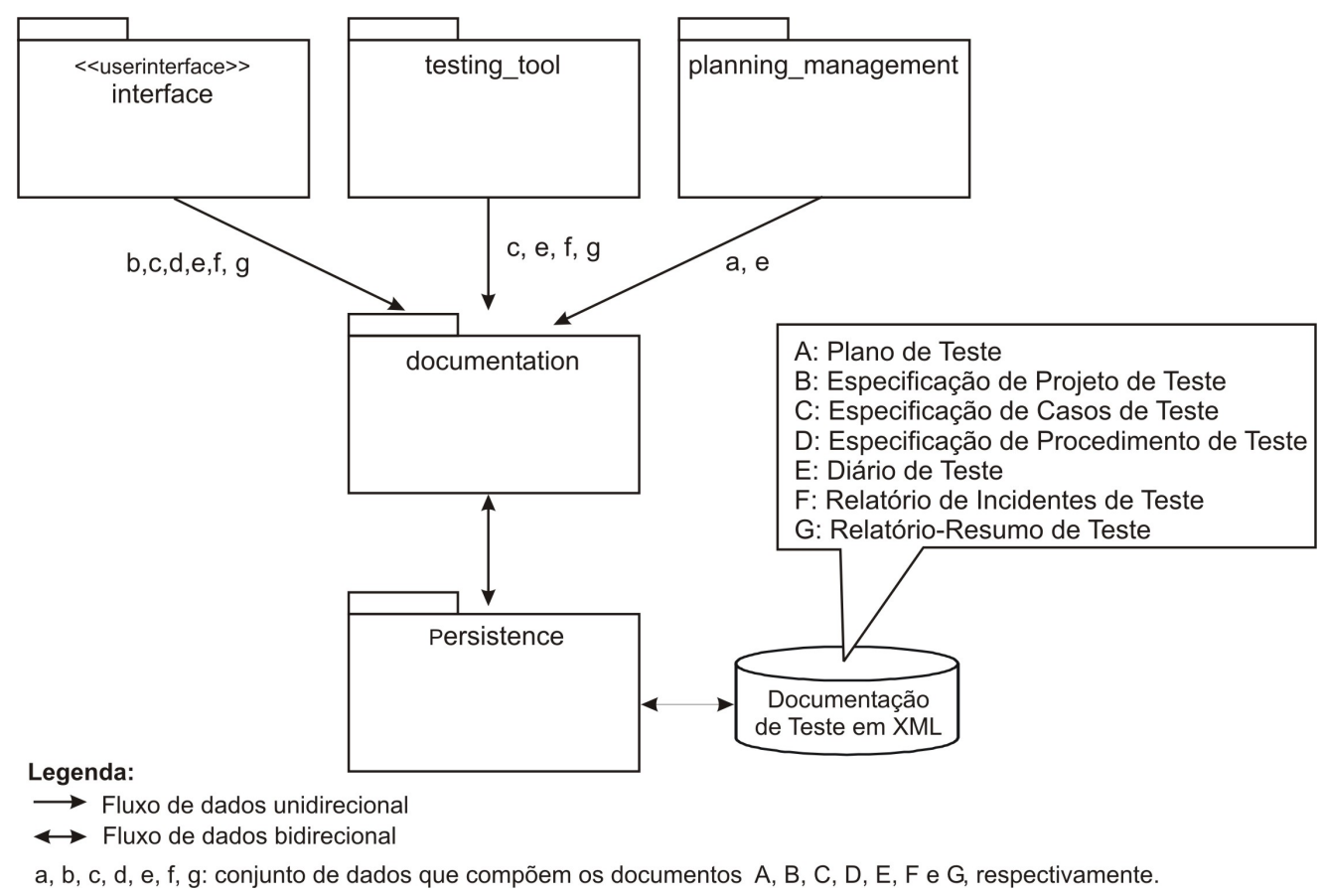

Figura 4.16: Origem dos Dados para a Documentação da Atividade de Teste

Assim, o módulo de documentação, resultante do framework transversal de documentação e representado como o pacote documentation na Figura 4.16, irá coletar dados do módulo testing_tool, bem como dos outros módulos interface e planning_management. Esses dados serão armazenados em arquivos no formato XML com base em um DTD (Document Type Definition) de documentação de teste pelo módulo resultante do framework transversal de persistência (representado pelo pacote Persistence). Considerando-se como base um padrão de documentação da atividade de teste de software, no caso o padrão IEEE 829/1998 e o proposto por Boas (2003) e Perry (1995), foi proposto o T2DTD (Testing Documentation Docu-

\footnotetext{
${ }^{3} \mathrm{O}$ módulo de planejamento e gerência é resultante de um FTO (Framework Transversal Organizacional), ou melhor, de um framework de planejamento e gerência.
} 
ment Type Definition), um DTD para documentação de teste de software composto basicamente de sete DTDs, um para cada meta-documento proposto para documentar o teste de software. $\mathrm{O}$ T2DTD é listado na íntegra no Apêndice B deste trabalho.

Na Figura 4.17 são mostradas duas situações: em (a) é ilustrada a janela da interface do usuário quando o módulo de documentação não é utilizado; e em (b) é ilustrado o conjunto de janelas quando o módulo de documentação está sendo utilizado. Vale ressaltar que quando o módulo de documentação está presente e o botão Documentation da interface é acionado, um aspecto intercepta essa ação e muda o comportamento da interface fazendo com que seja mostrada a janela específica para a atividade de documentação (janela Documentation of Testing Activity), como pode ser visto na Figura 4.17(b).

Como já discutido na Seção 3.5, a integração do módulo de documentação com os códigosbase (módulo base, interface do usuário ou módulo que implementam atividades organizacionais) é realizada por meio da utilização de aspectos. O projeto e a implementação desse módulo de documentação dá indícios de que a integração com os códigos-base, bem como a própria evolução da ferramenta de teste, é facilitada utilizando-se aspectos. Contudo, há a necessidade de mais pesquisas para comprovar o nível de acoplamento entre os módulos se comparado com a utilização de outros mecanismos para integração.

Na Figura 4.18 é mostrado em mais detalhes o modelo do módulo de documentação da atividade de teste de software ${ }^{4}$. A critério de clareza na representação, são mostrados nessa figura somente os elementos mais importantes. De modo geral, esse módulo é composto de:

- aspecto abstrato AbstractDocumentation: esse aspecto abstrato declara conjuntos de junção abstratos, implementa os comportamentos transversais (do inglês, advices) que obtêm os objetos de documentação ${ }^{5}$ interceptados e envia-os para outros objetos responsáveis por tratá-los. Observe que esse aspecto entrecorta o módulo base (pacote testing_tool), o módulo de planejamento e gerenciamento (pacote planning_management), bem como o conjunto de controladores, tais como o ControllerProcessProjectSpecification e o ControllerProcessTestCaseSpecification, responsáveis por processar dados de entradas feitas pelo usuário referente à documentação.

\footnotetext{
${ }^{4}$ Uma vez que não está ainda estabelecida uma notação largamente aceita para representar sistemas orientados a aspectos, neste trabalho utiliza-se como base a notação da UML na linha dos trabalhos de Aldawud et al. (2003), que usam basicamente elementos da UML, tais como os estereótipos, para representar elementos relacionados aos aspectos.

${ }^{5}$ Objetos de documentação contém dados relevantes para a elaboração da documentação da atividade de teste. Por exemplo, um objeto de documentação do tipo Test Ca se contém especificação de uma entrada (conjunto de dados necessários para uma execução do programa) e a correspondente saída esperada (resultado de uma execução do programa).
} 
(a)

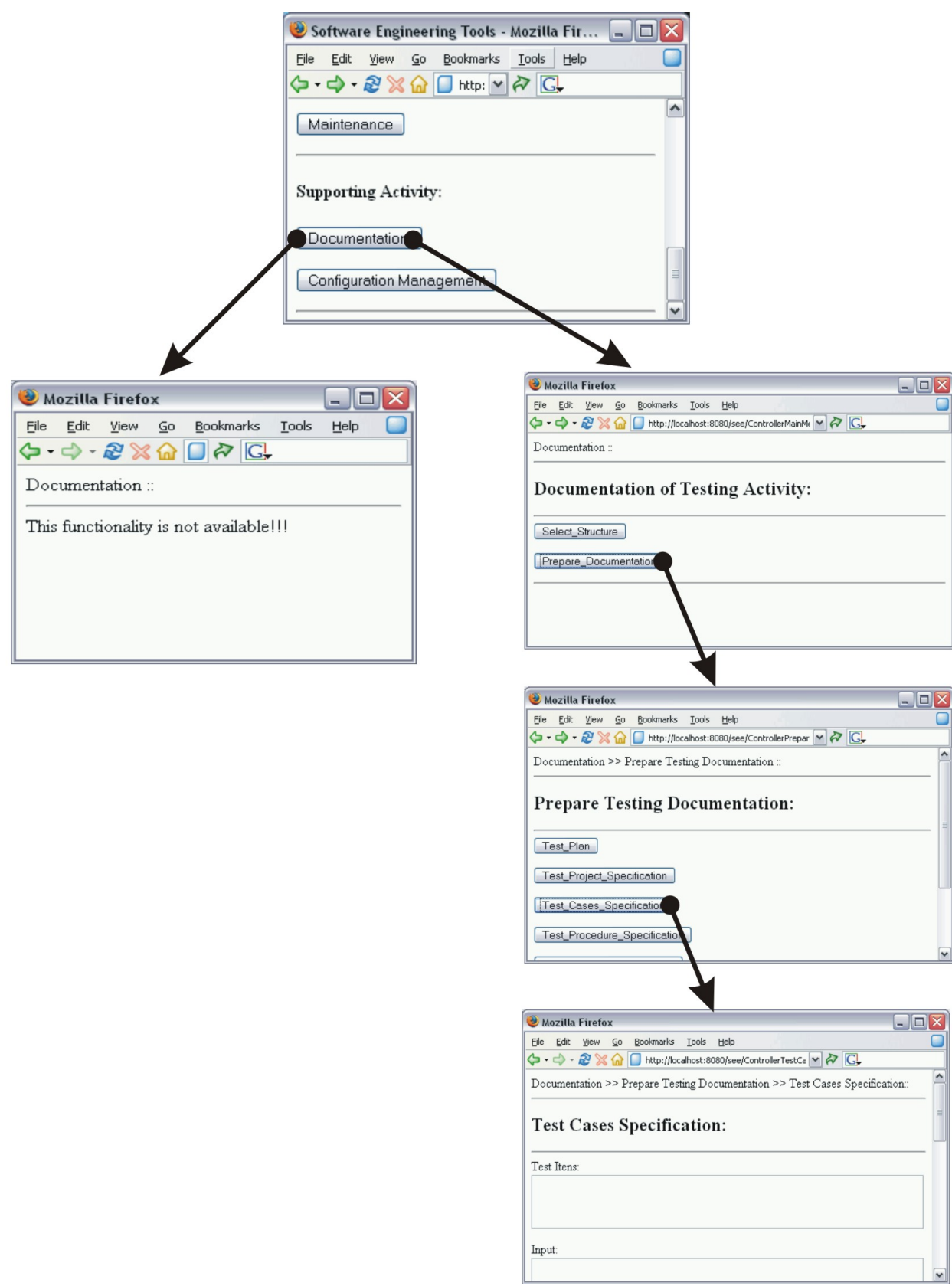

(b)

Figura 4.17: Sequiência de Interfaces: (a) Sem o Uso do Módulo de Documentação; (b) Com o Uso do Módulo de Documentação

Além disso, esse aspecto também muda o comportamento da interface do usuário, possibilitando a utilização das funcionalidades referentes à documentação da atividade de teste. Isso é feito por meio do entrecorte ao objeto do tipo Cont rol lerMa inMenuDocumentation e da invocação de operações do objeto do tipo UserInterface. Na Figura 4.19 é ilustrado parte desse aspecto; 


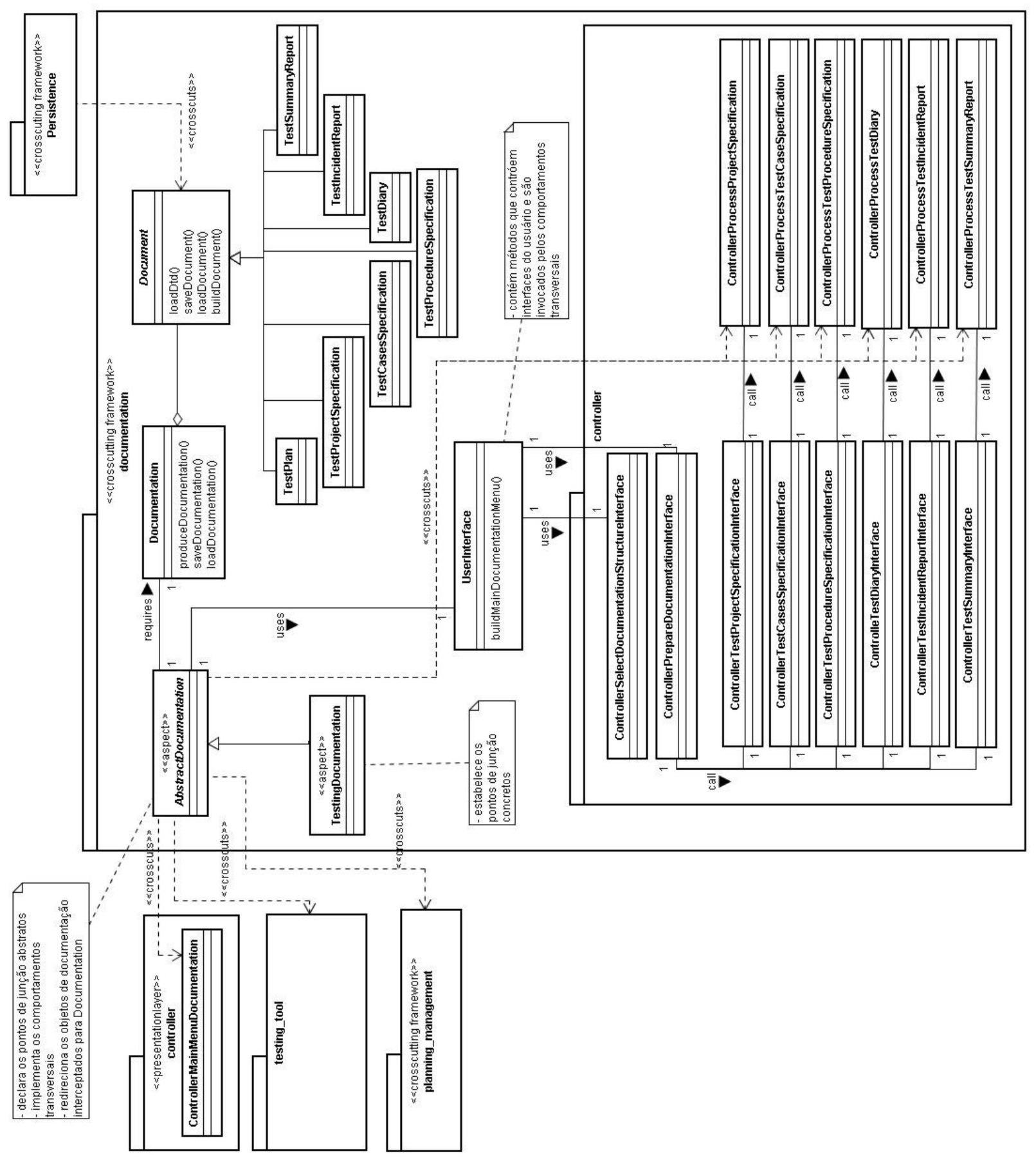

Figura 4.18: Módulo de Documentação de Teste

- aspecto concreto TestingDocumentation: esse aspecto estende o aspecto abstrato AbstractDocumentation e para cada um dos conjuntos de junção abstratos contidos nesse aspecto, são estabelecidos os pontos de junção nos módulos entrecortados. Na Figura 4.20 é listado parte do código-fonte desse aspecto; 


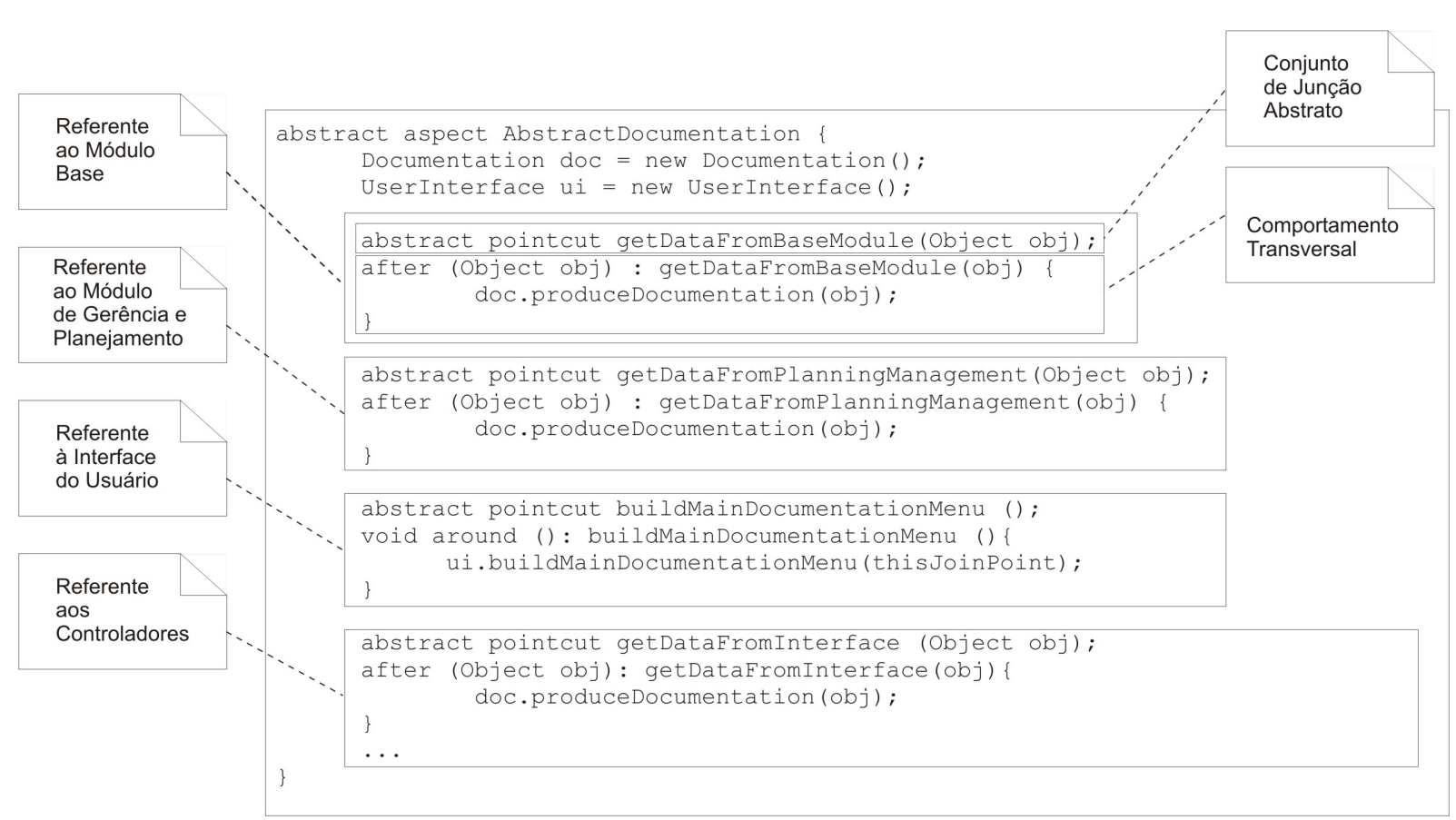

Figura 4.19: Aspecto Abstrato AbstractDocumentation

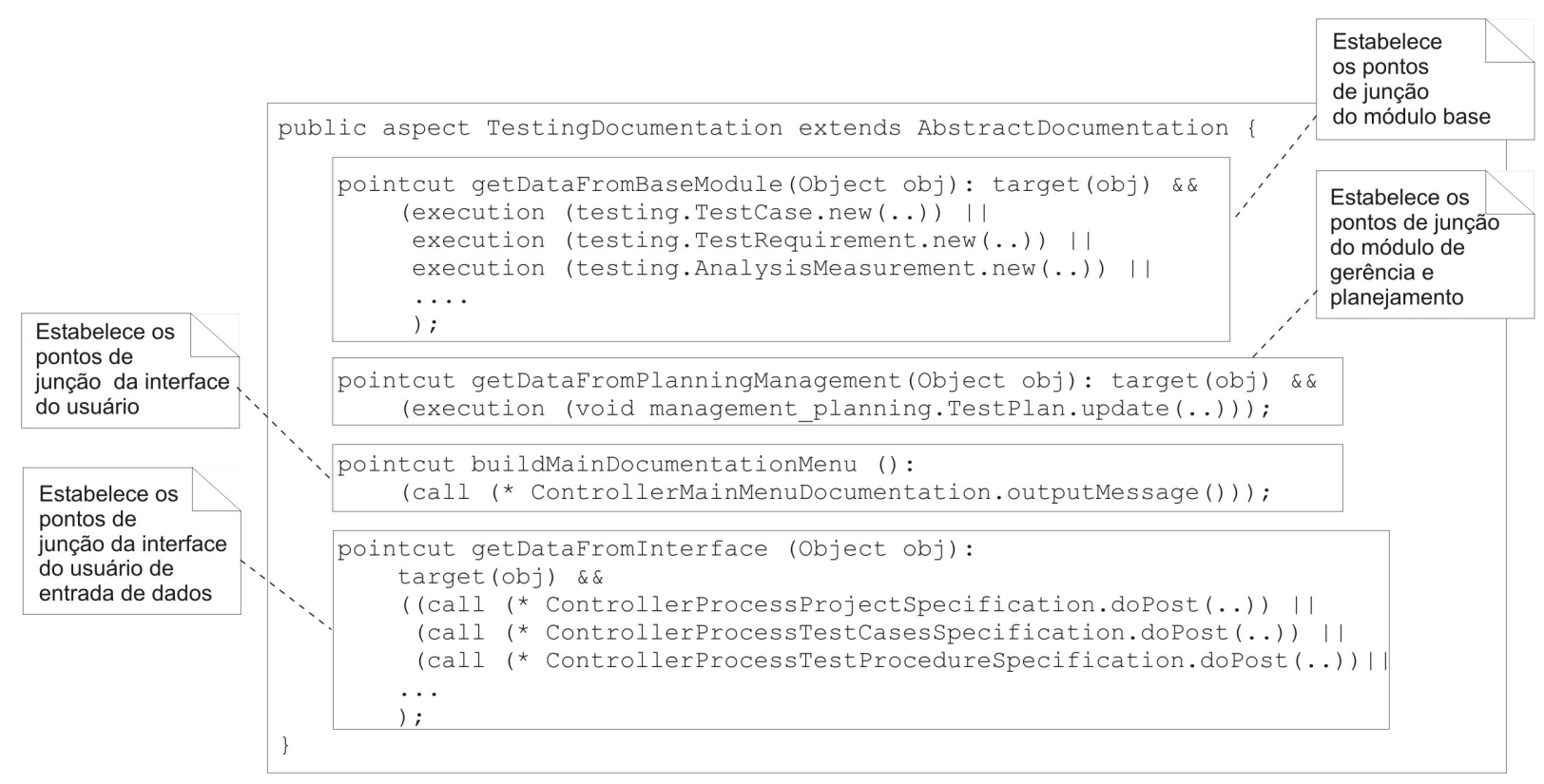

Figura 4.20: Aspecto Concreto TestingDocumentation

- classe UserInterface: contém um método responsável por construir a interface do usuário que disponibiliza as funcionalidades do módulo de documentação. Esse método é invocado por um comportamento transversal implementado pelo aspecto abstrato AbstractDocumentation; 
- classe Document e seus subtipos: a classe Document é especializada para todos os subtipos de documentos que compõem a documentação de teste. Cada uma dessas subclasses recebe os dados pertinentes oriundos de outros módulos e constrói um arquivo XML de documentação com base no T2DTD proposto. O framework transversal de persistência (pacote Persistence na Figura 4.18) proposto no trabalho de Camargo \& Masiero (2005) pode ser utilizado para dar apoio ao armazenamento de arquivos no formato XML. Para tanto, há a necessidade de estender esse framework para suprir essa funcionalidade;

- classe Documentation: tem a responsabilidade de receber objetos de documentação e redirecioná-los aos subtipos de Document correspondentes, para que esses possam tratar o conteúdo desses objetos para a criação da documentação; e

- pacote controller contido no pacote documentation: é responsável pela construção das interfaces do usuário específicas para a entrada de dados referente à documentação da atividade de teste. Além disso, é responsável também pelo processamento dos dados de documentação entrados pelo usuário por meio das interfaces do usuário.

Vale observar que, para que o módulo de documentação possa ser adequadamente integrado à ferramenta de teste em desenvolvimento, os aspectos contidos nesse módulo mudam tanto o comportamento da interface Web do usuário quanto as funcionalidades internas do código-base.

Pela própria concepção do módulo de documentação, esse pode ser abstraído em um framework transversal de documentação, no qual a instanciação refere-se à implementação dos subtipos de Document e das classes controladoras (contidos no pacote controller). Em seguida, a composição dá-se por meio da identificação dos pontos de junção no código-base que é feita dentro do aspecto concreto que foi especializado do aspecto abstrato Abst ractDocumentation e o fornecimento das regras de composição do código-base com o framework de documentação.

Na Figura 4.21 é proposto um modelo do framework transversal de documentação ${ }^{6}$ que pode ser utilizado na documentação das diversas atividades de Engenharia de Software. As classes e os aspectos pertencentes ao framework são indicados com o estereótipo «framework», enquanto que as classes e aspectos concretas que pertencem à aplicação são indicadas com «application». O estereótipo «adapt-static» indica que a generalização deve ser completada com classes da aplicação. A tag “...” indica que a classe, o aspecto e a generalização não estão representados na íntegra; por exemplo, na classe Document foram colocados somente

\footnotetext{
${ }^{6}$ Esse modelo é representado utilizando-se a UML-F, uma profile da UML proposta por Fontoura et al. (2002) para descrever frameworks. São também utilizadas extensões da UML para representar aspectos.
} 
as operações mais importantes. A tag (Cindica que o elemento está completo, ou seja, todos os métodos e atributos estão sendo mostrados; é o caso da classe UserInterface.

Um dos pontos relevantes de se ter frameworks é a disponibilidade de variabilidades alternativas (ou alternativas de composição). O framework de documentação proposto nesta seção não apresenta ainda explicitamente as alternativas de composição; contudo, na concepção desse framework foram consideradas que novas alternativas possam ser adicionadas ao framework, dando inclusive o apoio à documentação de outras atividades de Engenharia de Software. Mais especificamente, um mesmo módulo de documentação pode dar apoio à documentação de diversas atividades de Engenharia de Software em um AES. Para isso, os documentos que compõem a documentação de cada atividade devem ser subtipos de Document e deve-se ter controladores adequadas para as interfaces de documentação de cada atividade. Além disso, o aspecto AbstractDocumentatation deve ser especializado para cada atividade.

No caso do framework transversal de documentação de teste, uma das variabilidades é o padrão de documentação utilizado. Nesse estudo de caso, considerou-se o padrão IEEE 829/1998 - IEEE Standard for Software Test Documentation, no entanto, pode-se utilizar qualquer outro padrão, por exemplo, proposto por uma determinada organização (empresa) para uso próprio. Adotando-se um outro padrão, há a necessidade de especializar a classe Document para os subtipos de documentos desse padrão, bem como estabelecer DTDs específicos e os controladores (pacote controller) adequados. Há também a necessidade de concretizar os pontos de junção dentro do aspecto TestingDocumentation de modo a interceptar os objetos adequados ao novo padrão.

Considerando-se que os módulos da ferramenta de teste - módulo base e módulos de apoio e organizacionais - podem e devem ser reutilizados posteriormente, as interfaces requeridas e providas pelos módulos da ferramenta de teste devem estar bem estabelecidas. Nessa linha, a reutilização dos frameworks transversais utilizados para dar origem aos módulos de apoio e organizacionais é facilitada com a definição explícita das interfaces desses frameworks; assim como o estabelecimento de restrições no desenvolvimento do módulo base. Por exemplo, o módulo base deve possuir o tipo Testcase contendo os dados input e output. Um outro exemplo é o módulo de gerência e planejamento que deve conter o tipo TestPlan contendo os dados TestPlanobjective, Scope, References, TestModules, ExternalResources, ReferencedDocuments, FeaturesToBeTested, FeaturesNot Tested, Approach, ItemPassfailCriteria, SuspendResumeCriteria, TestDeliverables, TestingTasks, EnvironmentalNeeds, Responsabilities, StaffingTrainingNeeds, Schedule e Riskscontingencies, ditadas pelo próprio DTD de documentação de teste proposto. Vale ressaltar que embora alguns trabalhos defendam a inconsciência (do inglês, obliviouness) como 


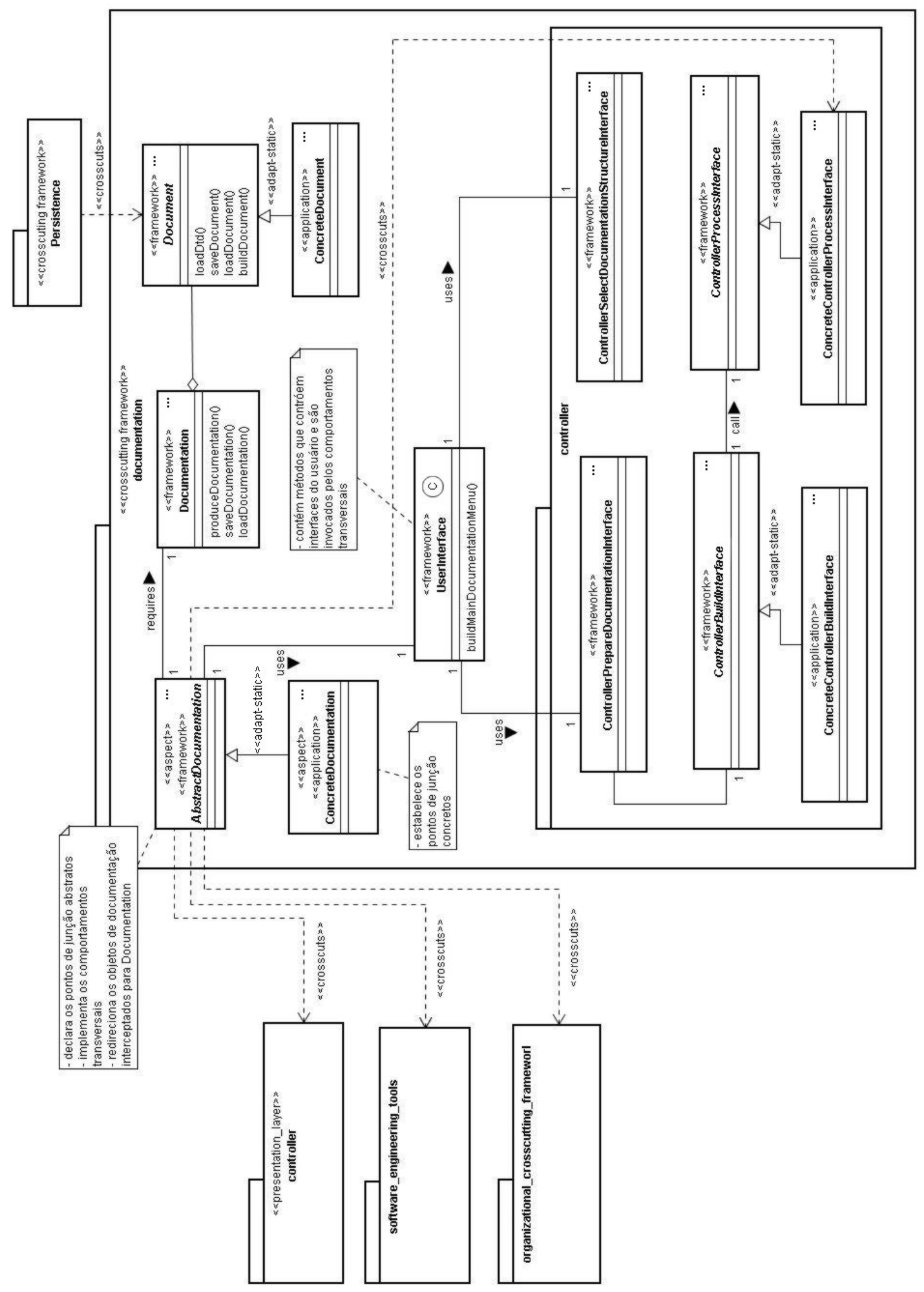

Figura 4.21: Modelo do Framework Transversal de Documentação 
um dos conceitos que pode ou deve ser adotado quando desenvolvendo um sistema orientado a aspectos (Filman \& Friedman, 2000), a preocupação no estabelecimento dos elementos que compõem o código-base contribui para a padronização e reutilização das ferramentas de teste construídas com base nessa arquitetura.

Como trabalhos futuros nessa linha, deve-se utilizar esse framework em outras ferramentas de teste, de modo a refiná-lo identificando outras variabilidades alternativas. Além disso, visando uma framework de documentação mais genérico que atenda às necessidades de documentação de qualquer atividade fundamental de desenvolvimento de software, há a necessidade de utilizá-lo em ferramentas de Engenharia de Software de outros domínio.

\subsubsection{Framework Transversal de Gerência de Configuração para Teste}

A atividade de gerência de configuração é considerada pela ISO/IEC 12207 como uma atividade de apoio e, podendo colaborar para a melhoria da qualidade das atividades fundamentais relacionadas ao desenvolvimento de software. Entende-se por gerência de configuração, um conjunto de atividades desenvolvidas para administrar modificações nos itens de informação (ou itens de configuração de software) ao longo do ciclo de vida do software, evitando assim que haja inconsistência entre os diversos itens. As tarefas que devem ser realizadas pela atividade de gerenciamento de configuração em um AES são: identificação dos itens de configuração, controle de configuração, controle de versão, controle de mudança, relato da situação, avaliação da configuração e gerência da liberação de produtos. Em ferramentas de gerência de configuração, tais como o CVS (Concurrent Versions System) (Free Software Foundation, 2006a), o RCS ${ }^{7}$ (Revision Control System) e a VersionWeb ${ }^{8}$, as funcionalidades comumente encontradas são:

- Cria/remove repositório de itens de configuração;

- Atualiza no repositório cada item de configuração alterado, colocando um item de configuração no repositório (também chamado de check-in);

- Retira um item de configuração do repositório e disponibiliza-o para o desenvolvedor (chamado também de check-out). Essa funcionalidade deve fazer controle de acesso a um item de configuração que foi retirado do repositório;

- Congela/descongela uma configuração;

- Compara configurações mostrando as diferenças entre elas;

\footnotetext{
${ }^{7}$ http: //www. cs.purdue.edu/homes/trinkle/RCS/ (acessado em 03/01/2006)

${ }^{8}$ http: //sourceforge. net/projects/versionweb/ (acessado em 03/01/2006)
} 
- Faz a união (merge) de configurações;

- Cria e gerencia versões e releases; e

- Visualiza configurações, histórico de acesso ao repositório e quem está editando um item de configuração.

A aplicação da gerência de configuração como elemento de melhoria de qualidade da atividade de teste ainda é uma questão em aberto, sendo que o trabalho de Boas (2003) é um dos poucos conduzidos nessa linha. Apesar disso, observa-se que o volume de dados gerados durante a atividade de teste de software torna essa atividade bastante complexa e de difícil controle, caso essa atividade não seja conduzida de forma sistemática e controlada. Assim, uma das maneiras de sistematizar e controlar a atividade de teste de software é a introdução da gerência de configuração. Segundo Boas (2003), a gerência de configuração é relevante no que tange aos benefícios trazidos por ela, pois as dados vindos da atividade de teste e manipulados com o uso da gerência de configuração possibilitam maior eficiência nas atividades de evolução, depuração e manutenção do software, uma vez que a gestão de configuração possibilita garantir a integridade dos dados gerados e, principalmente, a rastreabilidade a todos eles. Nesse contexto, a disponibilização de um mecanismo que possibilite e apóie o desenvolvimento de um módulo de gerência de configuração para a atividade de teste de software é certamente relevante. Assim, nesta seção é apresentada a proposta de um framework transversal de gerência de configuração para a atividade de teste.

Frente à quantidade e diversidade de dados gerados durante a atividade de teste, há a necessidade de estabelecer um critério para selecionar os dados a serem submetidos à gerência de configuração, ou seja, os dados que serão escolhidos para ser um ICT $^{9}$ (Item de Configuração do Teste). Basicamente, segundo Boas (2003), o conjunto de ICT, ou seja, a CT (Configuração de Teste), deve conter os elementos necessários à reexecução de uma dada sessão de teste ou à observação posterior dos resultados do teste, sem com isso causar algum tipo de distúrbio no ambiente de teste atual, seja em termos de retrabalho ou de tempo despendido para recriar o ambiente e reexecutar os testes. Com isso, pode-se supor que o critério básico para a escolha de candidatos a compor a CT é a escolha de informações importantes e/ou aquelas que são custosas de serem geradas novamente. O trabalho de Boas (2003) investiga a aplicação de gestão de configuração na atividade de teste e propõe os seguintes conjuntos de dados para compor a CT:

- plano de teste: deveria conter informações, tais como a identificação do programador/testador, objetivo do teste, identificação do programa testado, funções a serem testadas, critérios de

\footnotetext{
${ }^{9}$ Neste trabalho, o termo ICT (Item de Configuração do Teste) refere-se a um artefato consumido ou produzido no processo de teste de software e que está sob gerência de configuração.
} 
geração e adequação dos casos de teste e de encerramento da atividade de teste, ambiente de teste (versões das ferramentas, versão do sistema operacional, entre outros), conjunto de casos de teste, entre outros, na linha do que é proposto pelo padrão IEEE 829/1998 IEEE Standard for Software Test Documentation (IEEE, 1998a);

- programa em teste: refere-se ao programa que se deseja testar, podendo ser um códigofonte em uma determinada linguagem de programação, ou especificação de programa em uma técnica de especificação, tais como Redes de Petri e Statecharts;

- conjunto de casos de teste: corresponde ao conjunto de entradas e respectivas saídas esperadas utilizadas para executar o programa em teste e os requisitos de teste;

- conjunto de requisitos de teste: caso seja adotado um critério baseado em Fluxo de Dados, os requisitos são as associações. No caso do critério Análise de Mutantes, serão os mutantes. No caso do critério Fluxo de Controle, têm-se os os nós, arcos e caminhos;

- drivers e stubs utilizados: são os programas de apoio ao teste, ou seja, programas que ativam o programa em teste (drivers) e programas que simplesmente respondem a estímulos do programa em teste (stubs);

- informações de execução relativas ao critério de teste utilizado: corresponde às informações de execução como resultados, tempo de execução e falhas encontradas. Caso seja adotado um critério baseado em Fluxo de Dados, serão obtidas as associações cobertas. No caso do critério Análise de Mutantes, serão obtidos os mutantes mortos, os vivos e os equivalentes. Se o critério escolhido for Fluxo de Controle, serão obtidos os nós, arcos ou caminho cobertos e os não cobertos; $\mathrm{e}$

- relatório de teste: contém a identificação do testador, do plano de teste associado, resultados obtidos, problemas encontrados, análise de adequação, validação e data de encerramento do teste; e

- informações de análise dos resultados dos testes: pode ser obtida por meio da inspeção manual, ou automaticamente, com o uso da ferramenta de teste.

O módulo responsável pela atividade de gerência de configuração é resultante da instanciação de um framework transversal de gerência de configuração. Na Figura 4.22 é mostrado o modelo do módulo de gerência de configuração para a atividade de teste de software. De modo geral, esse módulo é composto de: 


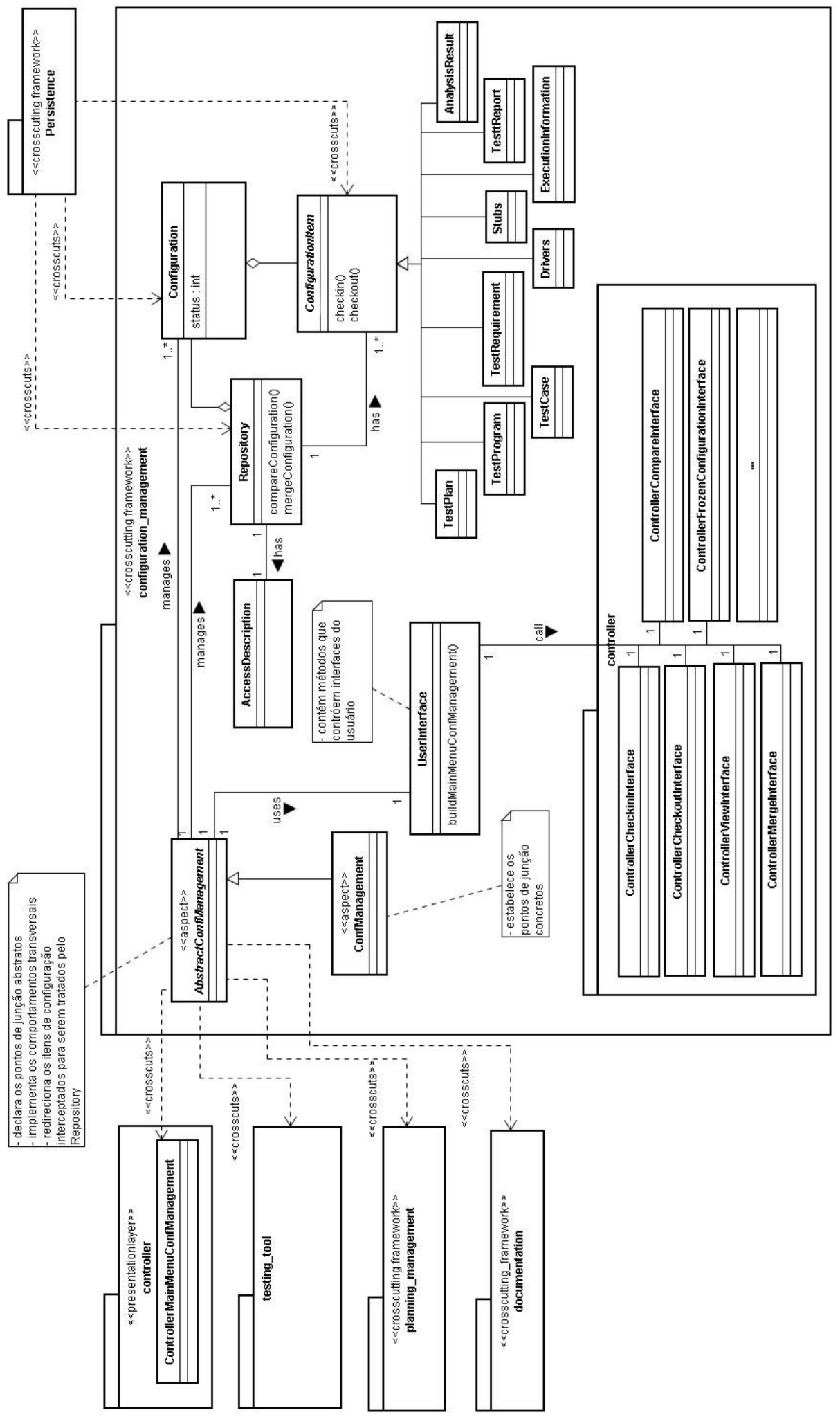

Figura 4.22: Módulo de Gerência de Configuração para Teste 
- aspecto abstrato AbstractConfManagement: esse aspecto abstrato declara conjuntos de junção abstratos, implementa os comportamentos transversais que obtêm os objetos de ICT e envia-os para o responsável por tratá-los. Esse aspecto apresenta comportamento bastante semelhante ao aspecto abstrato AbstractDocumentation do módulo de documentação;

- aspecto concreto ConfManagement: estabelece quais são os pontos de junção, ou seja, concretiza os pontos de junção. Esses pontos de junção estão localizados nos pacotes que contém as funcionalidades básicas da ferramenta de teste (testing_tool), o módulo de planejamento e gerência (planning_management), o módulo de documentação (documentation), bem como o pacote que contém os controladores (controller) da camada de apresentação;

- classe Repository: apresenta todas as funcionalidades referentes ao gerenciamento do repositório de configuração, tais como a criação de um repositório, a comparação e a união de configurações;

- classe Configuration: apresenta todas as funcionalidades referentes ao gerenciamento de uma CT;

- classe AccessDescription: tem a responsabilidade de armazenar o histórico de acesso ao repositório, assim como às configurações e aos itens de configuração;

- classe UserInterface: contém um método responsável por construir a interface do usuário disponibilizando as funcionalidades do módulo de gerência de configuração. Esse método é invocado por um comportamento transversal implementado pelo aspecto abstrato AbstractConfManagement;

- classe ConfigurationItem e e seus subtipos: a classe ConfigurationItem é especializada para todos os subtipos de ICT que compõem a CT. O framework transversal de persistência (pacote Persistence) pode ser utilizado para dar apoio ao armazenamento dos ICT, das CT e do repositório em um dispositivos de armazenamento secundário; e

- pacote controller contido no pacote configuration_management: é responsável pela construção das interfaces do usuário específicas para a entrada de dados referente à gerência de configuração da atividade de teste. Além disso, é responsável também pelo processamento dos dados de entrada feitos pelo usuário por meio das interfaces do usuário. 
Assim como ocorre com outros frameworks, um dos pontos relevantes de se ter frameworks é a disponibilidade de variabilidades alternativas (ou alternativas de composição). No caso do framework transversal de gerência de configuração, a principal variabilidade refere-se aos tipos de itens de configuração selecionado para ser gerenciado. A classe ConfigurationItem deve ser especializada para os subtipos que se desejar como item de configuração, havendo também a necessidade de concretizar os pontos de junção dentro do aspecto ConfManagement de modo a interceptar os objetos adequados.

A Figura 4.23 ilustra um modelo do framework transversal de gerência de configuração. Para a representação desse modelo, são aplicados os mesmos mecanismos que foram utilizados para a representação do framework transversal de documentação apresentado na seção anterior. Vale salientar que esse framework deve ser utilizado em diferentes ferramentas de teste, bem como em outras ferramentas do domínio de Engenharia de Software, para a identificação de variabilidades alternativas, de modo a consolidar um framework mais genérico e que atenda às necessidades de gerência de configuração das diversas atividades fundamentais de desenvolvimento de software.

\subsection{Projeto Arquitetural}

Como resultado da análise conduzida nos passos anteriores e para uma melhor descrição da arquitetura de referência proposta neste capítulo, são apresentados diversos modelos da RefTEST, cada qual cobrindo um aspecto dessa arquitetura. Com relação ao módulo base, derivado do modelo conceitual (já apresentado na Figura 4.11), foi construído um diagrama de pacotes desse módulo, apresentado na Figura 4.24. Cada pacote implementa um conjunto de funcionalidades referentes a um determinado conceito e que foram listadas anteriormente na Tabela 4.6. No tocante ao projeto e implementação, esses pacotes podem ser desenvolvidos como pacotes (conjunto de classes), componentes ou subsistemas. Vale ainda salientar que o desenvolvimento dos aspectos internos desses pacotes independe da abordagem de desenvolvimento, podendo-se utilizar a orientação a objetos ou mesmo a orientação a aspectos, o que for mais pertinente.

Na Figura 4.25 é ilustrado um modelo mais geral da RefTEST. Observa-se que esse modelo é semelhante à RefASSET (apresentado na Figura 3.1 do Capítulo 3), contudo tendo particularidades somente nas atividades fundamentais contidas na camada de aplicação e que correspondem ao módulo base.

Além dos modelos da RefTEST já mostrados, para melhor ilustrar essa arquitetura, é também apresentada sua descrição arquitetural, cobrindo as principais visões arquiteturais: a visão 


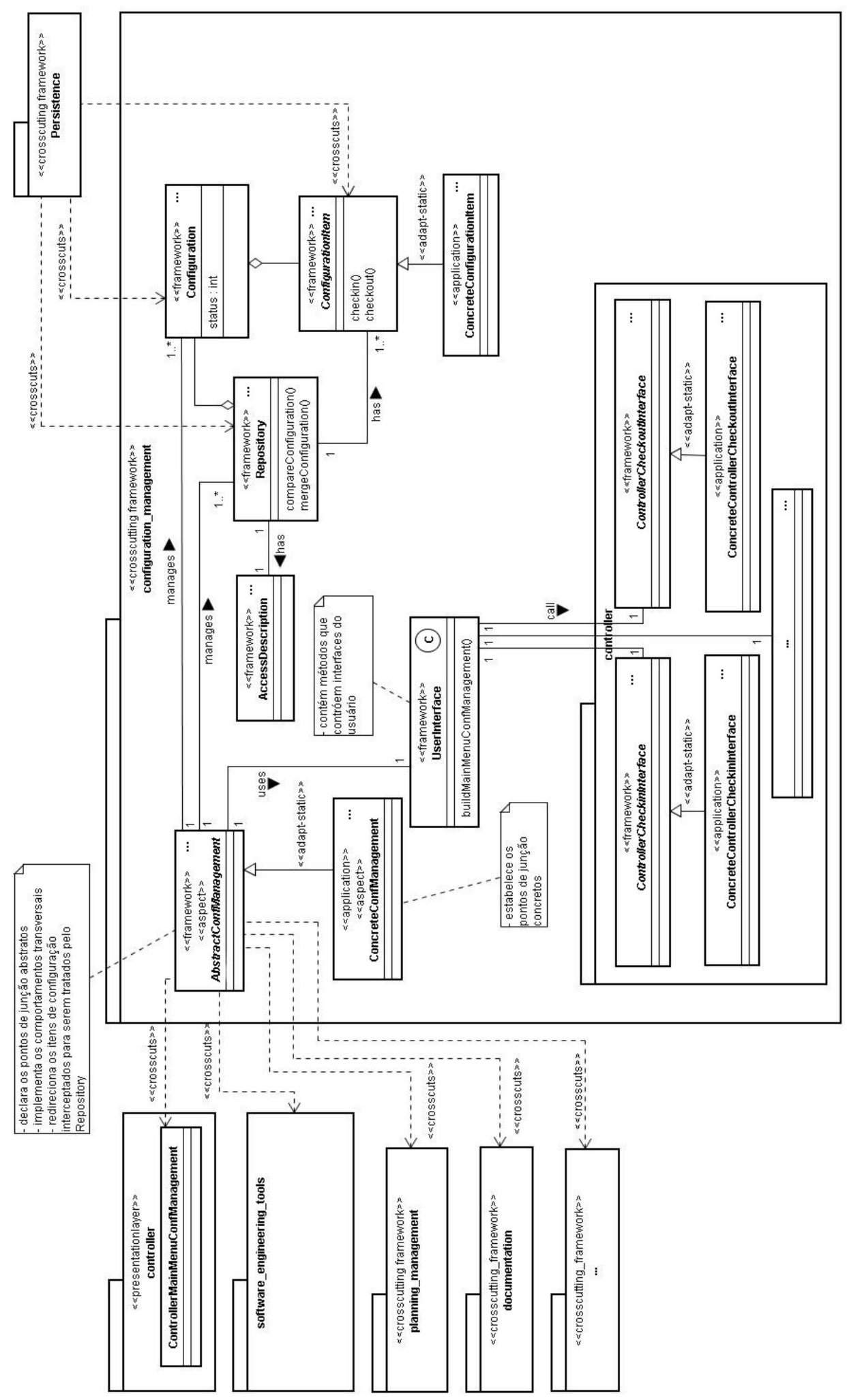

Figura 4.23: Modelo do Framework Transversal de Gerenciamento de Configuração 


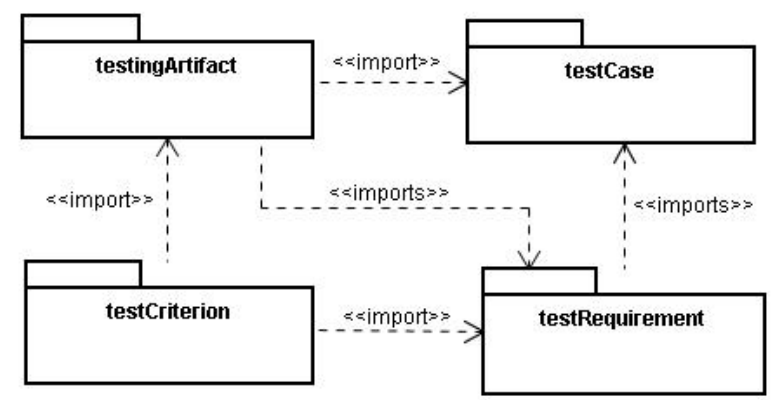

Figura 4.24: Diagrama de Pacotes do Módulo Base

de módulos, a visão em tempo de execução e a visão de implantação. A notação utilizada para representar essas visões é a mesma utilizada para representar a descrição arquitetural da RefASSET e apresentada na Seção 3.4. A visão de implementação e a visão de dados não foram construídas, visto que a RefTEST encontra-se em um nível de abstração alto para a qual esses modelos são inadequados. Em fases mais avançadas do ciclo de vida de desenvolvimento das ferramentas de teste, esses modelos podem ou devem ser construídos.

Na Figura 4.26 é mostrada a visão de módulos da RefTEST, considerando-se os frameworks transversais discutidos neste capítulo. De modo geral, observa-se que comunicação (integração) dos módulos resultantes dos frameworks transversais que implementam atividades de apoio (pacote supportting_crosscutting_frameworks) e atividade organizacionais (pacote organizational_crosscutting_frameworks) é realizada por meio de aspectos que afetam os demais módulos (pacotes testing_tool e controller). Da mesma maneira, os módulos resultantes de frameworks transversais de propósito geral (pacote general_crosscutting_frameworks) afetam os demais módulos.

Na Figura 4.27 é ilustrada a visão em tempo de execução da RefTEST que mostra a interação entre o módulo base (Testing), o módulo de persistência (Persistence), o módulo de segurança (Security) e os módulos de documentação (Documentation), de gerência e planejamento (Planning_Management) e de gerência de configuração (Configuration_Management).

Considerando-se a plataforma Web para a disponibilização de ferramentas de teste de software, na Figura 4.28 é mostrada uma das possíveis visões de implantação de ferramentas de teste desenvolvidas com base na RefTEST. Por meio de máquinas clientes (Internet User e Intranet Admin), o testador utiliza-se de um navegador Web para ter acesso e utilizar as funcionalidades da ferramenta de teste. O servidor de Web (Web server) é responsável por fornecer às máquinas clientes respostas às requisições feitas por meio do navegador. $\mathrm{O}$ servidor 


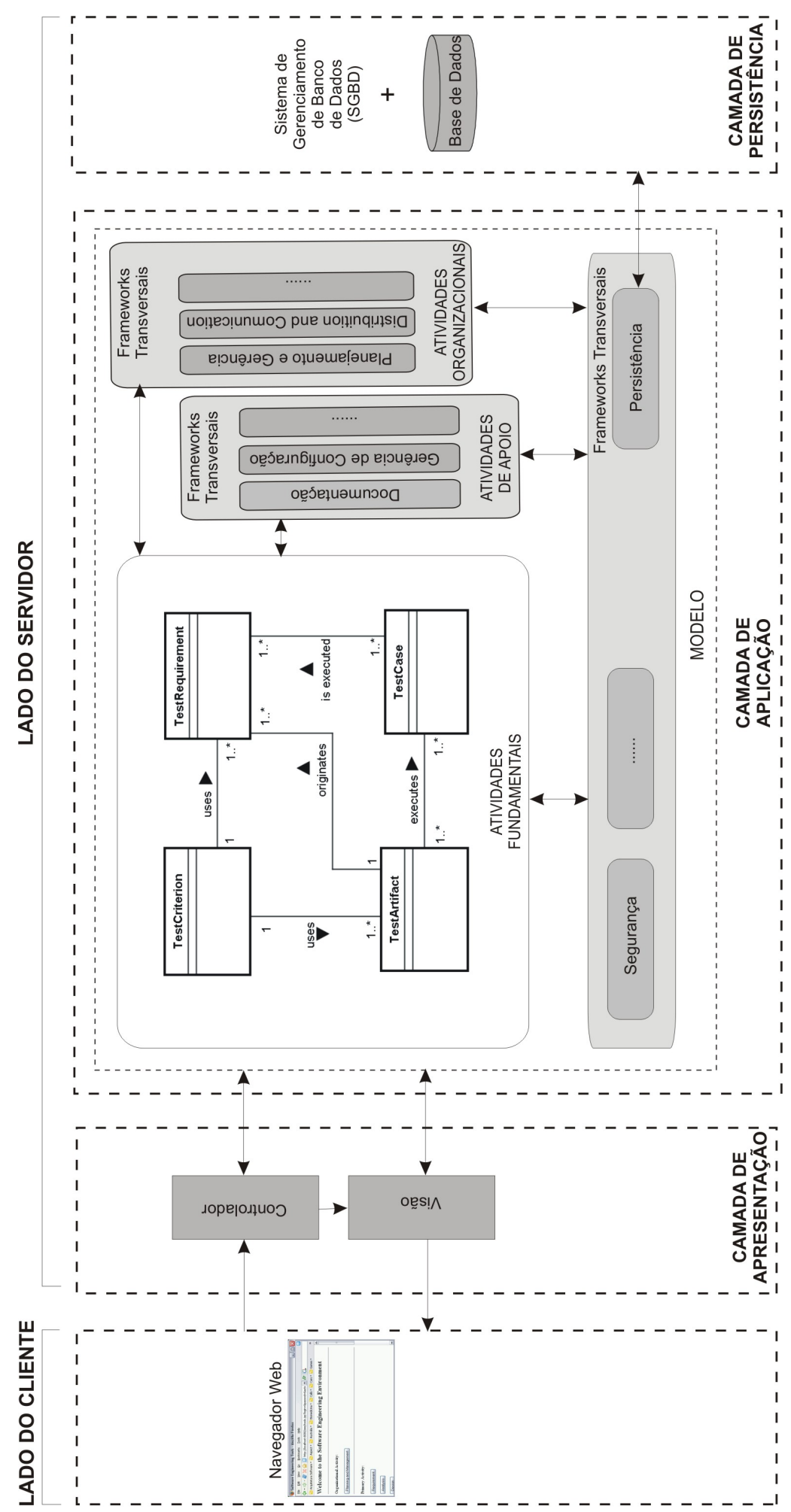

Figura 4.25: Arquitetura Geral Proposta para Ferramentas de Teste de Software 


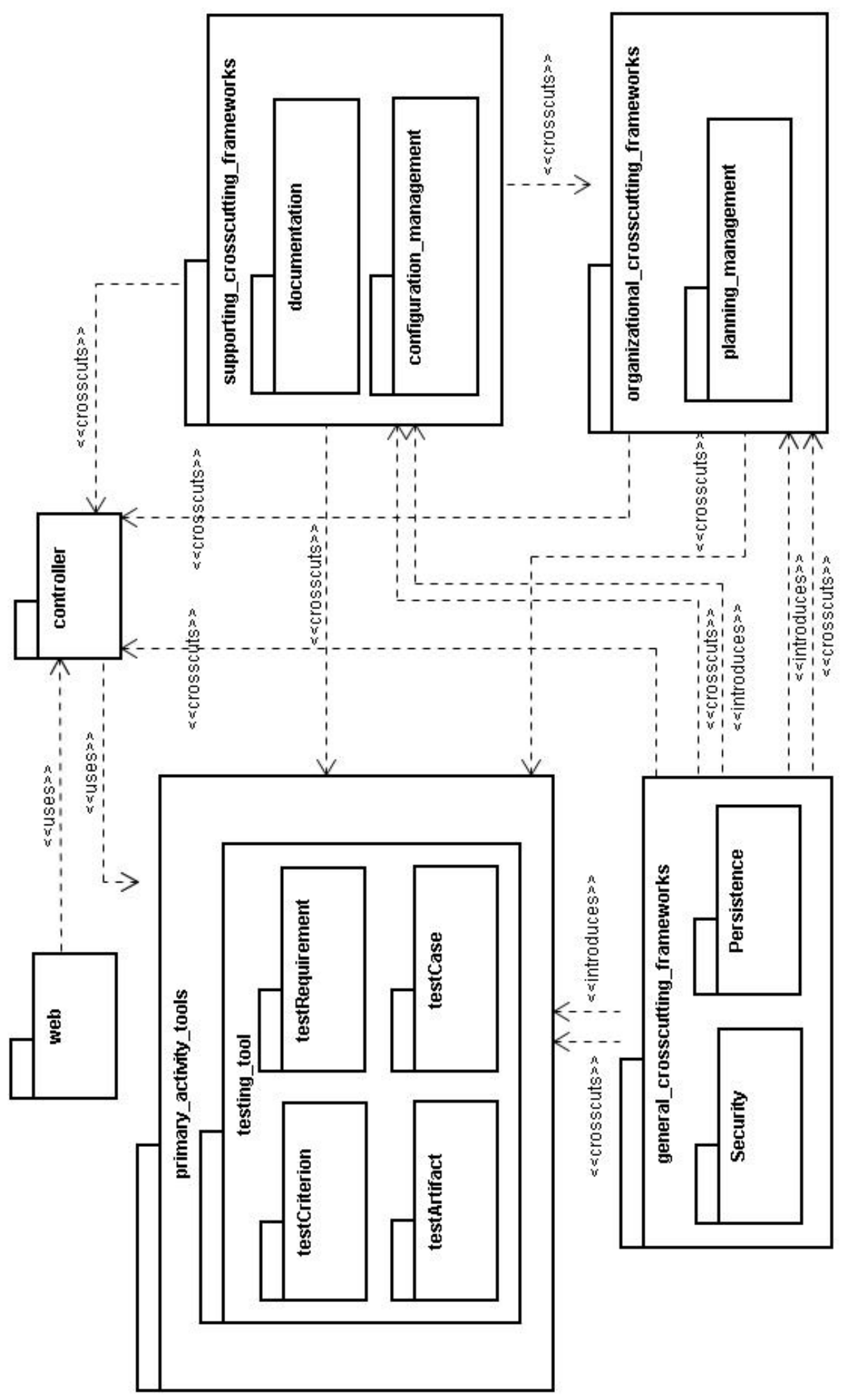

Figura 4.26: Visão de Módulos da RefTEST 


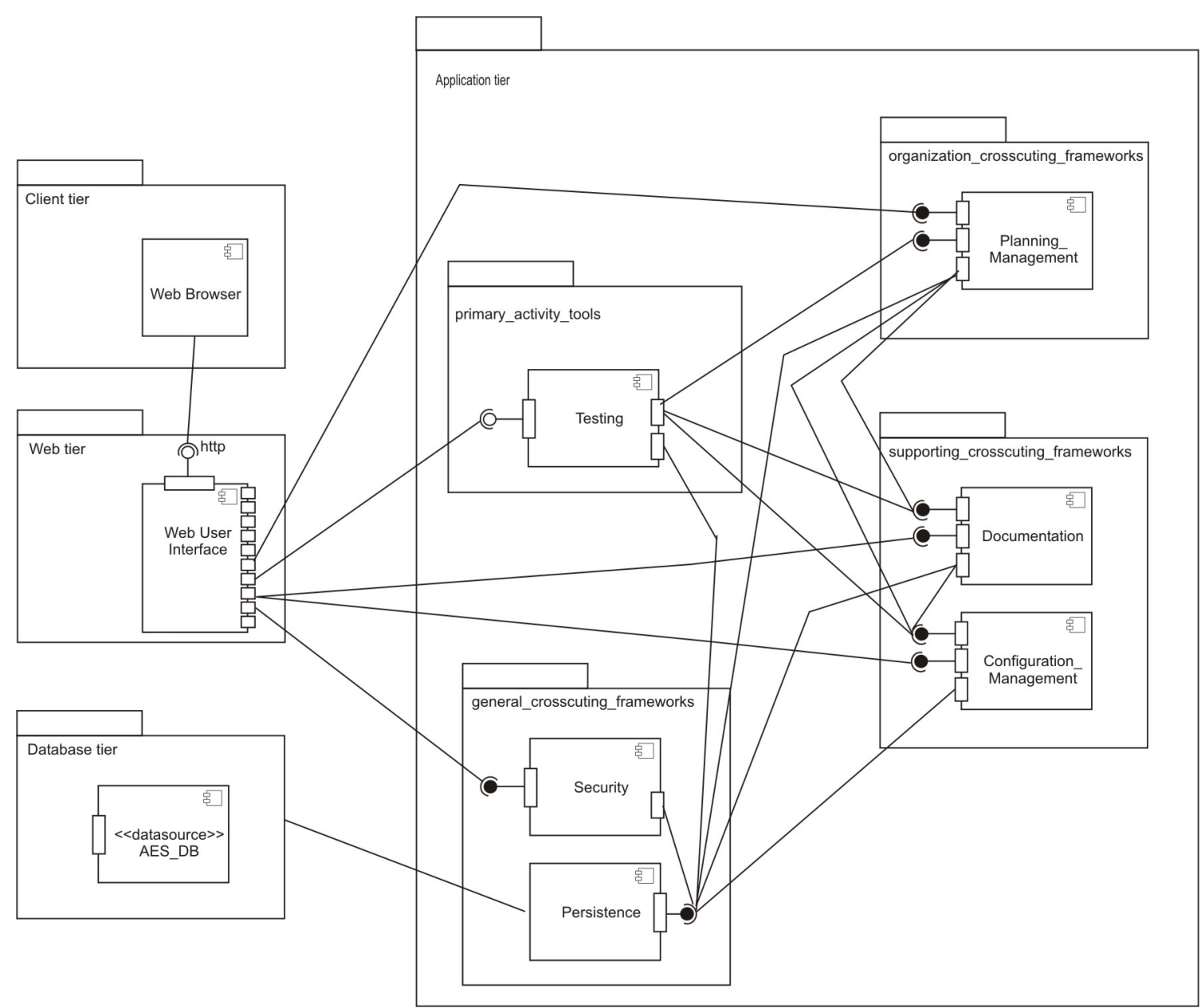

Figura 4.27: Visão em Tempo de Execução da RefTEST

de aplicação (Application server) contém todas as funcionalidades da ferramenta de teste (módulo base e módulos que implementam atividades de apoio, organizacionais e de propósito geral) e é responsável por processar as requisições enviadas pelas máquinas clientes. O servidor de base de dados (Database server) tem a responsabilidade de gerenciar o armazenamento dos dados produzidos e consumidos pela ferramenta de teste.

\subsection{Considerações Finais}

Frente à forte associação da atividade de teste de software, bem como de sua automatização, com a qualidade dos sistemas de software submetidos ao teste, neste capítulo foi apresentada a RefTEST, um mecanismo que apóia o projeto e a implementação de ferramentas de teste de software. A RefTEST é baseada na RefASSET, herdando, portanto, todas as características 


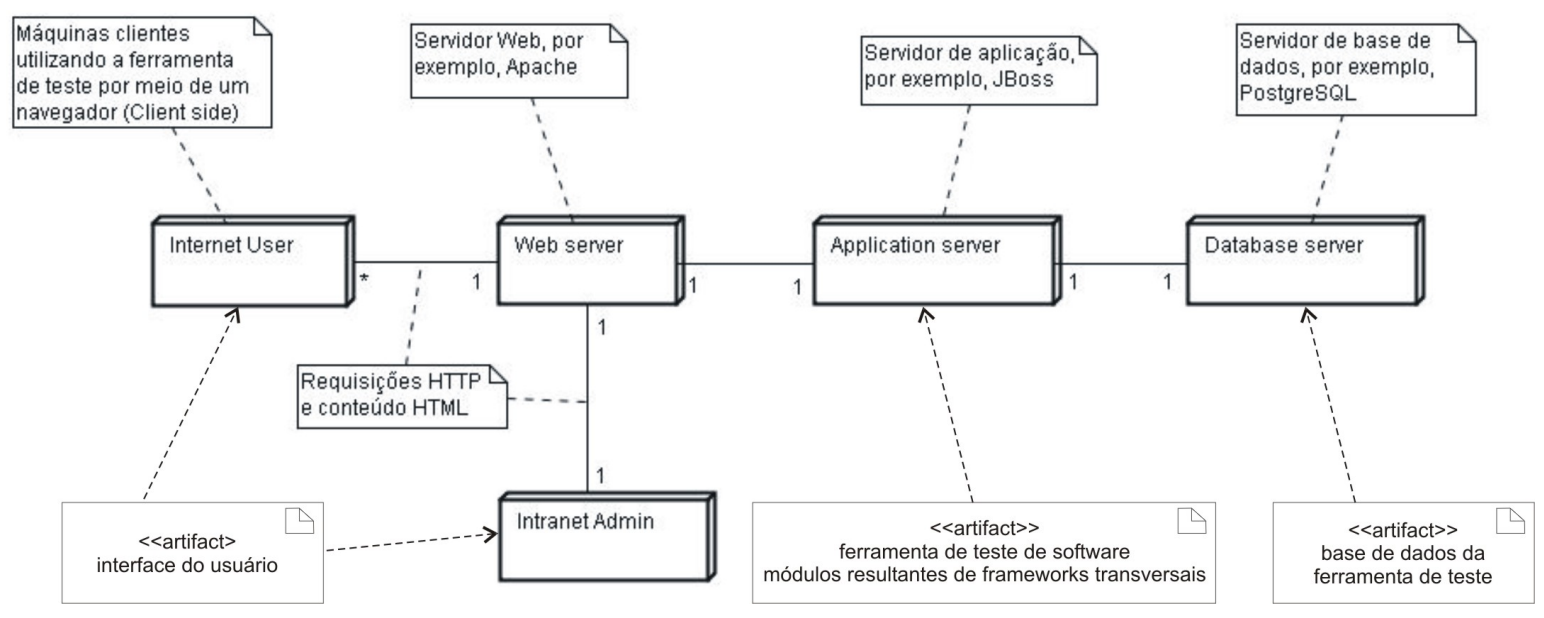

Figura 4.28: Visão de Implantação da RefTEST

dessa arquitetura. Em especial, a RefTEST é uma arquitetura baseada em interesses (aspectos) e que contribui fortemente para o desenvolvimento de ferramentas de teste de forma incremental e evolutiva, uma característica fundamental em se tratando da evolução contínua que a área de Teste de Software inevitavelmente tem sofrido. Salienta-se que a RefTEST é a primeira arquitetura de referência de ferramentas de teste de software detalhada o suficiente para apoiar de fato o desenvolvimento de ferramentas de teste, inclusive considerando a necessidade de evolução e crescimento incremental das ferramentas de teste.

O estabelecimento de uma arquitetura de referência para um domínio específico, nesse caso, para o teste de software, não é uma tarefa trivial. É importante ressaltar que o levantamento de conhecimento do domínio de teste foi essencial para essa tarefa, seja por meio da literatura disponível sobre o domínio, pelo estudo de outras ferramentas de teste, ou mesmo pela experiência no desenvolvimento de ferramentas pelo grupo de pesquisa ao qual a doutoranda faz parte.

Para a implementação dos diversos módulos que compõem uma ferramenta de teste, podese considerar a filosofia de software livre para isso, ou seja, a utilização de partes de códigosfontes de software livre com funcionalidade que sejam adequadas às necessidades da ferramenta de teste. Por exemplo, pode-se utilizar e adequar o código-fonte do $\mathrm{CVS}^{10}$, um sistema livre de gerência de configuração de larga utilização, para implementar o módulo de gerência de configuração nos moldes propostos neste capítulo.

Com relação aos usos da RefTEST, em particular, a utilização para o desenvolvimento de frameworks de ferramentas de teste, bem como na abordagem de linhas de produto, podem

\footnotetext{
${ }^{10} \mathrm{~A}$ versão estável mais atual do CVS (versão 1.11) está implementada na linguagem C. Assim, para ser utilizado no contexto do módulo de gerência de configuração proposto neste trabalho, há a necessidade de adequar esse código para o paradigma de orientação a objetos.
} 
ser consideradas linhas de pesquisa que merecem investigação. Vale ressaltar que ainda há uma carência de trabalhos envolvendo o desenvolvimento de ferramentas de teste e frameworks para o desenvolvimento de ferramentas de teste com base em arquiteturas de referência, provavelmente em virtude da falta de arquiteturas eficazes e adequadas que servissem de base à construção dessas ferramentas.

Com base na experiência adquirida para o estabelecimento da arquitetura de referência para o domínio de teste de software, no próximo capítulo é apresentado um processo preliminar de desenvolvimento de AESs com base na arquitetura de referência baseada em interesses proposta neste trabalho. Esse processo possibilita, inclusive, o estabelecimento de arquiteturas de referências de domínios específicos de Engenharia de Software. 


\begin{tabular}{l|c|}
\hline CAPítulo \\
\hline 5 \\
\hline
\end{tabular}

\section{Processo Baseado em Arquitetura de} Software

\subsection{Considerações Iniciais}

Observa-se que o desenvolvimento de sistemas de software de um dado domínio pode certamente ser facilitado se estiver disponível uma arquitetura de referência adequada àquele domínio, visto que essa arquitetura concentra o conhecimento do domínio, estabelece a estrutura e as restrições e caracteriza as funcionalidades comuns que sistemas de software daquele domínio devem apresentar. Dessa forma, a disponibilização de um processo que auxilie na tarefa de aplicação e uso da arquitetura de referência é relevante. Nessa linha, com base na experiência adquirida na condução do estudo de caso apresentado no capítulo anterior, neste capítulo é proposto um processo preliminar para o desenvolvimento de ambientes e ferramentas de Engenharia de Software com base em arquitetura de referência de AESs baseada em interesses (aspectos).

Neste capítulo é apresentado o ProSA ( Process based on $\underline{\text { Software }} \underline{\text { Architecture for software }}$ engineering environments), um processo que apóia o refinamento da arquitetura de referência de AESs - a RefASSET — para o estabelecimento de arquiteturas de referência de ferramentas 
de Engenharia de Software. Vale salientar que a aplicação repetitiva do ProSA culmina em um processo para o desenvolvimento incremental e evolutivo de AESs. O ProSA pode ser aplicado de forma paralela e independente, resultando no desenvolvimento de ferramentas independentes e, a seguir, integradas por construção em um AES.

De modo geral, esse processo introduz o uso dos termos especialização e instanciação no contexto de arquiteturas de software. Usualmente, esses termos têm sido utilizados na modelagem e na programação orientadas a objetos, bem como no contexto de processos de software quando refinando um processo padrão para ser utilizado em um projeto ou organização específica (Rocha et al., 2001b). Na Seção 5.2 é discutido como e quando esses dois termos são aplicados no refinamento de arquiteturas de software.

Em seguida, na Seção 5.3 são descritos em detalhes os passos do ProSA, que é basicamente composto de: investigação do domínio (Seção 5.3.1), análise arquitetural (Seção 5.3.2), tratamento de frameworks transversais (Seção 5.3.3), projeto arquitetural (Seção 5.3.4), desenvolvimento da ferramenta (Seção 5.3.5) e integração ao AES (Seção 5.3.6).

\subsection{Especialização e Instanciação Arquitetural}

Para o desenvolvimento de ferramentas de Engenharia de Software com base na RefASSET, existe a necessidade de, primeiramente, especializar essa arquitetura para um dado domínio ${ }^{1}$. Estabelece-se então arquiteturas de referência para esse domínio e, em seguida, implementa-se (instancia-se) essa arquitetura como sendo base de um sistema de software. O refinamento da RefASSET dá-se por meio de duas etapas, a saber, a especialização arquitetural e a instanciação arquitetural, ilustradas na Figura 5.1.

A especialização arquitetural possibilita que a RefASSET seja refinada de modo a explicitar detalhes de cada um dos grandes módulos dessa arquitetura, a saber, os módulos fundamentais (ou módulo base), os módulos que automatizam atividades de apoio, os módulos que automatizam atividades organizacionais e os módulos que implementam interesses não específicos do domínio, por exemplo, a persistência. De modo geral, o refinamento do módulo base refere-se à identificação das funcionalidades específicas de ferramentas daquele domínio e a identificação de um conjunto de conceitos relacionados àquelas funcionalidades, bem como os relacionamentos entre esses conceitos. O refinamento dos módulos que automatizam as atividades de apoio e as organizacionais referem-se à instanciação de FTAs (frameworks transversais de apoio) e

\footnotetext{
${ }^{1}$ Domínio refere-se a uma das atividades fundamentais, a saber, gerência de requisitos, análise/projeto, codificação, teste e manutenção.
} 


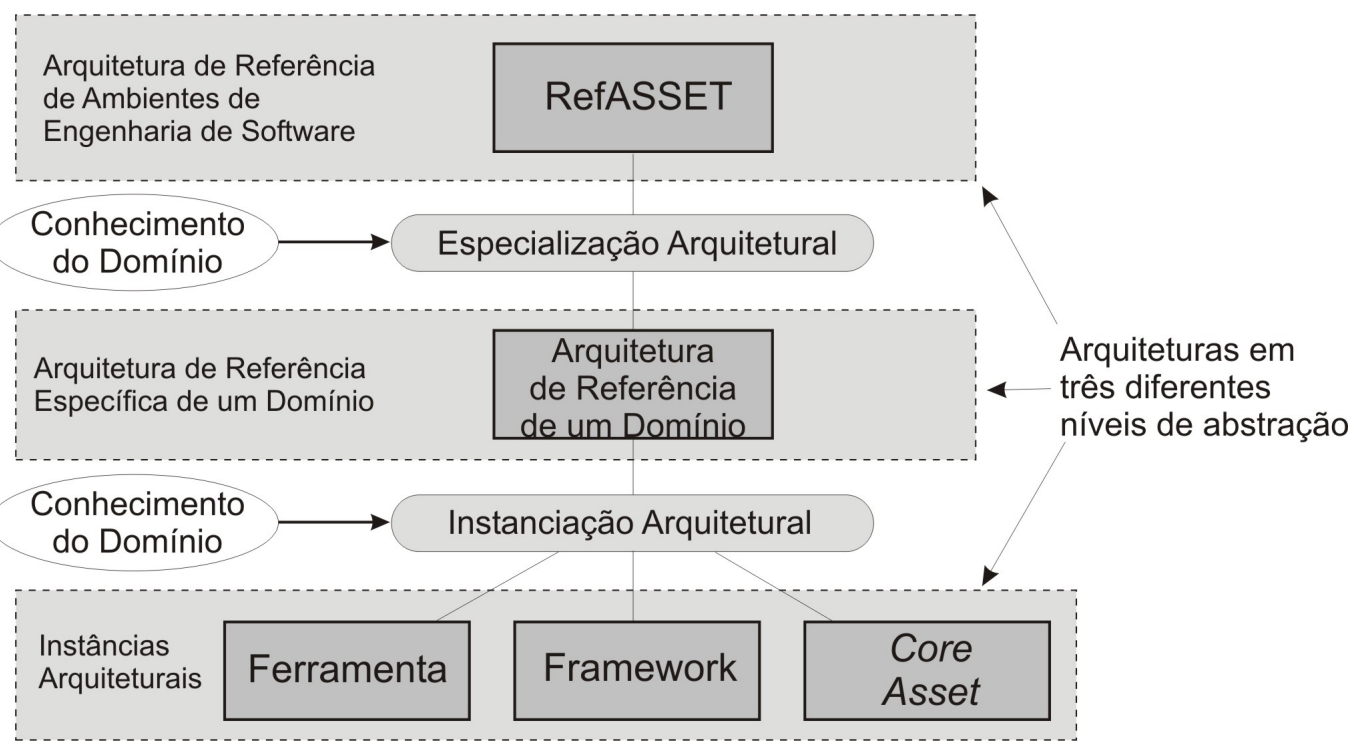

Figura 5.1: Especialização e Instanciação Arquitetural

de FTOs (frameworks transversais organizacionais), respectivamente. Por fim, o refinamento dos módulos de propósito geral refere-se à instanciação de FTPGs (frameworks transversais de propósito geral). Vale ressaltar que a especialização arquitetural pode ser bem sucedida se o arquiteto de software dispuser de um vasto conhecimento do domínio, inclusive experiência na utilização e desenvolvimento de ferramentas daquele domínio. Com isso, uma arquitetura de referência adequada e eficaz para aquele domínio pode ser estabelecida.

Já a instanciação arquitetural refere-se à utilização da arquitetura de referência no que tange ao projeto e à implementação de ferramentas e AESs, obtendo-se assim instâncias arquiteturais. Mais especificamente, refere-se à implementação da arquitetura de referência para o desenvolvimento de uma dada ferramenta ou mesmo, para o desenvolvimento de frameworks para geração de ferramentas daquele domínio. Vale ressaltar que, uma vez que a especialização resulta em arquiteturas de referência contendo conhecimento do domínio, inclusive com o estabelecimento das funcionalidades específicas às ferramentas daquele domínio, o desenvolvimento de frameworks de aplicação para a construção de ferramentas de Engenharia de Software para aquele domínio pode ser facilitada. Observa-se ainda uma carência de trabalhos abordando a construção de frameworks de aplicação com base em arquiteturas de referência, sendo uma linha de pesquisa que requer atenção dos pesquisadores. A instanciação arquitetural refere-se também ao uso da arquitetura de referência para a criação de bases arquiteturais que podem ser utilizadas como core asset em abordagens de desenvolvimento de software baseada em linhas de produto. 
As arquiteturas de software, assim como os modelos e os processos de software, podem apresentar-se em diferentes níveis de abstração, dependendo do nível de detalhamento apresentado pela arquitetura. Observa-se na Figura 5.1 que a RefASSET está em um nível de abstração mais alto, sem que detalhes específicos de um dado domínio estejam explicitados. Em um nível de abstração um pouco mais baixo estão as arquiteturas de referências dos domínios de Engenharia de Software. E, no mais baixo nível de abstração encontram-se as instância arquitetural de uma determinada ferramenta ou de um framework de aplicação. Ver arquiteturas de software em diferentes níveis de abstração é particularmente interessante se deseja-se considerá-las como elementos que podem ser refinados, detalhados, comparados, e mesmo medidos com o intuito de avaliar a sua qualidade.

A seguir, é descrito em mais detalhes um processo que envolve a especialização e a instanciação arquitetural e que dá apoio ao desenvolvimento de ambientes e ferramentas de Engenharia de Software.

\subsection{ProSA ( Process based on Software Architecture)}

ProSA é um processo de desenvolvimento de ambientes e ferramentas de Engenharia de Software tendo como base uma arquitetura de referência para AESs, no caso a RefASSET. Basicamente, esse processo estabelece os passos necessários para realizar o refinamento da RefASSET para uma instância arquitetural, com especial atenção às atividades envolvidas com a especialização arquitetural.

Como mostrado na Figura 5.2, uma das principais características desse processo é a sua iteratividade. Deve-se salientar que a sequiência de passos é flexível, e que o processo pode ser iterado quantas vezes for necessário. Isso possibilita que AESs desenvolvidos por meio desse processo possam acrescentar novos módulos base ou módulos que gerenciam atividades de apoio ou organizacionais, mesmo depois de terem sido liberados para utilização. Ou seja, os AESs podem evoluir continuamente conforme houver a necessidade de novos módulos ou ferramentas.

Além disso, duas ou mais instâncias desse processo podem ocorrer paralelamente e de forma independente, cada qual tratando de uma atividade fundamental. Isso possibilita que diferentes equipes cuidem de módulos distintos de um AESs, diminuindo inclusive o tempo de desenvolvimento do ambiente. Nesse caso, deve-se dar especial atenção à automatização de atividades de apoio e organizacionais, uma vez que os módulos que automatizam essas atividades são comuns a todas as ferramentas do domínio e que fazem parte de um único AES. 
Na Figura 5.2, os passos do ProSA são representados por retângulos com cantos arredondados e as setas indicam a sequiência de ocorrência dos passos. Por exemplo, estando no Passo 1 (Investigação do Domínio) pode-se ir para o Passo 2 (Análise Arquitetural); no entanto, estando no Passo 5 (Desenvolvimento da Ferramenta), pode-se ir tanto para o Passo 3 (Tratamentos de Frameworks Transversais) quanto para o Passo 6 (Integração do AES). O Passo 1 (Investigação do Domínio) é o primeiro que deve ocorrer.

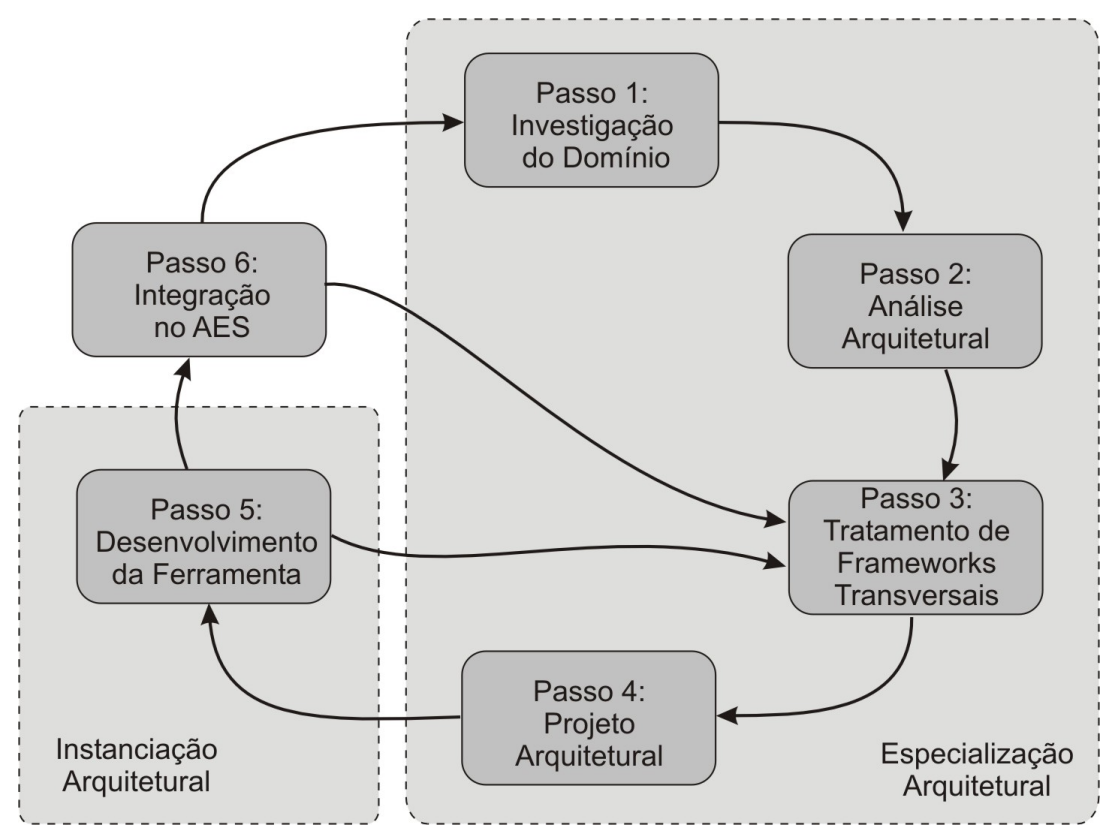

Figura 5.2: Visão Geral do ProSA

Para a sistematização da especialização e da instanciação arquitetural, o ProSA é dividido em seis passos, como mostrado na Figura 5.2, sendo que os quatro primeiros (Passos 1, 2, 3 e 4) correspondem à especialização arquitetural, o quinto passo (Passo 5) refere-se à instanciação arquitetural e o último passo (Passo 6) trata a integração da ferramenta ao AES.

O ProSA é mostrado em mais detalhes na Figura 5.3, no qual são indicados também os artefatos produzidos e consumidos em cada passo do processo. De modo geral, os Passos 1 e 2 referem-se ao refinamento do módulo base da arquitetura de referência, ou seja, concentra-se nas funcionalidades específicas das ferramentas do domínio. O Passo 3 refere-se ao tratamento dos módulos responsáveis pela automatização das atividades de apoio e organizacionais, bem como aquelas de propósito geral. Já o Passo 4 concentra-se no desenvolvimento do projeto arquitetural, mais especificamente, o estabelecimento da descrição arquitetural. O Passo 5 referese ao projeto e a implementação propriamente dita das ferramentas e, no Passo 6 é realizada a integração das ferramentas ao AES em desenvolvimento. Nas subseções a seguir, é descrito em detalhes cada um desses passos. 


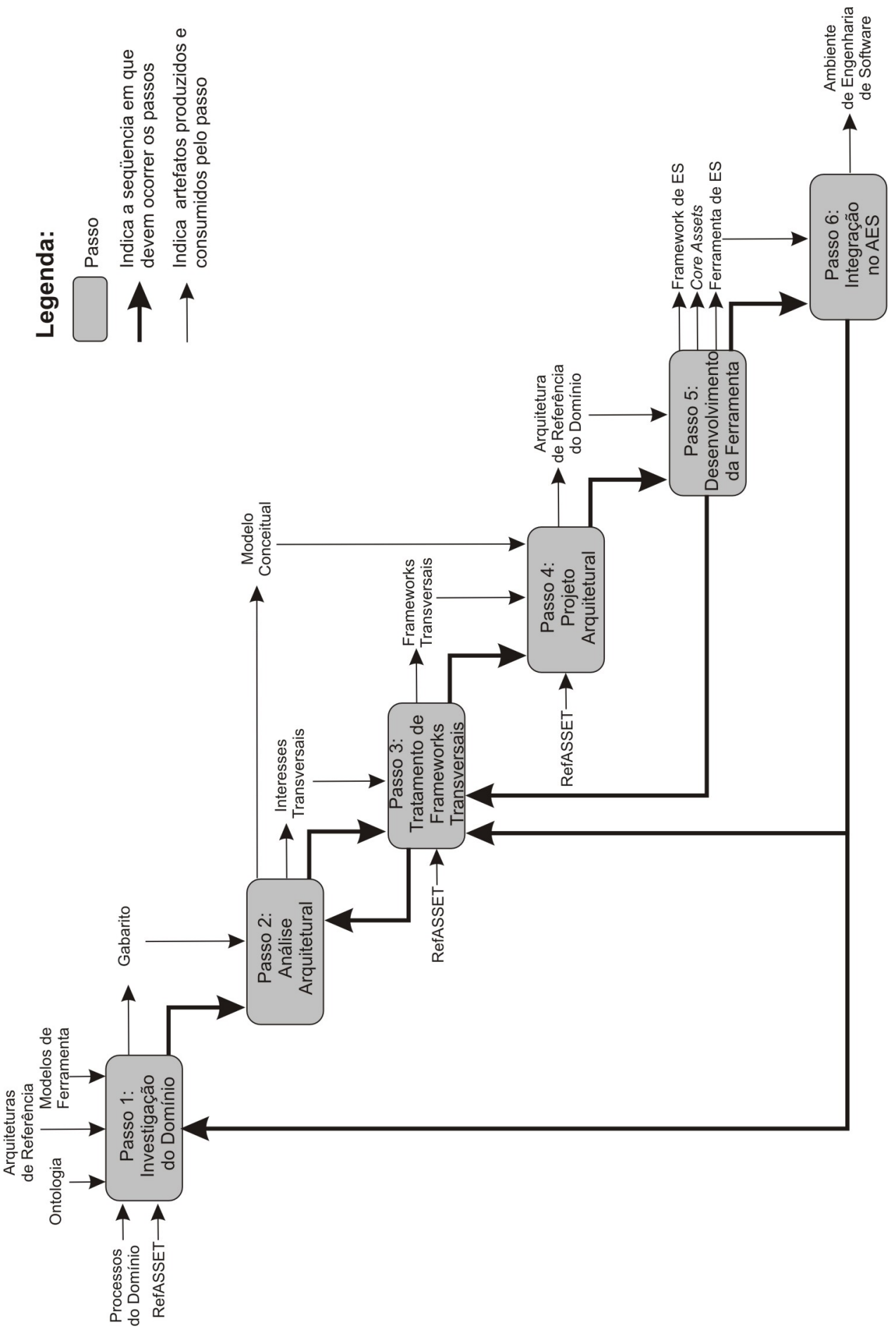

Figura 5.3: Visão Detalhada do ProSA

\subsubsection{Passo 1: Investigação do Domínio}

Esse é o primeiro passo da especialização arquitetural e, em linhas gerais, refere-se ao levantamento de conhecimento do domínio para o qual está sendo criada a arquitetura de referência. 
Para a realização desse passo, é requerido do arquiteto de software profundo conhecimento do domínio. Vale ressaltar que quanto maior o conhecimento do domínio, mais adequada e eficaz poderá ser a arquitetura construída e maiores as chances de sucesso na construção de ferramentas com base nessa arquitetura.

Basicamente, a Investigação do Domínio é composta de três passos: Identificação das Fontes do Domínio (Passo 1.1), Identificação das Funcionalidades (Passo 1.2) e Identificação dos Conceitos do Domínio (Passo 1.3), conforme mostra a Figura 5.4.

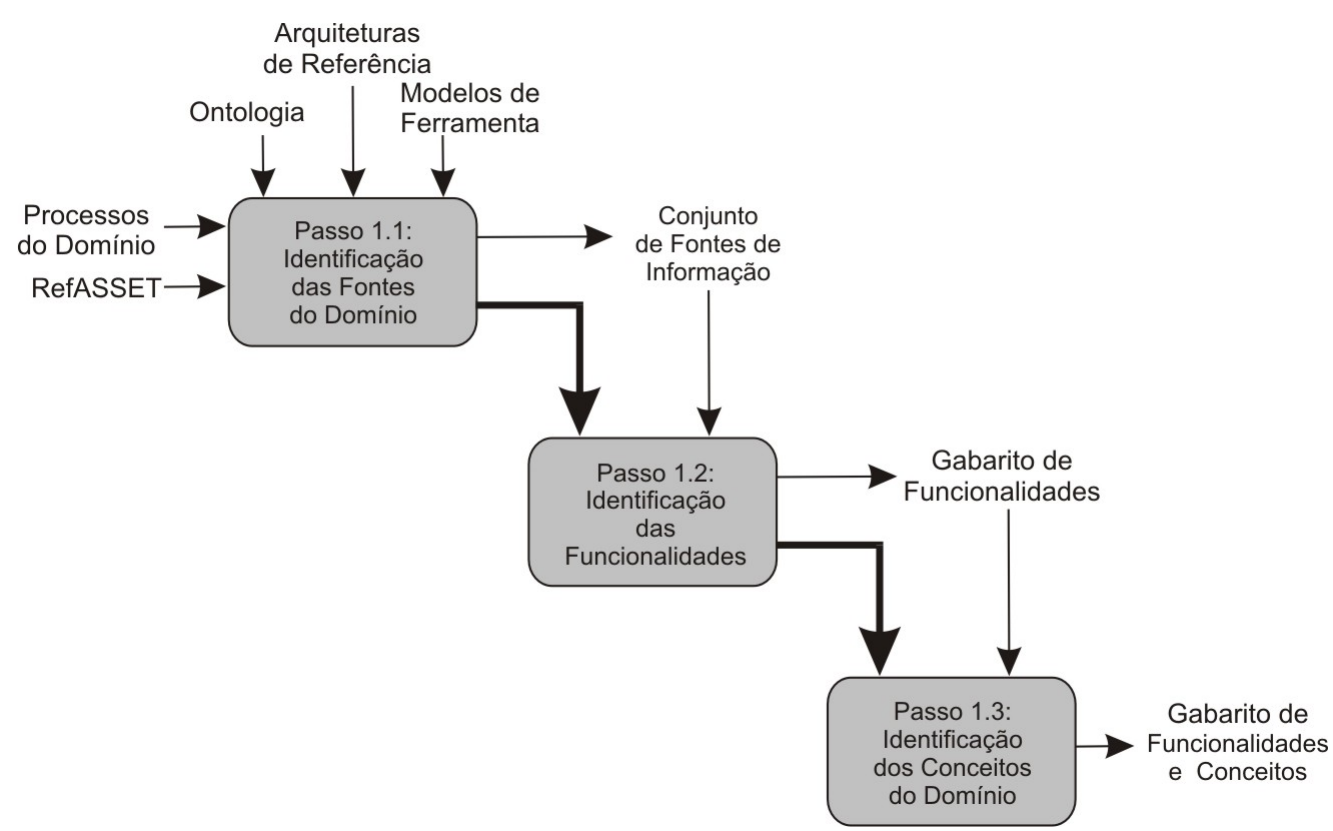

Figura 5.4: Refinamento do Passo 1 do ProSA

No Passo 1.1, diversos mecanismos podem ser utilizados como fonte de informação para formar o corpo de conhecimento do domínio. Um deles é o estudo de ferramentas do domínio, tanto do ponto de vista de utilização quando em termos de sua estrutura interna. O estudo do ponto de vista de utilização é mais fácil, uma vez que, muitas vezes, essas ferramentas são disponibilizadas para avaliação - como shareware, por exemplo - pelas organizações que as produzem, sejam essas organizações empresas ou mesmo universidades. No entanto, o estudo da estrutura interna dessas ferramentas já não é tão comum, uma vez que comumente não se costuma disponibilizar o código-fonte, a não ser que a ferramenta seja licenciada como software livre. Uma outra fonte de informação é a própria literatura do domínio que comumente descreve as ferramentas, suas arquiteturas e estruturas internas.

Além disso, a investigação e estudo de arquiteturas de referência do domínio são relevantes, uma vez que tratam-se de esforços já despendidos nessa linha, apesar de não ser ainda comum arquiteturas de referência para os domínios de Engenharia de Software. Por exemplo, 
para o domínio de teste de software, uma das únicas arquiteturas de referência já estabelecidas é o Eickelmann \& Richardson (1996).

Um outro mecanismo que possibilita entender a dinâmica associadas às tarefas de uma atividade fundamental de Engenharia de Software é a investigação de processos do domínio. Esses processos podem descrever a sequiência de tarefas, bem como os artefatos consumidos e gerados por essas tarefas. Investigar esse mecanismo é relevante, visto que as ferramentas do domínio precisam automatizar esses processos.

Atualmente, ontologias estão sendo utilizadas na área de Engenharia de Software com o intuito de armazenar conhecimento dessa área, a exemplo do que já ocorre em outras áreas. Como exemplo, pode-se citar a ontologia de processo de software (Falbo, 1998). Isso não é diferente para as atividades fundamentais de Engenharia de Software. Têm-se o trabalho de Huo et al. (2003) e de Barbosa et al. (2006), que estabelecem ontologias para o domínio de teste de software. Dessa forma, a investigação de ontologias do domínio e seu uso com o intuito de levantar conhecimento do domínio deve ser considerado.

Nesse passo, pode-se também aplicar conceitos de gerência de conhecimento (do inglês, knowledge management) (Nonaka \& Takeushi, 1997), bem como ferramentas de software associadas como mecanismos para levantar conhecimento do domínio. Basicamente, a gerência de conhecimento tem por objetivo transformar o conhecimento tácito dos especialistas, pesquisadores, desenvolvedores do domínio, entre outros, em conhecimento explícito.

Tendo-se o conjunto de fontes de informação, no Passo 1.2, deve-se dar atenção à identificação das funcionalidades (requisitos) das ferramentas do domínio. Como ilustrado no mapeamento FI-FE-C (Funcionalidade Identificada - Funcionalidade Específica - Conceito) da Figura 5.5, tendo-se as funcionalidades identificadas, deve-se fazer uma análise minuciosa para identificação das funcionalidades específicas do domínio. Por exemplo, no domínio de análise/projeto, a funcionalidade "Construir modelo de análise" é uma funcionalidade específica, enquanto que a funcionalidade "Cadastrar analistas no sistema" não é específica e sim, uma funcionalidade do módulo de gerência e planejamento, portanto uma funcionalidade que deve ser tratada no contexto de um interesse transversal organizacional.

Para registrar as funcionalidades específicas das ferramentas, é sugerido o uso do gabarito ilustrado na Tabela 5.1. Na primeira coluna anota-se a descrição da funcionalidade específica e na segunda coluna, a fonte de informação, ou seja, o mecanismo por meio do qual foi identificado aquela funcionalidade. Isso facilita a rastreabilidade das funcionalidades, caso essa informação seja necessária posteriormente. 


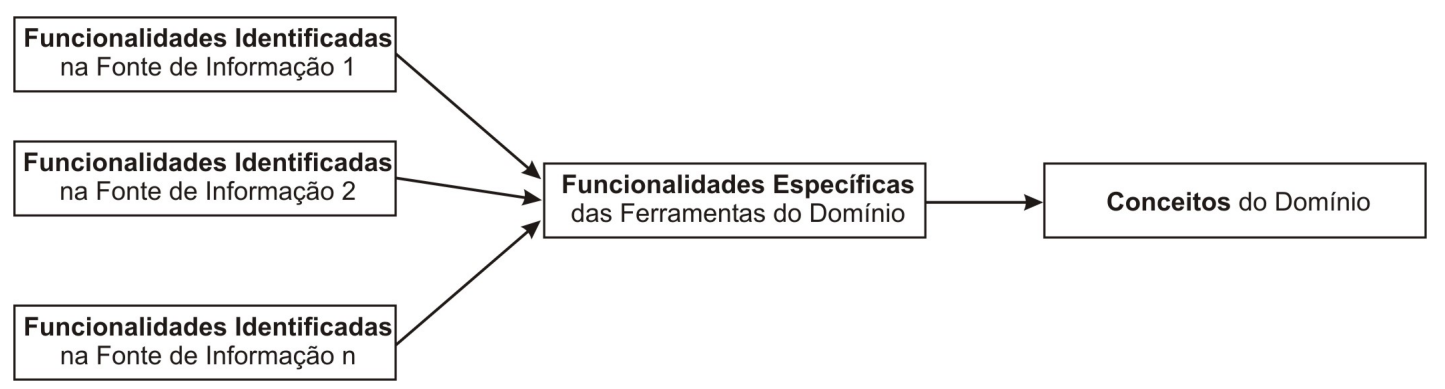

Figura 5.5: Mapeamento FI-FE-C no ProSA

Tabela 5.1: Gabarito para Anotação das Funcionalidades Específicas e dos Conceitos de um Dado Domínio

\begin{tabular}{|l|l|l|}
\hline Funcionalidade Específicas & Fonte & Conceito \\
\hline \hline & & \\
\hline & & \\
\hline & & \\
\hline
\end{tabular}

Nesse passo (Passo 1.2), as funcionalidades podem também ser descritas considerandose, por exemplo, as práticas recomendadas pelo padrão IEEE 830-1998 (IEEE, 1998b) para especificação de requisitos do software.

Em seguida, no Passo 1.3, são analisadas as funcionalidades específicas anotadas no gabarito e identificados os conceitos do domínio para o qual está relacionada cada uma das funcionalidades. Por exemplo, considerando-se novamente o domínio de análise/projeto, a funcionalidade "Construir modelo de análise" pode ser relacionada ao conceito "modelo de análise", um artefato produzido por ferramentas desse domínio e, provavelmente, um conceito relevante. Os conceitos identificados devem ser anotados na terceira coluna do gabarito.

Resumidamente, a partir das funcionalidades identificadas, são estabelecidas as funcionalidades específicas do núcleo das ferramentas do domínio em questão e, em seguida, estabelecemse os conceitos do domínio relacionados ao núcleo das ferramentas.

\subsubsection{Passo 2: Análise Arquitetural}

O segundo passo do ProSA, denominado Análise Arquitetural, refere-se basicamente à construção do modelo conceitual e a identificação dos elementos persistentes para aquele domínio. 
Como ilustrado na Figura 5.6, a Análise Arquitetural é composta de dois passos. Baseado nos conceitos identificados no passo anterior, no Passo 2.1 é construído um modelo conceitual ${ }^{2}$, no qual aparecem os conceitos identificados e o relacionamento entre esses conceitos. Diversas técnicas podem ser utilizadas para isso, desde o diagrama de estrutura estática da UML (Object Management Group, 2005), na linha do que é feito em (Larman, 2000), a mapas conceituais. Mapas conceituais representam os conceitos referentes a um domínio de conhecimento utilizando estruturas hierárquicas ou grafos orientados (Moreira \& Buchweitz, 1987; Novak, 1990), nos quais os nós contêm o nome de um conceito e os arcos entre os conceitos indicam o relacionamento existente entre os conceitos. Mapas conceituais têm sido empregados em diversas atividades associadas ao ensino e treinamento, na linha do trabalho de Barbosa (2004). Pode-se identificar ferramentas de apoio à construção de mapas conceituais. Como exemplos, pode-se citar a WebMap ${ }^{3}$, a Inspiration ${ }^{4}$ e a CMap $^{5}$.

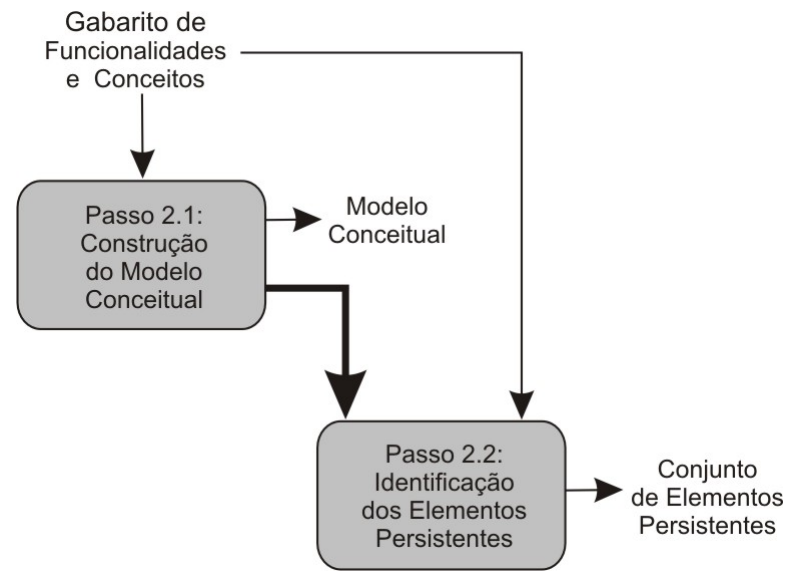

Figura 5.6: Refinamento do Passo 2 do ProSA

No caso de utilizar a UML para construir o modelo conceitual, diversas ferramentas que automatizam a construção desses modelos podem ser utilizadas. Ferramentas CASE (Computer Aided Software Engineering) para modelagem orientada a objetos, tais como a IBM Rational

\footnotetext{
${ }^{2}$ Um modelo conceitual é a representação dos conceitos de um dado domínio (Fowler, 1996), podendo conter conceitos, associações entre conceitos e atributos de conceitos (Larman, 2000).

${ }^{3}$ http://ksi.cpsc.ucalgary.ca/articles/WWW/WWW4WM/WWW4WM.html (acessado em 28/12/2005)

${ }^{4}$ http: / / www.ettc.net/techfellow/inspir.htm(acessado em 28/12/2005)

${ }^{5}$ http: / / cmap.ihmc.us / (acessado em 28/12/2005)
} 
Software Modeler ${ }^{6}$, o Jude ${ }^{7}$, o Poseidon ${ }^{8}$ e ferramentas livres, tais como o $\operatorname{ArgoUML}^{9}$, podem ser utilizadas.

Não há um critério a ser seguido para decidir quais elementos devem ser persistidos em ferramentas de Engenharia de Software, contudo, a grande maioria das ferramentas de Engenharia de Software requer que artefatos produzidos e consumidos sejam persistidos, principalmente aqueles elementos que são mais demorados ou trabalhosos de serem obtidos, ou mesmo aqueles que serão consumidos por outras ferramentas. Desse modo, o ProSA propõe no Passo 2.2 que se investiguem os conceitos que possuem características de persistência. Por exemplo, no domínio de análise/projeto, o conceito "modelo de análise" apresenta característica de persistência, visto que é um artefato de software que, muitas vezes, é consumido por outras ferramentas e trabalhoso de ser obtido. O resultado desse último passo influencia na facilidade de desenvolvimento do modelo da base de dados de ferramentas daquele domínio.

\subsubsection{Passo 3: Tratamento de Frameworks Transversais}

Basicamente, o passo de Tratamento de Frameworks Transversais é composto de três passos, como ilustrado na Figura 5.7, todos relacionados à investigação e instanciação de frameworks transversais que possam apoiar a implementação de interesses transversais, tanto aqueles relacionadas às atividades de apoio e organizacionais quanto aqueles relacionados aos interesses não-funcionais (não específicos de Engenharia de Software), tais como a segurança e a persistência. Esse passo é realizado se é desejado que a ferramenta disponibilize a automatização de atividades de apoio ou organizacionais. Quanto ao interesses não-funcionais, o uso de frameworks transversais para automatizá-los pode ser vantajoso.

Vale ressaltar novamente que há uma carência de frameworks transversais que implementam atividades de apoio e organizacionais do domínio de Engenharia de Software. Dessa forma, nesse passo, quando não se identifica um framework transversal para uma atividade que se deseja automatizar, há a necessidade de desenvolver um módulo que dê apoio à automatização dessa atividade. É interessante a construção desse módulo visando transformá-lo em um framework transversal, contribuindo, dessa forma, para reusar os esforços de desenvolvimento desse módulo, buscando sanar a carência de frameworks para esse contexto. Essa área de pesquisa ainda está emergindo e, portanto, evidenciando a necessidade de mais esforços.

\footnotetext{
${ }^{6}$ http://www-306.ibm.com/software/awdtools/modeler/swmodeler/ (acessado em 28/12/2005)

${ }^{7}$ http: / / www.esm.jp/ jude-web/index.html (acessado em 28/12/2005)

${ }^{8}$ http: / / gentleware.com/index.php (acessado em 28/12/2005)

${ }^{9}$ http: / / argouml.tigris.org/ (acessado em 28/12/2005)
} 


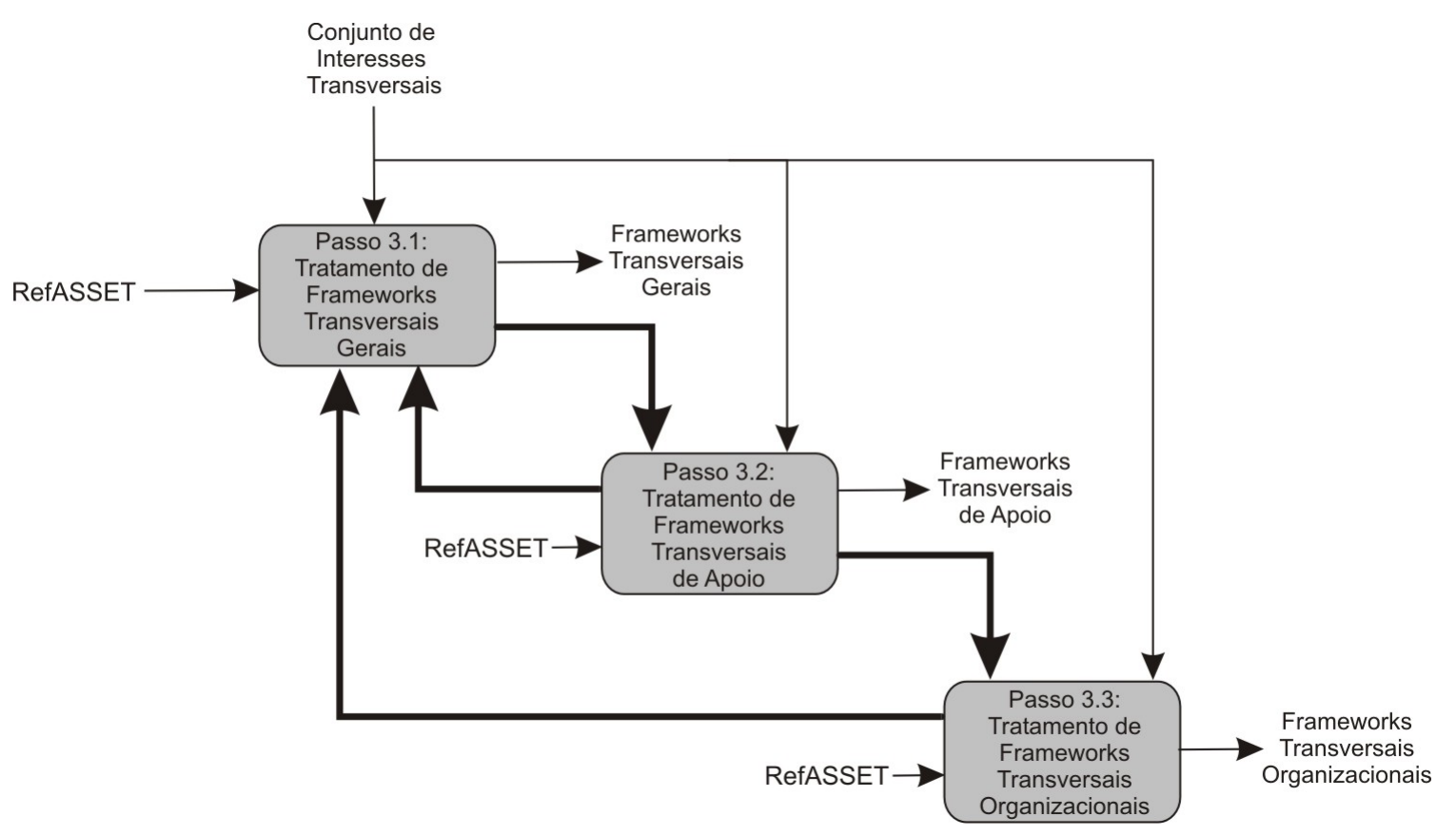

Figura 5.7: Refinamento do Passo 3 do ProSA

Primeiramente, no Passo 3.1 referente ao Tratamento de Frameworks Transversais Gerais são investigados frameworks que implementam interesses não-funcionais. Na literatura disponível sobre framework, são poucos ainda os trabalhos nessa linha, podendo-se citar o trabalho de Camargo \& Masiero (2005) que propõe frameworks para segurança e persistência. O Passo 3.2 (Tratamento de Frameworks Transversais de Apoio) investiga frameworks transversais que implementam atividades de apoio e, no Passo 3.3 (Tratamento de Frameworks Transversais Organizacionais), deve-se investigar frameworks que implementam atividades organizacionais. Essa investigação pode ser feita por meio da literatura disponível sobre framework e sobre desenvolvimento orientado a aspectos, ou mesmo, por meio dos repositórios de softwares livres, tais como o SourceForge ${ }^{10}$, o FreshMeat ${ }^{11}$ e o Código Livre ${ }^{12}$, apesar de atualmente não haver boas perspectivas de encontrar frameworks transversais que sejam livres.

Identificados os frameworks, devem ser investigados os mecanismos utilizados para comunicação com o código-base, bem como realizar a instanciação do frameworks para o domínio em questão. Por fim, uma vez estabelecido os frameworks transversais, para representá-los pode-se utilizar técnicas para documentar frameworks e aspectos. Dentre elas, pode-se citar as extensões propostos por Fontoura et al. (2000) para a UML.

\footnotetext{
${ }^{10}$ http: / / sourceforge. net/ (acessado em 15/03/2006)

${ }^{11}$ http: // freshmeat. net/ (acessado em 15/03/2006)

12 http: / / www. codigolivre.com.br/ (acessado em 15/03/2006)
} 


\subsubsection{Passo 4: Projeto Arquitetural}

Nesse passo, são construídos modelos da arquitetura de referência, buscando inclusive utilizarse de diferentes técnicas de modelagem para representar as diferentes visões em que podem ser apresentadas uma arquitetura. Basicamente, esse passo é dividido em: Construção dos Modelos Arquiteturais Gerais (Passo 4.1) e Construção da Descrição Arquitetural (Passo 4.2).

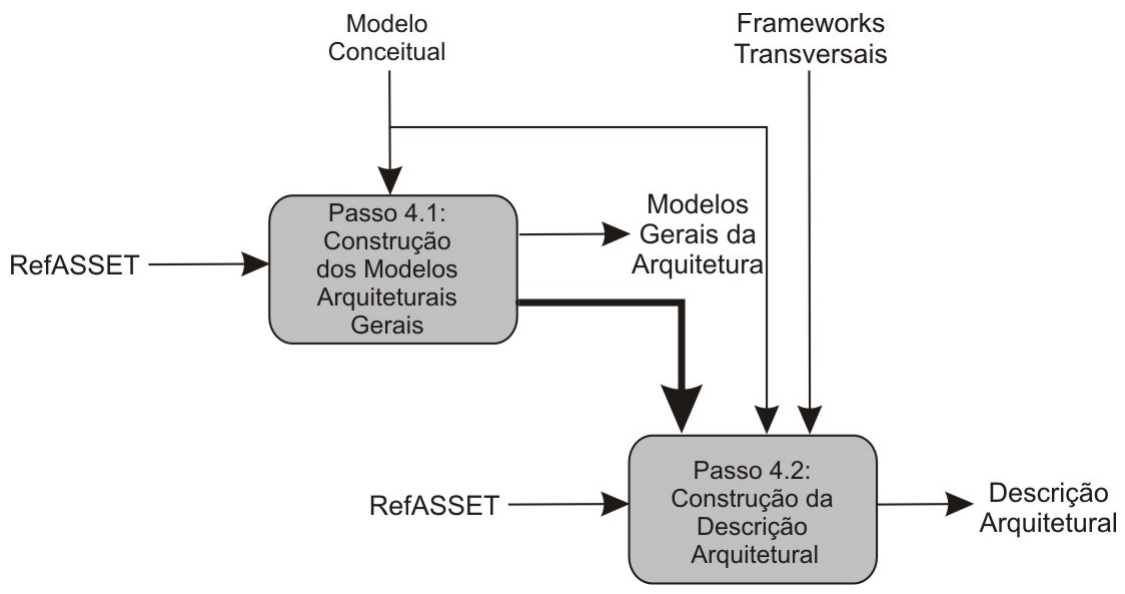

Figura 5.8: Refinamento do Passo 4 do ProSA

Com base na RefASSET, no Passo 4.1 são construídos os modelos gerais da arquitetura de referência, dando-se especial atenção ao módulo base de ferramentas do domínio em questão e construindo-se modelos que representem esse módulo. Na prática, constrói-se, por exemplo, o diagrama de pacotes do módulo base. No que tange ao projeto e implementação, esses pacotes podem ser desenvolvidos como pacotes (conjunto de classes), componentes ou subsistemas. Vale salientar que o desenvolvimento dos aspectos internos desses pacotes independe da abordagem de desenvolvimento, podendo-se utilizar, por exemplo, a orientação a objetos ou mesmo a orientação a aspectos, o que for mais adequado.

Já no Passo 4.2 é construída a descrição arquitetural, cobrindo as principais visões arquiteturais pertinentes: visão de módulos, visão em tempo de execução e visão de implantação. Para representar essas visões podem ser utilizadas as técnicas da UML, como o sugerido por Merson (2005). Por meio do estudo de caso, observa-se que as demais visões sugeridas por Merson (2005) - visão de implementação e visão de dados — não necessitam ser construídas, uma vez que a arquitetura de referência do domínio sendo estabelecida encontra-se em um nível de abstração alto para a qual esses dois modelos não são adequados. Essas duas visões arquiteturais podem ser desenvolvidas em fases posteriores do ciclo de vida de desenvolvimento da ferramenta do domínio. 
De modo geral, a visão de módulos da arquitetura mostra a estrutura do sistema em termos de módulos (unidades de código que implementam alguma funcionalidade, seja um pacote, interface, classe, aspecto, entre outros). Para representar essa visão, pode-se utilizar o diagrama de estrutura estático. Já a visão em tempo de execução mostra o sistema em execução, ao contrário da visão em módulos que apresenta a estrutura do código-fonte. Essa visão possibilita o entendimento do funcionamento do sistema e a análise das propriedades que se manifestam em tempo de execução, tais como a de desempenho (Merson, 2005). Essa visão também possibilita apresentar os grandes componentes e suas interações, as bases de dados, bem como aquelas que são compartilhadas, os elementos replicados, o fluxo de dados no sistema, além das partes do sistema que são executadas em paralelo. Para representar essa visão, Merson (2005) sugere o uso do diagrama de estrutura. A visão de implantação apresenta a estrutura de hardware na qual o sistema será executado, podendo ser representado utilizando-se o diagrama de implantação.

Utilizando-se a UML para representar essas visões da arquitetura, ferramentas CASE, tais como as citadas na Seção 5.3.2, podem e devem ser utilizadas como mecanismo de apoio ao desenvolvimento dessas visões.

\subsubsection{Passo 5: Desenvolvimento do Sistema}

O passo de Desenvolvimento do Sistema refere-se, basicamente, à instanciação arquitetural, na qual são criadas as instâncias arquiteturais de ferramentas e AESs, ou seja, são projetadas e implementadas as ferramentas e ambientes com base na arquitetura de referência que foi estabelecida.

Para tanto, apesar da arquitetura de referência trazer muito do conhecimento de um dado domínio, especificidades da ferramenta ou do framework a serem desenvolvidas não estão disponíveis. Por isso, há a necessidade de considerar atividades tradicionais de desenvolvimento de software, tais como a análise, o projeto, a implementação e o teste. Vale destacar que essas atividades são facilitadas, visto que arquitetura de referência dá respaldo para conduzi-las.

Em se tratando das bases da RefASSET, bem como a melhor separação de interesses que a orientação a objetos vem promovendo, a abordagem de orientação a objetos deve ser adotada. Adicionalmente, deve-se também adotar a orientação a aspectos, uma vez que aspectos são utilizados como mecanismos de integração. Dessa forma, método, técnicas, ferramentas e tecnologias que dão apoio à orientação a objetos e à orientação a aspectos devem ser utilizados. Se o AESs for desenvolvido para a plataforma Web, há a necessidade de utilizar métodos, técnicas, ferramentas e tecnologias adequadas ao desenvolvimento de sistemas Web. 


\subsubsection{Passo 6: Integração no Ambiente de Engenharia de Software}

Este passo refere-se à integração ao AES da ferramenta de Engenharia de Software desenvolvida com base na arquitetura de referência obtida. Vale observar que, por construção, as ferramentas resultantes do ProSA apresentam facilidade de integração, principalmente no que tange os módulos que implementam atividades de apoio e organizacionais.

Nesse passo, deve-se dar atenção aos módulos que implementam atividades de apoio e organizacionais, bem como aqueles que implementam interesses não-funcionais. Isso porque os módulos que implementam uma dessas atividades é único em um determinado AES. Por exemplo, o módulo de gerência de configuração é único em um determinado AES e deve atender a atividade de gerência de configuração de todos os módulos base.

Além disso, os mecanismos de integração entre os módulos base devem ser estabelecidos, seja por usar um SGBD ou por estabelecer a comunicação utilizando-se, por exemplo, o XML.

\subsection{Considerações Finais}

Processos são inerentemente relevantes na sistematização das atividades, e não sendo diferente quando se trata de sistematizar o uso de arquiteturas de software para o desenvolvimento de sistemas de software. Dessa maneira, neste capítulo foi apresentado o ProSA, um processo de desenvolvimento de AESs baseado em arquiteturas de software, mais especificamente, na arquitetura de referência de AESs proposta neste trabalho.

Como características mais relevantes do ProSA têm-se a iteratividade, o paralelismo e a independência, possibilitando, portanto, que AESs resultantes desse processo possam evoluir constantemente com a adaptação a novos contextos e de maneira incremental com a inserção de novas funcionalidades/módulos referentes às atividades de Engenharia de Software. Contribuição nessa linha são fundamentais na área de Engenharia de Software, considerando-se as dificuldades e desafios enfrentados pelos AESs atuais.

Como já citado anteriormente, o ProSA é resultado da abstração quando da condução de um estudo de caso. Evidentemente, como qualquer outro processo de desenvolvimento de software, o ProSA pode e deve ser evoluído e refinado à medida que esse for aplicado em diversos contextos. 
Buscando sintetizar a pesquisa conduzida nesta tese, no capítulo seguinte são apresentadas as conclusões deste trabalho, juntamente com os principais pontos referentes às contribuições, trabalhos relacionados e futuros, bem como as publicações esperadas. 


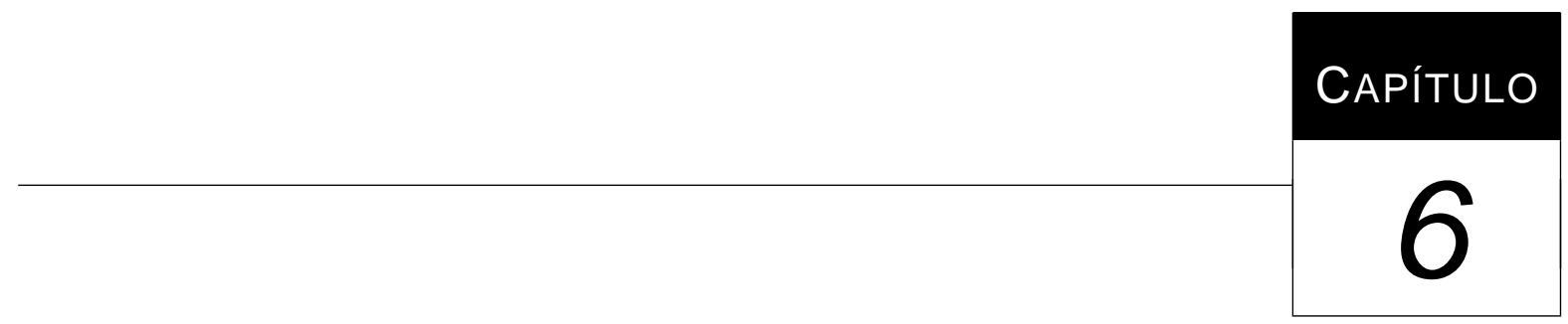

Conclusões

Neste capítulo é dada uma visão geral do trabalho realizado, descrevendo suas principais contribuições em função das linhas de pesquisa investigadas: AESs, Teste de Software e Arquitetura de Software. São também apresentadas as principais dificuldades, bem como os trabalhos relacionados a esta tese. Em seguida, são discutidas perspectivas futuras de pesquisa e publicações esperadas.

\subsection{Caracterização da Pesquisa Realizada}

O desenvolvimento de ambientes e ferramentas do domínio de Engenharia de Software é fundamental para melhorar a qualidade do processo de software e, conseqüentemente, a qualidade dos produtos de software resultantes desse processo. Assim, fornecer subsídios e facilidades para o desenvolvimento dessas ferramentas e ambientes é certamente relevante. Apesar disso, as dificuldades de integração e evolução que sistemas de software desse domínio têm apresentado vêm impactando na qualidade dessas ferramentas e ambientes. Vale observar que arquiteturas de software são elementos decisivos no sucesso e na qualidade dos softwares. Mais especificamente, arquiteturas de referência de um dado domínio são particularmente relevantes, uma vez que contêm conhecimentos resultantes de pesquisas e experiências daquele domínio. Dessa 
forma, uma arquitetura de referência adequada, recente e eficaz pode ser considerada um dos principais mecanismos que contribuem para o sucesso das ferramentas e AESs.

Nos últimos anos, a programação orientada a aspectos e, mais tarde, o desenvolvimento de software orientado a aspectos vieram reforçar a necessidade da separação de interesses no desenvolvimento de software. Inclusive, Harrison et al. (2000) apontam para a necessidade da separação de interesses adequada como um caminho que poderá melhorar a capacidade de evolução dos AESs.

Salienta-se que o reúso tem sido alvo de muitas das linhas de pesquisa em Engenharia de Software. Diversos mecanismos, tais como frameworks, linhas de produto, geradores de aplicação, componentes, a própria orientação a objetos e a orientação a aspectos, têm apontado nessa linha. Neste trabalho, é investigada a relevância do reúso de arquiteturas de software, em especial, as arquiteturas de referência no desenvolvimento de software, em particular, sistemas complexos como os AESs. Além disso, visto que o uso de frameworks para o desenvolvimento de software tem-se mostrado relevante, o desenvolvimento de módulos para compor as ferramentas e AESs a partir de frameworks é também relevante. Ainda mais se esses frameworks apresentarem facilidades de integração, como é o caso de frameworks transversais.

O Teste de Software é visto como uma das atividades que mais pode contribuir para a qualidade do software. Além disso, toda a literatura de Teste de Software concorda que essa atividade não é indicada para ser realizada de forma manual. Por isso, observa-se a proliferação de ferramentas de teste automatizando uma diversidade de técnicas e critérios de teste. Arquiteturas de software podem ser inseridas nessa linha, com a proposição de arquiteturas de referência que possam colaborar adequadamente para o desenvolvimento de ferramentas de teste.

A plataforma Web tem-se tornado atualmente o cenário da disponibilização de sistemas de software dos mais diversos domínios de aplicação. Isso também pode ser uma realidade para os ambientes e ferramentas de Engenharia de Software, apesar de que, atualmente, podese identificar somente algumas iniciativas. Pesquisa, investigação, proposição e uso de novas tecnologias devem ser considerados para que AESs possam ser completamente disponibilizados por meio dessa plataforma. Dessa forma, a proposição de uma arquitetura de referência que possibilite que AESs sejam projetados e implementados por meio dessa plataforma é um importante ponto de partida para que esses ambientes e ferramentas adotem a Web como um cenário para disponibilização e uso. 


\subsection{Contribuições}

Diante do cenário apresentado nas seções anteriores, pode-se destacar como principais contribuições deste trabalho nas seguintes linhas de pesquisa:

- Ambientes de Engenharia de Software: A principal contribuição deste trabalho é a proposição de uma arquitetura de referência para AESs - a RefASSET — baseada em interesses (aspectos) e construída com base no padrão internacional ISO/IEC 12207, nas arquiteturas de sistemas interativos e sistemas Web bastante consolidadas, nas ontologias relacionadas a processo de software, bem como no uso de frameworks transversais para a implementação de módulos que implementam interesses transversais. Pela própria concepção da RefASSET, AESs construídos com base nessa arquitetura possuem como característica chave a capacidade de evolução contínua, bem como o crescimento incremental por meio da inserção de novas funcionalidades/módulos ao ambiente.

Por meio da RefASSET, uma outra contribuição é o estabelecimento de uma visão clara de quais seriam as funcionalidades específicas (ou fundamentais) de AESs, ou seja, o que seria o núcleo das ferramentas que compõem o ambiente, separando aquelas funcionalidades que estão relacionadas às atividades de apoio e às organizacionais. A separação de interesses conduzida dessa maneira facilita, além da manutenção, a evolução desses ambientes.

Ainda nessa linha, uma outra contribuição deste trabalho refere-se ao uso de aspectos como mecanismo de integração em AESs. Em particular, aspectos podem ser utilizados para a integração de módulos que implementam atividades de apoio e organizacionais, bem como módulos que implementam interesses não-funcionais, aos módulos base. Destaca-se que este é um dos primeiros trabalhos a explorar o uso de aspectos como mecanismo de integração em AESs. Resultados preliminares alcançados neste trabalho mostram que integração e manutenção nos ambientes baseados na RefASSET é facilitada com o uso de aspectos.

Vale destacar que uma das características da RefASSET é a possibilidade de desenvolver ambientes que podem ser disponibilizados em plataforma Web. Além disso, ambientes stand-alone também podem ser originados dessa arquitetura, em virtude da organização estrutural adotada pela RefASSET. Portanto, a RefASSET propõe-se a ser uma arquitetura mais geral do que somente para AESs para plataforma Web.

- Teste de Software: Para a área de Teste de Software foi proposta a RefTEST, uma arquitetura de referência para o domínio de teste de software. Trata-se de uma das primeiras 
arquiteturas de referência desse domínio e foi construída visando a auxiliar o desenvolvimento de ferramentas de teste de forma evolutiva e incremental. De modo geral, essa arquitetura contém o conhecimento do domínio de teste, e que foi resultado de uma investigação e análise minuciosa de diversos elementos do domínio de teste de software. A RefTEST prevê a existência de módulos que implementam as atividades de apoio e organizacionais estabelecidas pelo padrão ISO/IEC 12207, contribuindo para o desenvolvimento de ferramentas de teste contendo módulos que implementam essas atividades.

Uma outra contribuição nessa linha é a proposição de um framework transversal de documentação da atividade de teste, com base em um padrão internacional para documentação. Observa-se que a documentação é um interesse transversal funcional, ao contrário do que ocorre com a maioria dos frameworks transversais que implementam interesses não-funcionais, tais como a persistência. Isso mostra que este trabalho tem-se adiantado na proposição de um framework transversal que trata um interesse transversal funcional do domínio de Engenharia de Software.

Assim como a RefASSET, a RefTEST tem potencial de colaboração no desenvolvimento de ferramentas de teste de software para plataforma Web, seguindo a tendência atual na maneira como sistemas de software vêm sendo disponibilizados aos seus usuários.

- Processo de Desenvolvimento de Software: Nessa linha de pesquisa, foi proposto um processo de desenvolvimento baseado em arquiteturas de software. Mais especificamente, para sistematizar o estabelecimento de arquiteturas de referência específicas de domínio, foi descrito o ProSA, um processo que descreve as tarefas de especialização e instanciação da RefASSET para um determinado domínio. Vale ressaltar que esse processo propõe o uso dos termos especialização e instanciação arquitetural no domínio de arquiteturas de software, adotado de áreas como a área de Processo de Software.

Esse processo norteia o desenvolvimento de AESs, atendendo às características da área de Engenharia de Software no que tange a sua evolução. O paralelismo, a independência e a iteratividade do ProSA são características que possibilitam que o desenvolvimento de AESs seja incremental e evolutivo.

\subsection{Dificuldades e Limitações}

Uma das dificuldades enfrentadas durante a condução deste trabalho foi a necessidade de investigação e estudo de uma diversidade de temas e linhas de pesquisa, e que foram desde o estudo teórico ao prático de alguns temas, tais como a programação orientada a aspectos. Contudo, 
vale observar que os próprios objetivos deste trabalho de fato requereram essa investigação e estudo. Uma outra dificuldade refere-se à falta de um AES já implementado nos moldes da RefASSET que pudesse servir de base para o desenvolvimento do framework transversal de documentação.

No tocante às limitações deste trabalho, não foram implementadas completamente ferramentas e ambientes baseados tanto na RefASSET quanto na RefTEST, de modo a comprovar de fato a viabilidade dessas arquiteturas como mecanismo de apoio ao desenvolvimento de ferramentas e ambientes. Contudo, as iniciativas de utilização dessas ferramentas, tanto no contexto deste trabalho quanto em trabalhos relacionados dá indícios da viabilidade dessas arquiteturas. Ainda nessa linha, ambas as arquiteturas não tiveram a sua qualidade avaliada, utilizando-se algum método de avaliação arquitetural. Além disso, quanto ao processo de desenvolvimento de AESs proposto neste trabalho, há a necessidade de validação por meio da aplicação desse processo em outros contextos. Essas e outras limitações devem ser superadas em trabalhos futuros e que são descritas em mais detalhes na Seção 6.5.

\subsection{Trabalhos Relacionados a esta Pesquisa}

A seguir são descritos sucintamente trabalhos relacionados à pesquisa desenvolvida nesta tese:

- No contexto do trabalho de Ferrari (2005), a JaBUTi (Vincenzi, 2004), uma ferramenta de teste de software que automatiza os critérios de Fluxo de Dados e Teste de Mutação e que foi implementada inicialmente para ser stand-alone, tem sido migrada para a plataforma Web tendo como base a arquitetura de referência do domínio de teste proposta neste trabalho;

- Embora o domínio de aplicação seja bastante diferente ao que está relacionada a RefASSET e a RefTEST, no Projeto Memória Virtual de São Carlos (Mem, 2004; Nakagawa, 2004b) ao qual a doutoranda atua como membro pesquisador, está sendo desenvolvido um sistema Web de gestão integrada de acervos históricos, chamado de Sistema Memória Virtual. Para a implementação desse sistema, foi selecionado a arquitetura em 3-camadas (Anderson, 2004) juntamente com o padrão arquitetural MVC (Buschmann et al., 1996), assim como são as bases da RefASSET e da RefTEST. Vale salientar que a adoção dessa arquitetura para o Sistema Memória Virtual tem contribuído para um desenvolvimento mais modular, para a facilidade de desenvolvimento, manutenção e evolução, uma vez que as partes encontram-se claramente separadas (Nakagawa et al., 2005); isso facilita 
também a construção de interfaces do usuário para esse sistema de forma independente, como foi explorado no trabalho de Orikasa (2005).

- Ainda no contexto do Projeto Memória Virtual de São Carlos, o mecanismo de ajuda (do inglês, help) tem sido explorado como um interesse transversal ao Sistema Memória Virtual. O trabalho de Silva (2005) tem como objetivo a investigação e o projeto de um módulo de ajuda para o Sistema Memória Virtual. Objetiva-se também a integração desse módulo (análogo aos módulos resultantes de frameworks transversais de apoio e organizacionais) ao Sistema Memória Virtual (análogo ao módulo base da RefASSET e da RefTEST) utilizando-se aspectos. Exercícios preliminares nesse sentido já têm sido realizados, com resultados positivos.

\subsection{Trabalhos Futuros}

Dando continuidade às atividades conduzidas durante este trabalho de doutorado, pode-se destacar como principais perspectivas futuras de pesquisa as seguintes linhas de atuação:

- Desenvolvimento de Ferramentas de Engenharia de Software: Como um dos principais trabalhos futuros tem-se a especialização da RefASSET para outros domínios, além do teste de software, e conseqüentemente, o projeto e implementação de ferramentas e AESs com base nessas arquiteturas. Ferramentas e ambientes disponibilizados na plataforma Web podem contribuir e facilitar no ensino dos conceitos de Engenharia de Software, podem apoiar a condução de estudos experimentais e mesmo facilitar a demonstração e treinamento nessas ferramentas e ambientes;

- Avaliação da Qualidade das Arquiteturas de Referência Propostas: Um outro trabalho refere-se à avaliação arquitetural com relação à qualidade da RefASSET e a da RefTEST, considerando-se trabalhos nessa linha, tais como o de Babar et al. (2004); Kazman et al. (1994) e Kazman et al. (1998), que propõem métodos para avaliação arquitetural. Por meio dessa avaliação, será possível ter subsídios para refinar ou reestruturar as arquiteturas, se necessário, dando respaldo para melhor explorar essas arquiteturas no desenvolvimento de ferramentas e ambientes;

- Explorar Outras Arquiteturas para Ambientes de Engenharia de Software: Neste trabalho foi adotada a arquitetura Cliente-Servidor (Tanenbaum, 1997) como base para a RefASSET e a RefTEST. Como trabalhos futuros, tem-se a investigação sobre a adequação de ferramentas e AESs para outras arquiteturas, tais como a arquitetura Cliente- 
Servidor Distribuído (Ramakrishnan \& Gehrke, 2000) e a arquitetura de serviços Web (W3C, 2006). Em particular, pode-se considerar a investigação de serviços Web por ser um tema de pesquisa recente e não serem localizadas na literatura iniciativas de ferramentas e AESs com base nessa arquitetura. Investigar as reais vantagens/benefícios, desvantagens e limitações de implementação dessas ferramentas sobre essa arquitetura é bastante relevante;

- Uso de Agentes em Ambientes de Engenharia de Software: Uma linha de pesquisa que tem emergido é o uso de agentes de software em ferramentas e AESs (Falbo et al., 2005; Huo et al., 2003). Assim, com base nos resultados alcançados neste trabalho, uma linha de pesquisa relevante é investigar a viabilidade do uso de agentes em AESs;

- Framework de Ferramentas de Teste de Software: Tendo-se a RefTEST que contém o conhecimento e a experiência do domínio de teste de software, o desenvolvimento de um framework de ferramentas de teste de software é certamente facilitado. Então, um outro trabalho futuro é o desenvolvimento desse framework. A geração de ferramentas Web de teste de software com base no framework pode contribuir no uso de ferramentas de teste no meio acadêmico (graduação e pós-graduação) para o ensino dos conceitos de teste de software, técnicas e critérios, frente a relevância que teste de software vem ganhando nos últimos anos dentro da área de Engenharia de Software;

- Refinamento do Framework de Documentação: Quanto ao framework de documentação proposto neste trabalho, é necessário investigar em detalhes a documentação de outras atividades de Engenharia de Software, resultando na identificação, implementação e disponibilização de outras variabilidades para esse framework. Esforços nesse sentido são relevantes, uma vez que se trata de um framework transversal que implementa um interesse funcional, sobre o qual a literatura carece de trabalhos;

- Desenvolvimento de Framework Transversais: Para possibilitar o desenvolvimento de ferramentas e AESs, a disponibilização de frameworks que implementam interesses transversais relacionados às atividades de apoio e organizacionais, tais como o gerenciamento de configuração e o gerenciamento e planejamento, é fundamental. Dessa forma, um trabalho futuro nessa linha consiste no projeto e na implementação de frameworks transversais para essas atividades, o que certamente contribuirá para o desenvolvimento de ferramentas e ambientes dentro das perspectivas da RefASSET; e

- Refinamento e Validação do ProSA: Na perspectiva de processo de desenvolvimento de AESs proposto neste trabalho, um outro trabalho que deve ser realizado é o refinamento 
e validação do ProSA. Para isso, deve-se aplicar esse processo para derivar arquiteturas de referência para diversos outros domínios, tais como para a atividade de gerência de requisitos e manutenção, e coletar as experiências e particularidades de cada caso e agregar ao ProSA.

\subsection{Publicações Esperadas}

Em decorrência dos resultados já alcançados, pretende-se submeter artigos em eventos e periódicos em nível nacional e internacional. As publicações esperadas são descritas a seguir:

- RefaSSET: Uma Arquitetura de Referência de Ambientes de Engenharia de Software: Motivado pela necessidade de mecanismos que auxiliem o desenvolvimento de ferramentas e AESs, esse artigo propõe a RefASSET, uma arquiteturas de referência baseada em interesses para o domínio de Engenharia de Software;

- Uso de Aspectos como Mecanismo de Integração em Ambientes de Engenharia de Software: Frente aos diversos mecanismos que têm sido propostos para a integração em AESs, neste artigo é explorado o uso de aspectos para esse fim, buscando demonstrar as vantagens de aspectos como mecanismo integrador;

- RefTEST: Uma Arquitetura de Referência para o Domínio de Teste de Software: Esse artigo propõe uma arquitetura de referência que pode ser aplicada na fase de projeto arquitetural de ferramentas de teste de software. Para isso, é também mostrada nesse artigo uma investigação do domínio de teste de software em que envolve outras ferramentas de teste e suas arquiteturas, outras arquiteturas de referência e, em especial, uma ontologia de teste de software;

- Implementação da Documentação como Interesse Transversal por Meio de um Framework Transversal: Motivado pela utilização de frameworks no desenvolvimento de software, é apresentado nesse artigo um framework transversal de documentação. Considerando-se a documentação como um interesse transversal, o framework pode ser acoplado ao módulo base de outras ferramentas de Engenharia de Software, possibilitando a documentação das diversas atividades de desenvolvimento de software; e

- ProSA: Desenvolvimento Baseado em Arquitetura: É apresentado nesse artigo um processo de desenvolvimento de ferramentas e AESs tendo como base arquiteturas de soft- 
ware, no caso a RefASSET. Esse processo propõe a adoção dos termos especialização e instanciação arquitetural para o contexto de arquiteturas de software. 


\section{Referências Bibliográficas}

Memória Virtual de São Carlos. Instituto de Ciências Matemáticas e de Computação ICMC/USP, São Carlos, SP. (Projeto aprovado no programa de políticas públicas da FAPESP e coordenado pelo Prof. Dr. José Carlos Maldonado)., 2004.

Agrawal, H.; Alberi, J.; Horgan, J. R.; Li, J.; London, S.; Wong, W. E.; Ghosh, S.; WILDE, N. Mining system tests to aid software maintenance. IEEE Computer, p. 64-73, 1998.

Aldawud, O.; Elrad, T.; BADER, A. A UML profile for aspect oriented modeling. In: Proc. of Third International Workshop on Aspect-Oriented Modeling, Boston, USA, 2003.

Allen, R. A formal approach to software architecture. Tese de Doutoramento, Carnegie Mellon, School of Computer Science, 1997.

AlWIS, B. Aspects of incremental programming. Dissertação de Mestrado, University of British Columbia, Vancouver, Canada, 2002.

Ambriola, V.; Conradi, R.; Fuggetta, A. Assessing process-centered software engineering environments. ACM Transactions on Software Engineering and Methodology, v. 6, n. 3, p. 283-328, 1997.

ANDERSON, D. J. Using MVC pattern in web interactions. [On-line], World Wide Web, disponível em: http://www.uidesign.net/Articles/Papers/ UsingMVCPatterninWebInter.html 3rd Edition, revised May 2004 (Acessado em 07/04/2005), 2004. 
Anderson, R. E. ACM code of ethics and professional conduct. Communications of the $A C M$, v. 35, n. 5, p. 94-99, 1992.

ANDRE, D. M. S. Pilot mutation system (pims) user's manual. Relatório Técnico GIT-ICS79/04, Georgia Institute of Technology, 1979.

ANDREWS, J. H. Relevant empirical testing research: challenges and responses. SIGSOFT Software Engineering Notes, v. 29, n. 5, p. 1-4, 2004.

AOSDBR Desenvolvimento de software orientado a aspectos. [On-line], World Wide Web, disponível em http://twiki.im.ufba.br/bin/view/AOSDbr/WebHome (Acessado em 20/02/2006), 2006.

Armour, P. G. The unconscious art of software testing. Communications of the ACM, v. 48 , n. 1 , p. $15-18,2005$.

Asklund, U.; BendiX, L. Configuration management for open source software. In: Proc. of the 1st Workshop on Open Source Software Development at ICSE 2001, Toronto, Canada, 2001.

ASSOCIAÇÃo BRASILEIRA DE NORMAS TÉCNICAS NBR ISO/IEC 12207. Tecnologia da informação - processo de ciclo de vida do software. 1998.

ASUNDI, J. Software engineering lessons from open source projects. In: Proc. of the 1st Workshop on Open Source Software Development at ICSE 2001, Toronto, Canada, 2001.

BABAR, M.; ZHU, L.; JEFFERY, R. A framework for classifying and comparing software architecture evaluation methods. In: Proc. of Australian Software Engineering Conference (ASWEC'04), Melbourne, Australia: IEEE Computer Society, 2004, p. 309-318.

Bachmann, F.; Garlan, D.; Ivers, J.; Little, R.; Nord, R.; Stafford, J. Software architecture in practice, cap. Documenting Software Architectures. The SEI Series in Software Engineering, 2 ed Addison-Wesley Publishing Company, p. 201-230, 2003.

Bandinelli, S.; Fuggetta, A.; Grigolli, S. Process modeling-in-the-large with SLANG. In: Proc. of the 2nd International Conference on the Software Process, Berlin, Germany: IEEE Computer Society Press, 1993, p. 75-83.

Bandinelli, S.; Nitto, E. D.; Fuggetta, A. Supporting cooperation in the SPADE-1 environment. IEEE Transactions on Software Engineering, v. 22, n. 12, p. 841-865, 1996. 
BArber, K. S.; Holt, J.; BAKer, G. Performance evaluation of domain reference architectures. In: Proc. of the 14th International Conference on Software Engineering and Knowledge Engineering, ACM Press, 2002, p. 225-232.

BARbosA, E. F. Uma contribuição para a determinação de um conjunto essencial de operadores de mutação no teste de programas $C$. Dissertação de Mestrado, ICMC-USP, São Carlos, SP, 1998.

BARbosA, E. F. Uma contribuição ao processo de desenvolvimento e modelagem de módulos educacionais. Tese de doutorado, Instituto de Ciências Matemáticas e de Computação ICMC/USP, São Carlos, SP, 2004.

Barbosa, E. F.; Maldonado, J. C.; Vincenzi, A. M. R. Towards the determination of sufficient mutant operators for C. In: First International Workshop on Automated Program Analysis, Testing and Verification, Limerick, Ireland, (Edição especial do Software Testing Verification and Reliability Journal, 11(2), 2001), 2000.

Barbosa, E. F.; Nakagawa, E. Y.; Maldonado, J. C. Ontotest: An ontology of software testing. In: 18th International Conference on Software Engineering and Knowledge Engineering (SEKE'06), San Francisco, Estados Unidos, (artigo submetido), 2006.

Baresi, L.; Garzotto, F.; Paolini, P. Extending UML for modeling web applications. In: Proc. of the 34th Hawaii International Conference on System Sciences, Maui, Hawaii, 2001, p. 3055-3064.

BARnES, A.; GrAY, J. Cots, workflow, and software process management: An exploration of software engineering tool development. In: 12th Australian Software Engineering Conference (ASWEC 2000), Canberra, Australia, 2000, p. 221-234.

Bass, L.; Clements, P.; KAZMAn, R. Software architecture in practice. The SEI Series in Software Engineering, 2 ed. Addison-Wesley Publishing Company, 2003.

Batory, D.; Coglianese, L.; Goodwin, M.; Shafer, S. Creating reference architectures: an example from avionics. In: SSR '95: Proc. of the 1995 Symposium on Software reusability, New York, NY, USA: ACM Press, 1995, p. 27-37.

BECK, H. Fine-grained representation of educational content based on ontologies. In: I PGLDB Research Conference (PGL DB 2003), Rio de Janeiro, RJ, 2003, p. 105-110.

BECK, K. Embracing change with extreme programming. IEEE Computer, v. 32, n. 10, p. $70-77,1999$. 
BECK, K. Extreme programming explained. Addison-Wesley Publishing Company, 2000.

BeCK, K.; Johnson, R. Patterns generate architectures. In: Proc. of ECOOP'94, Bologna, Italy, 1994, p. 139-149.

BEIZER, B. Software testing techniques. 2nd ed. New York: Van Nostrand Reinhold Company, 1990.

Belkhatir, N.; Estublier, J.; Melo, W. L. Adele 2: A support to large software development process. In: Proc. the 1st International Conference on the Software Process, Redondo Beach, CA, (USA), 1991, p. 159-170.

BELLI, F.; JACK, O. Implementation-based analysis and testing of Prolog programs. In: Proc. of the 1993 International Symposium on Software Testing and Analysis, Cambridge, Massachusetts, USA: ACM Press, 1993, p. 70-80.

Bergey, J.; Cohen, S.; Fisher, M.; Campbell, G.; Jones, L.; Krut, R.; Northrop, L.; O’Brien, W.; SMith, D.; Soule, A. Fourth DoD product line practice workshop report. Relatório Técnico CMU/SEI-2001-TR-017, Software Engineering Institute, 2001.

Bertolino, A. The (im)maturity level of software testing. SIGSOFT Software Engineering Notes, v. 29, n. 5, p. 1-4, 2004.

BIANCHI, T. Apoio ao projeto e implementação de um sistema web para gestão de acervos históricos. Relatório Final de Projeto de Iniciação Científica sob orientação de José Carlos Maldonado e Elisa Yumi Nakagawa, Instituto de Ciências Matemáticas e de Computação ICMC/USP, São Carlos, SP, 2005.

Bieman, J. M.; Ghosh, S.; Alexander, R. T. A technique for mutation of Java objects. In: Proc. of the 16th IEEE International Conference on Automated Software Engineering, San Diego, California, USA, 2001, p. 337-340.

BINDER, R. V. Testing object-oriented systems: A status report. American Programmer, v. 7, n. 4, p. 22-28, 1994.

BoAs, A. L. C. V. Gestão de configuração para teste de software. Dissertação de Mestrado, Faculdade de Engenharia Elétrica e de Computação, Universidade Estadual de Campinas (FEEC/UNICAMP), Campinas, SP, 2003.

Boegh, J. Quality evaluation of software products. Software Quality Professional, v. 1, n. 2, p. 26-37, 1999. 
BoEHM, B. W. A spiral model of software development and enhancement. IEEE Computer, v. 21, n. 5, p. 61-72, 1988.

Bollinger, T.; Beckman, P. Linux on the move. IEEE Software, v. 16, n. 1, p. 30-35, 1999.

Borges, K. N.; Ramos, F. S.; Maldonado, J. C.; Chaim, M. L.; Jino, M. Poke-Tool versão Clipper - Uma ferramenta para suporte ao teste estrutural de programas baseado em análise de fluxo de dados. In: Sessão de Ferramentas do IX SBES - Simpósio Brasileiro de Engenharia de Software, Recife - PE, 1995.

Boudier, G.; Gallo, F.; Minot, R.; Thomas, I. An overview of pcte and pcte+. ACM SIGPLAN Notices, v. 24, n. 2, p. 248-257, 1989.

Boyapati, C.; Khurshid, S.; Marinov, D. Korat: Automated testing based on Java predicates. In: ISSTA 2002 - International Symposium on Software Testing and Analysis, Rome, Italy: ACM, 2002, p. 123-133.

Braga, R.; Werner, C.; Mattoso, M. Odyssey: A reuse environment based on domain models. In: Proc. of IEEE Symposium on Application-Specific Systems and Software Engineering Technology (ASSET'99), Richardson, Texas, 1999, p. 49-57.

BRAGA, R. T. V. Um processo para construção e instanciação de frameworks baseados em uma linguagem de padrões para um domínio específico. Tese de Doutoramento, Instituto de Ciências Matemáticas e de Computação - ICMC/USP, São Carlos, SP, 2003.

BRANT, J. Hotdraw home page. [On-line], World Wide Web, disponível em: http:// st-www.cs.uiuc.edu/users/brant/HotDraw/HotDraw.htm, 1999.

Bray, T.; Paoli, J.; Sperberg-McQueen, C. M.; Maler, E.; Yergeau, F.; Cowan, J. Extensible markup language (XML) 1.1. Relatório Técnico, W3C, disponível em: http: //www.w3.org/TR/2004/REC-xml11-20040204/ (Acessado em 11/04/2004), 2004.

BRIAND, L.; LABICHE, Y. Empirical studies of software testing techniques: challenges, practical strategies, and future research. SIGSOFT Software Engineering Notes, v. 29, n. 5, p. 1-3, 2004.

Brown, A. W. Component-based software engineering: Selected papers from the SEI Software Engineering Institute, cap. Preface: Foundations for Component-Based Software Engineering Los Alamitos, CA, USA: IEEE Computer Society Press, 1996. 
Brownsword, L.; Oberndorf, T.; Sledge, C. A. Developing new processes for COTSbased systems. IEEE Software, v. 17, n. 4, p. 48-55, 2000.

BuDD, T. A. Mutation analysis: Ideas, example, problems and prospects, cap. Computer Program Testing North-Holand Publishing Company, p. 129-148, 1981.

Buschmann, F.; Meunier, R.; Rohnert, H.; Sommerlad, P.; Stal, M. Patternoriented software architecture: A system of patterns, v. 1. John Wiley \& Sons, 1996.

CAmargo, V. V.; Masiero, P. C. Frameworks orientados a aspectos. In: SBES'2005 Simpósio Brasileiro de Engenharia de Software, Uberlândia, Minas Gerais, 2005.

Camargo, V. V.; Ramos, R. A.; Penteado, R.; Masiero, P. C. Projeto baseado em aspectos do padrão camada de persistência. In: SBES'2003 - Simpósio Brasileiro de Engenharia de Software, Manaus, Amazonas, 2003.

Campbell, R. H.; Islam, N. Documenting the framework of an object-oriented system. In: Proc. of the 2nd International Workshop on Object-Orientation in Operating System, Paris, France, 1992.

Cao, S.; Grundy, J. C.; Hosking, J. G.; Stoeckle, H.; Tempero, E. D. An architecture for generating web-based, thin-client diagramming tools. In: 19th IEEE International Conference on Automated Software Engineering (ASE 2004), 2004.

CAPUTO, K. CMM implementation guide: Choreographing software process improvement. Massachusetts: Addison-Wesley Publishing Company, 1998.

Cass, A.; Völcker, C.; Panaroni, P.; Dorling, A.; Winzer, L. Spice for space: A method of process assessment for space software projects. In: SPICE 2000, Limerick, 2000, p. 21-31.

Ceri, S.; Fraternali, P.; Bongio, A. Web modeling language (WebML): a modeling language for designing web sites. In: Proc. of the 9th International Conference on the WWW (WWW9), Amsterdam, Holanda, 2000.

CHAFFEY, D. Groupware, workflow and intranets: Reengineering the enterprise with collaborative software. 1 ed. Butterworth-Heinemann, 1998.

ChAim, M. L. Poke-tool - uma ferramenta para suporte ao teste estrutural de programas baseado em análise de fluxo de dados. Dissertação de Mestrado, DCA/FEEC/UNICAMP, Campinas, SP, 1991. 
Chaim, M. L.; Maldonado, J. C.; Jino, M. Ferramenta para o teste estrutural de software baseado em análise de fluxo de dados: o caso Poke-Tool. In: Workshop do Projeto de Validação e Teste de Sistemas de Operação, Águas de Lindóia - SP, 1997, p. 29-39.

ChAng, J.; Richardson, D. J. Structural specification-based testing: automated support and experimental evaluation. In: ESEC/FSE-7: Proc. of the 7th European Software Engineering Conference held jointly with the 7th ACM SIGSOFT International Symposium on Foundations of Software Engineering, Springer-Verlag, 1999, p. 285-302.

Chavez, C. V. F. G. A model-driven approach to aspect-oriented design. Tese de Doutoramento, Departamento de Informática, Pontifícia Universidade Católica do Rio de Janeiro, Rio de Janeiro, RJ, 2004.

Chavez, C. V. F. G.; Garcia, A.; Kulesza, U.; Sant’ Anna, C.; Lucena, C. Taming heterogeneous aspects with crosscutting interfaces. In: SBES'2005 - Simpósio Brasileiro de Engenharia de Software, Uberlândia, MG, 2005.

Chen, J. J. CSPL: An Ada95-like, Unix based process environment. IEEE Transactions on Software Engineering, v. 23, n. 3, p. 171-184, 1997.

CHEN, Y. A process-centric approach for software product line evolution management. In: First International Software Product Lines Young Researchers Workshop (SPLYR 2004), In conjunction with the 3rd Software Product Line Conference, Boston, MA, Estados Unidos, 2004, p. $9-18$.

Chen, Y.; Gannod, G. C.; Collofello, J. S. A software product line process simulator. In: 6th International Workshop on Software Process Simulation and Modeling (ProSim 2005), St. Louis, Missouri, Estados Unidos, 2005.

Chevalley, P.; Thévenod-Fosse, P. A mutation analysis tool for Java programs. International Journal on Software Tools for Technology Transfer (STTT), v. 5, n. 1, p. 90-103, 2003.

Childers, B.; Soffa, M. L.; Beaver, J.; Ber, L.; Cammarata, K.; Kane, T.; LitMAN, J.; Misurda, J. Softtest: a framework for software testing of Java programs. In: Eclipse '03: Proc. of the 2003 OOPSLA workshop on eclipse technology eXchange, ACM Press, 2003, p. 79-83.

Choi, B. J.; DeMillo, R. A.; Krauser, E. W.; Mathur, A. P.; Martin, R. J.; OfFUtT, A. J.; Pan, H.; SPAFFord, E. H. The Mothra toolset. In: Twenty-Second Annual Hawaii International Conference on System Sciences, HI, 1989. 
Choi, B. J.; Mathur, A. P. High-performance mutation testing. The Journal of Systems and Software, v. 20, n. 2, p. 135-152, 1993.

Christie, A. M. Software process automation: The technology and its adoption. SpringerVerlag, 1995.

Chung, A.; Sidhu, D. Fault coverage of probabilistic test sequence. In: Proc. of the IFIP TC6 Third International Workshop on Protocol Test Systems, 1991.

Cibrán, M.; D’Hondt, M.; JonCKers, V. Aspect-oriented programming for connecting business rules. In: Proc. of the 6th International Conference on Business Information Systems (BIS’03), Colorado Springs, USA, 2003.

Clarke, S.; Baniassad, E. Aspect-oriented analysis and design: The theme approach. Object Technology. Addison-Wesley Publishing Company, 2005.

Clarke, S.; Walker, R. J. Composition patterns: An approach to designing reusable aspects. In: Proc. ICSE 2001 - International Conference on Software Engineering, Toronto, Ontario, Canada, 2001.

Clarke, S.; Walker, R. J. Towards a standard design language for aosd. In: AOSD '02: Proc. of the 1st international conference on Aspect-oriented software development, ACM Press, 2002, p. 113-119.

Cleaveland, J. C. Building application generators. IEEE Software, v. 5, n. 4, p. 25-33, 1988.

Clemens, P.; Bachmann, F.; Bass, L.; Garlan, D.; Iveers, J.; Little, R.; Nord, R.; STAFFORD, J. Documenting software architecture: Views and beyond. The SEI Series in Software Engineering, 3 ed. Boston, MA: Addison-Wesley Publishing Company, 640 p., 2003.

Clements, P.; Northrop, L.; Northrop, L. M. Software product lines: Practices and patterns. The SEI Series in Software Engineering, 1 ed. Boston, MA: Addison-Wesley Publishing Company, 608 p., 2002.

Clements, P. C.; Northrop, L. M. Salion, inc.: A software product line case study. Relatório Técnico CMU/SEI-2002-TR-038, SEI (Software Engineering Institute), disponível em: http://www.sei.cmu.edu/publications/documents/02.reports/02tr038.html (acessado em 14/12/2004), 2002. 
Coady, Y.; Kiczales, G.; Feeley, M.; Smolyn, G. Using AspectC to improve the modularity of path-specific customization in operating system code. In: GRUHN, V., ed. ESEC'01, ACM Press, 2001.

CockBurn, A. Selecting a project's methodology. IEEE Software, v. 17, n. 4, p. 64-71, 2000.

Cockburn, A.; Williams, L. The costs and benefits of pair programming. In: eXtreme Programming and Flexible Processes in Software Engineering, XP2000, Cagliari, Italy, 2000.

Conallen, J. Building web applications with UML. Addison-Wesley, 1999a.

Conallen, J. Web application architectures with UML. Communications of the ACM, v. 42, n. 10, p. 63-68, 1999b.

ConRAdi, E.; JACCHERI, M. L. Process modelling languages. In: Software Process: Principles, Methodology and Technology, Springer-Verlag, 1999, p. 27-52 (Lectures Notes in Computer Science, v.1500).

ConRAdi, R.; FugGetTA, A. Improving software process improvement. IEEE Software, v. 19, n. 4, p. 92-99, 2002.

Constantinides, C. A.; Bader, A.; Elrad, T. H.; Netinant, P.; Fayad, M. E. Designing an aspect-oriented framework in an object-oriented environment. ACM Computing Survey, v. 32, n. 1es, 2000.

Cook, J. E. Open-source software development. In: Proc. of the 2nd Workshop on Software Engineering over the Internet at ICSE'99, Los Angeles, USA, 1999.

Coplien, J. O. The patterns handbook: Techniques, strategies, and applications, cap. Software Design Patterns: Common Questions and Answers Cambridge University Press, p. 311$320,1998$.

Cranefield, S.; Purvis, M. UML as an ontology modelling language. In: Proc. of the IJCAI-99, Workshop on Intelligent Information, 16th International Joint Conference on AI, Stockholm, Sweden, 1999.

Cubranic, D.; Booth, K. S. Coordinating open-source software development. In: Eighth IEEE International Workshop on Enabling Technologies: Infrastructure for Collaborative Enterprises, Stanford, CA, USA: IEEE Computer Society Press, 1999, p. 61-65. 
Curtis, B.; Kellner, M.; Over, J. Process modeling. Communications of the ACM, v. 35, n. 9, p. 75-90, 1992.

Delamaro, M. E. Proteum: Um ambiente de teste baseado na análise de mutantes. Dissertação de Mestrado, ICMC/USP, São Carlos - SP, 1993.

Delamaro, M. E. Mutação de interface: Um critério de adequação inter-procedimental para o teste de integração. Tese de Doutoramento, Instituto de Física de São Carlos - Universidade de São Paulo, São Carlos, SP, 1997.

Delamaro, M. E.; Maldonado, J. C. Proteum - a tool for the assessment of test adequacy for C programs. In: Conference on Performability in Computing Systems (PCS'96), Brunswick, NJ, 1996, p. 79-95.

Delamaro, M. E.; Maldonado, J. C.; Jino, M.; Chaim, M. L. Proteum: Uma ferramenta de teste baseada na análise de mutantes. In: 7th Simpósio Brasileiro de Engenharia de Software, Rio de Janeiro - RJ, 1993, p. 31-33.

Delamaro, M. E.; Maldonado, J. C.; Mathur, A. P. Interface mutation: An approach for integration testing. IEEE Transactions on Software Engineering, v. 27, n. 3, p. 228-247, 2001.

DeMillo, R. A.; Gwind, D. S.; King, K. N.; McKraken, W. N.; Offutt, A. J. An extended overview of the Mothra testing environment. In: Software Testing, Verification and Analysis, Banff, Canada, 1988, p. 142-151.

DeMillo, R. A.; Lipton, R. J.; Sayward, F. G. Hints on test data selection: Help for the practicing programmer. IEEE Computer, v. 11, n. 4, p. 34-43, 1978.

Di Nitto, E.; Lavazza, L.; Schiavoni, M.; Tracanella, E.; Trombetta, M. Deriving executable process descriptions from UML. In: Proc. ICSE 2002 - International Conference on Software Engineering, Orlando, Florida, USA, 2002.

DiAZ, E.; TUYA, J.; BLANCO, R. A modular tool for automated coverage in software testing. In: Proc. of the Eleventh Annual International Workshop on Software Technology and Engineering Practice (STEP'03), Amsterdam, The Netherlands, 2003, p. 241-246.

DiJKstra, E. W. A discipline of programming. Prentice-Hall, 1976.

Domingues, A. L. S. Avaliação de critérios e ferramentas de teste para programas $O O$. Dissertação de Mestrado, ICMC-USP, São Carlos - SP, 2002. 
Domingues, A. L. S. Aplicações web: definição e análise de recursos de teste e validação. Exame Geral de Qualificação para Doutorado, ICMC/USP, São Carlos/SP - Brasil (Doutorado em andamento), 2005.

Draheim, D.; Fehr, E.; Weber, G. Improving the web presentation layer architecture. In: Proc. on 5th Asia-Pacific Web Conference, APWeb 2003, Xian, China, INCS 2642, 2003.

DuBois, P.; Widenius, M. MySQL. 1 ed. New Riders Publishing, 1999.

Dumas, M.; TER Hofstede, A. H. M. UML activity diagrams as a workflow specification language. In: UML'01: Proc. of the 4th International Conference on the Unified Modeling Language, Modeling Languages, Concepts, and Tools, London, UK: Springer-Verlag, 2001, p. 76-90.

AD E. MORRIS, F. L. An overview of pcte: A basis for a portable common tool environment. Relatório Técnico, SEI - Software Engineering Institute, cMU/SEI-93-TR-1, 1993.

ECLIPSE.ORG The AspectJ programming guide. [On-line], World Wide Web, disponível em http://www.eclipse.org/aspectj/doc/next/progguide/index.html (Acessado em 21/02/2006), 2006.

EdELSTEIn, H. Unraveling client/server architecture. DBMS, v. 34, n. 7, 1994.

Eickelmann, N. S.; Richardson, D. J. An evaluation of software test environment architectures. In: Proc. of the 18th International Conference on Software Engineering, Berlin, Germany: IEEE Computer Society Press, 1996, p. 353-364.

Elrad, T.; Aksits, M.; Kiczales, G.; Lieberherr, K.; Ossher, H. Discussing aspects of AOP. Communications of the ACM, v. 44, n. 10, p. 33-38, $2001 \mathrm{a}$.

Elrad, T.; Filman, R. E.; BADER, A. Aspect-oriented programming. Communications of the ACM, v. 44, n. 10, p. 29-32, 2001 b.

EMAN, K. E.; Drouin, J.; MELO, W. SPICE: The theory and practice of software process improvement and capability determination. IEEE Press, 1997.

EMmerich, W. Software process - standards, assessments and improvement. In: Software Process: Principles, Methodology and Technology, Springer-Verlag, 1999, p. 15-25 (Lectures Notes in Computer Science, v.1500). 
FABBRI, S. C. P. F. A análise de mutantes no contexto de sistemas reativos: Uma contribuição para o estabelecimento de estratégias de teste e validação. Tese de Doutoramento, IFSC-USP, São Carlos - SP, 1996.

Fabbri, S. C. P. F.; Delamaro, M. E.; Maldonado, J. C.; Masiero, P. C. Proteum/FSM - especificação de uma ferramenta para apoiar a validação de máquinas de estado finito pelo critério análise de mutantes. In: 12th Simpósio Brasileiro de Redes de Computadores, Curitiba - PR, 1994a, p. 284-304.

Fabbri, S. C. P. F.; Maldonado, J. C.; Delamaro, M. E.; Masiero, P. C. Proteum/FSM: A tool to support finite state machine validation based on mutation testing. In: XIX SCCC - International Conference of the Chilean Computer Science Society, Talca, Chile, 1999a, p. 96-104.

Fabbri, S. C. P. F.; Maldonado, J. C.; Masiero, P. C. Mutation analysis in the context of reactive system specification and validation. In: 5th Annual International Conference on Software Quality Management, Bath, UK, 1997, p. 247-258.

Fabbri, S. C. P. F.; Maldonado, J. C.; Masiero, P. C.; Delamaro, M. E. Mutation analysis testing for finite state machines. In: 5th International Symposium on Software Reliability Engineering (ISSRE'94), Monterey - CA, 1994b, p. 220-229.

Fabbri, S. C. P. F.; Maldonado, J. C.; Masiero, P. C.; Delamaro, M. E. Mutation analysis applied to validate specifications based on petri nets. In: FORTE'95 - 8th IFIP Conference on Formal Descriptions Techniques for Distribute Systems and Communication Protocols, Montreal, Canada, 1995, p. 329-337.

Fabbri, S. C. P. F.; Maldonado, J. C.; Sugeta, T.; Masiero, P. C. Mutation testing applied to validate specifications based on statecharts. In: ISSRE - International Symposium on Software Reliability Engineering, 1999b, p. 210-219.

Falbo, R.; NAtali, A.; Mian, P.; Bertollo, G.; Ruy, F. Ode: Ontology-based software development environment. In: IX Congreso Argentino de Ciencias de la Computación, La Plata, Argentina, 2003, p. 931-940.

FALBO, R. A. Integração de conhecimento em um ambiente de desenvolvimento de software. Tese de Doutoramento, COOPE/Universidade Federal do Rio de Janeiro, Rio de Janeiro/RJ, 1998. 
Falbo, R. A.; Menezes, C. S.; Rocha, A. R. A systematic approach for building ontologies. In: IBERAMIA '98: Proc. of the 6th Ibero-American Conference on AI, London, UK: Springer-Verlag, 1998, p. 349-360.

FAlbo, R. A.; Pezzin, J.; Shwambach, M. M. A multi-agent system for knowledge delivery in a software engineering environment. In: Proc. of the 17th International Conference on Software Engineering and Knowledge Engineering (SEKE'2005), Taipei, 2005, p. 253-258.

FAYAD, M. E.; E.JOHnson, R.; SCHMIDT, D. C. Building application frameworks: Objectoriented foundations offramework design. New York - NY, USA: John Wiley \& Sons, 1999a.

FAYAD, M. E.; JOHnSOn, R. E. Domain-specific application frameworks: Frameworks experience by industry. John Wiley \& Sons, 2000.

FAYAD, M. F.; SCHMIDT, D. C.; JOHnSON, R. E. Implementing application frameworks. John Wiley \& Sons, 1999 b.

Feng, L.; Chang, E.; Dillon, T. A semantic network-based design methodology for XML documents. ACM Transactions on Information Systems, v. 20, n. 4, p. 390-421, 2002.

Fernández, M.; Gómez-PÉrez, A.; Juristo, N. Methontology: From ontological art to ontological engineering. In: Workshop on Knowledge Engineering: Spring Symposium Series (AAAI97), Mellow Park, CA, 1997, p. 33-40.

FERrari, F. C. Estudo e Documentação de uma Ferramenta de Teste de Software Baseado em Teste de Mutação. Relatório Final de Projeto de Iniciação Científica sob orientação de José Carlos Maldonado e Elisa Yumi Nakagawa, , Instituto de Ciências Matemáticas e de Computação - ICMC/USP, São Carlos, SP, 2004.

Ferrari, F. C. Apoio ao Teste Estrutural e de Mutação de Software Orientado a Objetos e a Aspectos. Exame Geral de Qualificação para Mestrado, ICMC/USP, São Carlos/SP - Brasil (Mestrado em andamento), 2005.

FERris, C.; FARrell, J. What are web services? v. 46, n. 6, p. 31, 2003.

FILMAN, R.; FRIEDMAN, D. Aspect-oriented programming is quantification and obliviousness. In: Workshop on Advanced Separation of Concerns, OOPSLA 2000, Minneapolis USA, 2000, p. 21-35.

Finkelstein, A.; Kramer, J.; (EDS.), B. N. Software process modeling and technology. John Wiley \& Sons, 1994. 
Florac, W. A.; CARleton, A. D. Measuring the software process: Statistical process control for software process improvement. Massachusetts: Addison-Wesley Publishing Company, 1999.

Florac, W. A.; Carleton, A. D.; Barnard, J. R. Statistical process control: Analyzing a space shuttle onboard software process. IEEE Software, v. 17, n. 4, p. 97-106, 2000.

FonseCA, R. P. Suporte ao teste estrutural de programas Fortran no ambiente Poke-Tool. Dissertação de Mestrado, DCA/FEEC/UNICAMP, Campinas, SP, 1993.

Fontoura, M.; Pree, W.; Rumpe, B. UML-F: A modeling language for object-oriented frameworks. Lecture Notes in Computer Science, v. 1850, p. 63-84, 2000.

Fontoura, M.; Pree, W.; RumPe, B. The UML profile for framework architecture. Object Techonology Series. Addison-Wesley Publishing Company, 2002.

Foster-Johnson, E. Graphical applications with $T c l \& T k .2$ ed. New York: M\&T Books, 1997.

FOWLER, M. Analysis patterns: Reusable object models. Addison-Wesley Series in ObjectOriented Software Engineering. Addison-Wesley Publishing Company, 1996.

Frankl, F. G.; WeyUker, E. J. Data flow testing tools. In: Softfair II, San Francisco, CA, 1985, p. 46-53.

Frankl, P. G.; Weyuker, E. J. An applicable family of data flow testing criteria. IEEE Transactions on Software Engineering, v. 14, n. 10, p. 1483-1498, 1988.

FRANKL, P. G.; WeyUKer, E. J. Testing software to detect and reduce risk. The Journal of Systems and Software, v. 53, n. 3, p. 275-286, 2000.

FREE SOFTWARE Foundation Categories of free and non-free software. [On-line], World Wide Web, disponível em http://www.gnu.org/philosophy/categories.html (Acessado em 09/02/2006), 2001.

Free Software Foundation Cvs - concurrent versions system. [On-line], World Wide Web, disponível em http: / /www. nongnu.org/cvs / (Acessado em 09/01/2006), 2006a.

FreE SOFTWARE Foundation Various licenses and comments about them. [On-line], World Wide Web, disponível em http://www.gnu.org/philosophy/license-list.html (Acessado em 09/02/2006), 2006b. 
Friedman, G.; Hartman, A.; Nagin, K.; Shiran, T. Projected state machine coverage for software testing. In: ISSTA 2002 - International Symposium on Software Testing and Analysis, Rome, Italy: ACM, 2002.

Froehlich, G.; Hoover, H. J.; LiU, L.; Sorenson, P. Hooking into object-oriented application frameworks. In: Proc. of the 19th International Conference on Software Engineering, Boston, Massachusetts, USA, 1997, p. 491 - 501.

Fuggetta, A. Software process: A roadmap. In: Proc. of the 22nd International Conference on the Future of Software Engineering, Limerick, Ireland: ACM - Association for Computing Machinery, 2000, p. 25-34.

GAL, A.; SchröDER-PReIKSChAT, W.; SpInCZYK, O. Aspectc++: Language proposal and prototype implementation. In: Proc. of the OOPSLA 2001 Workshop on Advanced Separation of Concerns in Object-Oriented Systems, Tampa, Florida, USA, 2001.

Gamma, E.; Helm, R.; Johnson, R.; Vlissides, J. Design patterns - elements of reusable object-oriented software. Addison-Wesley Publishing Company, 1995.

GANGOPADHYAY, D.; MitRA, S. Understanding frameworks by exploration of examplars. In: Proc. of 7th International Workshop on Computer Aided Software Engineering, Torono, Canada, 1995.

Gao, J.; Chen, C.; Toyoshima, Y.; Leung, D. Development an integrated testing environment using the World Wide Web technology. In: COMPSAC'97 - 21st International Computer Software and Applications Conference, Washington, USA, 1997, p. 594-601.

García-Rubio, F.; Ruiz-González, F.; Piattini-Velthuis, M. Software process measurement. European Journal for the Informatics Professional, v. 5, n. 5, p. 53 - 58, 2004.

Garcia, A.; Chavez, C.; Soares, S.; Piveta, E.; Penteado, R.; De Camargo, V. V.; Fernandes, F. Relatório do 1. Workshop Brasileiro de Desenvolvimento de Software Orientado a Aspectos (WASP 2004). 2004.

GARCIA, A. F. From objects to agents: An aspect-oriented approach. Tese de Doutoramento, Departamento de Informática, Pontifícia Universidade Católica do Rio de Janeiro, Rio de Janeiro, RJ, 2004.

Garlan, D. Software architecture: a roadmap. In: ICSE '00: Proc. of the Conference on The Future of Software Engineering, New York, NY, USA: ACM Press, 2000, p. 91-101. 
GARlAn, D.; KompaneK, A. J. Reconciling the needs of architectural description with object-modeling notations. In: Proc. of the Third International Conference on the Unified Modeling Language (UML 2000), York, UK: Springer-Verlag, 2000.

GARlAn, D.; PERRY, D. Introduction to the special issue on software architecture. IEEE Transactions on Software Engineering, v. 21, n. 4, 1995.

Garzotto, F.; Paolini, P.; D. Bolchini, S. V. Modeling-by-patterns of web applications. In: Proc. International Workshop on the World Wide Web and Conceptual Modeling, Paris, França, 1999.

GILL, A. Introduction to the theory of finite state machines. New York: McGraw-Hill, 1962.

Ginige, A.; Murugesan, S. Web engineering: An introduction. IEEE Multimedia, v. 8, n. 1, p. 1-5, 2001.

Godfrey, M. W.; TU, Q. Evolution in open source software: A case study. In: Proc. of the International Conference on Software Maintenance (ICSM'00), San Jose, CA, USA: IEEE Computer Society Press, 2000, p. 82-83.

Gremba, J.; Myers, C. The IDEAL model: A practical guide for improvement. Software Engineering Institute, Carnegie Mellon University, disponível em http://www.sei. cmu.edu/ideal/ideal.bridge.html (Acessado em 23/11/2002), 1997.

Grieskamp, W.; Gurevich, Y.; Schulte, W.; Veanes, M. Generating finite state machines from abstract state machines. In: ISSTA 2002 - International Symposium on Software Testing and Analysis, Rome, Italy: ACM, 2002.

Grosso, W. Knowledge modeling at the milennium (the design and evolution of Protégé2000). In: Knowledge Acquisition Workshop, Banff, Canada, 1999.

GRUBER, T. R. Ontolingua: A mechanism to support portable ontologies. Relatório Técnico, Knowledge Systems Laboratory, Stanford University, California, USA, disponível em http://www.ksl.stanford.edu/knowledge-sharing/papers/index.html (Acessado em 13/02/2006), 1992.

Grundy, J.; Welland, R.; Stoeckle, H. Workshop on directions in software engineering environments (WoDiSEE). In: ICSE '04: Proc. of the 26th International Conference on Software Engineering, Washington, DC, USA: IEEE Computer Society, 2004, p. 768-769. 
GuARINO, N. Formal ontology in information systems. In: Proc. of (FOIS'98), Trento, Italy: IOS Press, 1998, p. 3-15.

HAmLeT, R. G. Testing programs with the aid of a compiler. IEEE Transactions on Software Engineering, v. SE-3, n. 4, p. 279-290, 1977.

Hammouda, I.; Pussinen, M.; Katara, M.; Mikkonen, T. UML-based approach for documenting and specializing frameworks using patterns and concern architectures. In: 4th AOSD Modeling With UML Workshop, San Francisco, CA, USA, 2003.

HAREL, D. Statecharts: A visual formalism for complex systems. Science of Computer Programming, v. 8, p. 231-274, 1987.

Harel, D.; Lachover, H.; NaAmad, A.; Pnueli, A.; Politi, M.; Sherman, R.; Shtull-Trauting, A.; Trakhtenbrot, M. STATEMATE: A working environment for the development of complex reactive systems. IEEE Transactions on Software Engineering, v. 16, n. 4, p. 403-414, 1990.

HARRISON, W.; OSSHER, H.; TARR, P. Software engineering tools and environments: a roadmap. In: ICSE '00: Proc. of the Conference on The Future of Software Engineering, New York, NY, USA: ACM Press, 2000, p. 261-277.

Harrold, M. J. Testing: A roadmap. In: Proc. of the 22th International Conference on Software Engineering, Limerick, Ireland: ACM Press, 2000, p. 366-375.

Hartman, A.; NAgin, K. The AGEDIS tools for model based testing. In: ISSTA '04: Proc. of the 2004 ACM SIGSOFT international symposium on Software testing and analysis, ACM Press, 2004, p. 129-132.

Hartmann, J.; Imoberdorf, C.; Meisinger, M. UML-Based integration testing. In: ISSTA'2000 - International Symposium on Software Testing and Analysis, Portland, Oregon, USA: ACM, 2000.

HECKER, F. Setting up shop: The business of open-source software. IEEE Software, v. 17, n. 1, p. 45-51, 1999.

Hendrickson, E.; FOWLER, M. The software engineering on internet software. IEEE Software, v. 19, n. 2, p. 25-32, 2002.

Herbsleb, J.; Goldenson, D. A systematic survey of CMM experience and results. In: 18th International Conference on Software Engineering (ICSE '96), Berlin, Germany, 1996. 
Herman, P. M. A data flow analysis approach to program testing. Australian Computer Journal, v. 8, n. 3, 1976.

Ho, I.; LIN, J.-C. Generating test cases for real-time software by time petri nets model. In: Eighth Asian Test Symposium, Shanghai, China, 1999.

Hoffman, D.; Strooper, P. Tools and techniques for Java API testing. In: 2000 Australian Software Engineering Conference, Gold Coast, Queensland, Australia, 2000, p. 235-245.

HOLlingSWORTH, D. Workflow management coalition - the workflow reference model. Relatório Técnico TC00-1003, Workflow Management Coalition, Hampshire, Inglaterra, disponível em http: //wfmc.org/standards/docs/tc003v11.pdf (Acessado em 07/01/2006), 1995.

Horgan, J. R.; Mathur, P. Assessing testing tools in research and education. IEEE Software, v. 9, n. 3, p. 61-69, 1992.

HuAikou, M.; Ling, L. A test class framework for generating test cases from z specifications. In: Proc. of the 6th IEEE International Conference on Complex Computer Systems (ICECCS'00), Tokyo, Japan: ACM Press, 2000, p. 164-171.

Humphrey, W. S. A discipline for software engineering. SEI Series in Software Engineering. Addison-Wesley Publishing Company, 1995.

HumPHREY, W. S. Introduction to the personal software process. Massachusetts: AddisonWesley Publishing Company, 1997.

Huo, Q.; Zhu, H.; Greenwood, S. A multi-agent environment for testing web-based applications. In: Proc. of the 27th Annual International Computer Software and Applications Conference (COMPSAC'03), Dallas, TX, USA: IEEE Computer Society, 2003, p. 210-216.

IBM Business process execution language for web services. [On-line], World Wide Web, disponível em http://www-128.ibm.com/developerworks/library/specification/ ws-bpel / (Acessado em 07/01/2006), 2002.

IBM IBM Rational software products. Disponível em: http://www-306. ibm.com/software/sw-bycategory/subcategory/rational/sw730.html (Acessado em 10/02/2006), 2006.

IEEE IEEE standard glossary of software engineering terminology. Standard 610.12, IEEE Press, 1990. 
IEEE 829-1998 - IEEE standard for software test documentation. 1998a.

IEEE 830-1998 - IEEE recommended practice for software requirements specifications. 1998b.

IEEE 1471-2000 - IEEE recommended practice for architectural description of softwareintensive systems. 2000 .

IEEE Standard upper ontology working group (SUO WG). [On-line], World Wide Web, disponível em http://suo.ieee.org/(Acessado em 19/07/2005), 2005.

SofTwARE ENGINEERING Institute Capability maturity model integration (CMMI). [On-line], World Wide Web, disponível em http://www.sei.cmu.edu/cmmi/models/ models.html (Acessado em 23/11/2002), 2002.

INTERNATIONAL ORGANIZATION FOR STANDARDIZATION ISO 9000-3. Quality management and quality assurance standards. part 3: Guidelines for the application of iso 9001 to the development, supply and maintenance of software. 1991.

INTERNATIONAL ORGANIZATION FOR STANDARDIZATION ISO/IEC 12207. Information technology - software life-cycle processes. 1995.

INTERNATIONAL ORGANIZATION FOR STANDARDIZATION ISO 9000-3. Quality management and quality assurance standards. part 3: Guidelines for the application of iso 9001:1994 to the development, supply, installation and maintenance of computer software. 1997.

INTERNATIONAL ORGANIZATION FOR STANDARDIZATION ISO/IEC 15504. Software process assessment. 1998.

Isakowitz, T.; Stohr, E. A.; Balasubramanian, P. RMM: A methodology for the design of structured hypermedia applications. Communications of the ACM, v. 38, n. 8, p. 34 44, 1995.

JACKSON, D.; WoODWARD, M. Parallel firm mutation of Java programs. In: Mutation 2000 Symposium, San Jose, CA, 2000.

JACYNTho, M. D.; SCHWABE, D.; Rossi, G. A software architecture for structuring complex web applications. Jornal of Web Engineering, v. 1, n. 1, 2002.

Jaghdeesan, L. J.; Porter, A.; Puchol, C.; Ramming, J. C.; Votta, L. G. Specification-based testing of reactive software: tools and experiments: experience report. 
In: ICSE '97: Proc. of the 19th International Conference on Software Engineering, ACM Press, 1997, p. 525-535.

JENSEN, K. A brief introduction to coloured petri nets. In: BRINKSMA, E., ed. Lecture Notes in Computer Science: Tools and Algorithms for the Construction and Analysis of Systems. Proc. of the TACAS'97 Workshop, Enschede, The Netherlands 1997, Springer-Verlag, 1997, p. 201-208.

JeOn, T.; SEUng, H. W.; LeE, S. Embedding built-in tests in hot spots of an object-oriented framework. SIGPLAN Not., v. 37, n. 8, p. 25-34, 2002.

JÄGer, D.; Schleicher, A.; Westfechtel, B. Using UML for software process modeling. In: Proc. of the 7th European Engineering Conferenceheld jointly with the 7th ACM SIGSOFT Symposium on Foundations of Software Engineering, Springer-Verlag, 1999, p. 113 (Lectures Notes in Computer Science, v.1500).

Johnson, D. L.; Brodman, J. G. Applying CMM project planning practices to diverse environments. IEEE Software, v. 17, n. 4, p. 40-47, 2000.

JoHnson, R. Documenting frameworks using patterns. In: Proc. of OOPSLA'92, Vancouver, Canada, 1992, p. 63-76.

Jones, N. D.; Glenstrup, A. J. Program generation, termination, and binding-time analysis. In: The ACM SIGPLAN/SIGSOFT Conference on Generative Programming and Component Engineering, Springer-Verlag, 2002, p. 1-31 (Lectures Notes in Computer Science, v.2487).

Junkermann, G.; Peuschel, B.; Schäfer, W.; Wolf, S. Merlin: Supporting cooperation in software development through a knowledge-based environment. In: NUSEIBEH, B.; Finkelstein, A.; Kramer, J., eds. Software Process Modelling and Technology, John Wiley \& Sons, 1994, p. 103-129.

Juristo, N.; Moreno, A. M.; Vegas, S. Towards building a solid empirical body of knowledge in testing techniques. SIGSOFT Software Engineering Notes, v. 29, n. 5, p. 1-4, 2004.

KALINOwsKi, M. Patternflow: um software de workflow para a implementação e execução de processos de negócio customizados. Projeto Final do Curso de Ciência da Computação, DCC/UFRJ, 2001. 
KALINOWSKI, M. Infra-estrutura computacional de apoio a processo de inspeção de software. Dissertação de Mestrado, COOPE/Universidade Federal do Rio de Janeiro, Rio de Janeiro, RJ, 2004.

Kazman, R.; BASs, L.; AвоwD, G.; WebB, M. SAAM: A method for analyzing the properties of software architectures. In: Proc. of the 16th International Conference on Software Engineering, Sorrento, Italy, disponível em http://www . sei.cmu .edu/publications / articles/saam-metho-propert-sas.html (Acessado em 23/11/2002), 1994, p. 81-90.

Kazman, R.; Klein, M.; Barbacci, M.; Longstaff, T.; Lipson, H.; Carriere, J. The architecture tradeoff analysis method. In: Proc. of Fourth IEEE International Conference on Engineering Complex Computer Systems (ICECCS'98), Monterey, CA, Estados Unidos, 1998, p. 68-78.

KeEnI, G. The evolution of quality processes at tata consultancy services. IEEE Software, v. 17, n. 4 , p. $79-88,2000$.

KEMMERER, R. A. Testing formal specifications to detect design errors. IEEE Transactions on Software Engineering, v. 11, n. 1, p. 32-43, 1985.

KERER, C.; KirdA, E. Layout, content and logic separation in web engineering. In: Web Engineering: Managing Diversity and Complexity of Web Application Development, SpringerVerlag, 2001, p. 135-147 (Lectures Notes in Computer Science, v.2016).

KerR, J.; Hunter, R. Inside RAD. McGraw-Hill, 1994.

Kiczales, G.; Hilsdale, E.; Hugunin, J.; Kersten, M.; Palm, J.; Griswold, W. G. Getting started with AspectJ. Communications of the ACM, v. 44, n. 10, p. 59-65, 2001a.

Kiczales, G.; Hilsdale, E.; Hugunin, J.; Kersten, M.; Palm, J.; Griswold, W. G. An overview of AspectJ. In: ECOOP '01: Proc. of the 15th European Conference on ObjectOriented Programming, Springer-Verlag, 2001b, p. 327-353.

Kiczales, G.; Irwin, J.; Lamping, J.; Loingtier, J.; Lopes, C.; MaedA, C.; MeNhDheKar, A. Aspect-oriented programming. In: Akşıt, M.; MatsuoKa, S., eds. Proc. of the European Conference on Object-Oriented Programming, Berlin, Heidelberg, and New York: Springer-Verlag, 1997, p. 220-242.

KIM, H. Aspectc\#: An aosd implementation for c\#. Dissertação de Mestrado, Trinity College, Dublin, 2002. 
KNAUber, P.; Succi, G. Perspectives on software product lines. Report on First International Workshop on Software Product Lines: Economics, Architectures, and Implications, Workshop \#15 at 22nd International Conference on Software Engineering (ICSE), 2000.

KnOWledge Systems LABORATORY Ontolingua. [On-line], World Wide Web, disponível em http://www.ksl.stanford.edu/software/ontolingua/ (Acessado em 15/02/2006), 2006.

Krasner, G. E.; POPE, S. T. A cookbook for using the model-view-controller user interface paradigm in smalltalk-80. Journal of Object Oriented Programming, 1988.

Krauser, E. W.; Mathur, A. P.; Rego, V. J. High performance software testing on simd machines. IEEE Transactions on Software Engineering, v. SE-17, n. 5, p. 403-422, 1991.

Kruchten, P. The 4+1 view model of architecture. IEEE Software, v. 12, n. 6, p. 42-50, 1995.

LARman, C. Utilizando UML e padrões. Porto Alegre: Bookman, 2000.

LeE, J.; Yost, G.; THE PIF Working GrouP The PIF process interchange format and framework. [On-line], World Wide Web, disponível em http://ccs.mit.edu/pifmain. html (Acessado em 07/01/2006), 1994.

LeE, Y.; Byun, Y.; XiaO, J.; Goh, O.; Wong, W. E.; LeE, A. A toolsuite for testing real-time Ada applications. In: 3rd IEEE Symposium on Application-Specific Systems and Software Engineering Technology (ASSET'00), Richardson Texas, USA, 2000, p. 65-69.

LEITÃo, P. S. J. Suporte ao teste estrutural de programas Cobol no ambiente Poke-Tool. Dissertação de Mestrado, DCA/FEE/UNICAMP, Campinas, SP, 1992.

Lemos, O. A. L. Teste de programas orientados a aspectos: Uma abordagem estrutural para AspectJ. Dissertação de Mestrado, ICMC/USP, São Carlos/SP - Brasil, 2005.

Lemos, O. A. L.; Vincenzi, A. M. R.; Maldonado, J. C.; Masiero, P. C. Teste de unidade de programas orientados a aspectos. In: Anais do $18^{\text {th }}$ Simpósio Brasileiro de Engenharia de Software (SBES'2004), Brasília/DF - Brasil, 2004, p. 55-70.

LI, J. J.; Horgan, J. R. A tool suite for diagnosis and testing of software design specifications. In: Proc. of the 2000 International Conference on Dependable Systems and Networks (DSN 2000), New York, USA, 2000, p. 295-304. 
LiU, C.; Kung, D. C.; Hsia, P.; Hsu, C. Structural testing of web applications. In: Proc. of the 11th International Symposium on Software Reliability Engineering (ISSRE'00), San Jose, California, USA, 2000.

LONCHAMP, J. An assessment exercise in software process modelling and technology, cap. 13 Research Studies Press, p. 335-356, 1994.

Luckhama, D. C.; Kenney, J. J.; Augustin, L. M.; Vera, J.; Bryan, D.; Mann., W. Specification and analysis of system architecture using rapide. IEEE Transactions on Software Engineering, v. 21, n. 4, p. 336-355, 1995.

Lucrédio, D.; Bianchini, C. P.; Prado, A. F.; Trevelin, L. C.; Almeida, E. S. Orion - a component-based software engineering environment. Journal of Object Technology (JOT), v. 4, n. 3, p. 51-74, special issue: TOOLS USA 2003, 2004.

LutZ, M. Testing tools. IEEE Software, v. 7, n. 3, 1990.

MA, Y.; OffutT, J.; Kwon, Y. R. Mujava: An automated class mutation system. Journal of Software Testing, Verification and Reliability, v. 15, n. 2, p. 97-133, 2005.

MA, Y.-S.; KWON, Y.-R.; OFFUTT, J. Inter-class mutation operators for Java. In: Proc. of the 13th International Symposium on Software Reliability Engineering, Annapolis, MD: IEEE Computer Society Press, 2002, p. 352-363.

Machado, C.; Oliveira, L.; Fernandes, R. Experience report - Restructure of processes based on ISO/IEC 12207 and SW-CMM in CELEPAR. In: Fourth IEEE International Symposium and Forum on Software Engineering Standards, Curitiba, PR, 1999.

MaCHADO, C. A. F. Qualidade de software: Teoria e prática, cap. NBR ISO/IEC 12207 Processo de Ciclo de Vida de Software. In: Rocha et al. (2001a), p. 9-16, 2001.

MAIDANTCHIK, C. L. L. Gerência de processos de software para equipes geograficamente dispersas. Tese de doutorado, COOPE/Universidade Federal do Rio de Janeiro, Rio de Janeiro - RJ, 1999.

Maldonado, J. C. Critérios potenciais usos: Uma contribuição ao teste estrutural de software. Tese de Doutoramento, DCA/FEE/UNICAMP, Campinas, SP, 1991.

Maldonado, J. C.; Barbosa, E. F.; Vincenzi, A. M. R.; Delamaro, M. E.; Souza, S. R. S.; JinO, M. Introdução ao teste de software. Notas Didáticas N. 65, Instituto de Ciências Matemáticas e de Computação, ICMC/USP, 2004. 
Maldonado, J. C.; Delamaro, M. E.; Fabbri, S. C. P. F.; Simão, A. S.; Sugeta, T.; Vincenzi, A. M. R.; MAsiero, P. C. Proteum: A family of tools to support specification and program testing based on mutation. In: Mutation 2000 Symposium - Tool Session, San Jose, CA: Kluwer Academic Publishers, 2000, p. 113-116.

Maldonado, J. C.; Vincenzi, A. M. R.; Barbosa, E. F.; Souza, S. R. S.; DelaMARO, M. E. Aspectos teóricos e empíricos de teste de cobertura de software. Relatório Técnico 31, Instituto de Ciências Matemáticas e de Computação - ICMC-USP, 1998.

Martin, R. C. Extreme programming development through dialog. IEEE Software, v. 17, n. 4, p. 12-13, 2000.

Martins, E.; Sabião, S. B.; Ambrosio, A. M. Condata: a tool for automating specification-based test case generation for communication systems. In: Proc. of the 33rd Hawaii International Conference on System Sciences, Maui, Hawaii, 2000.

Masiero, P. C.; Fortes, R. P. M.; Neto, J. E. S. B. Edição e simulação do aspecto comportamental de sistemas de tempo real. In: Anais do XI Congresso Nacional da SBC XVIII SEMISH, Santos, SP, 1991, p. 45-61.

Mathur, A. P.; KRAUSER, W. Mutant unification for improved vectorization. Relatório Técnico SERC-TR14-P, Software Engineering Research Center, Purdue University, 1988.

Maurer, F.; Dellen, B.; Bendeck, F.; Goldmann, S.; Holz, H.; Kötting, B.; SCHAAF, M. Merging project planning and web-enabled dynamic workflow technologies. IEEE Internet Computing, v. 4, n. 3, p. 65-74, 2000.

MAURER, F.; MARTEL, S. Extreme programming: Rapid development for web-based applications. IEEE Internet Computing, v. 6, n. 1, p. 86-90, 2002.

Maurer, F.; Succi, G.; Holz, H.; Kötting, B.; Goldmann, S.; Dellen, B. Software process support over the internet. In: Proc. of the 1999 International Conference on Software Engineering, Los Angeles, California, USA: IEEE Computer Society Press, 1999, p. 642-645.

Medvidovic, N.; Oreizy, P.; Robbins, J. E.; TAylor, R. N. Using object-oriented typing to support architectural design in the C2 style. In: Proc. of ACM SIGSOFT'96: Fourth Symposium on the Foundations of Software Engineering, San Francisco, CA, USA, 1996, p. 24-32. 
Medvidovic, N.; Rosenblum, D. S.; Redmiles, D. F.; Robbins, J. E. Modeling software architectures in the unified modeling language. ACM Trans. Softw. Eng. Methodol., v. 11, n. 1, p. 2-57, 2002.

Medvidovic, N.; TAYlor, R. N. A classification and comparison framework for software architecture description languages. IEEE Transactions on Software Engineering, v. 26, n. 1, p. 70-93, 2000.

Mendes, A. Arquitetura de software: Desenvolvimento orientado para arquitetura. Campus, 2002.

Merson, P. Como documentar arquiteturas de software. SEI/Carnegie Mellon University, Material de apoio, mini-curso do $19^{\circ}$ SBES (Simpósio Brasileiro de Engenharia de Software), 05 a 07/10/2005, Uberlândia, MG, 2005.

Mian, P. G. Oded: Uma ferramenta de apoio ao desenvolvimento de ontologias em um ambiente de desenvolvimento de software. Dissertação de Mestrado, UFES, Vitória, ES, 2003.

MiAO, H.; GAO, X.; LiU, L. An approach to testing the nonexistence of initial state in z specifications. In: Eighth Asian Test Symposium, Shanghai, China, 1999.

Misurda, J.; Clause, J.; Reed, J. L.; Childers, B. R.; Soffa, M. L. Demanddriven structural testing with dynamic instrumentation. In: Proc. of the 27th International Conference on Software Engineering (ICSE'05), St. Louis, Missouri, USA: ACM SIGSOFT, 2005a.

Misurda, J.; Clause, J.; Reed, J. L.; Gandra, P.; Childers, B. R.; Soffa, M. L. Jazz: A tool for demand-driven structural testing. In: Proc. of the 14th ETAPS International Conference on Compiler Construction (CC), Edinburgh, Scotland, 2005b.

MÜller, M. M.; TICHY, W. F. Case study: extreme programming in a university environment. In: Proc. of the 23rd International Conference on Software Engineering, Toronto, Ontario, Canada, 2001, p. 537-544.

Mockus, A.; Fielding, R. T.; JAmes Helbsled A case study of open source software development: The Apache server. In: Proc. of the 22nd International Conference on Software Engineering, Limerick, Ireland, 2000. 
Mockus, A.; Fielding, R. T.; Herbsleb, J. Two case studies of open source software development: Apache and Mozilla. ACM Transactions on Software Engineering and Methodology, v. 11, n. 3, p. 309-346, 2002.

Monday, P.; CARey, J.; DAngler, M. Sanfrancisco component framework: An introduction. Addison-Wesley Publishing Company, 2000.

Montangero, C. The software process: Modelling and technology. In: The Software Process: Principles, Methodology, and Technology, Springer-Verlag, 1999, p. 1-13 (Lectures Notes in Computer Science, v.1500).

Montangero, C.; Ambriola, V. Oikos: Constructing process centered SDEs. In: FinKelstein, A.; Kramer, J.; Nuseibeh, B., eds. Software Process Modelling and Technology, John Wiley \& Sons, 1994, p. 103-129.

Moreira, M. A.; Buchweitz, B. Instrumentos didáticos, de avaliação e de análise de currículo. São Paulo: Editora Moraes Ltda, 1987.

Morisio, M.; Tully, C.; EzRAn, M. Diversity in reuse processes. IEEE Software, v. 17, n. 4 , p. $56-63,2000$.

Mortensen, M.; Alexander, R. T. Adequate testing of aspect-oriented programs. Relatório Técnico CS 04-110, Department of Computer Science, Colorado State University, Fort Collins, Colorado, USA, 2004.

Moulding, P. PHP black box. The Coriolis Group, 2001.

Myers, G. J. The art of software testing. New York: John Wiley \& Sons, 1979.

Myers, G. J.; SAndler, C.; BAdgett, T.; Thomas, T. M. The art of software testing. 2nd. ed. John Wiley \& Sons, 2004.

NAKAGAWA, E. Y. An investigation of the open source development process. In: 4. JIISIC (Jornadas Iberoamericanas de Ingeniería del Software e Ingeniería del Conocimiento), Madri, Espanha, 2004a, p. 617-632.

NAKagAwa, E. Y. Software livre na informatização de acervos históricos. In: V Workshop sobre Software Livre, V Fórum Internacional Software Livre, Porto Alegre, RS, 2004b, p. $157-160$. 
Nakagawa, E. Y.; Bianchi, T.; Fischer, P.; Maldonado, J. C. Memória virtual: Estabelecimento da arquitetura e requisitos do sistema. In: VI Workshop sobre Software Livre, VI Fórum Internacional Software Livre, Porto Alegre, RS, 2005.

Nakagawa, E. Y.; Maldonado, J. C. Software livre: Conceitos e processo de desenvolvimento. Relatório Técnico, Instituto de Ciências Matemáticas e de Computação - ICMC/USP, São Carlos, SP, (Relatório técnico em preparação), 2006.

NakaZAto, K. K. Módulo de geração de seqüências de teste baseada em máquinas de estado finito. Dissertação de Mestrado, ICMC/USP, São Carlos, SP, 1995.

Nguyen, H. Q. Testing applications on the web. John Wiley \& Sons, 2001.

NguYen, M. N.; WAnG, A. I.; CONRADI, R. Total software process model evolution in EPOS. In: Proc. of the 1997 International Conference on Software Engineering, Boston, Massachusetts, USA: ACM Press, 1997, p. 390-399.

NiELsen, J. Usability engineering. Academic Press, 1993.

Nielsen, J. Projetando websites. Campus, 2000.

Nierstrasz, O.; GiBBs, S.; TsiChritZis, D. Component-oriented software development. Communications of the ACM, v. 35, n. 9, p. 160-165, 1992.

Niese, O.; Margaria, T.; Steffen, B. Automated functional testing of web-based applications. In: Proc. of the 5th International Conference on Software and Internet Quality Week Europe (QWE'02), Brussels, Belgium, 2002.

NIST PSL - process specification language. [On-line], World Wide Web, disponível em http: //www.mel.nist.gov/psl/ (Acessado em 07/01/2006), 2006.

Nonaka, I.; Takeushi, H. Criação de conhecimento na empresa. Campus, 1997.

NovaK, J. Concept mapping: A useful tool for science education. Journal of Research in Science Teaching, v. 27, n. 10, p. 937-949, 1990.

NunES, V. B. Integrando gerência de configuração de software, documentação e gerência de conhecimento em um ambiente de desenvolvimento de software. Dissertação de Mestrado, UFES, Vitória, Espírito Santo, 2005.

Nunes, V. B.; SoAres, A. O.; FAlbo, R. A. Apoio à documentação em um ambiente de desenvolvimento de software. In: VII Workshop Iberoamericano de Ingeniería de Requisitos y Desarrollo de Ambientes de Software (IDEAS'2004), Arequipa, Perú, 2004, p. 50-55. 
Object Management Group Unified modeling language. [On-line], World Wide Web, disponível em http: / /www. uml .org/ (Acessado em 24/12/2005), 2005.

OfFUTT, J. Quality attributes of web software applications. IEEE Software, v. 19, n. 2, p. 25-32, 2002.

OfFutT, J.; MA, Y.; KWON, Y. An experimental mutation system for Java. SIGSOFT Software Engineering Notes, v. 29, n. 5, p. 1-4, 2004.

Offutt, J.; Pargas, R.; Fichter, S.; Khambekar, P. Mutation testing of software using a MIMD computer. In: Proc. of the International Conference on Parallel Processing (ICPP' 92), Chicago, Illinois, 1992, p. II-257-266.

O'HARA, F. European experiences with software process improvement. In: Proc. of the 22nd International Conference on Software Engineering, Limerick, Ireland: ACM Press, 2000, p. 635-640.

Oliveira, K.; Menezes, C.; Travassos, G.; Rocha, A. Ambiente de desenvolvimento de software orientado a domínio. In: XIV Simpósio Brasileiro de Engenharia de Software, João Pessoa, PB, 2000, p. 275-290.

Olsina, L.; LAfuente, G.; Rossi, G. Specifying quality characteristics and attributes for websites. In: Web Engineering: Managing Diversity and Complexity of Web Application Development, Springer-Verlag, 2001, p. 266-278 (Lectures Notes in Computer Science, v.2016).

Open Source Initiative The open source initiative: The approved licenses. [Online], World Wide Web, disponível em http://www.opensource.org/licenses/index. html (Acessado em 09/02/2006), 2006.

O'Reilly, T. Lessons from open-source software development. Communications of the $A C M$, v. 42, n. 4, 1999.

ORIKASA, K. M. Investigação e apoio na implementação da interface do usuário de um sistema web para gestão integrada de acervos históricos. Relatório Final de Projeto de Iniciação Científica sob orientação de Elisa Yumi Nakagawa e José Carlos Maldonado, Instituto de Ciências Matemáticas e de Computação - ICMC/USP, São Carlos, SP, 2005.

Osterweil, L. J. Software processes are software too. In: Proc. 9th International Conference on Software Engineering, Monterey, California, USA: IEEE Computer Society Press, 
(Uma versão revisada do artigo foi publicada em 1997 no ICSE (International Conference on Software Engineering)), 1987, p. 2-13.

Osterweil, L. J. Software processes are software too (revised). In: Proc. of the 1997 International Conference on Software Engineering, Boston, Massachusetts, USA: ACM Press, 1997.

PAinter, R. A.; Turner, A. J. Introduction to VisualWorks. [On-line], World Wide Web, disponível em http://ftp.squeak.org/docs/VW/VWCover.html (Acessado em 18/02/2006), 1996.

Palmer, S. R.; Felsing, J. M. A practical guide to feature-driven development. 1 ed. Prentice Hall, 2002.

Paulk, M. C.; Curtis, B.; Chrissis, M. B.; Weber, C. V. CMM capability maturity model for software, version 1.1. TR 24, SEI - Software Engineering Institute, 1993.

PaulK, M. C.; Weber, C. V.; Curtis, B.; Chrissis, M. B. The capability maturity model: Guidelines for improving the software process. The SEI Series in Software Engineering. Massachusetts: Addison-Wesley Publishing Company, 1995.

PAZIN, A. Gawcre: Um de gerador de aplicações baseadas na web para o domínio de gestão de clínicas de reabilitação. Dissertação de Mestrado, Programa de Pós-Graduação em Ciência Da Computação, Universidade Federal ee São Carlos, 2004.

PERENS, B. Open sources: Voices of the open source revolution, cap. The Open Source Definition. 1 ed O’Reilly \& Associates, p. 171-188, 1999.

Perl Institute Perl Mongers. [On-line], World Wide Web, disponível em http://www . perl.org/ (Acessado em 23/11/2002), 2001.

PERROCHON, L. A reference architecture for multi-author world-wide web servers. In: COCS '95: Proc. of conference on Organizational computing systems, New York, NY, USA: ACM Press, 1995, p. 197-205.

PERRY, W. Effective methods for software testing. John Wiley \& Sons, 1995.

PessôA, M. S. P.; SPINOlA, M. M. Qualidade de software: Teoria e prática, cap. CMM. In: Rocha et al. (2001a), p. 22-28, 2001.

Peterson, J. L. Petri nets theory and modelling of systems. Eaglewood Cliffs - NJ: Prentice Hall, 1981. 
Petrenko, A.; Bochmann, G. V. On fault coverage of tests for finite state specifications. Relatório Técnico, Département d'Informatique et recherche opérationnelle - Université de Montréal, (http://www.iro.umontreal.ca/pub/teleinfo/TRs/Petr96b.ps.gz), 1996.

PHOHA, V. A standard for software documentation. IEEE Computer, v. 30, n. 10, p. 97-98, 1997.

Pinto, M.; Fuentes, L.; Fayad, M. E.; Troya, J. M. Separation of coordination in a dynamic aspect oriented framework. In: AOSD '02: Proc. of the 1st international conference on Aspect-oriented software development, New York, NY, USA: ACM Press, 2002, p. 134 140.

Pitterman, B. Telcordia technologies: The journey to high maturity. IEEE Software, v. 17, n. 4 , p. 89-96, 2000.

Pohl, K.; Weidenhaupt, K.; Dömges, R.; Haumer, P.; Jarke, M.; Klamma, R. PRIME: Towards Process-Integrated Modeling Environments. ACM Transactions on Software Engineering and Methodology, v. 8, n. 4, p. 343-410, 1999.

Poole, C.; Huisman, J. W. Using extreme programming in a maintenance environment. IEEE Software, v. 18, n. 6, p. 42-50, 2001.

PREE, W. Design patterns for object-oriented software development. New York-NY, USA: Addison-Wesley, 1995.

PreE, W. Hot-spot-driven development, cap. Framework Design by Systematic Generalization John Wiley \& Sons, p. 379-394, 1999.

Pressman, R. S. Software engineering - a practitioner's approach. 5 ed. McGraw-Hill, 2000.

Price, A. M.; Zorzo, A. Visualizando o fluxo de controle de programas. In: IV Simpósio Brasileiro de Engenharia de Software, Águas de São Pedro, SP, 1990.

Probert, R. L.; Guo, F. Mutation testing of protocols: Principles and preliminary experimental results. In: IFIP TC6 - Third International Workshop on Protocol Test Systems, North-Holland, 1991, p. 57-76.

RÉ, R. Um processo para construção de frameworks a partir da engenharia reversa de sistemas de informação baseados na web: Aplicação ao domínio dos leilões virtuais. Dissertação de Mestrado, ICMC/USP, São Carlos - SP, dissertação de Mestrado, 2002. 
RAmAKRishnan, R.; Gehrke, J. Database management systems. 2 ed. McGraw-Hill, 2000.

RAPPS, S.; WeYUKER, E. J. Selecting software test data using data flow information. IEEE Transactions on Software Engineering, v. SE-11, n. 4, p. 367-375, 1985.

Rashid, A.; Chitchyan, R. Persistence as an aspect. In: AOSD'03: Proc. of the 2nd International Conference on Aspect-oriented Software Development, New York, NY, USA: ACM Press, 2003, p. 120-129.

Rashid, A.; Moreira, A.; AraúJo, J. Modularisation and composition of aspectual requirements. In: AOSD'03: Proc. of the 2nd International Conference on Aspect-oriented Software Development, ACM Press, 2003, p. 11-20.

Rausch, A.; Rumpe, B.; Hoogendoorn, L. Aspect-oriented framework modeling. In: AkKawi, F.; Aldawud, O.; Booch, G.; Clarke, S.; Gray, J.; Harrison, B.; Kandé, M.; SteIn, D.; TARR, P.; ZAKARIA, A., eds. The 4th AOSD Modeling With UML Workshop, 2003.

RaYmond, E. S. The Cathedral and the Bazaar. O'Reilly \& Associates, 1999.

REIS, C. R. Caracterização de um processo de software para projetos de software livre. Dissertação de Mestrado, ICMC/USP, São Carlos - SP, dissertação de Mestrado, 2003.

REISS, S. P. Interacting with the FIELD environment. Software Practice Experience, v. 20, n. S1, p. 89-115, 1990.

REISS, S. P. FIELD: A friendly integrated environment for learning and development. Kluwer Press, 1994.

REISS, S. P. The Desert environment. ACM Transactions on Software Engineering and Methodology, v. 8, n. 4, p. 297-342, 1999.

RiccA, F.; Tonella, P. Analysis and testing of web applications. In: Proc. of the 23rd International Conference on Software Engineering, Toronto, Ontario, Canada, 2001, p. 25-34.

Richardson, D. J. TAOS: Testing with analysis and oracle support. In: Proc. of the 1994 International Symposium on Software Testing and Analysis, Seatle, Washington, USA: ACM Press, 1994, p. 138-153. 
Riesco, D.; Acosta, E.; Montejano, G. Uml and the unified process, cap. An extension to a UML activity graph from workflow Hershey, PA, USA: Idea Group Publishing, p. 294 314, 2003.

RISING, L.; JANOFF, N. S. The scrum software development process for small teams. IEEE Software, v. 17, n. 4, p. 26-32, 2000.

Roberts, D.; JOHNSOn, R. Evolving frameworks: A pattern language for developing object-oriented frameworks. [On-line], World Wide Web, disponível em http://st-www . cs.uiuc.edu/users/droberts/evolve.html (Acessado em 12/02/2006), 2006.

RochA, A. D. Uma ferramenta baseada em aspectos para apoio ao teste funcional de programas java. Dissertação de Mestrado, Instituto de Ciências Matemáticas e de Computação, Universidade de São Paulo, São Carlos, SP, 2005.

Rocha, A. R. C.; Aguiar, T. C.; SouzA, J. M. TABA: a heuristic workstation for software development. In: Proc. of the 1990 IEEE International Conference on Computer Systems and Software Engineering (COMPEURO'90), Tel Aviv, Israel, 1990, p. 126-129.

Rocha, A. R. C.; Maldonado, J. C.; Weber, K. C. Qualidade de software: Teoria e prática. 1 ed. São Paulo: Person Education do Brasil/Makron Books, 2001a.

Rocha, A. R. C.; Oliveira, K.; Machado, L. F.; Souza, G. S.; Travassos, G. H.; FAlbo, R.; RAPCham, F.; Menezes, C. Qualidade de software: Teoria e prática, cap. Automatização da Definição de Processos de Software. In: Rocha et al. (2001a), p. 192-199, $2001 b$.

RochA, V.; PAZ, C.; Guerra, E.; Ross, E. Arquitetura orientada a aspectos para construção de aplicações seguras. In: Anais do XXV Congresso Nacional da SBC - XXXII SEMISH, São Leopoldo, RS: ACM Press, 2005, p. 1887-1901.

Rossi, G.; Schwabe, D.; Guimarẽes, R. Designing personalized web applications. In: Proc. of the Tenth International Conference on World Wide Web, Hong Kong, Hong Kong: ACM Press, 2001, p. 275-284.

Royce, W. W. Managing the development of large software systems: Concepts and techniques. In: Proc. of IEEE WESTCON, Los Angeles, CA, USA: ACM - Association for Computing Machinery, 1970, p. 1-9.

Rumbaugh, J.; JacobSOn, I.; BoOCH, G. The unified modeling language reference manual. Massachusetts: Addison-Wesley Publishing Company, 1999. 
SAdoski, D.; COMElla-Dorda, S. Three tier software architectures. [On-line], World Wide Web, disponível em http://www.sei.cmu.edu/str/descriptions/threetier.html (Acesso em 28/03/2005), 1997.

SAFE Engenharia de Software Disponível a Todos (Software Engineering Available for Everyone). Disponível em: http://safe.icmc.usp.br/safe/ (Acesso em 09/02/2006) Instituto de Ciências Matemáticas e de Computação - ICMC/USP, São Carlos, SP. (Projeto aprovado na FINEP e coordenado pelo Profa. Dra. Renata Pontin de Mattos Fortes)., 2003.

SAMPAiO, A.; ChITCHYAN, R.; RAYson, P. Ea-miner: a tool for automating aspectoriented requirements identification. In: ASE '05: Proc. of the 20th IEEE/ACM international Conference on Automated software engineering, New York, NY, USA: ACM Press, 2005, p. 352-355.

SANADA, Y.; ADAMS, R. Representing design patterns and frameworks in uml: Towards a comprehensive approach. Journal of Object Technology (JOT), v. 1, n. 2, p. 143-154, 2002.

SANDKUHL, K.; MESSER, B. Towards reference architectures for distributed groupware applications. In: 8th Euromicro Workshop on Parallel and Distributed Processing, Rhodes, Greece, 2000.

SCACCHI, W. Software development practices in open software development communities. In: 1st Workshop on Open Source Software Engineering, Toronto, Ontario, 2001.

SCACCHI, W. Understanding the requirements for developing open source software systems. In: IEE Proc. - Software Engineering, 2002a.

SCACCHI, W. Understanding the social, technological, and policy implications of open source software development. In: NSF Workshop on Open Source Software, Toronto, Ontario, 2002b.

Scacchi, W.; Feller, J.; Fitzgerald, B.; Hissam, S.; Lakhani, K. Understanding free/open source software development processes. Software Process: Improvement and Practice, v. 11, n. 1, a ser publicado, 2006.

SCHMID, H. A. Creating the architecture of a manufacturing framework by design patterns. In: Proc. of OOPSLA'95, Austin, Texas, 1995, p. 370-384.

SCHMID, H. A. Building application frameworks, cap. Framework Design by Systematic Generalization New York - NY, USA: John Wiley \& Sons, p. 353-378, 1999. 
SchwaBE, D.; Rossi, G. The object-oriented hypermedia design model (OOHDM). Communications of the ACM, v. 38, n. 8, p. 45-46, 1995.

Schwabe, D.; Rossi, G.; Esmeraldo, L. Engineering web applications for reuse. IEEE Multimedia, v. 8, n. 1, p. 20-31, 2001.

SEI Component-based software development - cots integration. [On-line], World Wide Web, disponível em http://www.sei.cmu.edu/str/descriptions/cbsd.html (Acessado em 20/02/2006), 1997.

Sharon, D.; Anderson, T. A complete software engineering environment. IEEE Software, v. 14, n. 2, p. 123-127, 1997.

Shaw, M.; Clements, P. A field guide to boxology: Preliminary classification of architectural styles for software systems. In: Proc. COMPSAC97, 21st International Computer Software and Applications Conference, Washington, USA, 1997, p. 7-13.

SILVA, P. F. M. Investigação e projeto de um sistema de help para sistemas web. Plano de Projeto de Iniciação Científica sob orientação de Elisa Yumi Nakagawa e José Carlos Maldonado, , Instituto de Ciências Matemáticas e de Computação - ICMC/USP, São Carlos, SP, 2005.

SIMÃo, A. S. Proteum-RS/PN: Uma ferramenta para a validação de redes de petri baseada na análise de mutantes. Dissertação de Mestrado, ICMC/USP, São Carlos, SP, 2000.

SimÃo, A. S.; Maldonado, J. C. Geração de seqüências para redes de Petri baseadas em mutação. In: III Workshop de Métodos Formais, João Pessoa, in Portuguese, 2000.

Simão, A. S.; Maldonado, J. C.; Fabbri, S. C. P. F. Proteum-RS/PN: A tool to support edition, simulation and validation of Petri nets based on mutation testing. In: SBES'2000 Simpósio Brasileiro de Engenharia de Software, João Pessoa, 2000.

Simão, A. S. Aplicação da análise de mutantes no contexto do teste e validação de redes de petri coloridas. Tese de doutorado, Instituto de Ciências Matemáticas e de Computação ICMC/USP, São Carlos, SP, 2004.

Simon, I. The Cathedral and Bazaar. [On-line], World Wide Web, disponível em http://www.ime.usp.br/ is/ddt/mac333/aulas/tema-6-15abr99.html (Acessado em 23/11/2002), 2002. 
SMARAGDAKIS, Y.; BATORY, D. Encyclopedia of electrical and electronics engineering, cap. Application generators John Wiley and Sons, 2000.

Smaragdakis, Y.; HuAng, S. S.; ZoOK, D. Program generators and the tools to make them. In: Proc. of the 2004 ACM SIGPLAN symposium on Partial evaluation and semanticsbased program manipulation, ACM Press, 2004, p. 92-100.

SoARES, S.; LAUREANO, E.; Borba, P. Implementing distribution and persistence aspects with aspectj. In: OOPSLA '02: Proc. of the 17th ACM SIGPLAN conference on Objectoriented programming, systems, languages, and applications, New York, NY, USA: ACM Press, 2002, p. 174-190.

Software EngINEERING InStitute How do you define software architecture? [On-line], World Wide Web, disponível em http://www.sei.cmu.edu/architecture/definitions. html (Acessado em 22/05/2005), 2005.

Sommerville, I. Software process models. ACM Computing Surveys, v. 28, n. 1, p. 269$271,1996$.

Sommerville, I. Software engineering. 6 ed. Addison-Wesley Publishing Company, 2001.

SOURCEFORGE.NET Project based on aspect-oriented programming. [On-line], World Wide Web, disponível em http://sourceforge.net/softwaremap/trove_list.php?form_cat= 598 (Acessado em 21/06/2006), 2006.

Souter, A. L.; Pollock, L. L. OMEN: A strategy for testing object-oriented software. In: ISSTA’2000 - International Symposium on Software Testing and Analysis, Portland, Oregon, USA: ACM, 2000.

SouzA, S. R. S. Avaliação do custo e eficácia do critério análise de mutantes na atividade de teste de programas. Dissertação de Mestrado, ICMC-USP, São Carlos - SP, 1996.

Souza, S. R. S.; Maldonado, J. C.; Fabbri, S. C. P.; Masiero, P. C. Statecharts specifications: A family of coverage testing criteria. In: XXVI Conferência Latinoamericana de Informática - CLEI'2000, Tecnologico de Monterrey - México, (CD-ROM - Arquivo PDF código a000185), 2000a.

Souza, S. R. S.; Maldonado, J. C.; Fabbri, S. C. P. F.; Lopes de Souza, W. Mutation testing applied to Estelle specifications. In: 33rd Hawaii International Conference on 
System Sciences, Mini-Tracks: Distributed Systems Testing, Maui, Havaí, (Aceito para publicação no Software Quality Journal, Special Issue on Distributed Systems Testing), 2000b.

Souza, S. R. S.; Maldonado, J. C.; Masiero, P. C.; Fabbri, S. C. P. Coverage testing for specifications based on statecharts. In: 22nd International Conference on Software Engineering, Limerick, 1999.

SPINOLA, R. O. Uma infra-estrutura para integração de ferramentas CASE baseada em $X M L$, esquemas e ontologias. Dissertação de mestrado, COOPE/Universidade Federal do Rio de Janeiro, Rio de Janeiro/RJ, 2004.

Spinola, R. O.; Kalinowski, M.; Travassos, G. H. Uma infra-estrutura de integração de ferramentas CASE. In: SBES'2004 - Simpósio Brasileiro de Engenharia de Software, Brasília, DF, 2004.

StAllman, R. M. Using and porting the gnu compiler collection (gcc). iUniverse.com, 2000.

Stein, D.; Hanenberg, S.; Unland, R. An uml-based aspect-oriented design notation. In: Proc. of the 1st International Conference on Aspect-Oriented Software Development, Enschede, The Netherlands, 2002.

SUGETA, T. Proteum-RS/ST: Uma ferramenta para apoiar a validação de especificações statecharts baseada na análise de mutantes. Dissertação de Mestrado, ICMC-USP, São Carlos, SP, 1999.

SugEtA, T. Uma contribuição para o teste de especificações sdl: aspectos teóricos e empíricos. Tese de doutorado, Instituto de Ciências Matemáticas e de Computação - ICMC/USP, São Carlos, SP, 2004.

Sun, C.; LiU, C.; Jin, M.; Zhang, M. Architecture framework for software test tool. In: 36th International Conference on Technology of Object-Oriented Languages and Systems (TOOLS-Asia'00), Xi'an, China, 2000, p. 40-47.

SutTon, S. M. The role of process in a software start-up. IEEE Software, v. 17, n. 4, p. 33-39, 2000.

Sutton, S. M.; Heimbigner, D.; Osterweil, L. J. Appl/a: A language for software process programming. ACM Transactions on Software Engineering and Methodology, v. 4, n. 3, p. 221-286, 1995. 
Sutton, S. M.; Osterweil, L. J. The design of a next-generation process language. In: Proc. of the 6th European Conference held jointly with the 5th ACM SIGSOFT Symposium on Software Engineering, Zurich, Switzerland: Springer-Verlag, 1997, p. 142-158.

Suvée, D.; Fraine, D. B.; VAnderperren, W. Fusej: An architectural description language for unifying aspects and components. In: Proc. of the 1st Workshop on Software Engineering Properties of Languages for Aspect Technologies (SPLAT'05), Chicago, USA, 2005.

SuzUKi, J.; Yамамото, Y. Extending UML with aspects: Aspect support in the design phase. In: Proc. of the Workshop on Object-Oriented Technology, Springer-Verlag, 1999, p. 299-300.

SzE, S. K. S.; LyU, M. R. ATACOBOL: A Cobol test coverage analysis tool and its applications. In: ISSRE'2000 - International Symposium on Software Reliability Engineering, San Jose, CA, 2000, p. 327-335.

Tanenbaum, A. S. Redes de computadores. 3 ed. Campus, 1997.

TARR, P. L.; OSShER, H.; HARRISON, W. H.; JR., S. M. S. N degrees of separation: Multidimensional separation of concerns. In: International Conference on Software Engineering, 1999, p. 107-119.

TAYlor, R.; Tracz, W.; Coglianese, L. Software development using domain-specific software architecture: Cdrl a011a curriculum module in the SEI style. SIGSOFT Software Engineering Notes, v. 20, p. 27-37, 1995.

Taylor, R. N.; Belz, F. C.; Clarke, L. A.; Osterweil, L.; Selby, R. W.; Wileden, J. C.; Wolf, A. L.; Young, M. Foundations for the Arcadia environment architecture. SIGSOFT Softw. Eng. Notes, v. 13, n. 5, p. 1-13, 1988.

Telcordia Technologies Telcordia software visualization and analysis toolsuite (xSuds). [On-line], World Wide Web, disponível em: http://xsuds.argreenhouse.com/ (Acessado em 14/05/2005), 2005.

Temple, A.; Mello, R. F.; D. T. Calegari, D. T.; Schiezaro, M. Programação web com JSP, Servlets e J2EE. [On-line], World Wide Web, disponível em: http://143.107. 183.115/mellooutros/livro-v03-figuras.pdf (Acessado em 21/02/2005), 2004. 
Tikir, M.; Hollingsworth, J. Efficient instrumentation for code coverage testing. In: ISSTA 2002 - International Symposium on Software Testing and Analysis, Rome, Italy: ACM, 2002.

Travassos, G. H. O modelo de integração de ferramentas da estação TABA. Tese de Doutoramento, COPPE/UFRJ, Rio de Janeiro, RJ, 1994.

VAn Der Hoek, A. Configuration management and open source projects. In: Proc. of the 3nd Workshop on Software Engineering over the Internet at ICSE'00, Limerick, Ireland, 2000.

VILELA, P. R. S. Uma ferramenta para auxílio visual ao teste e depuração de programas. Dissertação de Mestrado, DCA/FEE/UNICAMP, Campinas, SP, 1994.

Vilela, P. R. S.; Maldonado, J. C.; Jino, M. Program graph visualization. Software Practice and Experience, v. 27, n. 11, p. 1245-1262, 1997.

VINCENZI, A. M. R. Subsídios para o estabelecimento de estratégias de teste baseadas na técnica de mutação. Dissertação de Mestrado, ICMC-USP, São Carlos - SP, 1998.

VINCENZI, A. M. R. Orientação a objeto: definição, implementação e análise de recursos de teste e validação. Tese de doutorado, Instituto de Ciências Matemáticas e de Computação - ICMC/USP, São Carlos, SP, 2004.

Vincenzi, A. M. R.; Delamaro, M. E.; Simão, A. S.; Maldonado, J. C. Muta-pro: Towards the definition of a mutation testing process. In: Proc. of the 6th IEEE Latin American Test Workshop, Salvador, Bahia, 2005.

Vincenzi, A. M. R.; Maldonado, J. C.; Barbosa, E. F.; Delamaro, M. E. Unit and integration testing strategies for $\mathrm{C}$ programs using mutation-based criteria. Software Testing Verification and Reliability Journal, v. 11, n. 4, p. 249-268, 2001.

Vincenzi, A. M. R.; Nakagawa, E. Y.; Maldonado, J. C.; Delamaro, M. E.; RoMERO, R. A. F. Bayesian-learning based guidelines to determine equivalent mutants. International Journal of Software Engineering and Knowledge Engineering - IJSEKE, v. 12, n. 6, p. 675-689, 2002.

VIXIE, P. Open sources: Voices of the open source revolution, cap. Software Engineering. 1 ed O’Reilly \& Associates, p. 91-100, 1999.

Vogel, P. A. An integrated general purpose automated test environment. In: Proc. of the 1993 International Symposium on Software Testing and Analysis, Cambridge, Massachusetts, USA: ACM Press, 1993, p. 61-69. 
W3C Web ontology language (OWL). [On-line], World Wide Web, disponível em http: //www.w3.org/2004/owL/ (Acessado em 15/02/2006), 2006.

W3C Web services architecture working group. [On-line], World Wide Web, disponível em http: / /www.w3.org/2002/ws/arch/ (Acessado em 28/02/2006), 2006.

Warboys, B. Meta-process. In: The Software Process: Principles, Methodology, and Technology, Springer-Verlag, 1998, p. 53-93 (Lectures Notes in Computer Science, v.1500).

Wasserman, A. I. Tool integration in software engineering environments. In: Proc. of the international workshop on environments on Software engineering environments, New York, NY, USA: Springer-Verlag New York, Inc., 1990, p. 137-149.

WASSERman, A. I. Toward a discipline of software engineering. IEEE Software, v. 13, n. 6, p. 23-31, 1996.

Welch, B. B. Practical programming in Tcl and Tk. 2 ed. Prentice Hall, 1997.

Welling, L.; Thomson, L. Php and Mysql web development. 1 ed. Sams, 2001.

WFMC Workflow management coalition - interface 1: Process definition interchange process model. Relatório Técnico WfMC TC-1016-P, Workflow Management Coalition, Hampshire, Inglaterra, disponível em http://www.wfmc.org/standards/docs/TC-1016-P_v11_IF1_ Process_definition_Interchange.pdf (Acessado em 07/01/2006), 1999a.

WFMC Workflow management coalition - terminology and glossary. Relatório Técnico WFMC-TC-1011 (3. Edição), Workflow Management Coalition, Hampshire, Inglaterra, disponível em http://www.wfmc.org/standards/docs/TC-1011_term_glossary_v3.pdf (Acessado em 07/01/2006), 1999 b.

WFMC Process definition interface - XML process definition language. Relatório Técnico WFMC-TC-1025 (versão 2.0), Workflow Management Coalition, Lighthouse Point, Estados Unidos, disponível em http://www.wfmc.org/standards/docs.htm (Acessado em 07/01/2006), 2005.

WFMC Workflow management coalition. [On-line], World Wide Web, disponível em http: //www.wfmc.org/ (Acessado em 06/01/2006), 2006.

Williams, L.; Kessler, R.; Cunningham, W.; ; JefFries, R. Strengthening the case for pair-programming. IEEE Software, v. 17, n. 4, p. 19-25, 2000. 
Yamauchi, Y.; Yokozawa, M.; Shinohara, T.; Ishida, T. Collaboration with lean media: How open-source software succeeds. In: Proc. of the ACM 2000 Conference on Computer Supported Cooperative Work, Philadelphia, Pennsylvania, United States: ACM Press, 2000, p. 329-338.

YAnG, J.; HuAng, J.; WANG, F.; CHU, W. C. An object-oriented architecture supporting web application testing. In: Twenty-Third Annual International Computer Software and Applications Conference, Phoenix, Arizona, USA, 1999, p. 122-127.

YANO, T. Estudo do teste de mutação em programas funcionais SML. Dissertação de Mestrado, ICMC/USP, 2004.

Yano, T.; Simão, A.; Maldonado, J. C. Proteum/SMl: Uma ferramenta de apoio ao teste de mutação para a linguagem Standard ML. In: Sessão de Ferramentas do XVII SBES Simpósio Brasileiro de Engenharia de Software, Manaus - AM, 2003.

ZAPF, C. N. Medusamothra-a distributed interpreter for the mothra mutation testing system. Dissertação de Mestrado, Clemson University, Clemson, SC, 1993.

ZDUn, U. Reengineering to the web: A reference architecture. In: Sixth European Conference on Software Maintenance and Reengineering, Budapest, Hungary, 2002.

ZhaO, L.; Elbaum, S. A survey on quality related activities in open source. ACM Sigsoft, v. 25, n. 5, p. 54-57, 2000.

Zhao, W.; Kearney, D. Deriving architectures of web-based applications. In: Proc. on 5th Asia-Pacific Web Conference, APWeb 2003, Xian, China, INCS 2642, 2003.

Zhu, H.; Hall, P.; MAY, J. Software unit test coverage and adequacy. ACM Computing Surveys, v. 29, n. 4, p. 366-427, 1997.

ZHu, H.; HuO, Q. Software evolution with UML and XML, cap. Developing A Software Testing Ontology in UML for A Software Growth Environment of Web-Based Applications Idea Group, p. 263-295, 2004.

Zlot, F. Conhecimento de tarefa em ambientes de desenvolvimento de software orientados a domínio. Dissertação de Mestrado, COOPE/Universidade Federal do Rio de Janeiro, Rio de Janeiro, RJ, 2002. 


$\sqrt{1}$

\section{OntoTest: Uma Ontologia de Teste de Software ${ }^{1}$}

Neste apêndice será apresentada a OntoTest, uma ontologia que vem sendo proposta para o domínio de teste de software. Em virtude da complexidade do domínio de teste de software, a OntoTest é apresentada em dois níveis, como mostrada na Figura A.1. No nível de abstração mais alto tem-se a ontologia principal de teste de software (a Ontologia de Teste Principal) que tem o objetivo de capturar os principais conceitos e as relações entre esses conceitos. Em um nível mais baixo, encontram-se as sub-ontologias, nas quais alguns conceitos específicos da ontologia principal - Passo de Teste (TestingStep), Artefato de Teste (TestingArtifact), e Recurso de Teste (TestingResource) — são refinados e tratados em mais detalhes.

Para captura da ontologia de teste de software, ou seja, para identificação e organização dos conceitos e relações entre esses conceitos, foi utilizada uma linguagem gráfica para a construção do modelo conceitual, no caso a UML, juntamente com um dicionário de termos. A ontologia principal de teste de software é apresentada na Figura A.2 e parte do dicionário de dados é ilustrada na Tabela A.1. E, nas Figuras A.3, A.4 e A.5 são mostradas, respectivamente, as sub-ontologias de Passos de Teste, de Artefatos de Teste e de Recursos de Teste.

\footnotetext{
${ }^{1}$ Este apêndice é baseado em um trabalho em desenvolvimento e que vem sendo consolidado em (Barbosa et al., 2006). Muitos dos termos utilizados neste apêndice foram mantidos como no original.
} 


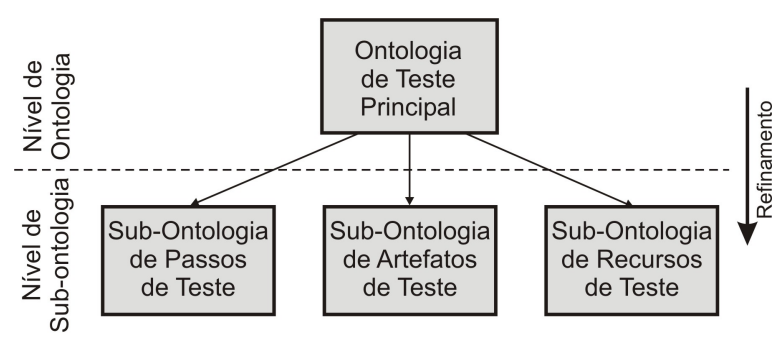

Figura A.1: Estrutura da OntoTest

Tabela A.1: Principais Conceitos Definidos na Ontologia de Teste de Software

\begin{tabular}{|l|l|}
\hline Conceito & Descrição \\
\hline \hline TestingActivity & $\begin{array}{l}\text { Task performed to test a program. This task can be classified in primary (example, } \\
\text { test case generation), organizational (example, planning and control) or supporting } \\
\text { (example, testing documentation). }\end{array}$ \\
\hline TestingArtifact & Artifact of software that is consumed or produced during testing activity. \\
\hline TestingCriterion & $\begin{array}{l}\text { Systematic way to obtain a test case set (i.e. a finite subsets of the input domain of } \\
\text { a program) that is effective to identify software errors. }\end{array}$ \\
\hline TestingLifecycle & A series of stages through which the testing of a program passes during its lifetime. \\
\hline TestingPhase & $\begin{array}{l}\text { A distinguishable part of testing life cycle that depending on requirement to be } \\
\text { tested can be classified in unit, integration, system and regression testing. }\end{array}$ \\
\hline TestingProcedure & $\begin{array}{l}\text { A particular way of accomplishing a testing step. } \\
\text { A series of STEP followed in a regular definite order to execute a testing step. }\end{array}$ \\
\hline TestingProcess & $\begin{array}{l}\text { A sequence of steps required to develop and maintain the software testing activity. } \\
\text { It incorporates technical activities (example, test case design and resultant data col- } \\
\text { lection and evaluation) as well as management activities (example, human resource } \\
\text { management and test planning). }\end{array}$ \\
\hline TestingResource & Element of hardware, software or human that supports the testing activity. \\
\hline TestingStep & $\begin{array}{l}\text { Set of testing activities that can be classified in testing planning, design, execution } \\
\text { and analysis. }\end{array}$ \\
\hline TestingStrategy & $\begin{array}{l}\text { A well-planned series of steps that integrates a combination of testing criteria and } \\
\text { phases aiming to maximize the quality of testing activity. }\end{array}$ \\
\hline TestingTechnique & $\begin{array}{l}\text { Depending on the source used to determine the testing requirements, testing techni- } \\
\text { ques can be classified as functional, structural, fault-based, and state-based. }\end{array}$ \\
\hline
\end{tabular}

Com o objetivo de representar formalmente o modelo conceitual, uma linguagem formal foi utilizada. Os conceitos e as relações, bem como suas definições, restrições e propriedades foram representadas por meio de axiomas (Falbo et al., 1998; Fernández et al., 1997). A seguir, por questões de espaço, são apresentados somente um pequeno subconjunto dos axiomas; mais especificamente, esses axiomas referem-se à ontologia principal de teste de software. 


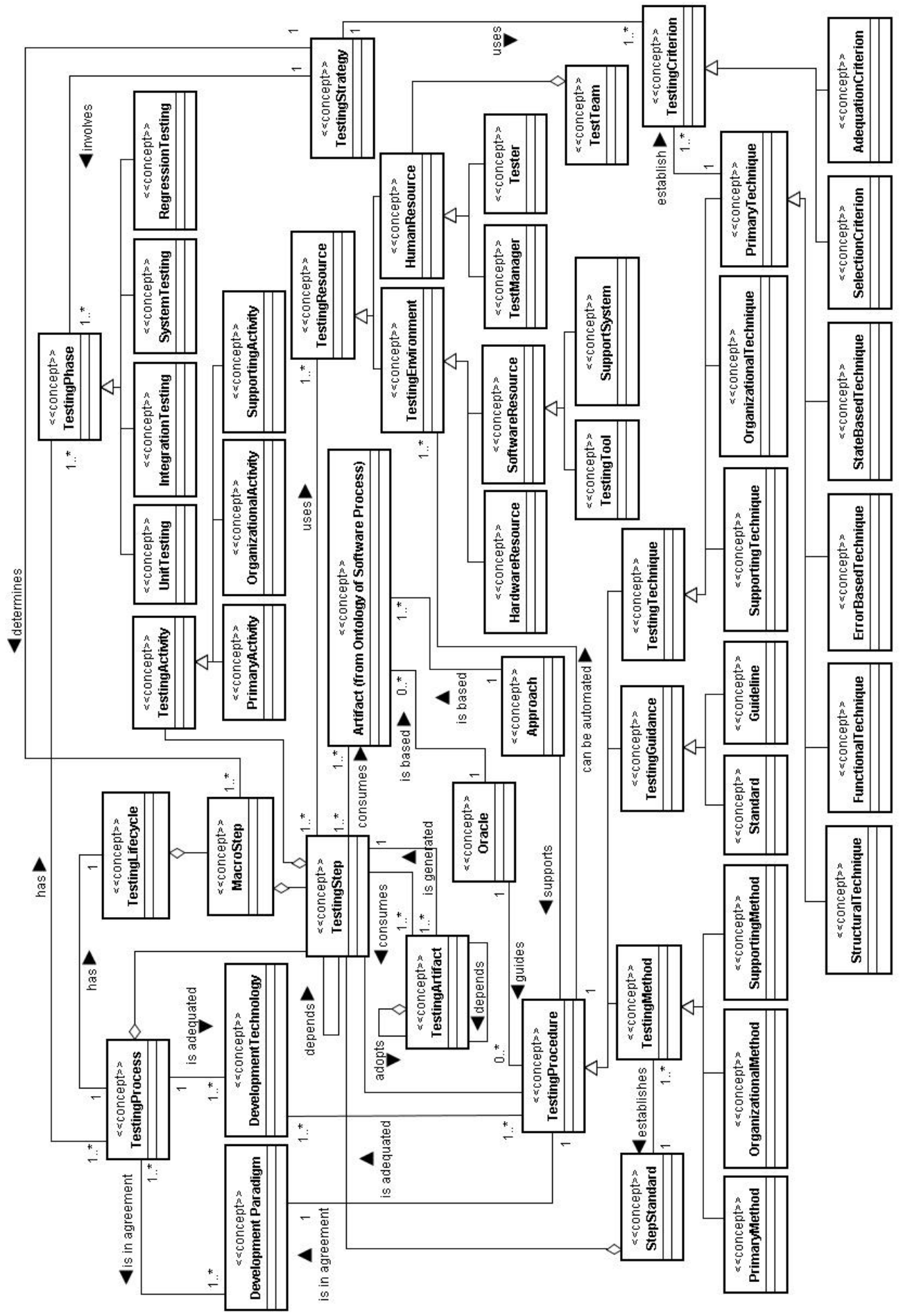

Figura A.2: Ontologia de Teste de Software

Por exemplo, para a formalização das fases de teste, foram definidos os seguintes predicados, representando cada fase de teste na relação de sub-tipo: TestingPhase( $p$ ) denota que $p$ 


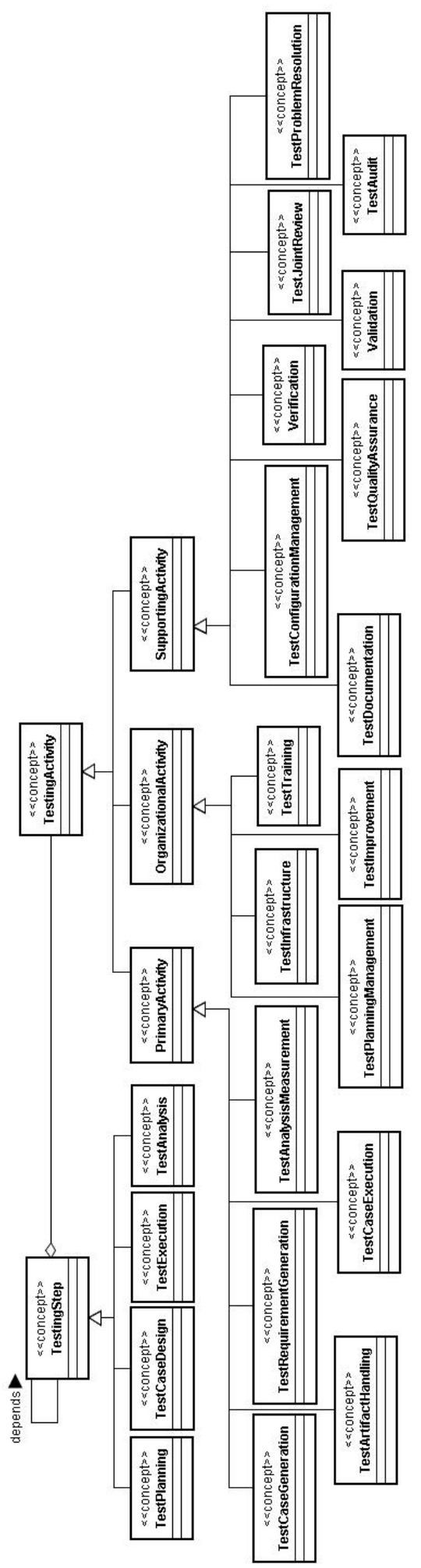

Figura A.3: Sub-Ontologia de Passos de Teste 


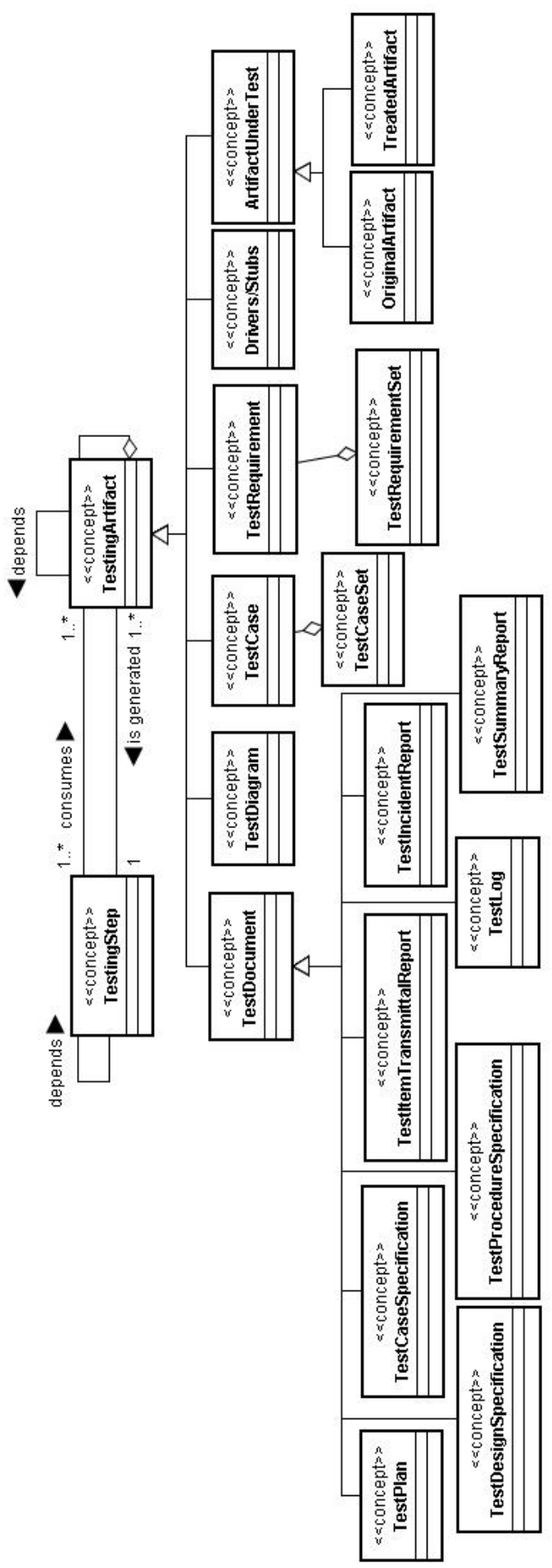

Figura A.4: Sub-Ontologia de Artefatos de Teste

é uma fase de teste; UnitTesting $(p)$ denota que $p$ é um teste de unidade; IntegrationTesting $(p)$ denota que $p$ é um teste de integração; SystemTesting $(p)$ denota que $p$ é um teste de sistema; e 
RegressionTesting $(p)$ denota que $p$ é um teste de regressão, como mostrados nos axiomas A1 a A4 apresentados a seguir:

$(\forall p)($ UnitTest $(p) \rightarrow$ TestingPhase $(p))(\mathrm{A} 1)$

$(\forall p)($ IntegrationTest $(p) \rightarrow$ TestingPhase $(p))(\mathrm{A} 2)$

$(\forall p)(\operatorname{SystemTest}(p) \rightarrow$ TestingPhase $(p))(\mathrm{A} 3)$

$(\forall p)($ RegressionTest $(p) \rightarrow$ TestingPhase $(p))(\mathrm{A} 4)$

O axioma A5 mostra a relação de composição (todo-parte) entre processo de teste e passos de teste. Essa relação é formalizada pelo predicado TestingProcessComposition $\left(p, s_{1}, \ldots, s_{n}\right)$ que denota que um processo de teste $p$ é uma composiçãp de passo de teste $s_{1}, \ldots, s_{n}$.

$\left(\forall p, s_{1}, \ldots, s_{n}\right)\left(\right.$ TestingProcessComposition $\left(p, s_{1}, \ldots, s_{n}\right) \rightarrow$ TestingProcess $(p) \wedge$ TestingStep $\left(s_{1}\right) \wedge \ldots \wedge$ TestingStep $\left.\left(s_{n}\right)\right)($ A5) 


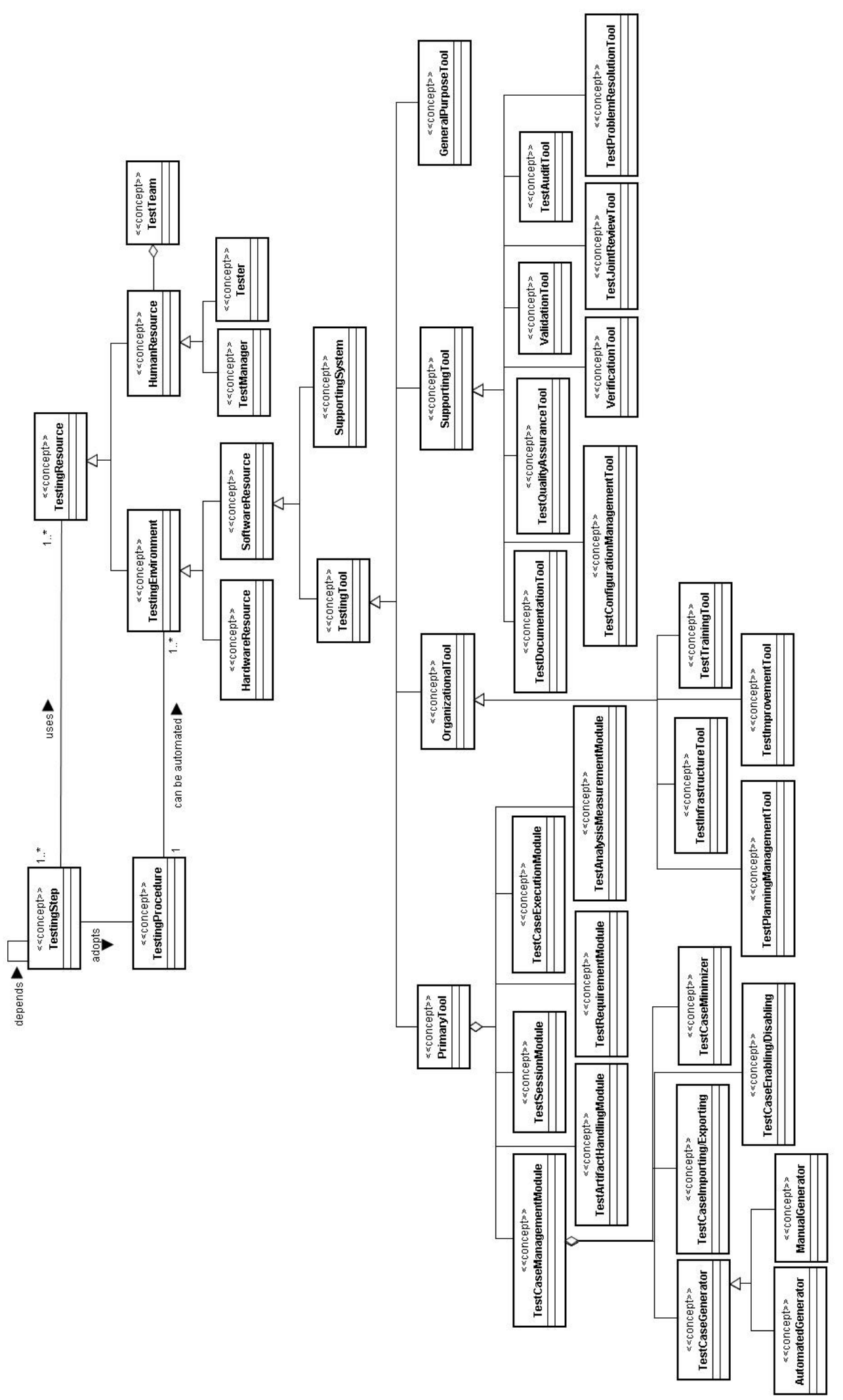

Figura A.5: Sub-Ontologia de Recursos de Teste 
APÊNDICE

$B$

\section{DTD de Documentação de Teste}

Neste apêndice é apresentado o T2DTD (Testing Documentation Document Type Definition), uma DTD (Document Type Definition) proposta no contexto deste trabalho para documentação da atividade de teste de software. O T2DTD é baseado no padrão de documentação de teste IEEE 829/1998 (IEEE, 1998a) e no proposto por Boas (2003).

Para facilitar a apresentação desse DTD, esse foi dividido nas Figuras B.1 a B.8 que ilustram, respectivamente, o DTD geral que faz o apontamento para os demais DTDs, o DTD do plano de teste, da especificação de projeto de teste, da especificação de casos de teste, da especificação de procedimento de teste, do diário do teste, do relatório de incidentes de teste e do relatórioresumo do teste.

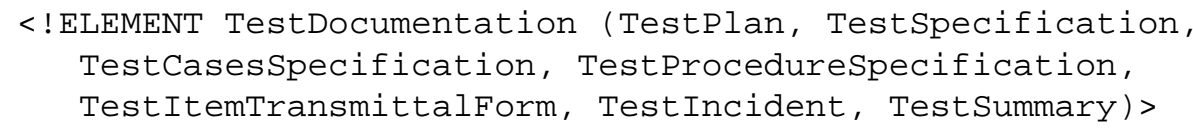

Figura B.1: DTD de Documentação de Teste (Geral) 


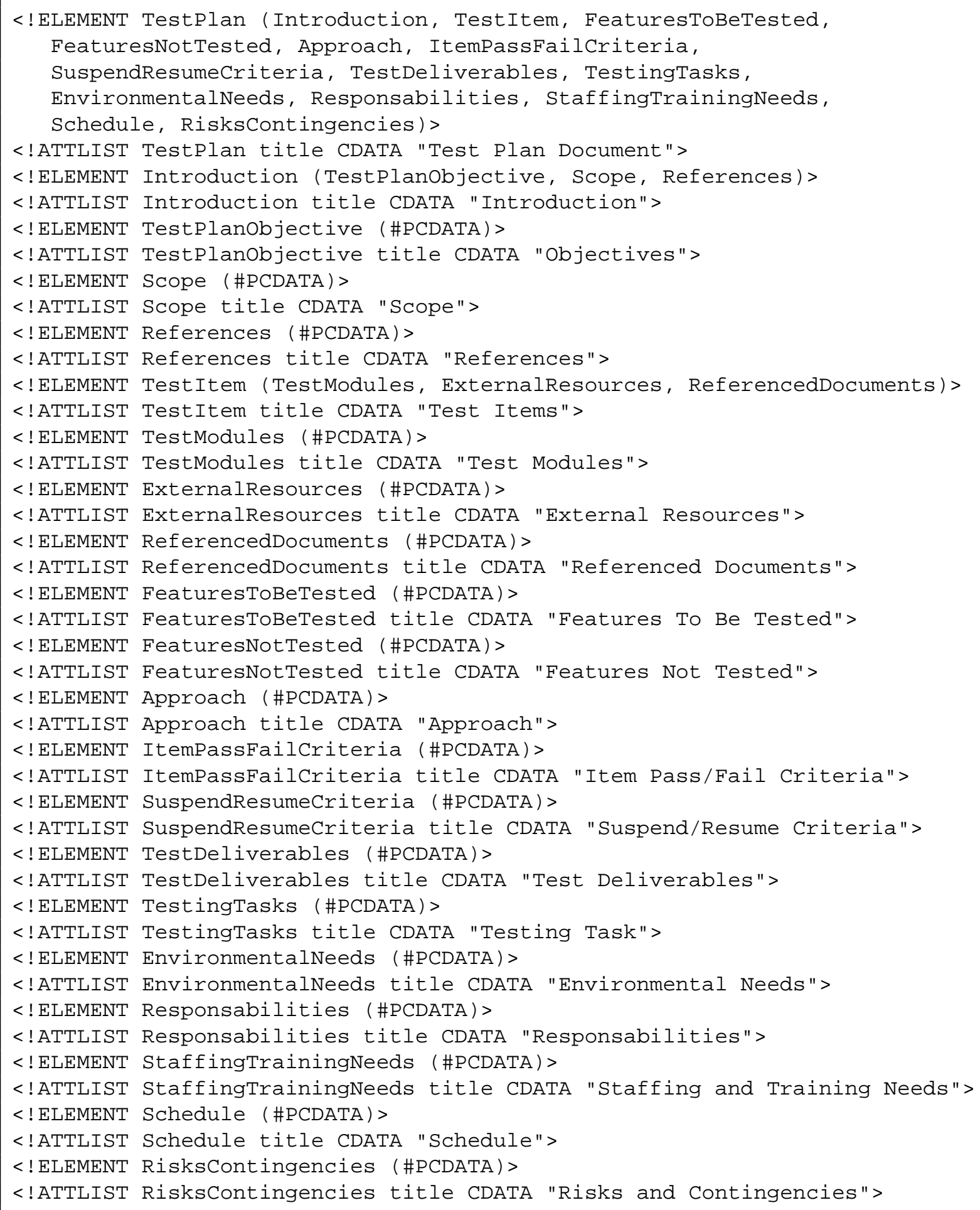

Figura B.2: DTD de Documentação de Teste (Plano de Teste) 


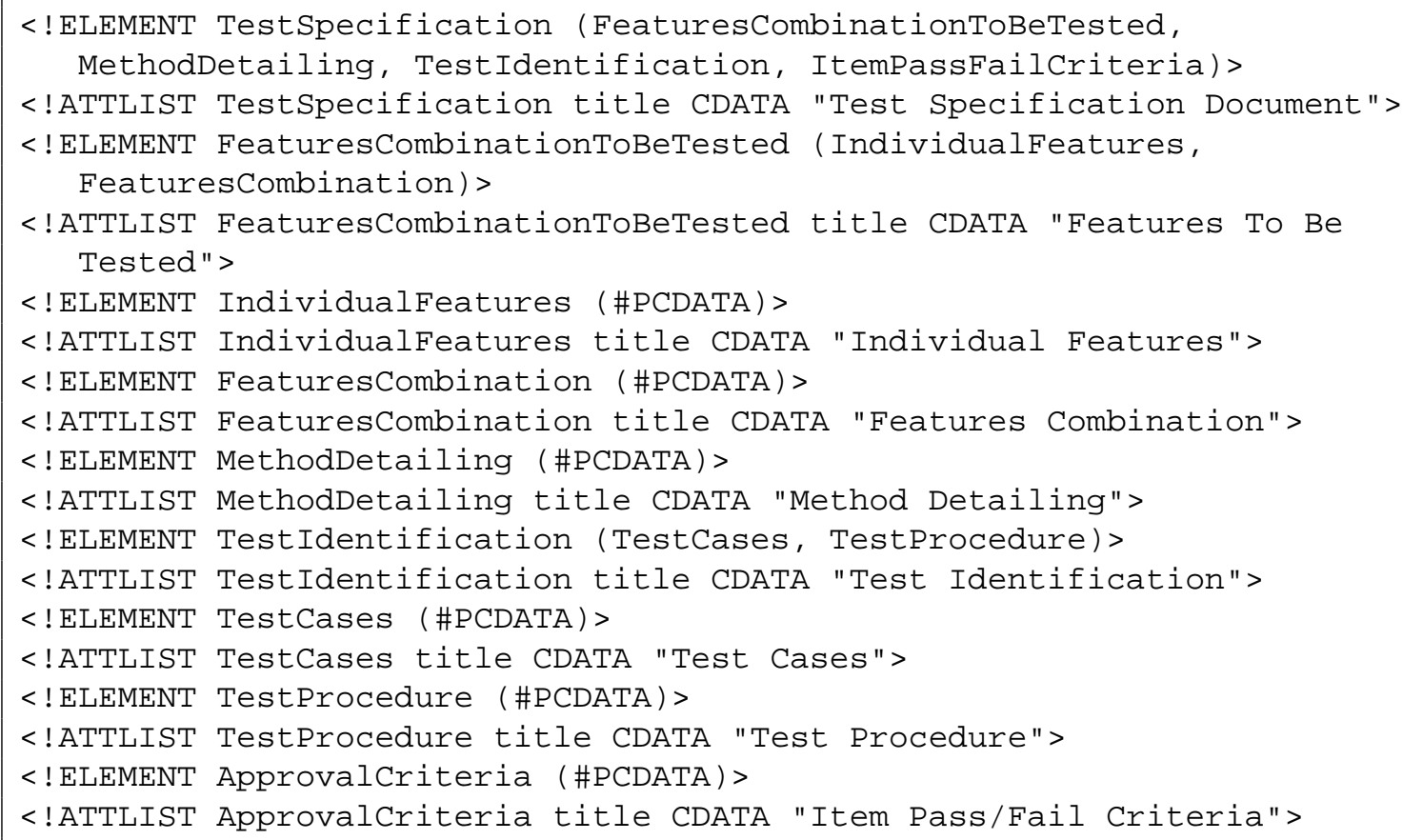

Figura B.3: DTD de Documentação de Teste (Especificação de Projeto de Teste)

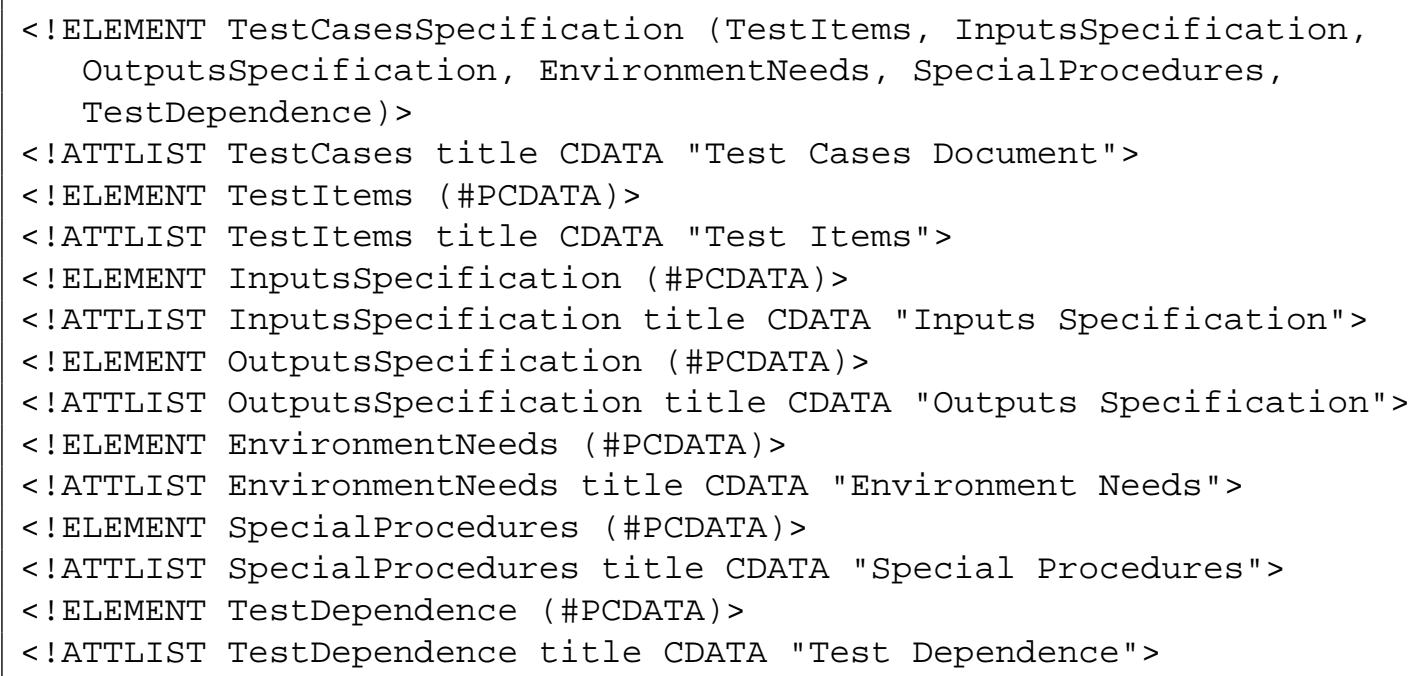

Figura B.4: DTD de Documentação de Teste (Especificação de Casos de Teste) 


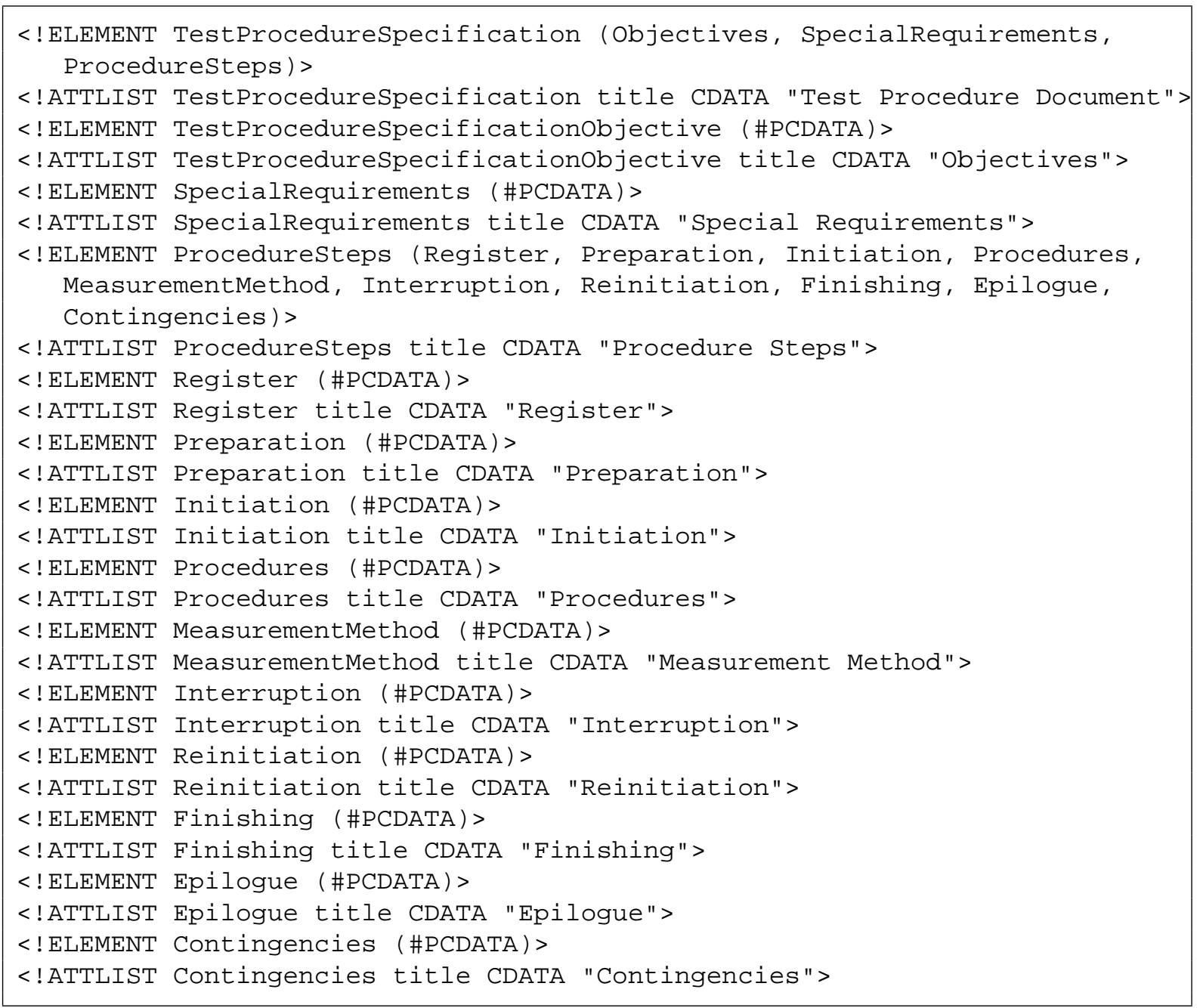

Figura B.5: DTD de Documentação de Teste (Especificação de Procedimento de Teste) 
<!ELEMENT TestItemTransmittalForm (Description, ActivityEventsRegister) >

$<$ ! ATTLIST TestItemTransmittalForm title CDATA "Test Item Transmittal Form and Test Logs">

$<$ !ELEMENT Description (\#PCDATA) >

$<$ !ATTLIST Description title CDATA "Description">

<!ELEMENT ActivityEventsRegister (ExecutionDescription, Results, EnvironmentInformation, AnomalousEvents, TestIncidentReportIdentification) >

<!ATTLIST ActivityEventsRegister title CDATA "Activity and Events Register">

$<$ !ELEMENT ExecutionDescription (\#PCDATA) >

$<$ !ATTLIST ExecutionDescription title CDATA "Execution Description">

$<$ !ELEMENT Results (\#PCDATA) >

$<$ !ATTLIST Results title CDATA "Obtained Results">

$<$ !ELEMENT EnvironmentInformation (\#PCDATA) >

<!ATTLIST EnvironmentInformation title CDATA "Environment Information">

$<$ !ELEMENT AnomalousEvents (\#PCDATA) >

$<$ !ATTLIST AnomalousEvents title CDATA "Anomalous Events">

$<$ !ELEMENT TestIncidentReportIdentification (\#PCDATA) >

$<$ !ATTLIST TestIncidentReportIdentification title CDATA "Test Incident Report Identification">

Figura B.6: DTD de Documentação de Teste (Diário de Teste)

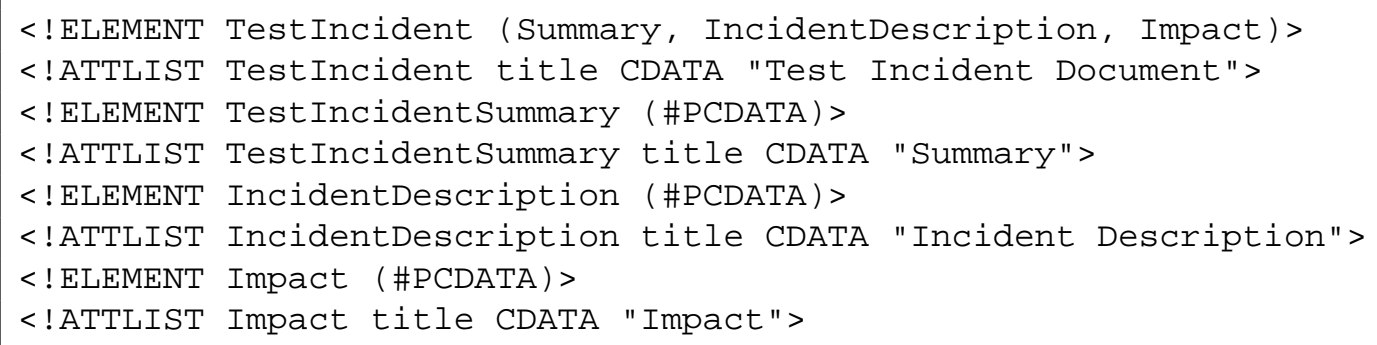

Figura B.7: DTD de Documentação de Teste (Relatório de Incidentes de Teste) 


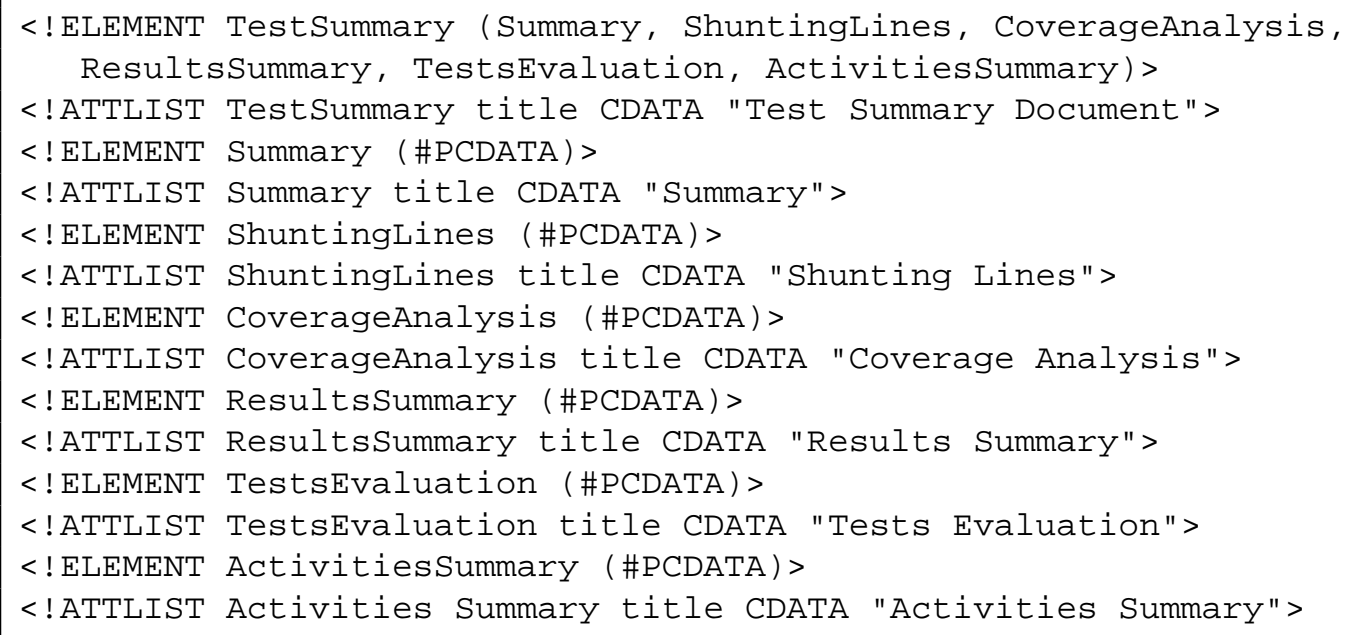

Figura B.8: DTD de Documentação de Teste (Relatório-Resumo de Teste) 